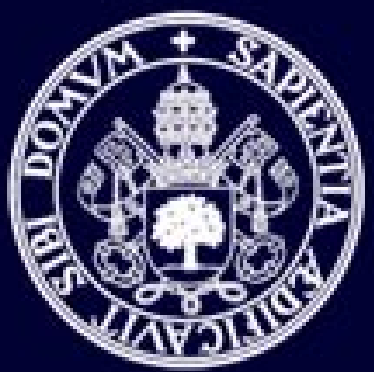

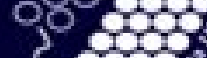
UVA का? ()

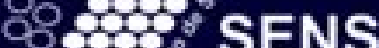
Pros? Pros

\title{
Sensor arrays for Anology applications: Using nanoscience for grape analysis
}

Cristina Medina Plaza Doctoral Thesis 



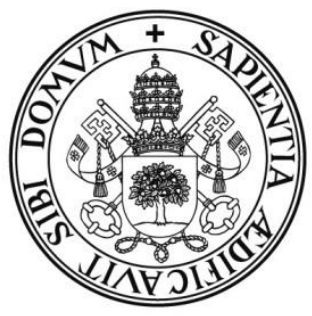

\title{
Universidad deValladolid
}

ESCUELA DE INGENIERÍAS INDUSTRIALES

DEPARTAMENTO DE QUÍMICA FÍSICA Y QUÍMICA INORGÁNICA

\section{TESIS DOCTORAL:}

Sensor arrays for Enology applications: Using nanoscience for grape analysis

Presentada por Cristina Medina Plaza para optar al grado de Doctora por la Universidad de Valladolid

\author{
Dirigida por:
}

Prof. Dra. María Luz Rodríguez Méndez

Valladolid, 2016 



\section{AUTORIZACIÓN DE LA DIRECTORA DE TESIS}

Da María Luz Rodríguez Méndez, con D.N.I: n 50305983-S, Catedrática de Universidad del Departamento de Química Física y Química Inorgánica de la Escuela de Ingenierías Industriales, como Directora de la Tesis Doctoral titulada "Sensor arrays for Enology applications: Using nanoscience for grape analysis", presentada por $\mathrm{D}^{\mathrm{a}}$. Cristina Medina Plaza, alumna del programa "Doctorado en Física" impartido por la Facultad de Ciencias, autoriza la presentación de la misma, considerando que cumple todos los requisitos para ello.

Valladolid, 15 de Abril de 2016

La Directora de la Tesis

Fdo. María Luz Rodríguez Méndez 

"Soy de las que piensan que la ciencia tiene una gran belleza. Un cientéfica en su labaratorion na es sála un técnica, es tambien un niña calocado ante fenömenos naturales que le impresionan cama un cuenta de hadas"

Marie Curie 



\section{TABLE OF CONTENTS}

List of Abbreviations and Acronyms......................................................1-4

Justifications and Objectives..................................................................5-10

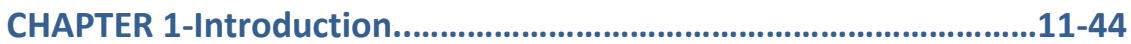

1.1 GRAPES

1.1.1 Chemical composition of the grapes...................................15

1.1.2 Berry ripening .................................................................16

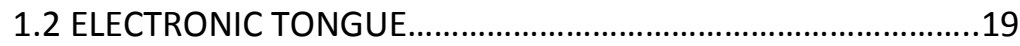

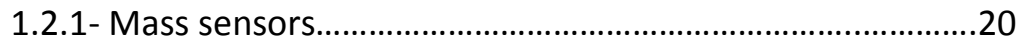

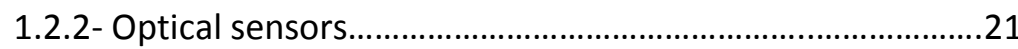

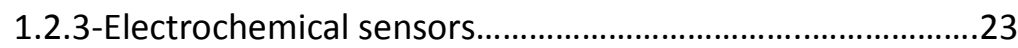

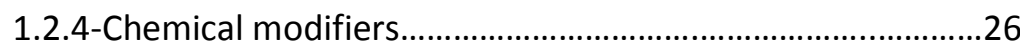

1.2.5-Preparation of voltammetric sensors.....................................32



CHAPTER 2- Analysis of Organic Acids and Phenols of Interest in the Wine Industry using Langmuir-Blodgett Films Based on Functionalized

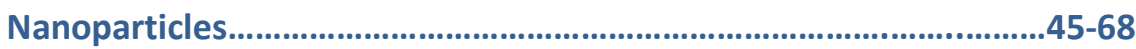

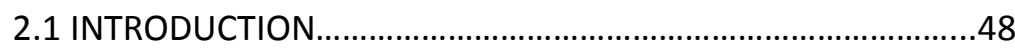

2.2 MATERIALS AND METHODS..................................................49

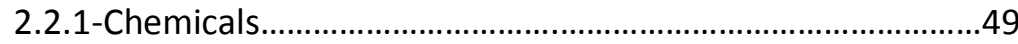

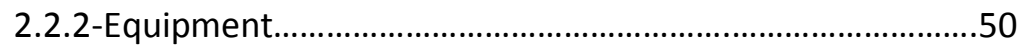


2.2.3-Preparation of nanoparticles................................................50

2.2.4-Preparation of LB films.........................................................50

2.2.5- Electrochemical studies.......................................................51

2.3 RESULTS AND DISCUSSION......................................................

2.3.1-Structural characterization....................................................

2.3.2-Electrochemical response in simple electrolytes................52

2.3.3-Electrocatalytic effect of $S_{D O D} A U N P-L B$ towards organic acids.

2.3.4-Electrocatalytic effect of $\mathrm{S}_{\mathrm{DOD}}$ AuNP-LB towards phenolic acids.

2.3.5-Response of $S_{D O D A U N P-L B}$ towards mixtures of organic acids and phenols.

2.3.6-Electrode repeatability and reproducibility. .62

2.4 CONCLUSIONS. .62

References. .64

CHAPTER 3- Structural and Electrochemical Properties of Lutetium BisOctachloro-Phthalocyaninate Nanostructured Films. Application as Voltammetric Sensors $.69-94$

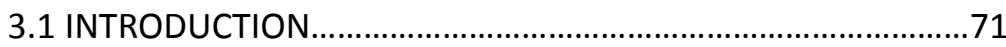

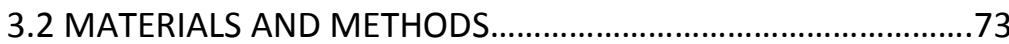

3.2.1-Chemicals .73

3.2.2-Langmuir, LB and LS films.................................................73

3.2.3-Film characterization........................................................... 
3.3 RESULTS AND DISCUSSION......................................................75

3.3.1-Langmuir films...................................................................

3.3.2-LB and LS films. Growth monitored by UV-Vis absorption.....................................................................................

3.3.3-LB and LS films. Molecular organization determined by FTIR . .78

3.3.4-Surface Enhancement Resonance Scattering

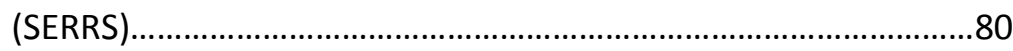

3.3.5-Electrochemical properties...................................................

3.3.6-Electrochemical detection of catechol...................................83

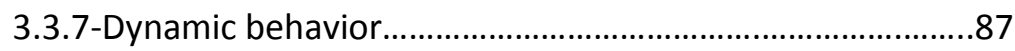

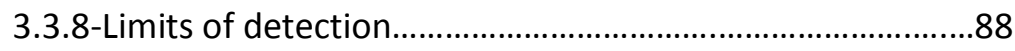

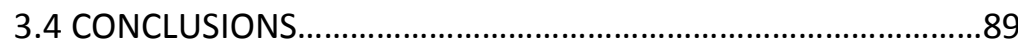

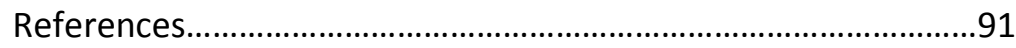

CHAPTER 4- Synergistic Electrocatalytic Effect of Nanostructured Mixed Films Formed by Functionalized Gold Nanoparticles and Bisphthalocyanines $.95-136$

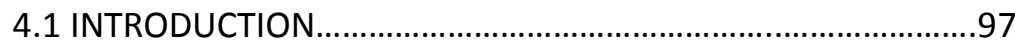

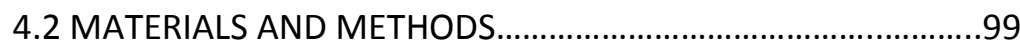

4.2.1-Langmuir monolayers and Langmuir-Blodgett films..........99

4.2.2-Films characterization..........................................................101

4.3 RESULTS AND DISCUSSION.................................................102

4.3.1-Langmuir monolayers.......................................................102 
4.3.2-Langmuir-Blodgett films characterization.........................104

4.3.3-Electrochemical characterization.......................................107

4.3.4-Electrocatalytic properties. Voltammetric sensors..........109

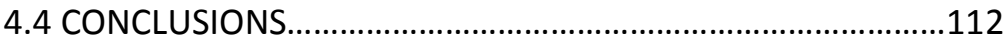

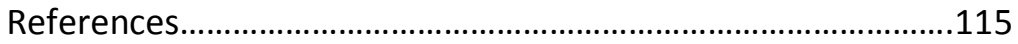

CHAPTER 5- Bioelectronic Tongue Based on Lipidic Nanostructured Layers Containing Phenol Oxidases and Lutetium Bisphthalocyanine for the Analysis of Grapes

119-142

5.1 INTRODUCTION.

5.2 MATERIALS AND METHODS 124

5.2.1-Chemicals 124

5.2.2-Langmuir and Langmuir-Blodgett films

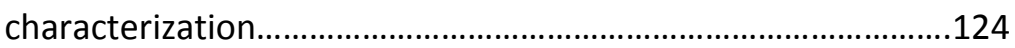

5.2.3-Electrochemical measurements........................................125

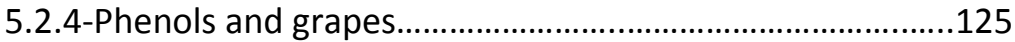

5.2.5-Statistical analysis. Data treatment....................................126

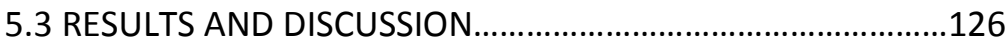

5.3.1-Langmuir monolayers and Langmuir-Blodgett

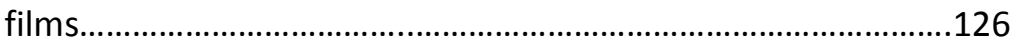

5.3.2-Electrochemical response towards phenols......................129

5.3.3-Array of sensors. Discrimination of phenolic compounds..............................................................................135

5.3.4-Array of sensors. Response towards grapes.....................136 
5.4 CONCLUSIONS

References .139

CHAPTER 6-Array of Biosensors for Discrimination of Grapes According to Grape Variety, Vintage and Ripeness.

6.1 INTRODUCTION 145

6.2 MATERIALS AND METHODS .147

6.2.1-Chemicals .147

6.2.2-Grape samples. 148

6.2.3-Langmuir-Blodgett films .148

6.2.4-Electrochemical measurements 149

6.2.5-Statistical analysis 149

6.3 RESULTS AND DISCUSSION 150

6.3.1-Characterization of Langmuir-Blodgett films 150

6.3.2-Discrimination of must obtained from different varieties of grapes harvested in two consecutive vintages .152

6.3.3-Monitoring the grape ripeness by means of the bioelectronic tongue .155

6.3.4-Multiparametric correlations between the bioelectronics tongue and the classical chemical analysis. 156

6.4. CONCLUSIONS 157

References. 159 
CHAPTER 7- Electrochemical Characterization of Dilithium Phthalocyanine Carbonaceous Electrodes........................................163-180

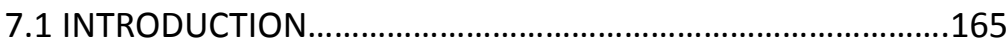

7.2 MATERIALS AND METHODS...............................................167

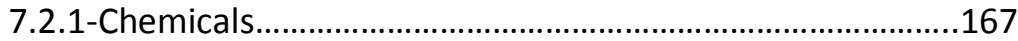

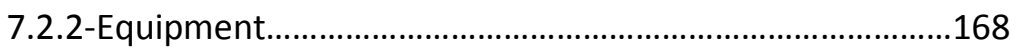

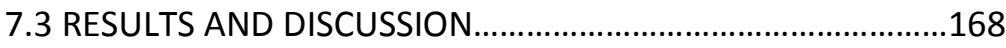

7.3.1-Electrochemical characterization.........................................168

7.3.2-Analysis of simple electrolytes...........................................172

7.3.3-Analysis of citric acid...........................................................174

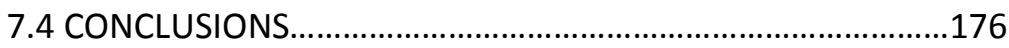

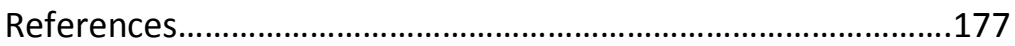

CHAPTER 8-Electronic Tongue Formed by Sensors and Biosensors Containing Phthalocyanines as Electron Mediators. Application to the Analysis of Red Grapes. .181-206

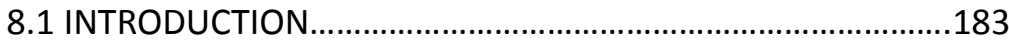

8.2 MATERIALS AND METHODS.................................................185

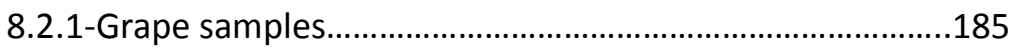

8.2.2-Reagents and solutions.....................................................186

8.2.3-Preparation of the electrodes..............................................186

8.3 RESULTS AND DISCUSSION..................................................189

8.3.1-Response of the array of CPE sensors modified with phthalocyanines 189 
8.3.2-Response of the array of biosensors formed by CPEs modified with phthalocyanines and tyrosinase.

8.3.3-Response of the array of biosensors formed by CPEs modified with phthalocyanines and glucose oxidase.................194

8.3.4-Response towards musts....................................................196

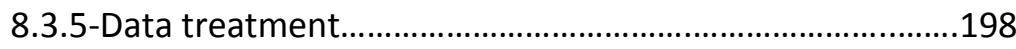

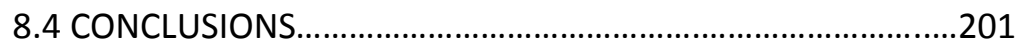

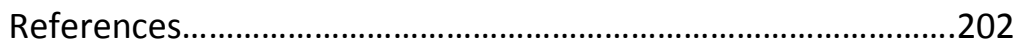

CHAPTER 9- The Advantages of Disposable Screen-Printed Biosensors in a Bioelectronic Tongue for the Analysis of Grapes.....................207-230

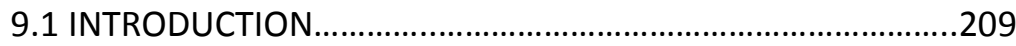

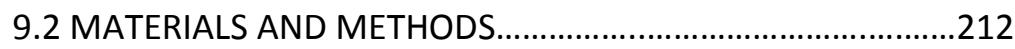

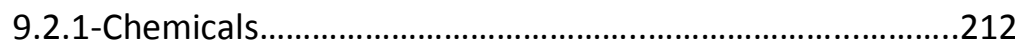

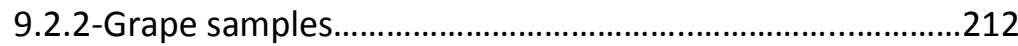

9.2.3-Screen-printed electrodes and biosensors.........................213

9.2.4-Electrochemical measurements..........................................215

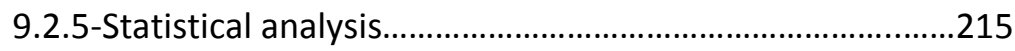

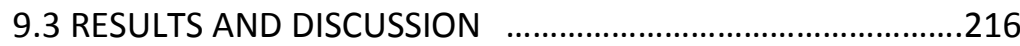

9.3.1-Measurements in glucose and catechol..............................216

9.3.2-Measurements in musts. Optimization of the experimental

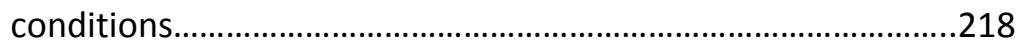

9.3.3-Bioelectronic tongue. Statistical analysis............................223

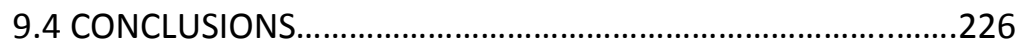


References. 228

CHAPTER 10- Nanoscale Au-In Alloy-Oxide Core-Shell Particle as Electrocatalysts for Efficient Hydroquinone Detection. $.231-252$

10.1 INTRODUCTION 233

10.2 MATERIALS AND METHODS .235

10.2.1-Synthesis of $A u_{x} \mid n_{1-x}$ alloy nanoparticles. .235

10.2.2-Characterization of Au-In alloy nanoparticles. .235

10.2.3-Electrochemical characterization .236

10.3 RESULTS AND DISCUSSION 236

10.3.1-Structural characterization 236

10.3.2-Electrocatalytical properties. .241

10.3.3-Dynamic behavior .247

10.3.4-Limits of detection .248

10.4 CONCLUSIONS. 250

References. 251

CHAPTER 11- Final Conclusions $.253-258$

Resumen en español $.259-276$

1- INTRODUCCIÓN .261

2- OBJETIVOS. 264

3- METOdOLOGÍA Y RESULTADOS. .265

3.1-Sensores nanoestructurados mediante la técnica de Langmuir-Blodgett 265 
3.2-Sensores de pasta de carbono.................................................270

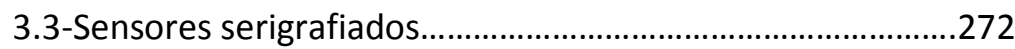

3.4-Sensores modificados con nanopartículas core-shell...........273

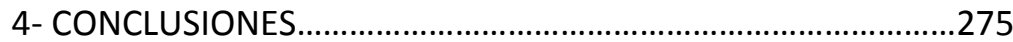

Anex 



\section{List of Abbreviations and Acronyms}

AA

AFM

AuNP

BAM

C

Caf

Cat

CNT

CoPc

$\mathrm{CP}$

CPE

CuPc

CV

DC

DOD

DODAB

DP

EDP

EDS

EF
Arachidic Acid

Atomic Force Microscopy

Gold Nanoparticle

Brewster Angle Microscopy

Cabernet-Sauvignon

Caffeic Acid

Catechol

Carbon Nanotubes

Cobalt Phthalocyanine

Conductive Polymer

Carbon Paste Electrode

Copper Phthalocyanine

Cyclic Voltammetry

Direct Current

Dodecanethiol

Dimethyldiocatdecylammonium bromide

Diffraction Pattern

Electrodeposition

Energy Dispersive X-ray Spectroscopy

Enhancement factor 


\begin{tabular}{ll} 
Enz & Enzyme \\
ET & Electronic Tongue \\
FDH & D-Fructose Dehydrogenase \\
FTIR & Fourier Transform Infrared \\
G & Garnacha \\
GCE- & Glassy Carbon Electrode \\
GOx & Glucose Oxidase \\
GPH & Graphene \\
HPLC & High Performance Liquid Comatography \\
HQ & Hydroquinone \\
ISS & Low-energy lon-Scattering Spectroscopy \\
ITO & Indium Tin Oxide \\
Lac & Laccase \\
LB & Langmuir-Blodgett \\
LbL & Localized Surface Plasmon Resonance \\
Li ${ }_{2} P c$ & Layer by Layer \\
LnPc & Lilithium phthalocyanine \\
LOD & Lantanoid Bisphthalocyanine \\
\hline &
\end{tabular}




\begin{tabular}{|c|c|}
\hline $\mathrm{LuPc}_{2} \mathrm{Cl}_{32}$ & $\begin{array}{l}\text { Bis }[2,3,9,10,16,17,23,24- \\
\text { octachlorophtalocianate] lutetium (III) }\end{array}$ \\
\hline LV & Latent Variables \\
\hline M & Mencía \\
\hline MIP & Molecular Imprinted Polymer \\
\hline MONP & Metal Oxide Nanoparticle \\
\hline $\mathrm{MPc}_{2}$ & Metallophthalocyanine \\
\hline MWCNT & Multiwall Carbon Nanotubes \\
\hline NiONP & Nickel Oxide Nanoparticle \\
\hline NPc & Naphthalocyanine \\
\hline PB & Prussian Blue \\
\hline PBS & Buffer Phosphate \\
\hline Pc & Phthalocyanine \\
\hline PC & Principal Component \\
\hline PCA & Principal Component Analysis \\
\hline PLS & Partial Least Squares \\
\hline PP & Prieto Picudo \\
\hline Pyr & Pyrogallol \\
\hline QCM & Quartz Crystal Microbalance \\
\hline RMSEC & Root Mean Square Error of Calibration \\
\hline RMSEP & Root Mean Square Error of Prediction \\
\hline RRS & Resonance Raman-Scattering \\
\hline
\end{tabular}




$\begin{array}{ll}\text { RSD } & \text { Relative Standard Deviation } \\ \text { SAM } & \text { Self-Assembly Monolayer } \\ \text { SAuNP } & \begin{array}{l}\text { (11-mercaptoundecyl)tetra(ethylenglycol) } \\ \text { functionalized gold nanoparticle }\end{array} \\ \text { SAW } & \text { Surface Acoustic Wave } \\ \text { SDODAuNPs } & \begin{array}{l}\text { n-dodecanethiol } \\ \text { nanoparticle }\end{array} \\ \text { SEM } & \text { Scanning Electron Microscopy } \\ \text { SERRS } & \text { Surface-Enhanced Resonance Raman Scattering } \\ \text { SPE } & \text { Screen Printed Electrode } \\ \text { T } & \text { Tempranillo } \\ \text { TEM } & \text { Transmission Electron Microscopy } \\ \text { TPI } & \text { Total Polyphenol Index } \\ \text { Tyr } & \text { Tyrosinase } \\ \text { UHV } & \text { Ultrahigh Vacuum } \\ \text { UV-Visible } & \text { Ultravioleta Visible } \\ \text { Van } & \text { Vanillic Acid } \\ \text { XnPc } & \end{array}$




\section{JUSTIFICATION\&OBJECTIVES}


The present thesis entitled "Sensor arrays for Enology applications: Using nanoscience for grape analysis" has been developed in the Group of Sensors of the University of Valladolid (UVaSens). This document is presented to obtain the International Ph.D. Mention. For this reason and according to the regulations of the University of Valladolid it is written in English and includes a summary of the results and the general conclusions written in Spanish.

The Group of Sensors works simultaneously on basic and applied research. The basic research is focused on the preparation and characterization of new electrochemical sensors and their application for complex liquids analysis such as wines, oils, beers... The applied research is devoted to the development of electronic tongues where arrays of sensors coupled to the appropriate pattern recognition software are used to the organoleptic characterization of food and beverages. In the last years, the group has focused its research on the enology sector carrying out analysis of musts and wines. These researchs are developed with the collaboration of Instituto Tecnológico Agrario de Castilla y León (ITACyL), Bodega Cooperativa de Cigales and Estación Enológica de Castilla y León.

The success of previous research on the enology area made the group to go in depth in this field. This thesis tackles the development of new sensors based on different electroactive materials by means of different techniques. Different strategies have been foreseen to improve the performance and selectivity of the sensors by including enzymes and new electrocatalytic materials. Efforts have been undertaken to develop new nanostructured and biomimetic biosensors that can improve the performance of the system. These new sensors have been combined to form arrays of sensors and biosensors applied for the analysis of grapes quality and ripening control.

According to these general ideas, the objectives of this thesis are:

1- To desig new voltammetric sensors and biosensors using different electrocatalytic materials (nanoparticles, phthalocyanines) and 
enzymes (tyrosinase, laccase, glucose oxidase, D-fructose dehydrogenase).

2- To develop new methodologies to deposit the sensing materials and to immobilize the enzymes. Methods ranging from simple techniques which allow preparing simple and cheap sensors to more sophisticated techniques which produce nanostructured sensors with better performances but at higher cost will be employed.

3- To test these new sensors towards analytes present in must such as antioxidants, sugars and organic acids.

4- To combine sensors and biosensors in order to get different (bio)electronic tongues able to discriminate grapes with different organoleptic characteristics.

5- To develop a bioelectronic tongue containing enzymes devoted to the analysis of phenols and sugars applied to monitor the ripening process.

The work presented here is placed on the cross-road between enology and material science and has been financed by MINECO (AGL200912660/ALI and AGL2012-33535), Junta de Castilla y Leon (VA-032U13) and by a scholarship (PIF-UVa).

The present memory is organized as follows:

Chapter 1 presents a general overview about electronic tongues to help the understanding of the basis of this dissertation. This chapter presents a short synopsis about the composition of grapes. A section focused on electronic tongues and the different techniques employed to develop them is also included.

Chapters 2 to 10 encompass the experimental block of the dissertation. Each chapter is self-consistent and presents 4 sections: "introduction", "materials and methods", "results and discussion" and "conclusions". 
Chapters 2 to 6 are centered on the development of nanostructured sensors prepared using Langmuir-Blodgett (LB) technique. Different strategies to prepare good quality LB films from different materials (gold nanoparticles, phthalocyanines, enzymes) are presented. Chapter 2 research was developed in the collaboration with Prof. Kawai from Tokyo University of Science (Japan) and is focused on the preparation of LB films and nanostructured sensors containing functionalized gold nanoparticles. Chapter 3 is devoted to the development of sensors containing a bisphthalocyanine by means of LB and LS. A methodology to co-immbolize two electrocatalytic materials in the LB film and the evaluation of their synergistic effect are presented in chaper 4. The results presented in this chapter were obtained on collaboration with researchers from UNESP (Brazil). Similarly, a method to co-immobilize an enzyme with the electron mediator and the effect of the biomimetic environment is discussed on chapters 5 and 6 . In all the cases, structural and electrochemical characterization of the films and sensors is presented. Arrays of sensors combined with pattern recognition software are presented in chapters 5 and 6 . These bioelectronic tongues are dedicated not only to the analysis of standard solutions but also to the analysis of grapes.

Despite the excellent performance of nanostructure (bio)sensors, classical techniques were used to obtain cheaper sensors to form arrays that could be easily applied in the industrial environment. This idea has been developed in chapters 7 to 9 .

Chapters 7 and 8 are focused on Carbon Paste Electrodes. Different carbonaceous materials are tested on chapter 7 whereas chapter 8 is devoted to the evaluation of different phthalocyanines as electron mediator in a bioelectronic tongue. The latest is used to the discrimination of musts.

Chapter 9 presents a bioelectronic tongue made by disposable screen printed electrodes devoted to the analysis of phenols and sugars. Discrimination capability towards red grapes juice is also showed. 
During my 3-month research stay at Brookhaven National Laboratory (NY,USA) I joined Dr. Eli Sutter's group. This research group is focused on the development of new nanomaterials with environmental or energy applications. The research done during those 3 months is presented in chapter 10.

The synthesis of Au-In core-shell nanoparticles and their structural and electrochemical characterization is showed in chapter 10. Their electrocatalytical properties towards the analysis of hydroquinone, a hazardous byproduct of some industries, are discussed and compared with classical nanoparticles.

Chapter 11 presents the final conclusions of the work. 
CHAPTER 1

Introduction 

Agrofood sector constitutes one of the most important bases of the economy in Castilla y León, manufacturing almost a fourth of the industrial production of the region. In the national ranking, Castilla y León is on the top positions of food and agriculture production.

In the last years, enology sector has been confirmed as one of the most dynamic parts of the agrofood sector in Castilla y León. This sector has experienced a huge expansion due to the strict selection of the seeds, improvement of the cultivation, severe control of the berries ripening, winemaking process under firm quality controls and settled-down commercialization.

The region presents more than 75000 hectares of vineyards with more than 5750 workers. It presents 530 cellars which produce around 200 million of liters of wine per year. The region has ten designation of origin (denominación de origen D.O.) and the $86 \%$ of the vineyards are dedicated to this sign of quality. In 2013, the economic value of this sector reached more 738 million of euros being 134 generated by exportation ${ }^{1}$.

The main objectives of the technologies carried out during winemaking process are focused on an effective extraction of phenolic compounds which are responsible of the color, taste and aroma of the wines and a control of sugar fermentation which is directly related to the alcoholic degree of the final product.

As raw material of the wine industry, quality of grapes must be controlled since it directly influences the quality of the final product. In order to obtain grapes with the best characteristics, not only the ripe berry need to be controlled but also the ripening process. A good understanding of grape composition and ripening is essential to comprehend the process of winemaking and making better quality wine. 
Due to the research line of this thesis is devoted to the analysis of grapes and musts the following section describes the structure of the grapes and the classical methods used to analyze their composition.

\subsection{GRAPES}

The structure of the grape berry can be divided into three parts: skin, flesh, and seed $^{2}$ (Figure 1.1). The chemical composition of each of these parts is different and directly influences the final quality of the grapes and therefore the wine ${ }^{3}$.

Under the outer layer of skin cells, grapes present a flattened layer of cells that tend to accumulate phenolic compounds in relatively high concentrations as the grape berry matures ${ }^{4}$. These compounds strongly influence aroma, flavor and color attribute. Hence, they play a key role in determining final juice and wine quality and sensory characteristics.

The compounds concentrated in these cells include tannins, which strongly influence mouthfeel such as astringency, flavor such as bitterness and many specific taste notes. Most of these compounds are accumulated during early berry development, prior to veraison. The concentration of tannins does not appear to be much altered in the skin during the later stages of grape berry maturation, but the chemical structure of the tannins is modified. These changes lead to less astringency, less bitterness and a smoother mouthfeel. Pigments, mainly anthocyanins in red grapes, start being accumulated in these cells at veraison.

The cells that form the berry flesh contain the juice and are the primary sites for the accumulation of sugars during grape berry ripening. Acids and phenolic compounds are also concentrated in these cells, with the primary acids being tartaric and malic acid. In contrast with those located in the skin, acids and tannins located in the flesh tend to decrease in per-berry concentration during berry ripening.

The seed coat also contains relatively high concentrations of tannins. Similar to the tannins and phenols found in the flesh, these tannins are 
reduced in concentration as the berries mature ${ }^{5}$. In addition, phenols responsible for bitterness become less soluble/extractable.

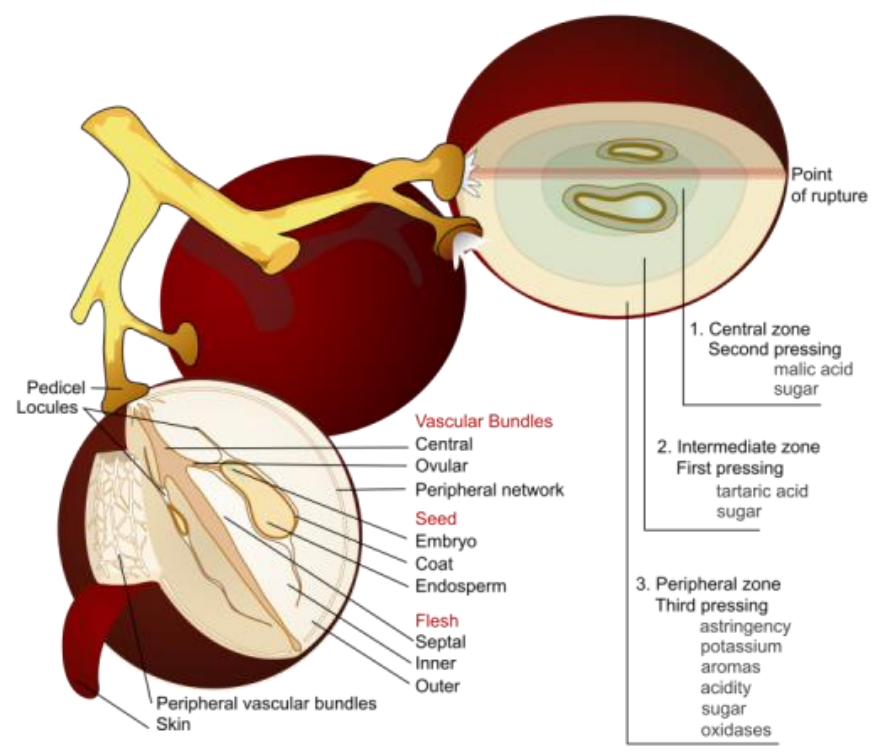

Figure 1.1. Structure of a grape berry partially sectioned to show internal parts. Principal compounds found in each part are also pointed.

\subsection{1-Chemical composition of the grapes}

Grape juice consists of 70 to $80 \%$ water and many dissolved solids. These soluble solids include numerous organic and inorganic compounds. The important groups of compounds, from the winemaking point of view, include sugars, organic acids and phenolic compounds.

A large portion of the soluble solid in grapes is sugars. Glucose and fructose are the main sugars in the juice ${ }^{6}$ and their concentration varies between 150 to $250 \mathrm{~g} / \mathrm{L}$. In unripe berries, glucose is the predominant sugar. At the ripening stage, glucose and fructose are usually present in equal amounts (1:1 ratio). In overripe grapes, the concentration of fructose exceeds that of glucose.

Glucose and fructose are converted by the yeast to alcohol and carbon dioxide during the fermentation process and their concentration is 
directly related to the amount of alcohol produced. Hence, sugar levels determine the price and the quality of the grapes.

Next to sugars, organic acids are the most abundant solids present in grape juice. They are very important components of juice and wine. As they are responsible for the sour taste and have a marked influence on wine stability, color and $\mathrm{pH}$. The principal organic acids found in grapes are tartaric, malic and in a small extent, citric acid ${ }^{7}$. During the early period of berry growth, concentration of tartaric and malic acids increases in the fruit. With the onset of ripening, while sugar accumulates in the berry, the acid concentration decreases. Generally the reduction in malic acid is greater and consequently mature grapes contain more tartaric than malic acid.

Phenolic compounds are important constituents of grapes and wine. Following sugars and acids, they are the most abundant elements present in grapes. Phenolic compounds are a group of molecules that are structurally diverse and that play a vital role in wine's color and flavor. They are involved in browning reactions in grapes and wines and they also play a key role in the aging and maturation of the final product. The phenolic compounds are primarily located in the seeds and skins of the berry ${ }^{8,9}$. Phenolic compounds present great interest in the food industry due to their antioxidant capacity and their potential health benefits. Their detection and assessment can be carried by means of fluorescence, absorbance and high performance liquid chromatography (HPLC) among others. Due to their redox properties they can also be detected by electrochemical methods.

The two main molecule families included in this group of compounds are anthocyanins and tannins. Anthocyanins are pigments and they are responsible for the red and purple color of the grapes and wines. During processing and aging, the tannins polymerize making them insoluble; their precipitation leads to a decrease in wine's astringency. 


\subsection{2-Berry ripening}

Three stages of grape berry development have been identified ${ }^{10}$. During stage I, starting at fruit set, berries expand in volume and accumulate solutes such as tartaric and malic acids, but little sugars. At stage II, called the lag phase, berries have reached half of their final size and continue to accumulate acids and tannins. Stage III starts at veraison, when berries change color, accumulate sugars and metabolize acids. After veraison, significant changes occur including decrease on malic acid and seed tannins content and increase on glucose and fructose concentration (Figure 1.2).

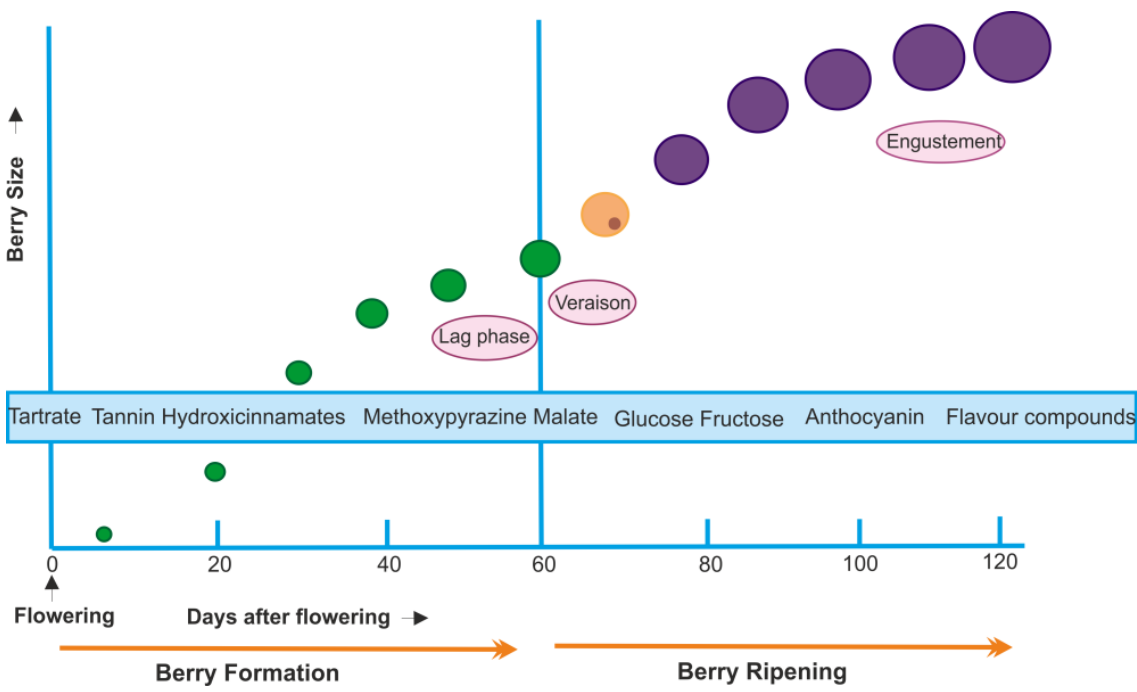

Figure 1.2. Diagram showing berries size and color at the different stages of development.

There are some correlations that theoretically determine the optimum ripeness of the berry called "ripeness indexes". They consist on certain formulation proposed to estimate the optimum maturation of the berry and fix the harvesting day.

"Physical maturation indexes" determine quantitatively some characteristics of the berry ripening such as color and weight of the bunch. 
"Chemical maturation indexes" are based on the analytical determination of several characteristic compounds whose concentration increase or decrease during ripening process. The traditional criteria usually used to determine the day of harvesting are the weight of berry, sugar content and $\mathrm{pH}$.

Once the grapes have been crushed and the musts have been obtained and clarified using the same methods that will be employed on the winemaking process, sugar content, $\mathrm{pH}$, total acidity, tartaric and malic acid concentrations and total polyphenol index are analyzed using traditional methods ${ }^{11}$.

In those criteria, aromatic compounds, fundamental in the winemaking process, and polyphenolic content, an important parameter in the elaboration of red wines are not taken into account. Nowadays, the study of polyphenolic content is taking on a great importance in the case of red winemaking process and some strategies to asses it have been developed.

Regarding sensory analysis, panels of trained experts are required. Panels need a considerable amount of resources, time and money and suffers from some drawbacks like discrepancies due to human fatigue or stress and clearly cannot be used for online measurements. The "Estación Enológica de Haro" has developed a sensory method to control grape ripeness taking into account four kinds of maturity: sugars/acidity, flesh aroma, skin aroma and tannins ${ }^{12}$. Hence, the implementation of analytical systems in fruit juice processing and quality control that could improve the actual instrumentation and will permit freshness evaluation, shelf life, and authenticity assessment and quantitative analysis is relevant.

In recent years, a new class of instruments called electronic tongues has been successfully applied to the analysis of wines ${ }^{13,14}$ including quality control $^{15-18}$, ageing control ${ }^{19,20}$ or detection of fraudulences ${ }^{21}$ among others. The use of arrays of sensors is of particular interest in the field of wines due to the importance of antioxidants, which are responsible of 
their organoleptic characteristics and also for their health benefits. Electronic tongues could also be used for the analysis of grapes.

\subsection{ELECTRONIC TONGUE}

According to the IUPAC, an electronic tongue is a multisensor system which consists of a number of low-selective sensors and cross-sensitivity to different species in solution and an appropriate method of pattern recognition and/or multivariate calibration for data processing ${ }^{22-28}$.

The pattern recognition techniques consist of four sequential stages: signal pre-processing, dimensionality reduction, prediction and validation. The signal pre-processing prepares the feature vector for future processing. It includes compensation for sensor drift, scaling of the data and extracting representative parameters. The intrinsic complexity of the signals generated by voltammetric sensor arrays can difficult the data processing. One solution to simplify the high dimensionality is to employ a feature extraction stage such as the kernel method $^{29}$.

A dimensionality reduction stage projects this initial feature onto a lower dimensional space. This is usually done using a non-supervised technique such as Principal Component Analysis (PCA). Using PCA, it is possible to discriminate between samples with different characteristics.

The resulting low dimensional feature vector is the one used to solve a given prediction problem, typically classification, regression or clustering. In regression tasks, the goal is to establish a predictive model from a set of independent variables (i.e. sensor responses) to a second set of variables that are the properties of the sample analysed (e.g. concentration, quality). They are usually carried out using Partial Least Squares (PLS) regression models ${ }^{30}$.

The heart of any electronic tongue is the array of sensors. Sensors play a decisive role in the performance of an electronic tongue, for this reason many efforts have been dedicated to the development of new sensors with improved characteristics. In general, sensors feature two functional 
components: a recognition element to provide selective/specific binding with the analyte and a transducer component for signaling the binding act. Sensors efficiency relies on these two components for the recognition process in terms of response time, signal/noise ratio, selectivity and limits of detection. Therefore, designing sensors with higher efficiency depends on the development of new materials and preparation techniques in order to improve recognition and transduction processes. Sensors used in electronic tongues can use several measurement principles including mass, optical or electrochemical transduction.

\subsection{1-Mass sensors}

Mass sensors are miniaturized solid-state devices which exploit the piezoelectric effect. Most of the mass sensors developed in order to analyze complex liquid samples are based on quartz crystal microbalance (QCM) principles. A QCM is a mass-sensitive detector based on an oscillating piezoelectric quartz crystal that resonates at a fundamental frequency. The changes in the resonance frequency are related to the changes in the mass of the substances that are adhered onto the surface of the electrode ${ }^{31}$ (Figure 1.3). In quartz resonators the acoustic wave can be propagated through the bulk material or/and on the surface. Thus there are many possible modes of operation. Although the durability of mass sensors is comparable with other sensors used in electronic tongue systems, their selectivity is limited due to their working principle (i.e. adsorption).

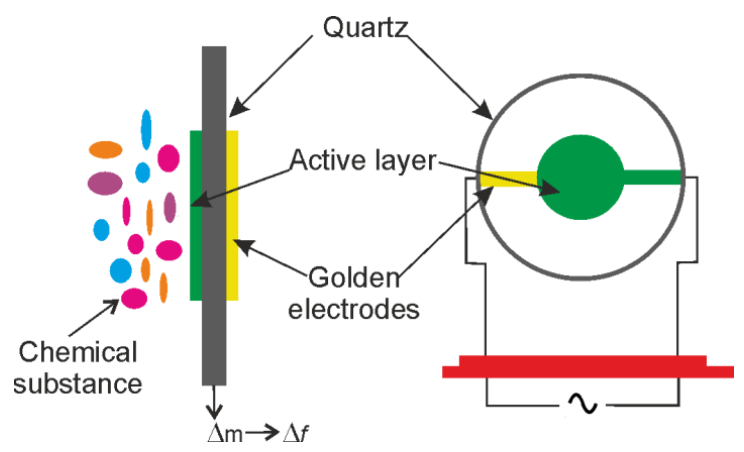

Figure 1.3. Working principle of a mass sensor. 
The sensing materials which modify the surface of the electrodes are indispensable for achieving highly sensitive and selective detection of a specific chemical. For instance, polymer-coated QCM sensors have been employed for the detection of organic compounds ${ }^{32}$, detection and quantification of metal ions in aqueous solution has been carried out using coatings of imprinted polymers ${ }^{33,34}$, silica mesoporous materials ${ }^{35}$ and sol gel films ${ }^{36}$ among others.

Arrays of sensors based on QCM principles have been devoted to the analysis of different kinds of samples such as water ${ }^{37,38}$ or grapes $^{39}$. A system based on surface acoustic wave (SAW) sensors could correctly classify basic taste substances without a selective chemical coating, but measuring different mechanical and electrical characteristics (viscosity, permittivity, conductivity). In addition, acoustic sensors placed in a microfluidic cell have been used for thedetermination of $\mathrm{pH}$, the classification of beverages and the estimation of freshness and fat content in milk ${ }^{40}$. QCM sensors coated with lipid membranes have been applied to beer recognition ${ }^{41}$.

\subsection{2- Optical sensors}

Optical sensors are based on the interaction between light and matter to determine some properties of the latest. Such sensors include an excitation source, a sensing element, a photodetector and the electronic circuitry. The light source is tuned to the specific analytical wavelength to obtain the best sensitivity. The sensor can present a chemosensitive layer, e.g. a polymeric membrane containing appropriate indicator molecules. That indicator changes its optical properties when exposed to a target analyte influencing the absorbance or fluorescence intensity of the membrane.That change is monitored by the detector (usually a photodiode or photomultiplier) whose aim is to convert the optical signal into an electric one (Figure 1.4). 


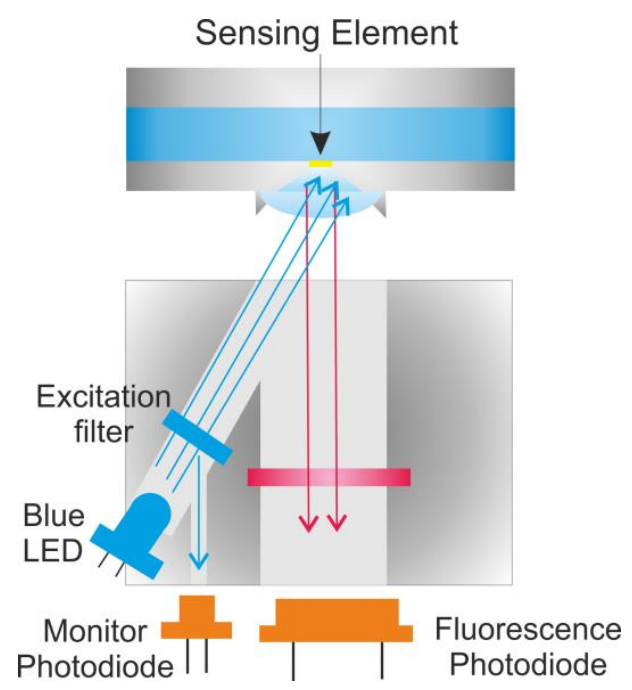

Figure 1.4. Working principle of an optical sensor.

There are many possible modes of operation of optical sensors including the acquisition of fluorescence intensity ${ }^{42,43}$, absorbance ${ }^{44-46}$ or reflectance $^{47,48}$.

Optical electronic tongues involve several optical sensors, usually based on polymeric microspheres with a chemically modified surface which allows covalent bonding to various receptors ${ }^{46}$. The microspheres can be placed in microwells fabricated in silicon structures with microchannels, where the samples are injected. The microspheres modified with various receptors are organized in a sensor array whose signals can be recorded with the use of a CCD camera. The change of microsphere colors or fluorescence caused by the interaction with the analyte creates a characteristic pattern, which can be analyzed with pattern recognition methods. Thanks to a wide variety of compounds that can be used to modify the microsphere surfaces, lots of substances can be analyzed: $\mathrm{pH}^{50,51}$, dissolved oxygen ${ }^{52}$, chlorine ${ }^{53}$ and metals ${ }^{54,55}$ among others. 


\subsection{3-Electrochemical sensors}

Electrochemical sensors (including potentiometric, amperometric, voltammetric and impedimetric sensors) are the most widely used sensing units in electronic tongues because of their specificity, high sensitivity, short response time and simple operation ${ }^{56,57}$.

\subsubsection{1-Potentiometric sensors}

In potentiometric sensors, the concentration of certain ions in a solution can be quantified by measuring the membrane potential created across an ion selective membrane at zero-current conditions. The potential created at the membrane/solution interphase depends on the nature of the electrode material and on the composition of the solution. Potentiometric sensors can be prepared from different materials, membranes and techniques ${ }^{27,58}$.

The first electronic tongue system that became commercially available was potentiometric and it was presented by Toko and coworkers ${ }^{59}$. The proposed sensor array -a multichannel electrode called a "taste sensor"consisted of potentiometric electrodes with lipid-polymeric membranes (PVS membranes with lipid derivates). Similarly to lipid layers in the cell walls in taste buds, synthetic lipid membranes were capable of perception of the five basic tastes ${ }^{60}$, thanks to that feature they could differentiate between substances exhibiting various tastes.

Potentiometric sensor arrays have been widely used to analyze complex samples such as hone ${ }^{61,62}$, fruit juices ${ }^{63,64}$, wines ${ }^{68,66}$, dairy products ${ }^{67,68}$, coffee $^{69}$ and tea ${ }^{70}$ among others.

\subsubsection{2-Impedimetric sensors}

Impedance spectroscopy has also been used as a transduction method to analyze wines. Electrodes modified with various organic materials (including conducting polymers, perylenes, phthalocyanines or carbon nanotubes) have demonstrated their capability to detect molecules present in wines ${ }^{71}$. The presence of insecticides in water has also been analyzed by means of molecular imprinted polymer (MIP) sensors ${ }^{72}$. Rotaxanes have been used to detect toxic metals such us $\mathrm{Hg}^{2+}, \mathrm{Cu}^{2+}$ and 
$\mathrm{Pb}^{2+} 71$. A composite sensor aray based on carbon nanotubes and carbon black dispesed in polymeric matrices and doped polythiophenes was used to discriminate basic tastes ${ }^{74}$.

\subsubsection{3-Amperometric sensors}

The simplest form of amperometric detection is single-potential or direct current (DC) amperometry. A voltage (potential) is applied between two electrodes positioned in the column effluent. The measured current changes when an electroactive analyte is oxidized at the anode or reduce at the cathode. The applied potential can be adjust to maximize the response towards the analyte of interest while minimizing the response for interfering analytes.

Amperometric electrodes arrays have been employed to analyze wines ${ }^{75}$ and wastewater quality ${ }^{76}$ among others.

\subsubsection{4-Voltammetric sensors}

Voltammetric sensors are based on the same principles as potentiometric sensors but in this case the potential is variable. The curves obtained as a result of the analysis are called voltammograms and the peaks shown are associated with the oxidation and reduction of the molecules present in the solution, being their intensity proportional to the concentration. Voltammetry or voltamperometric technique involves different techniques of electrochemical analysis (cyclic voltammetry, square wave voltammetry and pulse differential voltammetry) making this kind of system more versatile.

Voltametric electronic tongues have been widely used in the enology industry either analyzing musts ${ }^{76-79}$ or wines ${ }^{80,81}$. Other kinds of beverages have been also analyzed by means of electronic tongue including beer ${ }^{82}$, fruit juice, tea, milk, and coffee ${ }^{83}$.

The main success in voltammetric electronic tongues has been obtained using chemically modified electrodes. They were developed for the first time by our group ${ }^{84}$ and this strategy has been adopted by many groups $^{85-88}$. 
The modification of the electrode surface with electroactive and electrocatalytic materials (e.g. phthalocyanines, conducting polymers or nanoparticles) provides electrodes with improved selectivity ${ }^{89-91}$.In this case voltammograms show redox peaks associated not only with the solution but also with the electrode (Figure 1.5). Simultaneously, the interactions between the electrode and the solution improve extraordinarily the selectivity of the electrodes. Such interactions include among others: i) the oxidant or reducing character of the solution that can modify the oxidation potential of the electrode material; ii) the electrocatalytic activity of the electrode material that can facilitate the oxidation of the compounds solved in the analyzed solution; iii) the acid or basic character of the solution can protonate/deprotonate the electrode; iv) the nature and concentration of ions present in the solution that diffuse inside the sensing layer to maintain the electroneutrality. These interactions produce changes on the intensities and positions of the redox peaks and are the reason of the important cross-selectivity achieved with these sensors. Metal nanoparticles, polymeric materials, graphene, carbon nanotubes, perylenes and phthalocyanines among others, have been used as modifiers in order to get sensors with different/complementary analytical properties.

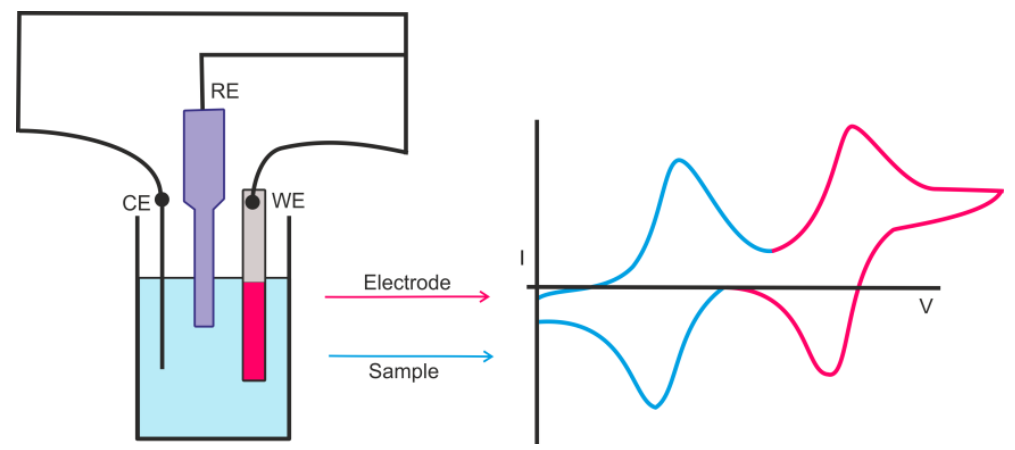

Figure 1.5. Working principle of a modified voltammetric sensor. 


\subsection{4- Chemical modifiers}

The following sections present the chemical modifiers used in of this work.

\subsubsection{1-Metal nanoparticles}

Nanoparticles are defined as particles between 1 to $100 \mathrm{~nm}$ whose physicochemical properties differ from the bulk counterpart due to their small size. A reduction in the particle size causes three main changes: i) structural changes where cell parameters could be altered even resulting in non-stoichometric particles; ii) the electronic properties can also be changed, due to the quantum confinement effect; iii) they provide high surface-volume ratio, increasing the surface area for electron exchange. All these properties can be tuned by varying their size, shape and surrounding chemical environment.

*Gold Nanoparticles (AuNPs)- AuNPs present physical and chemical attributes that make them excellent scaffolds for the fabrication of novel sensors $^{92}$. They can be synthesized straightforward and can be made highly stable. The binding between the sensor and the analyzed molecule can alter physicochemical properties of transducer AuNPs, such as plasmon resonance absorption, conductivity, redox behavior... that can generate detectable response signals. In addition, they present excellent electrocatalytic properties due to enhancement on the surface-volume ratio. The fact that AuNPs can be functionalized with a wide range of ligands leads to the detection of small molecules or non easily detectable targets.

* Metal Oxide Nanoparticles (MONPS)- MONPs can be used in electroanalysis of different kinds of analytes ${ }^{93}$. Their magnetic properties can be employed for the separation of analytes while the semiconductive properties of certain MONPs can also be used for the electrochemical detection of selected analytes. Many MONPs have been used in electrochemical analysis such us nickel, iron, zinc, titanium, cerium and manganese oxides due to their electrocatalytic behavior. The use of mixed metal oxides has also become increasingly prevalent due to 
the limited methods to increase the activity of an oxide containing single metal oxide.

*Core-shell Nanoparticles- Core-shell NPs are composed of two or more materials. This type of nanoparticles can be broadly defined as comprising a core (inner material) and a shell (outer layer material). These particles can consist of a wide range of different combinations in close interaction including inorganic/inorganic, inorganic/organic, organic/inorganic and organic/organic. The choice of the shell material of the core-shell NP is generally dependent on the end application and use. Nanoparticles coated with a functional material such us noble metal, semiconductor or appropriate oxide increase the physical properties (i.e. optical, catalytic activity, electrical, magnetic and thermal) of the combined particles compared with the pure core particles. Regarding electrochemistry applications mainly noble metal cores and metal oxide shells have been used for the analysis.

\subsubsection{2-Phthalocyanines}

The compound known as phthalocyanine (Pc) is a symmetrical macrocycle formed by four isoindol units (Figure 1.6).

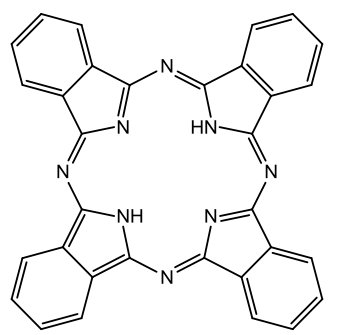

Figure 1.6. Phthalocyanine ring.

The simplest phthalocyanine is the metal-free $\mathrm{Pc}\left(\mathrm{H}_{2} \mathrm{Pc}\right)$. Metallophthalocyanines (termed as MPc) consist of a phthalocyanine ring coordinated with a metallic ion $(+2)$ placed in the central cavity (Figure 1.7.a). A large variety of phthalocyanine derivatives can be obtained by modification of the aromaticity of the ring system. As an 
example, Figure 1.7.b illustrates the structure of a family of Pc derivatives called naphthalocyanines (NPc) characterized by extended conjugated structures. Phthalocyanines can also form sandwich type rare-earth complexes where a lanthanoid ion is coordinated with two phthalocyanine rings $\left(\mathrm{LnPc}_{2}\right)$ (Figure 1.7.c). Heteroleptic analogues containing different tetrapyrrole ligands have also attracted considerable interest (Figure 1.7.d) ${ }^{94}$. Double or triple decker complexes, usually exhibit strong $\pi-\pi$ interactions resulting in intriguing electronic and optical properties.

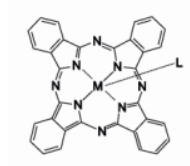

a)

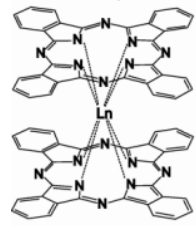

c)

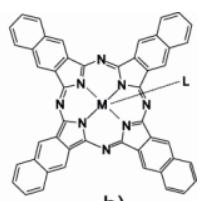

b)

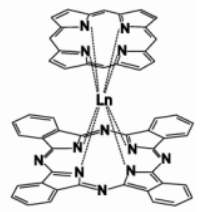

d)

Figure 1.7. a) Metallophthalocyanine. b) Naphthalocyanine. c) Lanthanoid bisphthalocyanine. d) Heteroleptic phthalocyanine-porphyrin.

Phthalocyanine structures permit chemical modification through change of the central metal ion, through symmetric and asymmetric substitution of the main phthalocyanine skeleton and through axial ligation to the central metal. This wide range of possibilities explains the huge number of phthalocyanine molecules synthesized until now and the increasing number of Pc molecules tested as sensitive materials.

The properties which render metal phthalocyanine species valuable as electrochemical sensing materials are related to their semiconducting properties and electrochemical behavior ${ }^{95,96}$.

*Semicoductivity: MPcs which are p-type semiconductors when doped with oxygen with conductivities ranging from $10^{-10}$ to $10^{-12} \mathrm{~S} \cdot \mathrm{cm}^{-1}$ at 300K. Particularly interesting is the case of $\mathrm{LnPc}_{2}$ that have particularly high intrinsic conductivities $\left(\sigma=10^{-6}-10^{-3} \mathrm{~S} \cdot \mathrm{cm}^{-1}\right.$ at $\left.\mathrm{T}=300 \mathrm{~K}\right)$. This behavior 
is due to their neutral radical state and the strong electronic interaction between the two tightly bound Pc rings.

*Electrochemical properties: Phthalocyanines have attracted considerable attention for their electrochemical, electrocatalytic and electrochromic properties. The Pc ring is an 18 electron aromatic system that in the neutral state carries two negative charges $\operatorname{Pc}(-2)$. Electron structure of phthalocyanines allows both the oxidation of the Pc ring by one or two electrons forming $\mathrm{Pc}(-1)$ and $\mathrm{Pc}(0)$, and the reduction of the $\mathrm{Pc}$ ring by one to four electrons, to yield $\mathrm{Pc}(-3), \mathrm{Pc}(-4), \mathrm{Pc}(-5)$ and $\mathrm{Pc}(-6)$. In addition variation of the oxidation state of the central metal ion can also occur. The electrochemical potentials at which the oxidations or the reduction occur depend on the nature of the metal ion, the class of phthalocyanine and the presence of substituents in the phthalocyanine ring. Changes in the oxidation state are usually accompanied by changes in the electronic absorption spectra and $\mathrm{LnPc}_{2}$ are well known as electrochromic materials.

\subsubsection{3- Enzymes}

In order to make sensors more specific for the analysis of target molecules, enzymes are deposited on the surface of the electrode, obtaining sensor units called biosensors. Enzymes are macromolecular biological catalysts ${ }^{97}$. They accelerate chemical reaction by decreasing the activation energy. As the rest of catalysts, enzymes are not consumed on the reaction process and they do not alter the equilibrium between species. Enzymes activity can be affected by other molecules called inhibitors that can decrease enzymes activity or denaturalize them. Generally, enzymes are globular proteins formed by linear chains of amino acids that folds in a three-dimensional structure. The sequence of these amino acids specifies the structure which in turn, determines the catalytic activity of the enzyme. The reaction takes place in a small part of the enzyme called active site in which the substrate is hold by the amino acids around while the reactions take places. This makes the enzymes specific for one reaction, as the other molecules do not fit into the active site. Enzymes' name is derived from the substrate or the 
chemical reaction they catalyze, with the word ending -ase, e.g. oxireductases are the enzymes that catalyzes oxidation/reduction reactions. In this research, two phenol oxidases (tyrosinase and laccase), glucose oxidase and D-fructose dehydrogenase have been used in order to improve the selectivity of the sensors.

Phenol oxidases are copper containing-enzymes that catalyze hydroxylation of phenols producing the corresponding benzoquinones. Tyrosinase and laccase are two of the most known phenol oxidases.

*Tyrosinase (Tyr)- Tyr carries out the oxidation of o-diphenols using dioxygen $\left(\mathrm{O}_{2}\right)$. Hydrogens removed from the phenol combine with oxygen to form water. Tyr can be isolated from a wide variety of plants, fungal and animal species. These different origins confer them great diversity in terms of structural and chemical properties. No common Tyr protein structure occurring across all species has been found (Figure 1.8).

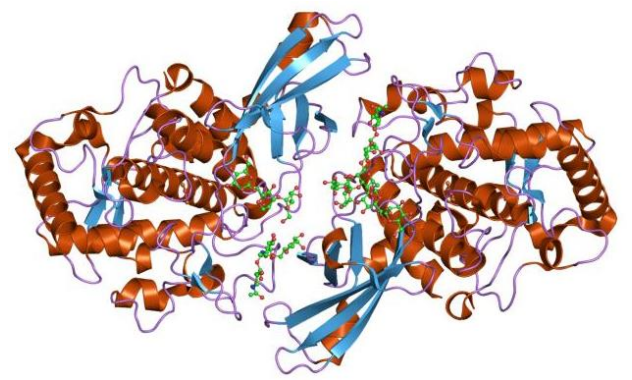

Figure 1.8. Three dimensional structure of tyrosinase.

* Laccase (LaC)- Lac is found in many plants, fungi and bacteria species. It presents 4 copper atoms that are bound in three different sites, presenting diverse functions. Lac acts on $p$-phenols and similar molecules, carrying out a one-electron oxidation. As oxidative enzyme it requires oxygen as a second substrate. Copper type I is the active site where the phenol is oxidized and type II and type III is where the oxygen is reduced producing water. It can be polymeric, and the enzymatically active form can be a dimer or trimer. 
*Glucose oxidase (GOx)- GOx catalyzes the oxidation of glucose to hydrogen peroxide and D-glucono-o-lactone which then hydrolyzes to gluconic acid (Figure 1.9). GOx is a dimeric protein covered with carbohydrate chains as it acts outside cells. The active site where glucose binds is a deep pocket. Glucose presents equilibrium between $\alpha$ and $\beta$ anomers and at $\mathrm{pH} 7$ the proportion is c.a. $37 \%$ and $63 \%$ respectively. GOx binds specifically to $\beta$-D-Glucose and does not react with $\alpha$-D-Glucopyranose however all the glucose in solution is oxidized due to the equilibrium is driven towards $\beta$ side as it is consumed in the reaction.

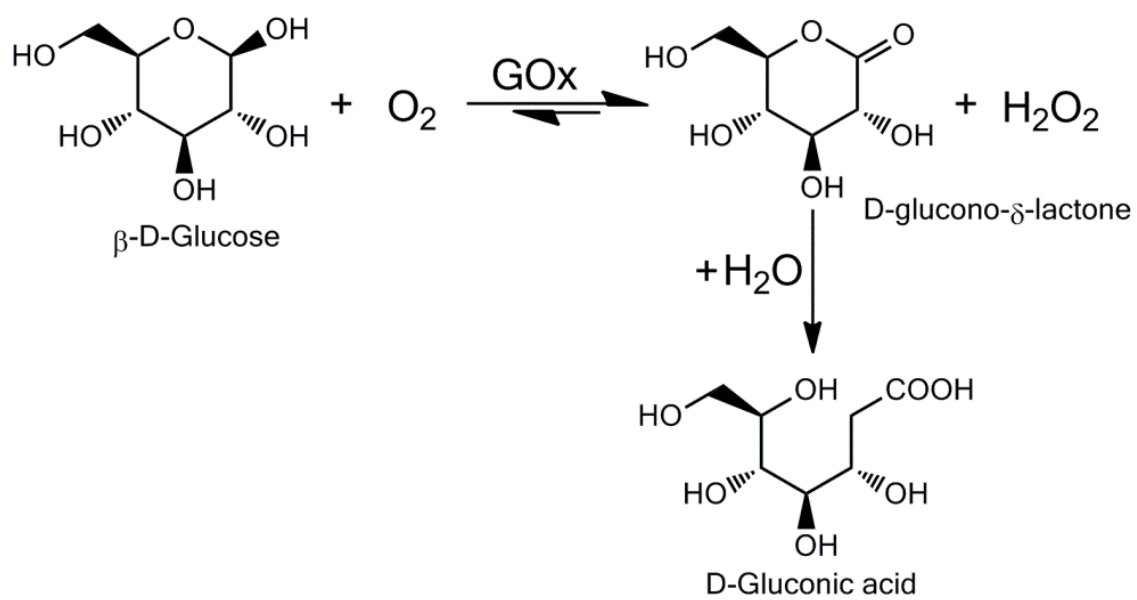

Figure 1.9. Reaction process of the oxidation of glucose by Glucose oxidase.

${ }^{*} D$-Fructose dehydrogenase (FDH)- FDH is a membrane enzyme that catalyzes the oxidation of $\mathrm{D}$-fructose to 5 -dehydro-D-fructose. It belongs to the family of oxidoreductases and it is isolated from Gluconobacter, an acetic acid bacter ${ }^{98}$.

\subsection{5- Preparation of voltammetric sensors: Deposition techniques}

Voltammetric sensors and biosensors can be prepared using a variety of techniques. Depending on the method used, different surface morphologies can be obtained which have a direct effect on the sensing behavior of the sensor. Methods range from simple techniques which allow preparing simple and cheap sensors to more sophisticated 
techniques which produce nanostructured sensors with better performances but at higher cost.

\subsubsection{1-Classical sensors}

* Casting: In this simple method, a drop of the solution of the sensitive material is deposited on the electrode surface. Then, the solvent evaporates leaving behind a layer of the sensing material ${ }^{99,100}$.

*Adsorption: Adsorption of the modifier molecule on graphite or carbon materials is one of the most popular methods due to its simplicity. The adsorption of the molecules on the electrode surface is achieved by immersing the electrode in a solution of the corresponding molecule in an appropriate solvent for several minutes ${ }^{101}$.

* Carbon Paste Electrodes (CPE): CPEs are prepared by mixing graphite (or other carbonaceous material such as carbon nanotubes) with the modifier and a mineral oil or an epoxy resin ${ }^{13,102,103}$. This mixture is introduced in a tube and a metallic wire is used as a contact.

* Spin-Coated films: The material contained in a solution is deposited using centrifugal forces. The first stage is the deposition of the coating fluid onto the substrate. Then, the substrate rotates at a constant speed. This causes the spreading of the solution and a gradual fluid thinning until the solvent evaporates completely (Figure 1.10). The thickness of the film depends on the concentration and the viscosity of the solution and on the rate of rotation of the substrate. These characteristics make spin-coating one of the most promising methods to be used in cheap commercial sensors ${ }^{104}$.

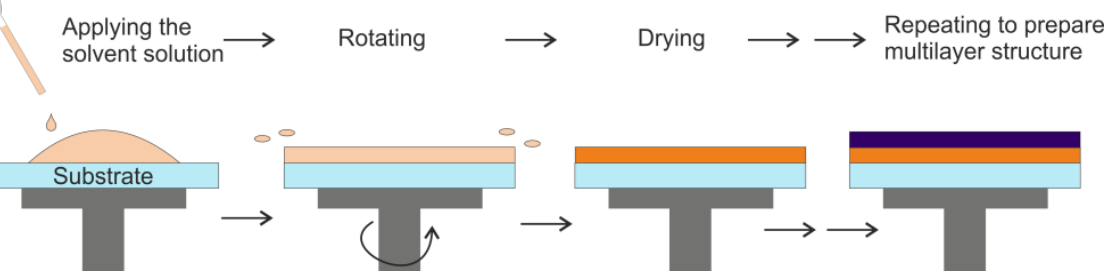

Figure 1.10. Spin coating process. 
*Screen printing: Layers of the different materials such as graphite, metal oxides or phthalocyanine derivates are printed as thick pastes by pressing the paste through a pattern on a screen. This method has been widely used for the preparation of electrochemical sensors. Screen printed electrodes containing the working electrode, the reference electrode and the counter electrode on the same device are commercially available $e^{101,105}$.

\subsubsection{2-Nanostructured sensors}

Nanostructured thin films have shown great potential on improving the sensitivity of chemical sensors. The first reason is that ultra-thin films present high surface uniformity and enhanced surface to volume ratio allowing the analyte molecules to be adsorbed or desorbed from the molecular sites more readily. Secondly, the organization of the structure at the nanometric level causes the film properties to differ from those obtained with the same materials in the form of thick films. Finally, the control of the film structure allows miming biological environment leading to the development of biosensors with improved sensitivity and better working. Typical methods used to fabricate nanostructured films include self-assembly, layer by layer or the Langmuir-Blodgett technique.

*Self-Assembled Monolayers (SAMs): The term self-assembling refers to the spontaneous formation of self-organized monolayers adsorbed on solid inorganic substrates. SAMs are created by chemisorptions of head groups onto the substrate from vapor or liquid phase. The strength of the interactions depends on the substrate and on the head groups. SAM can be defined as a head group, tail and a functional group (Figure 1.11). Common head groups include silanes, thiols, phosphonates, etc. ${ }^{106}$.

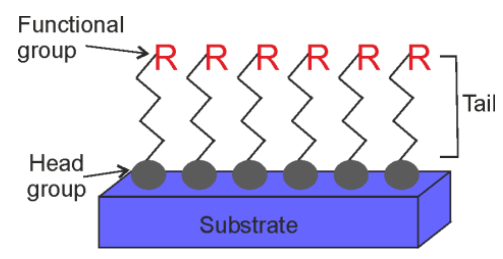

Figure 1.11. Self-Assembled Monolayer. 
*Layer by Layer method ( $L b L)$ : Multilayers can be prepared by depositing alternatively cationic and anionic compounds or polyelectrolytes with wash steps in between (Figure 1.12). This LbL self-assembly method is easy, fast and the structure, layer composition and thickness of the films can be accurately controlled. The LbL technique provides a tool to construct extremely interesting structures combining a variety of reactants such as $\mathrm{Au}$ nanoparticles, polyallylamine and phthalocyanines ${ }^{39,107}$.


Figure 1.12. Layer by layer process.

* Langmuir-Blodgett (LB) films: LB films are formed by spreading a solution of the film forming molecule onto the water surface contained in a Langmuir trough. Upon compression, the molecules are oriented at the interface giving rise to an ordered monolayer. This floating monolayer can be transferred onto a solid substrate by dipping the substrate perpendicularly to the water sub-phase. Repeated dippings allow multilayers to be obtained where the thickness can be controlled by the number of dipping cycles. Monolayers are usually composed of amphiphilic molecules with hydrophilic head and hydrophobic tail. LB technique has been widely used to prepare mixed films spreading different kinds of molecules (phthalocyanines, lipids, nanoparticles...) onto the subphase $\mathrm{e}^{79,108,109}$.

It is well known that different types of sensors show different structures and number of effective sites. For this reason, different sensors show different performances. This aspect will be investigated in this work. 


\section{References}

1. Consejería de Agricultura. Junta de Castilla y León.

2. Hidalgo Togores, J. Tratado de Enología I, 2003. Ed. Mundi-Prensa. Madrid (Spain).

3. Fanzy, C. Enología: Fundamentos científicos y tecnológicos, 2002. Ed. Mundi-prensa. Madrid (Spain).

4. Moutounet, M., Cheynier, V., Sarni-Manchado, P. Los compuestos fenólicos in Enología: Fundamentos científicos y tecnológicos, 2002, 1141136. Ed. Mundi-prensa. Madrid (Spain).

5. Kennedy, J.A., Matthews M.A., Waterhouse, A.L. Phytochem. 2000, $55,77-85$.

6. Ribereau-Gayon, P., Dubourdieu, D., Doneche, B., Lonvaud, A. Handbook of Enology. The Microbiology of Wine and Vinifications, 2005. Wiley, New York (USA).

7. Vincent, J.E. Let's make wine!, 2011. lulu.com

8. Darias-Martin, J., Carrillo, M., Diaz, E., Boulton, R.B. Food Chem. 2001, 73, 217-220.

9. Lerno, L.A., Reichwage, M., Ponangi, R., Hearne, L., Block, D.E., Oberholster, A. Am. J. Enol. Vitic. 2015, 66, 444-453.

10. Keller, M. The Science of Grapevines - Anatomy and Physiology, 2010. Ed. Elsevier. Philadelphia (USA).

11. OIV. Compendium of International Methods of Analysis of Wines and Musts. 2013.

12. Melendez, E., Iñiguez Crespo, M., Puras, P. Cuaderno de campo. 2011, 34-39. 
13. Medina-Plaza, C., Revilla, G., Muñoz, R., Fernandez-Escudero, J.A., Barajas, E., Medrano, G., de Saja, J.A., Rodriguez-Mendez, M.L. J. Porphyrins Phtahlocyanines. 2014, 17,1-11.

14. Moreno-Codinachs, L., Kloock, J.P., Schöning, M.J., Baldi, A., Ipatov, A., Bratov, A., Jiménez-Jorquera, C. Analyst. 2008, 133, 1440-1448.

15. Peris, M., Escuder-Gilabert, L. Anal. Chim. Acta. 2013, 804, 29-36.

16. Buratti, S., Ballabio, D., Giovanelli, G., Dominguez, C.M., Moles, A., Benedetti, S., Sinelli, N. Anal. Chim. Acta. 2011, 697, 67-74.

17. Chung, S., Park, S.T., Park, S.H., Kim, J.Y., Par, S., Son, D., Bae, Y.M., Cho, S.I. Sensors. 2015, 15, 18197-18208.

18. Costa, A.M.S., Sobral, M.M.C., Delgadillo, I., Cerdeira, A., Rudnitskaya, A. Sensor Actuat. B. 2015, 207, 1095-1103.

19. Apetrei, C., Apetrei, I., Nevares, I., del Alamo, M., Parra, V., Rodriguez-Mendez, M.L., de Saja, J.A. Electrochim. Acta. 2007, 52, 25882594 .

20. Gay, M., Apetrei, C., Nevares, I., del Alamo, M., Zurro, J., de Saja, J.A., Rodriguez-Mendez, M.L. Electrochim. Acta. 2010, 55, 6782-6788.

21. Parra, V., Arrieta, A., Fernandez-Escudero, J.A., Rodriguez-Mendez, M.L., de Saja, J.A. Sensors Actuat. B. 2006, 118, 448-453.

22. Vlasov, Y., Legin, A., Rudnitskaya, A., Di Natale, C., D'Amico, A. Pure Appl. Chem. 2005, 77, 1965-1983.

23. Winquist, F. Microchim. Acta. 2008, 163, 3-10.

24. Rodriguez-Mendez, M.L., de Saja, J.A., Medina-Plaza, C., GarciaHernandez, C. Electronic tongues for the organoleptic characterization of wines" in Electronic tongues and noses in food science. 2016. Ed. Elsevier. Philadelphia (USA).

25. Escuder-Gilabert, L., Peris, M. Anal. Chim. Acta. 2010, 665, 15-25. 
26. Riul, A. Jr., Dantas, C.A.R., Miyazaki, C.M., Oliveira, O.N.Jr. Analyst. 2010, 135, 2481-2495.

27. Ciosek, P., Wroblewski, W. Sensors. 2011, 11, 4688-4701.

28. Del Valle, M. Sensors. 2011, 11, 10180-10186.

29. Parra, V., Hernando, T., Rodríguez-Méndez, M.L., de Saja, J.A. Electrochim. Acta. 2004, 49, 5177-5185.

30. Kirsanov, D., Mednova, O., Vietoris, V., Kilmartin, P.A., Legin, A. Talanta. 2012, 90, 109-116.

31. Sauerbrey, G. Z., Physik, 1959, 206-212.

32. Fan, X., Du Sens, B. Sensors Actuat. B. 2011, 160, 724-729.

33. Tokuyama, H., Kitamura, E., Seida, Yoshimi. Talanta. 2016, 146, 507509.

34. Yang, Z.P., Zhang, C.J. Sensors Actuat. B. 2009, 142, 210-215.

35. Lou, H., Zhang, Y., Xiang, Q., Xu, J., Li, H., Xu, P., Li, X. Sensors Actuat. B. 2012, 166-167, 246-252.

36. Su, P.G., Hung, F.C., Lin, P.H. Mater. Chem. Phys. 2012, 130-136.

37. Erbahar, D.D., Gurol, I., Gumus, G., Musluoglu, E., Ozturk, Z.Z., Ahsen, V., Harbeck, M., Sensors Actuat. B. 2012, 562-568.

38. White, C., Pejcic, B., Myers, M., Qi, X. Sensors Actuat. B. 2014, 70-77.

39. Garcia-Hernandez, C., Medina-Plaza, C., Garcia-Cabezon, C., MartinPedrosa, F., del Valle, I., de Saja, J.A., Rodriguez-Mendez, M.L. Sensors. 2015, 15, 29233-29249.

40. Cole, M., Sehra, G.S, Gardner, J.W. Varadan, V.K. Proceedings of IEEE Sensors. 2002, 1, 237-241. 
41. Kaneda, H., Takashio, M., Okahata, Y. J. Am. Soc. Brew.Chem. 2005, 63, 89-94.

42. Aziz, A.A.A., Seda, S.H., Mohammed, S.F. Sensors Actuat. B. 2016, 223, 566-575.

43. Elabd, A.A., Elhefnawy, O.A. J. Fluorescence. 2016, 26, 271-276.

44. Abolghasemi, M.M., Sobhi, M., Piryaei, M. Sensors Actuat. B. 2016, 224, 391-395.

45. Rouis, A., Darbost, U., Bonnamour, I., Ouada, H.B. Mat. Chem. Phys. 2015, 164, 145-149.

46. Wang, Y., Wu, F. Polymer. 2015, 56, 223-228.

47. Coelho, L., Viegas, D., Santos, J.L., Marques Martins de Almedia, J.M. Talanta. 2016, 148, 170-176.

48. Mishra, V., Patel, P.N., Tiwari, V. Opt. Quant. Electron. 2015, 47, 2299-2310.

49. Hogan, H. Photonics Spec. 2007, 41, 30.

50. Chamkouri, N., Niazi, A., Zare-Shahabadi, V. Spectrochim. Acta. Part A. 2016, 156, 105-111.

51. Timbo, A.P., Pinto, P.V.F., Pinho, H.A., de Moura, L.P., Chretien, J.B., Viana, F.W., Filho, R.G.D., da Silva, E.B., da Silva, M.E.R., Menezes, J.W.M., Guimaraes, G.F., Fraga, B.W. Sensors Actuat. B. 2016, 223, 406410.

52. Chu, C.S., Lin, K.Z., Tang, Y.H. Sensors Actuat. B. 2016, 223, 606-612.

53. Szili, M., Kasik, Matejec, V., Nagy, G., Kovacs, B. Sensors Actuat. B. 2014, 192, 92-98.

54. Zhao, L., Li, M., Liu, M., Zhang, Y., Wu, C., Zhang, Y. J. Hazard Mater. 2016, 15, 233-241. 
55. Chen, Y., Wu, Y., Weng, B., Wang, B., Li, C. Sensors Actuat. B. 2016, 223, 689-696.

56. del Valle, M. Electroanal. 2010, 22, 1539-1555.

57. Kimmel, D.W., LeBlanc, G., Meschievitz, M.E., Cliffel, D.E. Anal. Chem. 2010, 84, 685-707.

58. Bratov, A., Abramova, N., Ipatov, A. Anal. Chim. Acta. 2010, 678, 149159.

59. Toko, K. Sci. Eng. C. 1996, 4, 69-82.

60. Toko, K. Sens. Update. 1998, 3, 131-160.

61. Major, N., Markovic, K., Krpan, M., Saric, G., Hruskar, M., Vahcic, N. Talanta. 2011, 85, 569-574.

62. Escrichea, I., Kadar, M., Domenech, E., Gil-Snachez, L. J. Food Eng. 2012, 109, 449-456.

63. Kraujalyte, V., Venskutonis, P.R., Pukalskas, A., Cesoniene, L., Daubaras, R. Food Chem. 2015, 188, 583-590.

64. Ciosek, P., Augustyniak, E., Wroblebwski, W. Analyst. 2004, 129, 639644.

65. Paolesse, R., Lvova, L., Nardis, S., Di Natale, C., D Amico, A., Lo Castro, F. Microchim. Acta. 2008, 163, 103-112.

66. Costa, A.M., Sobral, M.M.C., Delgadillo, I., Cerdeira, A., Rudnitskaya, A. Sensors Actuat. B. 2015, 207, 1095-1103.

67. Hruskar, M., Major, N., Krpan, M., Vahcic, N. Talanta. 2010, 82, 12921297.

68. Hruskar, M., Major, N., Krpan, M. Talanta, 2010, 81, 398-403. 
69. Buratti, S., Sinelli, N., Bertone, E., Venturello, A., Casiraghi, E., Geobaldo, F. J. Food Agriculture. 2015, 95, 2192-2200.

70. He, W., Hu, X., Zhao, L., Liao, X., Zhang, Y., Zhang, M., Wu, J. Food Research Int. 2009, 42, 1462-1467.

71. Volpati, D., Aoki, P.H.B., Dantas, C.A.R., Paulovich, F.V., de Oliveira, M.C.F., Oliveira, O.N., Riul, A., Aroca, R.F., Constantino, C.J.L. Langmuir. 2012, 28, 1029-1040.

72. Bakas, I., hayat, A., Piletsky, S., Piletska, E., Chehimi, M.M., Noguer, T., Rouillon, R. Talanta. 2014, 130, 294-298.

73. Teka, S., Gaied, A., Jaballah, N., Xiaonan, S., Majdoub, M. Mat. Research Bull. 2016, 74, 248-257.

74. Pioggia, G., Di Francesco, F., Marchetti, A., Ferro, M., Leardi, R., Ahluwalia, A. Biosens. Bioelectron. 2007, 22, 2624-2628.

75. Pigani, L., Culetu, A., Ulrici, A., Foca, G., Vignali, M., Seeber, R. Food Chem. 2011, 129, 226-233.

76. Czolkos, I., Dock, E., Tonning, E., Christensen, J., Winther-Nielsen, M., Carlsson, C., Mojzikova, R., Skladal, P., Wollenberger, U., Norgaard, L., Ruzgas, T., Emneus, J. Biosens. Bioelectron. 2016, 75, 375-382.

77. Granato, D., Margraf, T., Brotzakis, I., Capuano, E., van Ruth, S.M. J. Food Sci. 2016, 80, C55-C65.

78. Campos, I., Bataller, R., Armero, R., Gandia, J.M., Soto, J., MartinezManez, R., Gil-Sanchez, L. Food Res. Int. 2013, 54, 1369-1375.

79. Medina-Plaza, C., de Saja, J. A., Rodriguez-Mendez, M. L. Biosens. Bioelectron. 2014, 57, 276-283.

80. Gutierrez-Capitan, M., Capdevilla, F., Vila-Plaza, J., Domingo, C., Buttgenbach, S., Ilobera, A., Puig-Pujol, A., Jimenez-Jorquera, C. J. Sensors. 2014, 598317. 
81. Ceto, X., Gonzalez-Calabuig, A., Capdevilla, J., Puig-Pujol, A., del Valle, M. Sensors Actuat. B. 2015, 207, 1053-1059.

82. Blanco, C.A., de la Fuente, R., Caballero, I., Rodriguez-Mendez, M.L. J. Food Eng. 2015, 157, 57-62.

83. Rodriguez-Mendez, M.L. Electronic Noses and Tongues in Food Science. 2016. Ed. Elsevier. Philadelphia (USA).

84. Arrieta, A.A., Apetrei, C., Rodriguez-Mendez, M.L., de Saja, J.A. Electrochim. Acta. 2004, 49, 4543-4551.

85. de As, A.C., Cipri, A., Gonzalez-Calabuig, A., Stradiotto, N.R., del Valle, M. Sensors Actuat. B. 2016, 222, 645-653.

86. Bagnsaco, L., Cosulich, M.E., Speranza, G., Medini, L., Oliveri, P., Lanteri, S. Food Chem. 2014, 157, 421-428.

87. Ghosh, A., Bag, A.K., Sharma, P., Tudu, B., Sabhapondit, S., Baruah, B.D., Tamuly, P., Bhattacharyya, N., Bandyopadhyay, R. IEE Sensors J. 2015, 11, 6255-6262.

88. Wang, L., Niu, Q.F., Hui, Y.B., Jin, H.L. Sensors. 2015, 7, 17767-17785.

89. Rodriguez-Mendez, M.L., Parra, V., Apetrei, C., Villanueva, S., Gay, M., Prieto, N., Martinez, J., de Saja, J.A. Microchim. Acta. 2008, 163, 2331.

90. Garcia-Hernández, C., Garcia-Cabezón, C., Medina-Plaza, C., MartinPedrosa, F., Blanco, Y., de Saja, J.A., Rodriguez-Mendez, M.L. Beilstein J. Nanotechnol. 2015, 6, 2052-2061.

91. Medina-Plaza, C., Garcia-Cabezon, C., Garcia-Hernandez, C., Bramorski, C., Blanco-Val, Y., Martin-Pedrosa, F., Kawai, T., de Saja, J.A., Rodriguez-Mendez, M.L. Anal. Chim. Acta. 2015, 853, 572-578.

92. Alex, S., Tiwari, A. J. Nanosc. Nanotech. 2015, 15, 1869-1894.

93. Lim, W.Q., Gao, Z.Q. Electroanal. 2015, 27, 2074-2090. 
94. Jiang, J. Functional Phthalocyanine Molecular Materials. Series: Structure and Bondings. 2010. Ed. Springer. Berlin (Germany)

95. Zagal, J.H., Griveau, S., Silva, J.F., Nyokong, T., Bedioui, F. Coord. Chem. Ver. 2010, 254, 2755-2791.

96. Rodriguez-Mendez, M.L. Sensing properties of phthalocyanines in Encyclopedia of sensors. 2006, 111-134. Eds. Grimes, C.S., Dickey, E.C., Pishko, M.V. Ed. America Scientific Publishers. California (USA).

97. Palmer, T., Bonner, P.L. Enzymes: Biochemistry, Biotechnology, Clinical Chemistry. 2007. Ed. Woodhead Publishing. New Delhi (India).

98. Yamada, Y., Aida, K., Uemura, T. Agr. Biol. Chem. 1966, 30, 95-96.

99. Zhou, J., Li, X., Yang, L.L., Yan, S.L., Wang, M.M., Cheng, D., Chen, Q., Dong, Y.L., Liu, P., Cai, W.Q., Zhang, C.C. Anal. Chim. Acta. 2015, 899, 5765.

100. Wang, W.J., Gao, J., Wang, L., Ye, B.X. Anal. Methods. 2015, 7, 8847-8856.

101. Medina-Plaza, C., García-Hernández, C., de Saja, J.A., FernándezEscudero, J.A., Barajas, E., Medrano,G., García-Cabezón,C., MartinPedrosa, F., Rodriguez-Mendez, M.L. LWT-Food Sci. Tech. 2015, 62, 940947.

102. Mukdasai, S., Crowley, U., Pravda, M., He, X.Y., Nesterenko, E.P., Nesterenko, P.N., Paull, B., Srijaranai, S., Glennon, J.D., Moore, E. Sensors Actuat. B. 2015, 218, 280-288.

103. Baghizadeh, A., Karimi-Maleh, H., Khoshnama, Z., Hassankhani, A., Abbasghorbani, M. Food Anal. Methods. 2015, 8, 549-557.

104. Gay-Martin, M., Diez-Arevalo, E., Rodriguez-Mendez, M.L., de Saja, J.A. Sensors Actuat. B. 2013, 185, 24-31.

105. www.dropsens.com 
106. Li, Y.F., Ye, Z., Luo, P.L., Li, Y., Ye, B.X. Anal. Methods. 2014, 6, 19281935.

107. Raoof, J.B., Ojani, R., Baghayeri, M. Turkish J. Chem. 2013, 37, 3650.

108. Medina-Plaza, C., Furini, L.N., Constantino, C.J.L., de Saja, J.A., Rodriguez-Mendez, M.L. Anal. Chim. Acta. 2014, 851, 95-102.

109. Zou, L.N., Li, Y.F., Cao, S.K., Ye, B.X. Talanta. 2013, 117, 333-337. 



\section{CHAPTER 2}

Analysis of Organic Acids and Phenols of Interest in the Wine Industry using Langmuir-Blodgett Films Based on Functionalized Nanoparticles 

As stated on the introduction, antioxidants (i.e. phenols) present great interest for the enology industry due not only to their influence on the organoleptic characteristics of the final product but also due to their health benefits. Free-radical theory of aging states that organisms age because cells tend to accumulate free radical damage over time. In some model organism, such as yeast, there are evidences that reducing oxidative damage can extend life span. It has been demonstrated that antioxidants are helpful in reducing and preventing damage from free radical reactions because of their ability to neutralize them. Although a variety of methods have been described to detect antioxidants and to evaluate the antioxidant capacity of foods, up to now, a single method has not been recognized as the most adequate. Antioxidants are usually electroactive compounds and this property can be exploited for electrochemical detection.

In addition, organic acids present in grapes and wines need to be monitored as they are related to the $\mathrm{pH}$, acidity and mouthfeel among other properties of the wine. They also influence the stability of the final product and "control" the microbiological modifications that can occur along the winemaking process.

In this chapter ITO modified with gold nanoparticles deposited by Langmuir-Blodgett technique are used to analyze standard solution of phenols (caffeic and gallic acid) and organic acids (tartaric, malic, citric and lactic acids) present in musts. The modification of the electrode using LB technique allow preparing thin films well organized and structured, increasing the number of active sites on the surface and improving the analytical properties of the sensor. The electrocatalytic properties, the dynamic character and the detection limits of these amphiphilic gold nanoparticles modified with $n$-dodecanethiol will be evaluated. Moreover, mixtures of tartaric and caffeic acids will be analyze in order to detect possible interferences during the analysis. This research has been developed in collaboration with Prof. Kawai from Tokyo University of Science (Japan) and has been published in Analytica Chimica Acta. 


\subsection{INTRODUCTION}

The organoleptic and antioxidant properties of grapes and wines are closely related to their chemical composition. The organic acid content of grapes, musts and wines is of interest because its important influence on their sensory properties such as flavor, taste, color and aroma. Organic acids also affect the juice stability and are used as indicators of microbiological alterations in the beverage ${ }^{1,2}$. The principal organic acids found in grapes and therefore in wines, are tartaric and malic acids. Other acids such as citric acid are present in smaller amounts ${ }^{3}$. During the course of winemaking and in the finished wines other acids such as lactic acid can play significant roles.

Grapes and wines are also rich in phenolic compounds. Such compounds have attracted great interest due to their antioxidant activity and their important influence in the organoleptic properties ${ }^{4,5}$. In particular, phenolic acids, such as gallic and caffeic acids have been studied for their antioxidant capacity and for acting as venous dilators ${ }^{6}$.

Various analytical methods have been reported for the determination of organic acids and phenolic compounds in wines and grapes including gas chromatography, HPLC, spectroscopic or electrochemical techniques ${ }^{7-9}$. Electrochemical measurements have certain advantages for the determination of antioxidants. For instance, the oxidation potentials measured by cyclic voltammetry (CV) have been used to compare the antioxidant strength of compounds such as phenolic acids, flavonoids, cinnamic acids, etc. being the glassy carbon electrode (GCE) the more frequently used electrode ${ }^{10-14}$. Chemically modified electrodes have also been successfully used as sensitive and selective tools for determination of many organic substances and some of them have been dedicated to the detection of organic acids and/or phenolic compounds ${ }^{15-18}$. Voltammetric electrodes have been successfully integrated in multisensory systems for the analysis of complex liquids ${ }^{19,20}$.

Gold nanoparticles (AuNPs), have received great interest in the field of electrochemical sensors ${ }^{21}$. Their small size provides high surface to volume ratios which are the reason of their unique electronic and 
catalytic properties ${ }^{22-26}$. However, in a number of applications, the benefits of using nanoparticles have not been fully exploited due to the lack of strategies for positioning the particles in ordered, homogeneous and reproducible solid-state devices. Recently, attempts have been made to immobilize NPs onto solid substrates using the LangmuirBlodgett (LB) technique ${ }^{27-30}$. In order to obtain such ordered monolayers, nanoparticles must be capped to induce the amphiphilic character necessary for the LB technique ${ }^{31}$.

\subsection{MATERIALS AND METHODS}

\subsection{1- Chemicals}

All experiments were carried out in deionized Milli-Q water (Millipore, Bedford, MA). Inorganic salts, organic acids (DL-malic acid, L(+)-tartaric acid and lactic acid), phenolic acids (caffeic and gallic acids), dodecanethiol, tetrachloroaurate tetrahydrate, tetraoctylammonium bromide and $\mathrm{NaBH}_{4}$ were purchased from Sigma-Aldrich. Commercially available reagents and solvents were used without further purification.

$10^{-3} \mathrm{~mol} \cdot \mathrm{L}^{-1}$ stock solutions of organic acids and phenolic compounds were prepared by solving the corresponding compound in $\mathrm{KCl}(0.1 \mathrm{~mol}$. $\mathrm{L}^{-1}$ ). Solutions with lower concentration were prepared from the stock solutions by dilution. The mixtures phenol/organic acid were prepared by mixing the corresponding volume of the $10^{-3} \mathrm{~mol} \cdot \mathrm{L}^{-1}$ stock solutions in proportions $40: 10,25: 25$ and $10: 40$ to obtaining $50 \mathrm{~mL}$ as final volume.

The final concentrations of the mixtures were $8 \times 10^{-4}: 2 \times 10^{-4}$, $5 \times 10^{-4}: 5 \times 10^{-4}$ and $2 \times 10^{-4}: 8 \times 10^{-4} \mathrm{~mol} \cdot \mathrm{L}^{-1}$ respectively.

\subsection{2- Equipment}

LB films were prepared in a USI-3-22 film balance (USI Co. Ltd.) equipped with a Wilhelmy plate to measure the surface pressure. TEM Images were obtained using a Jeol JEM-1011 electron microscope operated at an accelerating voltage of $100 \mathrm{kV}$. The electrochemistry was carried out in an EG\&G PARC 273 potentiostat/galvanostat. 


\subsection{3- Preparation of nanoparticles}

Dodecanethiol-functionalized $\mathrm{Au}$ nanoparticles ( $\mathrm{S}_{\mathrm{DOD}} \mathrm{AuNP}$ ) were prepared using the Brust's two-phase method ${ }^{32}$. A quantity $15.8 \mathrm{~mL}$ of a $24.3 \times 10^{-3} \mathrm{~mol} \cdot \mathrm{L}^{-1}$ aqueous solution of $\mathrm{HAuCl}_{4}$ was added to a $2.29 \times 10^{-3}$ $\mathrm{mol} \cdot \mathrm{L}^{-1}$ phase transfer reagent, tetraoctylammonium bromide, dissolved in toluene $(15 \mathrm{~mL})$, and the mixture was stirred for $10 \mathrm{~min}$. The toluene phase was subsequently collected and $1.5 \mathrm{~mL}$ of a $49 \times 10^{-3} \mathrm{~mol} \cdot \mathrm{L}^{-1}$ toluene solution of dodenanethiol (DOD) was added. The solution was stirred for $2 \mathrm{~h}$. Then, $2 \mathrm{~mL}$ of a $2.11 \mathrm{~mol} \cdot \mathrm{L}^{-1}$ aqueous solution of $\mathrm{NaBH}_{4}$ was added. The reaction mixture was vigorously stirred at room temperature for $12 \mathrm{~h}$ and the toluene phase was collected. Since the size distribution of the resulting $S_{D O D} A u N P$ was quite broad, the dispersion was refluxed at $80^{\circ} \mathrm{C}$ for $24 \mathrm{~h}$ to obtain monodisperse $S_{D O D} A u N P$. The resulting $S_{D O D} A u N P$ were washed five times with acetone to remove the phase transfer reagent, excess DOD and reaction byproducts. The resulting particles have a narrow size distribution with an average diameter of $4.9 \pm 0.5 \mathrm{~nm}$.

\subsection{4- Preparation of LB films}

The toluene dispersion of $S_{D O D} A u N P$ was spread onto the air/water interface to make the monolayer of AuNPs. The surface pressure-area $(\pi-A)$ isotherm was measured at room temperture using a Wilhelmy plate. The monolayer of $S_{D O D} A u N P$ was then transferred onto ITO substrates at a surface pressure of $10 \mathrm{mN} \cdot \mathrm{m}^{-1}$ to obtain LB films.

\subsection{5- Electrochemical studies}

The LB films were used as working electrodes of a conventional three electrode cell. The reference electrode was $\mathrm{Ag} \mid \mathrm{AgCl} / \mathrm{KCl} 3 \mathrm{M}$ and the counter electrode was a platinum plate. Cyclic voltammetry was carried out at room temperature with a scan rate of $0.1 \mathrm{~V} \cdot \mathrm{s}^{-1}$ in the potential range of $-1.0 \mathrm{~V}$ and $+1.0 \mathrm{~V}$.

The repeatability of the voltammograms was evaluated from 5 repetitions on each sample. The reproducibility of data provided by the $S_{\text {DOD }} A u N P$ was evaluated by comparing data provided by three sensors measuring identical samples in different days. 
The dynamic behavior of the films was characterized by registering voltammograms at increasing scan rates from 0.010 to $1.0 \mathrm{~V} \mathrm{~s}^{-1}$.

The calibration curves were constructed from solutions with concentrations ranging from $1 \times 10^{-3}$ to $1 \times 10^{-5} \mathrm{~mol} \cdot \mathrm{L}^{-1}$.

The limits of detection (LOD) were calculated following the $3 \mathrm{~s}_{\mathrm{d}} / \mathrm{m}$ criterion, where $\mathrm{m}$ is the slope of the calibration graph, and $s_{d}$ was estimated as the standard deviation $(n=5)$ of the voltammetric signals at the concentration level corresponding to the lowest concentration of the calibration plot $^{33}$.

\subsection{RESULTS AND DISCUSSION}

\subsection{1- Structural characterization}

Figure 2.1 shows a TEM image of LB monolayer of $S_{D O D} A u N P$ transferred onto a TEM-copper grid at a surface pressure of $10 \mathrm{mN} \cdot \mathrm{m}^{-1}$, which is the same transfer condition used to prepare $\mathrm{S}_{\mathrm{DOD}} \mathrm{AuNP}$ monolayer onto ITO substrates. $\mathrm{S}_{\mathrm{DOD}} \mathrm{AuNP}$ were in a relatively random array, but the single layer was densely covered with the substrate. The diameter of $S_{D O D} A u N P$ was $4.9 \pm 0.5 \mathrm{~nm}$. The density of $\mathrm{S}_{\mathrm{DOD}} A \mathrm{AuNP}$ was evaluated from the TEM image and found to be $\sim 30 \mathrm{~nm}^{2} /$ particle.

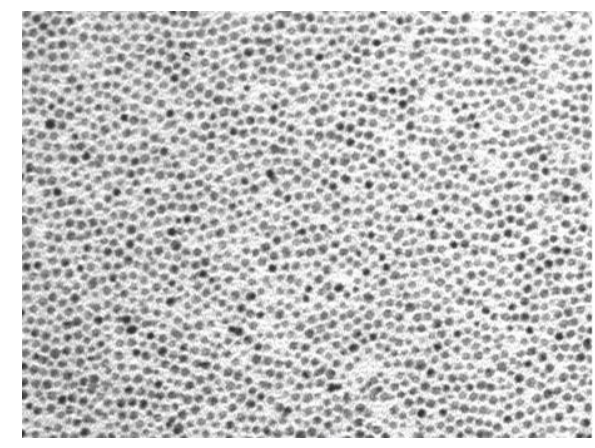

Figure 2.1. TEM image of $S_{D O D} A u N P$ LB monolayer transferred onto a TEMcopper grid. 


\subsection{2- Electrochemical response in simple electrolytes}

As a first electrochemical characterization, cyclic voltammograms of bare ITO and of $\mathrm{S}_{\text {DOD }}$ AUNP-LB on ITO immersed in $0.1 \mathrm{~mol} \cdot \mathrm{L}^{-1}$ solutions of different electrolytes $\left(\mathrm{KCl}, \mathrm{KBr}, \mathrm{KNO}_{3}, \mathrm{KClO}_{4}\right.$ and $\left.\mathrm{MgCl}_{2}\right)$ were registered. Figure 2.2 compares the voltammograms obtained from a bare ITO and from $S_{D O D} A u N P-L B$ electrode in $\mathrm{KCl}$ and $\mathrm{MgCl}_{2}$ solutions over a potential range from -1.0 to $+1.0 \mathrm{~V}$.


Figure 2.2. Cyclic voltammograms of bare ITO (blue line) and $S_{D O D} A u N P-L B$ (red line) sensors immersed in a) $0.1 \mathrm{~mol} \cdot \mathrm{L}^{-1} \mathrm{KCl}$ and b) $0.1 \mathrm{~mol} \cdot \mathrm{L}^{-1} \mathrm{MgCl}_{2}$. Scan rate, $0.1 \mathrm{~V} \cdot \mathrm{s}^{-1}$.

For the bare ITO electrode, no observable faradaic current appeared either on the forward or reverse scans regardless the electrolyte used. Whereas, the cyclic voltammogram for the $\mathrm{S}_{\mathrm{DOD}} \mathrm{AuNP}$-LB modified electrode immersed in $\mathrm{KCl}$ (Figure 2.2.a) showed the typical response of gold nanoparticles with the oxidative peak at $0.7 \mathrm{~V}$ corresponding to gold oxide formation during the forward scan alongside the reduction peak at $0.17 \mathrm{~V}$ responsible for the reduction of gold oxide during the reverse $\operatorname{scan}^{32,33}$. The reduction of protons from water was promoted in the presence of $S_{D O D} A u N P$ as indicated by the presence of a cathodic peak at $c a .-0.75 \mathrm{~V}$ that was absent on neat ITO glass.

Voltammograms registered in the presence of other electrolytes containing potassium ion $\left(\mathrm{KBr}, \mathrm{KNO}_{3}\right.$ or $\left.\mathrm{KClO}_{4}\right)$ were quite similar. The peak positions did not change and only small modifications in the redox 
peak currents were observed. However, in the presence of a divalent cation (such as $\mathrm{Mg}^{2+}$ from $\mathrm{MgCl}_{2}$ ) the intensity of the redox peaks corresponding to gold oxidation/reduction decreased. Simultaneously, the peak corresponding to the reduction of protons from water was displaced to more negative potentials (Figure 2.2.b).

From these results, it can be concluded that cations instead of anions diffuse inside the films to maintain the electroneutrality during the scan. In addition, when the cation radius increased, the redox peak potential of the reduction of protons from water moved to more negative potentials decreasing the electrocatalytic activity of the $S_{D O D} A u N P-L B$ sensor.

In all electrolytes analyzed, the intensity of the peaks increased linearly with the scan rate pointing to an electron transfer limited process (due to the electrochemical activity of the nanoparticles deposited at the surface of the electrode) with regression coefficients in the range 0.990 0.995 .

\subsection{3- Electrocatalytic effect of $S_{\mathrm{DOD}} \mathrm{AuNP}-\mathrm{LB}$ towards organic} acids

$S_{D O D} A U N P-L B$ modified electrodes were used to analyze organic acids typically found in grapes and wines. The study included the two main organic acids present in wines (tartaric and malic acids), one acid present in minor proportion (citric acid) -all of them coming from the oxidation of sugars-, along with lactic acid which is an example of acid generated by microbial activity. The electrocatalytic effect of $S_{D O D} A u N P$ $\mathrm{LB}$ electrodes was analyzed in $10^{-3} \mathrm{~mol} \cdot \mathrm{L}^{-1}$ solutions of the corresponding organic acid by comparing the cyclic voltammograms observed at the bare ITO electrode and at the $S_{\text {DOD }}$ AuNP-LB electrodes (Figure 2.3).

None of the organic acids studied produced noticeable electrochemical responses when analyzed with a bare ITO electrode. However, the modified electrode catalyzed the reduction of the liberated protons and intense oxidation/reduction processes were observed at negative potentials. 
The different electrochemical behaviors were related to the chemical nature of the acids analyzed. The voltammetric response of lactic acid (monoprotic acid, $\mathrm{pK}_{\mathrm{a}}=3.90, \mathrm{pH}$ of a $10^{-3} \mathrm{~mol} \cdot \mathrm{L}^{-1}$ solution=3.43) showed only one reduction peak at $-0.85 \mathrm{~V}$ that corresponds to the reduction of the dissociated $\mathrm{H}^{+}$proton. In malic acid (diprotic acid, $\mathrm{pK}_{1}=3.48$ and $\mathrm{pK}_{2}=5.10, \mathrm{pH}$ of a $10^{-3} \mathrm{~mol} \cdot \mathrm{L}^{-1}$ solution=3.18), two well-separated electrochemical reduction peaks for each one of the dissociated protons were observed at about -0.85 and $-0.95 \mathrm{~V}$. The corresponding oxidations occurred at $-0.4 \mathrm{~V}$ and $-0.5 \mathrm{~V}$. The response of tartaric acid (diprotic acid, $\mathrm{pKa}_{1}=2.98$ and $\mathrm{pKa}_{2}=4.34, \mathrm{pH}$ of a $10^{-3} \mathrm{~mol} \cdot \mathrm{L}^{-1}$ solution $=2.93)$ also showed the reduction of the two protons $(-0.85 \mathrm{~V}$ and $-0.9 \mathrm{~V})$. The oxidations were observed at $-0.4 \mathrm{~V}$ and $-0.5 \mathrm{~V}$. It is important to notice that in tartaric acid, the redox peaks were not well resolved in both the forward and the reverse scans. It is also interesting to remark that the $I_{a} / I_{c}$ ratio was much higher for tartaric acid than for malic acid. The fact that tartaric and malic acids showed different responses is of particular interest for the wine industry since tartaric and malic acids are the most prevalent acids present in wines. Moreover, malic acid shows a continuous decrease during ripening whereas tartaric acid remains almost unchanged. Therefore, different ratios can be obtained during ripening and the optimum harvest date can be established from their ratio. The response of citric acid (triprotic acid, $\mathrm{pK}_{1}=3.09, \mathrm{pK}_{2}=4.75$ and $\mathrm{pKa}_{3}=6.41, \mathrm{pH}$ of a $10^{-3} \mathrm{~mol} \cdot \mathrm{L}^{-1}$ solution=2.97) was similar to that of tartaric acid and two not well resolved cathodic peaks were observed. The similitude could be easily explained taking into account the weak acidity of the third acidic proton of the citric acid.

According to the enhancement in current responses, it is possible to conclude that $S_{D O D} A u N P$-LB electrodes show an intense electrocatalytic effect towards the reduction of protons, and that voltammetric responses are different for the main acids found in wines. In addition, the observation of distinct redox processes associated with first and second dissociated protons is a remarkable result of our $\mathrm{S}_{\text {DOD }}$ AuNP-LB electrodes since bulk gold electrodes are not able to discriminate among acids or to provide distinct signals for different protons ${ }^{36}$. 

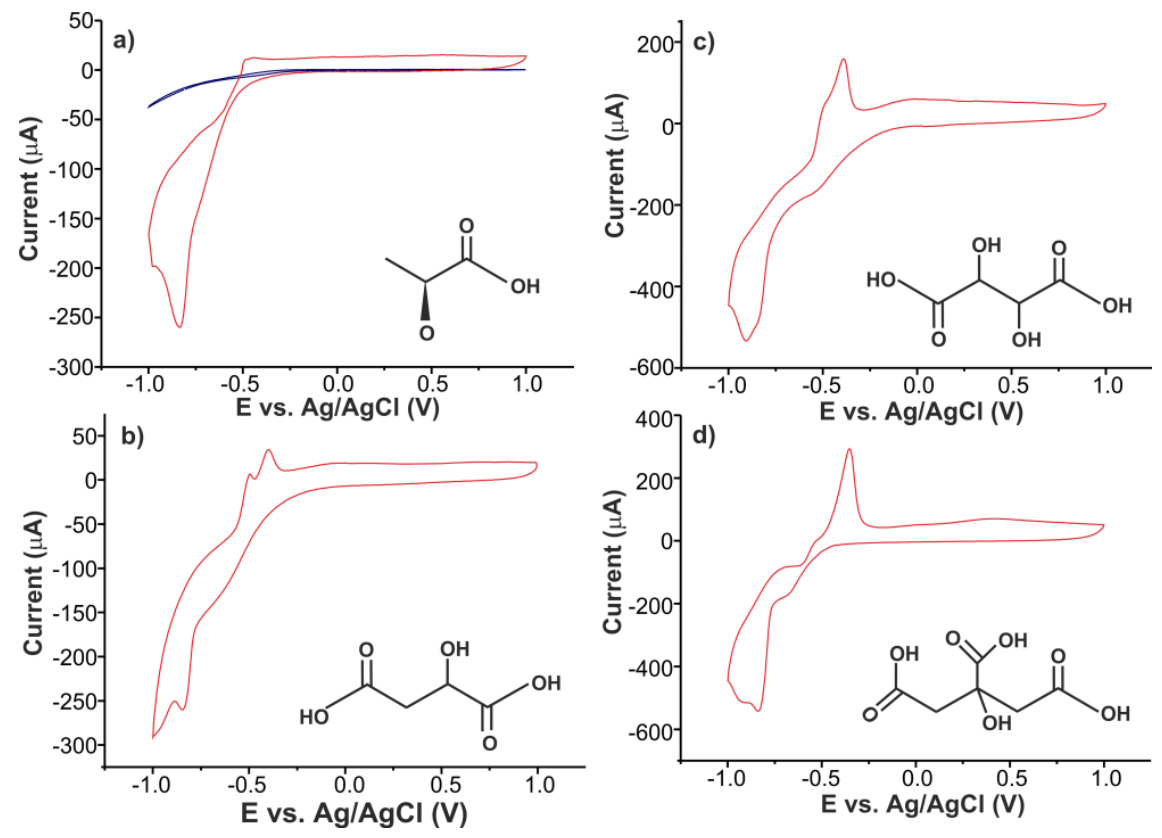

Figure 2.3. $\mathrm{CV}$ of a bare ITO (blue line) and $\mathrm{S}_{\mathrm{DOD}} \mathrm{AuNP}-\mathrm{LB}$ (red line) towards $10^{-3}$ $\mathrm{mol} \cdot \mathrm{L}^{-1}$ of a) Lactic, b) Malic, c) Tartaric and d) Citric acids. Scan rate, $0.1 \mathrm{~V} \cdot \mathrm{s}^{-1}$.

The influence of the potential scan rate on the peak height was also investigated between 0.01 and $1.0 \mathrm{~V} \cdot \mathrm{s}^{-1}$. The intensity of the cathodic peaks increased linearly with the square root of the scan rate and conformed to the Randles-Sevcik equation (Equation 2.1):

$$
I=2.687 \times 10^{5} n^{3 / 2} v^{1 / 2} D^{1 / 2} \mathrm{AC} \text { (Equation 2.1) }
$$

Where $I$ is the peak current $(A), C$ represents concentration of the electroactive species $\left(\mathrm{mol} \cdot \mathrm{L}^{-1}\right), v$ potential scan rate $\left(\mathrm{V} \cdot \mathrm{s}^{-1}\right), \mathrm{A}$ electrode surface $\left(\mathrm{cm}^{2}\right), D$ diffusion coefficient of the analytes $\left(\mathrm{cm}^{2} \cdot \mathrm{s}^{-1}\right)$, and $\mathrm{n}$ number of electrons transferred in the redox process. In all cases, the correlation coefficient $\mathrm{R}^{2}$ was higher than 0.990 , pointing to a diffusion limited process (Table 2.1).

The logarithm of peak current changed linearly with the logarithm of scan rate with a slope value close to 0.5 for tartaric and lactic acids 
confirming ideal diffusion controlled mechanism. In the case of citric and malic acids, the slopes were found to be lower than 0.5. A closer look to the graphs showed that the increase in the scan rate caused a shift of the cathodic peaks towards more negative potentials. At scan rates higher than $0.05 \mathrm{~V} \cdot \mathrm{s}^{-1}$, the peaks could not be longer observed. The slopes recalculated for citric and malic acids using scan rates from 0.01 to $0.05 \mathrm{~V} \cdot \mathrm{s}^{-1}$ were close to 0.4 pointing also to a diffusion controlled process.

Table 2.1. Slope and regression coefficients obtained from the voltammograms registered at different scan rates for the organic acids. Intensities measured using the cathodic wave at $-0.85 \mathrm{~V}$.

\begin{tabular}{|c|c|c|c|c|}
\hline \multirow{2}{*}{$\begin{array}{l}\text { Organic } \\
\text { acid }\end{array}$} & \multicolumn{2}{|c|}{$\begin{array}{l}\text { Relationship with scan rate } \\
I_{c}(\mu \mathrm{A}) \text { vs. } v^{1 / 2}\left(\mathrm{mV} \cdot \mathrm{s}^{-1}\right)^{1 / 2}\end{array}$} & \multicolumn{2}{|c|}{$\begin{array}{l}\text { Relationship with scan rate } \\
\log I_{c}(\mu \mathrm{A}) \text { vs. } \log v\left(\mathrm{mV} \cdot \mathrm{s}^{-1}\right)\end{array}$} \\
\hline & Slope & $\mathrm{R}^{2}$ & Slope & $\mathbf{R}^{2}$ \\
\hline Lactic & -24.14 & 0.990 & 0.48 & 0.990 \\
\hline Malic & -9.39 & 0.980 & 0.24 & 0.982 \\
\hline Tartaric & -47.15 & 0.992 & 0.45 & 0.991 \\
\hline Citric & -22.69 & 0.981 & 0.26 & 0.982 \\
\hline
\end{tabular}

In contrast, the anodic wave showed a tricky behavior. At low scan rates, a linear dependence with the square root of the scan rate was observed, but at scan rates higher than $0.5 \mathrm{~V} \cdot \mathrm{s}^{-1}$ the voltammograms presented distorted shapes and decreased their intensity while a new broad peak at $0.5 \mathrm{~V}$ grew progressively. These facts could be explained assuming that adsorption/polymerization processes are involved in the oxidations, causing the mentioned distortion ${ }^{37}$.

The effect of the concentration in the sensor response was studied by immersing the electrode in organic acid solutions with concentrations ranging from $1 \times 10^{-5}$ to $1 \times 10^{-3} \mathrm{~mol} \cdot \mathrm{L}^{-1}$. The influence of increasing concentrations is illustrated in Figure 2.4 for citric acid. When representing the calibration curve for the cathodic peak (at $-0.85 \mathrm{~V}$ ), an increase in the intensity of the peaks with the concentration was 
observed. The limit of detection (LOD) calculated following the $3 \mathrm{~s}_{\mathrm{d}} / \mathrm{m}$ criterion was $5.6 \times 10^{-6} \mathrm{~mol} \cdot \mathrm{L}^{-1}$ (Table 2.2 ). The anodic peak was only observed at concentrations higher than $10^{-4} \mathrm{~mol} \cdot \mathrm{L}^{-1}$. This observation could be explained taking into account the dissociation constants of the acids $\left(\mathrm{pK}_{\mathrm{a}}\right)$ and the change of the $\mathrm{pH}$ caused by the concentration. The $\mathrm{pH}$ of a $10^{-3} \mathrm{~mol} \cdot \mathrm{L}^{-1}$ citric acid solution $\left(\mathrm{CitH}_{3}\right)$ is 2.97 and the predominant species is $\mathrm{CitH}_{2}{ }^{-}$whereas the $\mathrm{pH}$ of the $10^{-5} \mathrm{~mol} \cdot \mathrm{L}^{-1}$ solution is 5.01 and the predominant species is $\mathrm{CitH}^{2-}$ so, the anodic wave could only be observed when the predominant specie was $\mathrm{CitH}_{2}{ }^{-}$. A similar behavior was observed in the rest of organic acids studied. For instance, tartaric acid can be present in wine and juice as tartaric acid $\left(\mathrm{TH}_{2}\right)$, bitartrate $\left(\mathrm{TH}^{-}\right)$or tartrate $\left(\mathrm{T}^{2-}\right)$. The ratio of these species depends mainly on the $\mathrm{pH}$ of the wine. The anodic wave was only observed when the predominant species was bitartrate $\mathrm{TH}^{-}$(maximum concentration of $\mathrm{TH}^{-}$ occurs at $\mathrm{pH} 3.7$ and at $\mathrm{pH} 5.0$, the predominant species is $\mathrm{T}^{2-}$ ).

Due to the non-linear behavior of the anodic wave, in all organic acids analyzed the LODs were calculated by analyzing the intensity of the cathodic peaks at $-0.85 \mathrm{~V}$ following the $3 \mathrm{~s}_{\mathrm{d}} / \mathrm{m}$ criterion. As observed in Table 2.2, they were in the range of $10^{-5}-10^{-6} \mathrm{~mol} \cdot \mathrm{L}^{-1}$.

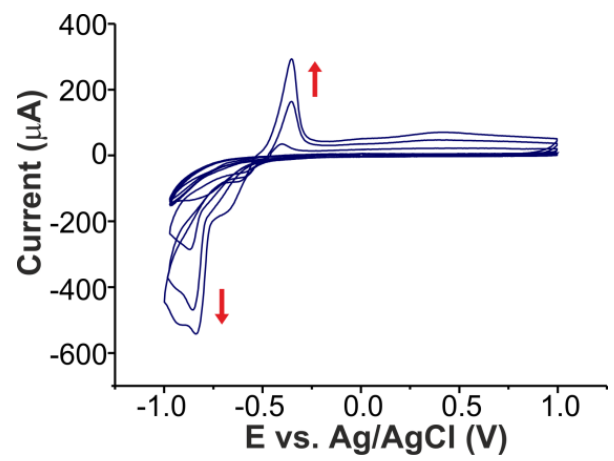

Figure 2.4. $C V$ of a $L B$ film of $S_{D O D} A U N P-L B$ immersed in increasing amounts of citric acid $\left(10^{-5}\right.$ to $\left.10^{-3} \mathrm{~mol} \cdot \mathrm{L}^{-1}\right)$. 
Table 2.2. LOD, sensitivity and regression coefficient $\left(R^{2}\right)$ calculated from the cathodic peak at ca. $-0.85 \mathrm{~V}$ for the four organic acids under study.

\begin{tabular}{|l|r|r|c|}
\hline Organic acid & LOD $\left(\mathbf{m o l}^{-\mathbf{- 1}}\right)$ & Slope & $\mathbf{R}^{\mathbf{2}}$ \\
\hline Lactic & $17.6310^{-6}$ & -0.19 & 0.980 \\
\hline Malic & $5.9110^{-6}$ & -0.53 & 0.999 \\
\hline Tartaric & $4.7310^{-6}$ & -0.66 & 0.990 \\
\hline Citric & $5.6210^{-6}$ & -0.56 & 0.999 \\
\hline
\end{tabular}

Taking into account that in the must obtained from grapes, tartaric acid is found in the range 3-7 g. $\mathrm{L}^{-1}$ and malic acid in the range $1-3 \mathrm{~g} \cdot \mathrm{L}^{-138}$ the linear range and the LOD found here is adequate for the concentration usually found in such products.

\subsection{4- Electrocatalytic effect of $S_{\text {DoDAuNP-LB }}$ towards phenolic acids}

Phenolic acids are also important ingredients of grapes and wines. Their interest relies on their antioxidant activity and on the key role they play in the organoleptic characteristics of wines. The electrochemical techniques are also appropriate to evaluate the antioxidant (or electrochemical) activity of the phenols. It has been established that the redox activity of these compounds can be measured using a glassy carbon electrode ${ }^{10,15,39}$. Depending on their chemical structure phenolic compounds can show low oxidation potentials (at $c a .0 .5 \mathrm{~V}$ ) or high oxidation potential (at $c a .0 .8 \mathrm{~V}$ ). In this chapter, the electrocatalytic effect of $S_{D O D} A u N P-L B$ on the electrochemical response of two phenolic acids commonly found in wines, one with low oxidation potential (caffeic acid) and one with high oxidation potential (gallic acid) is analyzed (Figure 2.5).

The electrochemical response of caffeic acid at a bare ITO was characterized by a redox pair with the anodic wave at $0.55 \mathrm{~V}$ and the cathodic at $0.25 \mathrm{~V}$ assigned to the oxidation/reduction of the diphenol to the o-quinone (Figure 2.5.a). The peak current of the electro-oxidation of caffeic acid at the $\mathrm{S}_{\mathrm{DOD}} \mathrm{AuNP}$-LB sensor was clearly enhanced from 170 $\mu \mathrm{A}$ to $270 \mu \mathrm{A}$ (an increase of the $75 \%$ ) evidencing the catalytic effect of 
the modified electrode. The electrocatalytic effect was even more pronounced in gallic acid (a triphenol of high oxidation potential). As shown in Figure 2.5.b the gallic acid could not be oxidized nor reduced on a bare ITO glass at the potential range from $-1.0 \mathrm{~V}$ to $+1.0 \mathrm{~V}$. However, at the modified electrode, an intense and irreversible peak appeared at $0.75 \mathrm{~V}$. The enhancement in current response was a clear evidence of the catalytic effect of the $S_{D O D} A U N P-L B$ modified electrode towards the oxidation of gallic acid.
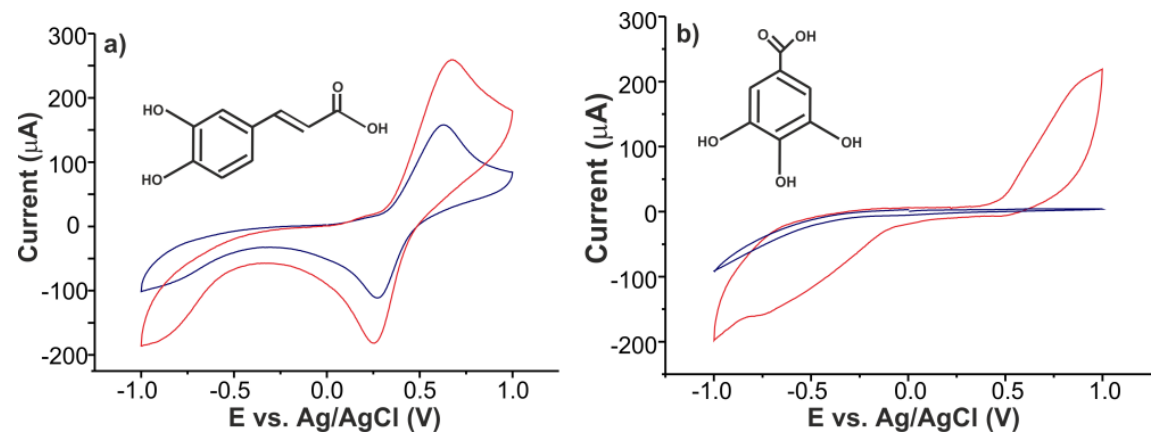

Figure 2.5. Voltammetric response at a bare ITO electrode (blue line) and $\mathrm{S}_{\mathrm{DOD}}$ AuNPs-LB electrode (red line) towards a) caffeic acid and b) gallic acid $10^{-4}$ $\mathrm{mol} \cdot \mathrm{L}^{-1}$.

The influence of the potential sweep speed on the peak height was studied in $10^{-3} \mathrm{~mol} \cdot \mathrm{L}^{-1}$ solutions. The scan rate varied between 0.01 and $1.0 \mathrm{~V} \cdot \mathrm{s}^{-1}$. A linear increment in the redox peak currents as a function of the square root of the scan rate was observed (with $R^{2}$ of 0.990 ) indicative of a diffusion-controlled electrode process. The correlation between the logarithm of peak current and the logarithm of scan rate was linear and slopes were close to 0.5 (0.55 for caffeic acid, 0.42 for gallic acid). Thus, the diffusion controlled mechanism was further confirmed.

Voltammograms were registered using phenolic solutions with different concentrations. A linear relation between the peak currents and caffeic acid concentration in the range between $1 \times 10^{-3} \mathrm{~mol} \cdot \mathrm{L}^{-1}$ and $1 \times 10^{-5}$ 
$\mathrm{mol} \cdot \mathrm{L}^{-1}$ was obtained. The LOD calculated was $0.67 \times 10^{-6} \cdot \mathrm{mol} \cdot \mathrm{L}^{-1}$ and $1.21 \times 10^{-6} \mathrm{~mol} \cdot \mathrm{L}^{-1}$ (for the anodic and cathodic peak respectively). Simultaneously, the $\mathrm{pH}$ variation produced a progressive shift of the redox potential to higher values. This in good agreement with previously published studies that have proved that $\mathrm{pH}$ affects the redox potentials of the phenols ${ }^{10}$. CV plots recorded in gallic acid showed a similar behavior. A clear oxidation peak at $c a .0 .75 \mathrm{~V}$ was observed that increased its intensity with the concentration (Figure 2.6). The obtained calibration graph showed a linear dependence between peak height and gallic acid concentration (oxidation: $R^{2}=0.997$ / reduction: $R^{2}=0.997$ ). The LOD calculated according with the $3 \mathrm{~S}_{\mathrm{d}} / \mathrm{m}$ criterion was $0.51 \times 10^{-6} \mathrm{~mol} \cdot \mathrm{L}^{-1}$.

This LOD obtained using the $\mathrm{S}_{\mathrm{DOD}}$ AuNP-LB sensors was much lower than the values reported for glassy carbon electrodes $\left(c a .10^{-4} \mathrm{~mol} \cdot \mathrm{L}^{-1}\right)^{10}$ and similar to the LOD obtained using electrocatalytic LB films prepared from organic compounds ${ }^{38}$. It is also important to notice that the linear range was clearly enhanced with respect to that observed in glassy carbon electrodes, indicating that the contamination of the electrodes by the oxidation products is less important ${ }^{41}$.
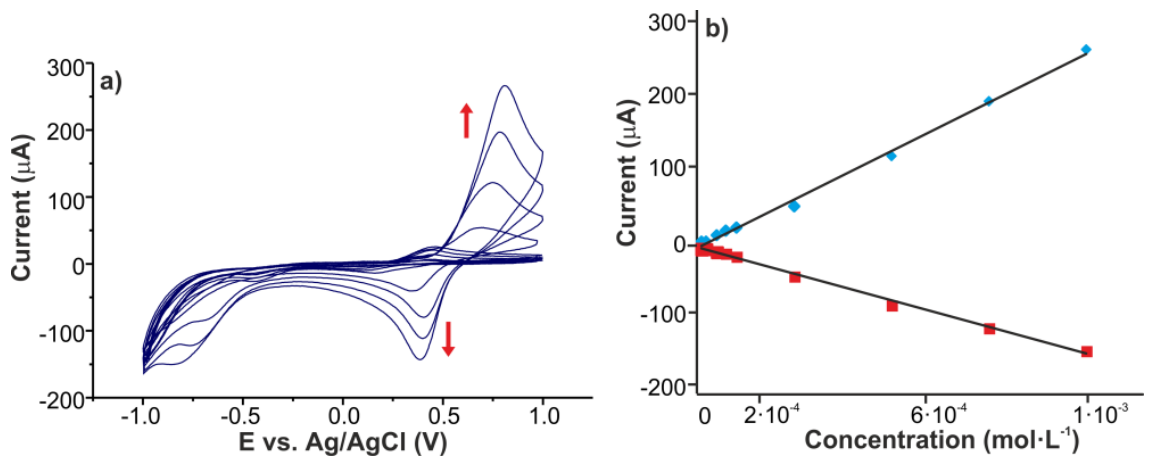

Figure 2.6. a) Cyclic voltammograms obtained for different caffeic acid concentrations from $10^{-5}$ to $10^{-3} \mathrm{~mol} \cdot \mathrm{L}^{-1}$. b) Calibration graph for the determination of caffeic acid, ( $\mathbf{r}$ reduction peak, oxidation peak). 


\subsection{5- Response of $S_{D O D A u N P-L B}$ towards mixtures of organic acids and phenols}

In this section, experiments were made varying the acidity of the solution using mixtures of caffeic acid and tartaric acid (the majoritarian acid in wine and the main responsible of its acidity) in the range of $\mathrm{pHs}$ and concentrations found in wines. Experiments were carried out in caffeic:tartaric mixtures $40: 10,25: 25$ and 10:40 (corresponding to $8 \times$ $10^{-4}: 2 \times 10^{-4}, 5 \times 10^{-4}: 5 \times 10^{-4}, 2 \times 10^{-4}: 8 \times 10^{-4} \mathrm{~mol} \cdot \mathrm{L}^{-1}$ respectively). Figure 2.7 shows the voltammetric responses of mixtures of caffeic and tartaric acid analyzed using the $S_{\text {DODAuNP-LB electrodes. }}$

As expected, the intensity of both oxidation and reduction peaks, $I_{a}$ and $I_{c}$, of caffeic acid increased linearly with the concentration. At low concentrations of tartaric acid, the only peaks observed were produced by the oxidation/reduction of caffeic acid. Increasing amounts of tartaric acid decreased progressively the $\mathrm{pH}$ and the redox activity of the dissociated protons could be observed at negative potentials. Tartaric acid and caffeic acid did not show important interferences in the studied range, except a slight shift in the positions of caffeic acid peak due to the change in the $\mathrm{pH}$ caused by tartaric acid. The LOD obtained were similar to those obtained separately confirming the possibility of using the $\mathrm{S}_{\mathrm{DOD}} \mathrm{AuNP}-\mathrm{LB}$ sensor for the simultaneous determination of acidity and

caffeic acid in the range of concentrations usually found in wines. Similar results were obtained for gallic acid.

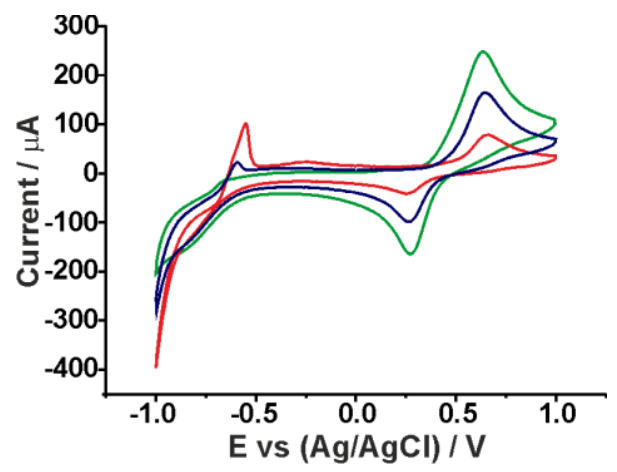


Figure 2.7 CV registered using $S_{\text {DOD }} A$ UNP-LB electrode immersed in caffeic:tartaric mixtures: 40:10 (green line), 25:25 (blue line), 10:40 (red line).

\subsection{6- Electrode repeatability and reproducibility}

In order to characterize the repeatability of the measurements registered with the $S_{D O D} A u N P-L B$ electrode, repetitive measurements were carried out in $10^{-3} \mathrm{~mol} \cdot \mathrm{L}^{-1}$ solutions. For all the samples analyzed, the results of 5 consecutive measurements showed a relative standard deviation (RSD) lower than $2 \%$.

Also the reproducibility of the electrodes was examined by the determination of $10^{-3} \mathrm{~mol} \cdot \mathrm{L}^{-1}$ caffeic acid using three electrodes prepared using the same method. RSD of anodic peak potential was found to be less than $4 \%$, confirming the reproducibility of the method.

\subsection{CONCLUSIONS}

In this chapter, electrodes chemically modified with functionalized gold nanoparticles were achieved by Langmuir-Blodgett technique. The modified $S_{D O D} A u N P-L B$ electrodes demonstrated efficient interfacial properties being able to detect organic acids responsible of the acidity of grapes, musts and wines and phenolic acids with antioxidant properties. The LB technique applied to these amphiphilic nanoparticles produced sensors with high surface to volume ratios and efficient electrocatalytic behavior (increased peak currents) with limits of detection much lower than those obtained on bare ITO glass (in the range of $10^{-6} \mathrm{~mol} \cdot \mathrm{L}^{-1}$ ). In addition, the $\mathrm{S}_{\mathrm{DOD}} A \mathrm{AuNP}-\mathrm{LB}$ sensors were able to discriminate the predominant species indicated by the $\mathrm{pK}_{\mathrm{a}}$ and the $\mathrm{pH}$. Finally, the simultaneous detection of organic acids and phenols was possible due to the lack of interferences in the $\mathrm{pH}$ and concentrations rage found in wines and musts. 


\section{References}

1. Ali, K., Maltese, F., Choi, Y.H., Verpoorte, R. Phytochem. Rev. 2010, 9, 357-378.

2. Lima, M.S., Silani, I.S.V., Toaldo, I.M., Correa, L.C., Biasoto, A.C.T., Pereira, G.E., Bordignon-Luiz, M.T., Ninow, J.L. Food Chem. 2014, 161, 94-103.

3. Soyer, Y., Koca, N., Karadeniz, F. J. Food Comp. Anal. 2003, 16, 629636.

4. Vauzour, D., Rodriguez-Mateos, A., Corona, G., Oruna-Concha, M.J., Spencer, J.P.E. Nutrients. 2010, 2, 1106-1131. 
5. Teissedre, P.L., Jourdes, M. Tannins and Anthocyanins of Wine: Phytochemistry and Organoleptic Properties, in Natural Products, 2013, 2255-2274. Ed. Springer, Berlin (Germany).

6. Mudnic, I., Modun, D., Rastija, V., Vukovic, J., Brizic, I., Katalinic, V., Kozina, B., Medic-Saric, M., Boban, M. Food Chem. 2010, 119, 12051210.

7. Organisation Internationale de la Vigne et du Vin, "Recueil des methods internationals d'analyse des vins et des mouts, edition 2011", 8th Assemblée Générale, 21 June 2010, Paris, 2011.

8. Lee, J. Food Sci. Nutr. 2014, 2, 1-8.

9. Prehn, R., Gonzalo-Ruiz, J., Cortina-Puig, M. Current Anal. Chem. 2012, $8,472-484$.

10. Kilmartin, P.A., Zou, H.L., Waterhouse, A.L. J. Agric. Food Chem. 2001, 49, 1957-1965.

11. Bortolomeazzi, R., Sebastianutto, N., Toniolo, R., Pizzariello, A. Food Chem. 2007, 100, 1481-1489.

12. Abou Samra, M., Chedea, V.S., Economou, A., Calokerinos, A., Kefalas, P. Food Chem. 2011, 125, 622-629.

13. Yakovleva, K.E., Kurzeev, S.A., Stepanova, E.V., Fedorova, T.V., Kuznetsov, B.A., Koroleva, O.V. Appl. Biochem. Microbiol. 2007, 43, 661668.

14. Arteaga, J.F., Ruiz-Montoya, M., Palma, A., Alonso-Garrido, G., Pintado, S., Rodriguez-Mellado, J.M. Molecules. 2012, 17, 5126-5138

15. Kilmartin, P.A., Zou, H.L., Waterhouse, A.L. Am. J. Enol. Vitic. 2002, 53, 294-302.

16. Schmitt, R.E., Molitor, H.R., Wu, T.S. Int. J. Electrochem. Sci. 2012, 7, 10835-10841. 
17. Bianchini, C., Curulli, A., Pasquali,M., Zane, D. Food Chem. 2014, 156, 81-86.

18. Matemadombo, F., Apetrei, C., Nyokong, T., Rodríguez-Méndez, M.L., de Saja, J.A. Sens. Actuators B. 2012, 166-167, 457-466.

19. Gay-Martin, M., de Saja, J.A., Muñoz, R., Rodriguez-Mendez, M.L. Electrochim. Acta. 2012, 68, 88-94.

20. Apetrei, I.M., M.L. Rodríguez-Méndez, M.L., Apetrei, C., Nevares, I., del Alamo, M., de Saja, J.A. Food Res. Int. 2012, 45, 244-249.

21. Daniel, M.C., Astruc, D. Chem. Rev. 2004, 104, 293-346.

22. Campbell, F.W., Compton, R.G. Anal. Bioanal. Chem. 2010, 396, 241259.

23 Pingarron, J.M., Yañez-Señedo, P., Gonzalez-Cortes, A. Electrochim. Acta. 2008, 53, 5848-5866.

24. White, R.J., Luque, R., Budarin, V.L., Clark, J.H., Macquarrie, D.J. Chem. Soc. Rev. 2009, 38, 481-494.

25. Fan, M.K., Andrade, G.F.S., Brolo, A.G. Anal. Chim. Acta. 2011, 693, 725.

26. Baghbamidi, S.E., Beitollahi, H., Mohammadi, S.Z., Tajik, S., SoltaniNejad, S., Soltani-Nejad, V. Chin. J. Catal. 2013, 34, 1869-1875.

27. Wang, L., Chen, X.H., Wang, X.L., Han, X.P., Liu, S.F., Zhao, C.Z. Biosens. Bioelectron. 2013, 30, 151-157.

28. Huang, X.J., Choi, Y.K. Sensors Actuat. B. 2007, 122, 659-671.

29. Sanders, T.A., Sauced, M.N., Dahl, J.A. Mater. Lett. 2014, 120, 159162.

30. Supian, F.L., Richardson, T.H., Nabok, A.V., Deasy, M., Syahriman, M., Azmi, M. Adv. Mat. 2014, 895, 520-525. 
31. Capone, S., Manera, M.G., Taurino, A., Siciliano, P., Rella, R., Luby, S., Benkovicova, M., Siffalovic, P., Majkova, E. Langmuir. 2014, 30, 11901197.

32. Brust, M., Fink, J., Bethell, D., Schiffrin, D.J., Kiely, C. J. Chem. Soc., Chem. Commun. 1995, 1655-1656.

33. Nomenclature. "Symbols, Units and Their Usage in Spectrochemical Analysis-II Data Interpretation". Analytical Chemistry Division, IUPAC 1978.

34. Alonso-Lomillo, M.A., Yardimci, C., Dominguez-Renedo, O., ArcosMartinez,M.J. Anal. Chim. Acta. 2009, 633, 51-56.

35. Fu, Y.Y., Liang, F.F., Tian, H.F., Hu, J.B. Electrochim. Acta. 2014, 120, 314-318.

36. Escobar, J.D., Alcaniz, M., Masot, R., Fuentes, A., Bataller, R., Soto, J., Barat, J.M. Food Chem. 2013, 138, 814-820.

37. Arteaga, J.F., Ruiz-Montoya, M., Palma, A., Alonso-Garrido, G., Pintado, S., Rodriguez-Mellado, J.M. Molecules. 2012, 17, 5126-5138.

38. Cabanis, J.C., Flanzy, C. Oenologie, Technique \& Documentation, 1998, Ed. Lavoisier, Paris (France).

39. Apetrei, C., Apetrei, I., de Saja, J.A., Rodriguez-Méndez, M.L. Sensors. 2011, 11, 1328-1344.

40. Giuliani, E., Fernandes, R., Brazaca, L.C., Rodríguez-Méndez, M.L., de Saja, J.A., Zucolotto, V. Biosens. Bioelectron. 2011, 26, 4715-4719.

41. Ferreira, M., Varela, H., Torresi, R.M., Tremiliosi-Filho, G. Electrochim. Acta. 2006, 52, 434-442. 
Chapter 2: References 



\section{CHAPTER 3}

Structural and Electrochemical Properties of Lutetium Bis-Octachloro-Phthalocyaninate Nanostructured Films. Application as Voltammetric Sensors 

The modification of ITO using Langmuir-Blodgett (LB) technique has shown to be very useful to get nanostructured sensors with high number of active sites leading to an improvement on the electrochemical analysis of antioxidants. Other technique to obtain this kind of nanostructures is Langmuir-Schaeffer (LS) in which the transfer of the thin films onto the substrate is made horizontally instead of vertically. In this chapter, differences between sensors prepared by both techniques will be discussed.

In this case, the electrocatalytic modifier is a phthalocyanine derivate bis[2,3,9,10,16,17,23,24-octachlorophthalocyaninate] lutetium(III) complex $\left(\mathrm{LuPc}_{2} \mathrm{Cl}_{32}\right)$. As detailed on the introduction, phthalocyanines are among the most suitable materials for electrochemical sensors due to their versatility and to their unique electrochemical and electrocatalytic properties. Electrochemical sensors based on phthalocyanine derivates have been widely used to analyze food and beverages, focusing on their antioxidant capacity.

Electrochemical and structural properties of voltammetric sensors prepared using LB and LS will be analyzed in this chapter. Their application as sensing units for detecting catechol (a polyphenol model molecule) will be discussed on the basis of their stability and limits of detection.

This work has been published in Journal of Nanoscience and Nanotechnology and was carried out in collaboration with researchers from UNESP (Brazil).

\subsection{INTRODUCTION}

Phthalocyanines are a large family of compounds that have been extensively studied as sensitive materials for electrochemical sensors due to their well-known electrocatalytic properties ${ }^{1}$. These metal complexes act as mediators by lowering the overpotential of oxidation or reduction of the target molecules or by increasing the intensity of the observed peaks. Therefore, phthalocyanine sensors have been applied in 
amperometric, voltammetric or potentiometric electrocatalytic determination of several organic and inorganic compounds ${ }^{2,3}$.

Metallophthalocyanine complexes (MPcs) are the most widely studied derivatives as electrochemical sensors ${ }^{2,5}$. In MPcs, the phthalocyanine ring (in oxidation state -2 ) is coordinated with a range of transition metal ions (in oxidation state +2 ). The number of works published using MPcs as sensitive material is large and includes a variety of phthalocyanine derivatives (e.g. central metal ions, substituents), electrode designs, preparation techniques and target molecules ${ }^{2-6}$. Other families of phthalocyanines such as the bisphthalocyanines $\left(\mathrm{LnPc}_{2}\right)$ have been less studied. $\mathrm{LnPc}_{2}$ are sandwich type compounds with free radical character and ring oxidation state $-1.5^{7-9}$. This specific electronic structure, characterized by the presence of an unpaired electron and by the intramolecular interaction between the ligand $\pi$ systems, allows sandwich complexes to find applications in many fields, including the fabrication of sensors ${ }^{10-12}$. $\mathrm{LnPc}_{2}$ have demonstrated to be particularly interesting sensing materials for voltammetric sensors due to their remarkable electrochemical and electrocatalytic properties ${ }^{13,14}$. They have been successfully used to detect phenolic compounds, a complex group of substances of great interest due to their antioxidant activity ${ }^{15}$.

The control of the structure at the nanometric level (size, orientation, alignment, thickness, etc.) is an important tool used to modulate the sensor response. Nanostructured films prepared by Langmuir-Blodgett $(\mathrm{LB})^{6,16,17}$, Layer-by-Layer (LbL) ${ }^{18,19}$, self-assembling ${ }^{20}$ or electrodeposition (EDP) techniques ${ }^{12}$ exhibit enhanced surface to volume ratios and well controlled structures that facilitate the diffusion of ions inside the film. For these reasons, nanostructured sensors show higher sensitivity, faster kinetics and better reproducibility than non-nanostructured films ${ }^{16,21}$.

The sensing properties of bisphthalocyanines can be modulated by varying the nature of the central rare earth ion and/or by introducing substituents in the phthalocyanine rings ${ }^{4,22,23}$. Unlike the tetrasubstituted compounds, which are normally formed as a mixture of isomers and used as such, the octa-substituted derivatives can be 
synthesized isomerically pure, a feature which should encourage molecular ordering in nanostructured films.

\subsection{MATERIALS AND METHODS}

\subsection{1- Chemicals}

The bis[2,3,9,10,16,17,23,24-octachlorophthalocyaninate] lutetium (III) complex ( $\mathrm{LuPc}_{2} \mathrm{Cl}_{32}$ ), was synthesized according to a previously published procedure ${ }^{24}$ and the molecular structure is shown in Figure 3.1. The solvents (Merck) were of HPLC grade. The ultrapure water $(18.2 \mathrm{M} \Omega \cdot \mathrm{cm})$ was acquired from a Milli-Q water purification system model Simplicity. Catechol and other reactants were purchased from Sigma-Aldrich.

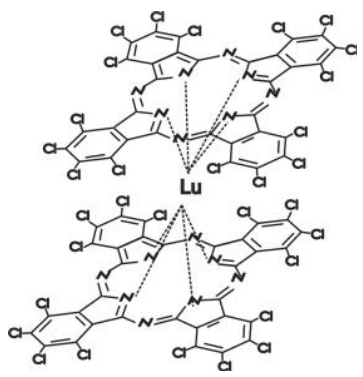

Figure 3.1. Structure of the $\mathrm{LuPc}_{2} \mathrm{Cl}_{32}$.

\subsection{2- Langmuir, LB and LS films}

The $\mathrm{LuPC}_{2} \mathrm{Cl}_{32}$ Langmuir, LS and LB films were fabricated using a Langmuir trough KSV model 2000. The Langmuir films were produced by spreading $1000 \mu \mathrm{L}$ of $8.4 \times 10^{-5} \mathrm{~mol} \cdot \mathrm{L}^{-1}$ solution of $\mathrm{LuPc}_{2} \mathrm{Cl}_{32}$ dissolved in THF onto the water subphase. The Langmuir monolayers were characterized by surface pressure versus mean molecular area $(\pi-A)$ isotherms at $21^{\circ} \mathrm{C}$ using the Wilhelmy method. The monolayer was symmetrically compressed under a constant barrier speed at $10 \mathrm{~mm} \cdot \mathrm{min}^{-1}$.

The LB and the LS films were obtained by transferring the floating Langmuir monolayers from the air/water interface to different solid substrates depending on the characterization technique to be applied. The surface pressure was kept constant at $30 \mathrm{mN} \cdot \mathrm{m}^{-1}$. For $L B$ films upstroke and downstroke speeds of 0.5 to $3.0 \mathrm{~mm} \cdot \mathrm{min}^{-1}$ were used. Under such conditions Y-type LB films with a transfer ratio close to unity 
were obtained. LB and LS films containing up to 10 layers were deposited onto quartz substrate for UV-Vis absorption spectroscopy characterization. 20 LB layers and 10 LS layers were deposited onto ZnSe for FTIR analysis in transmission mode and 10 LS layers were deposited onto Ag mirror for the FTIR analysis in reflection mode. LB and LS monolayers were deposited on $\mathrm{Ag}$ islands (evaporated film of $\mathrm{Ag}$ containing $6 \mathrm{~nm}$ thickness) and glass for Surface-Enhanced Resonance Raman Scattering (SERRS) and Resonance Raman Scattering (RRS) measurements, respectively. For cyclic voltammetry and sensing studies 4 and 8 LS layers and 10 and 20 LB layers were deposited onto ITO electrodes.

\subsection{3- Film characterization}

The UV-Vis absorption spectroscopy analysis was carried out using a Varian spectrophotometer (model Cary 50) from 190 to 1000 nm. FTIR were performed in a Bruker spectrometer model tensor 27 with spectral resolution of $4 \mathrm{~cm}^{-1}, 128$ scans in the transmission mode. The reflection spectra were recorded at an incident angle of $80^{\circ}$ using an A118 Bruker accessory. The Raman analysis was carried out using a micro-Raman Renishaw spectrograph model in-Via equipped with a Leica microscope, CCD detector, laser at $633 \mathrm{~nm}$, and 1800 grooves $\cdot \mathrm{mm}^{-1}$ gratings. In this system a 50X objective allows collecting spectra with $c a .1 \mu \mathrm{m}^{2}$ spatial resolution.

The cyclic voltammetry (CV) was carried out using an EG\&G PARC 263A potentiostat/galvanostat (M270 Software) with a conventional threeelectrode cell. The reference electrode was $\mathrm{Ag} \mid \mathrm{AgCl} / \mathrm{KCl}$ sat. and the counter electrode was a platinum plate. Cyclic voltammograms were registered from -1.0 up to $+1.0 \mathrm{~V}$ at a scan rate of $0.1 \mathrm{~V} \cdot \mathrm{s}^{-1}$ (except otherwise indicated).

\subsection{RESULTS AND DISCUSSION}

\subsection{1- Langmuir films}

The $\pi$-A isotherms were recorded by spreading a THF solution of $\mathrm{LuPC}_{2} \mathrm{Cl}_{32}$ onto an ultrapure water (MilliQ) subphase kept at a constant 
temperature at $21^{\circ} \mathrm{C}$. After solvent evaporation (20 minutes), the phthalocyanine molecules were compressed at a constant rate of 10 $\mathrm{mm} \cdot \mathrm{min}^{-1}$ until the film pressure rose sharply, indicating that a continuous surface film was formed (condensed phase). Reproducible $\pi$ $A$ isotherms were recorded and some of them are given in Figure 3.2.a. The extrapolated area ( $A_{\text {ext }}$ in Figure 3.2.a) estimated by extrapolating the condensed phase to $\pi=0$ was $52 \AA^{2}$, smaller than the values observed for unsubstituted $\mathrm{LuPc}_{2}{ }^{16,25}$ and for $\mathrm{LuPc}_{2}$ substituted derivatives ${ }^{26-28}$. The limiting area obtained here for $\mathrm{LuPC}_{2} \mathrm{Cl}_{32}$ suggests an edge-on orientation; the face-on orientation (lying flat) would occupy an area of approximately 160 and $170 \AA^{2}{ }^{29-31}$. The stacking of the $\mathrm{LuPc}_{2} \mathrm{Cl}_{32}$ molecules forming molecular aggregates is another possibility. For instance, an aggregate with 3 molecules in a face-on orientation would also lead to an extrapolated area of ca. $53 \AA^{2}$. The monolayer showed a collapse with a surface pressure of $40 \mathrm{mN} \cdot \mathrm{m}^{-1}$, which is close to the collapse observed for the unsubstituted and substituted $\mathrm{LuPc}_{2}{ }^{25}$ and indicates high molecular packing.

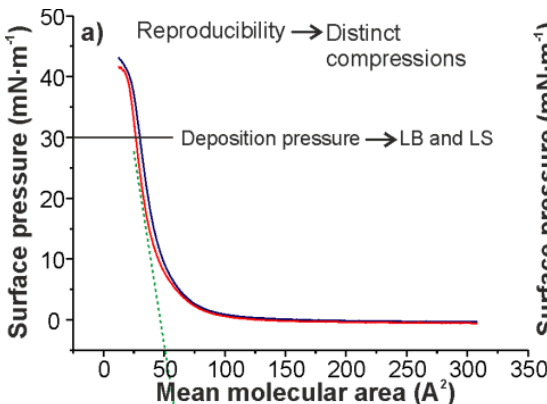

$A_{e x t}$
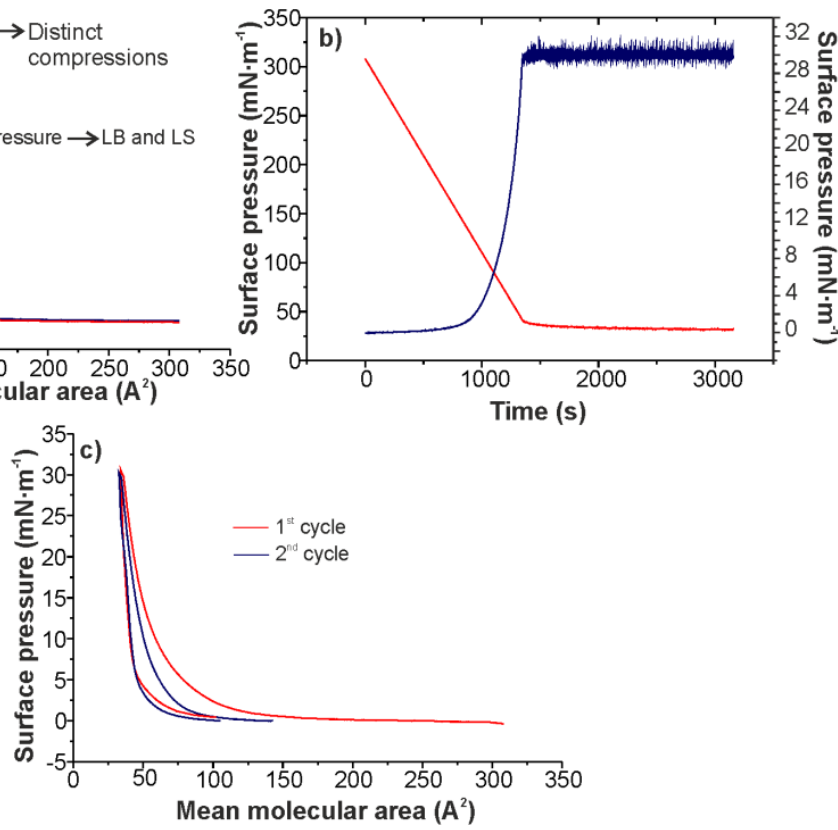
Figure 3.2. a) $\pi$-A isotherms registered at $21^{\circ} \mathrm{C}$. b) Stability test at $30 \mathrm{mN} \cdot \mathrm{m}^{-1}$. c) compression/expansion cycles for $\mathrm{LuPc}_{2} \mathrm{Cl}_{32}$.

Stability tests (i.e. displacement of the barriers to keep constant the surface pressure in a value within the condensed phase of the film) proved that the $\mathrm{LuPC}_{2} \mathrm{Cl}_{32}$ monolayer is very stable at the condensed phase (Figure 3.2.b). A decrease of ca. $10 \%$ in the mean molecular area was observed during the first 20 minutes, keeping constant after that. Successive compression/expansion curves until the condensed phase (surface pressure at $30 \mathrm{mN} \cdot \mathrm{m}^{-1}$ ) revealed a hysteresis of the thermodynamic process (Figure 3.2.c). It can be noted that the second compression was shifted to lower areas however, for the first and the second expansion processes the same mean molecular area was reached. The latter is consistent with the formation of molecular aggregates at the air/water interface during the first compression, which is not reversible with expansion. Besides, the same area values at the condensed phase found for both compressions indicate the Langmuir film reaches the same structure, independent of the compressing/expansion cycles.

\subsection{2- LB and LS films. Growth monitored by UV-Vis absorption}

The Langmuir films were transferred onto solid substrates at a pressure of $30 \mathrm{mN} \cdot \mathrm{m}^{-1}$ using both LS and LB techniques. The electronic absorption spectra for the $\mathrm{LuPC}_{2} \mathrm{Cl}_{32}$ in THF solution, LB film (5 up to 10 layers) and LS film (2 up to 10 layers) deposited onto a quartz substrates are given in Figure 3.3. The UV-Vis spectrum of the $\mathrm{LuPC}_{2} \mathrm{Cl}_{32}$ THF solution showed the characteristic features of macrocyclic compounds. The spectrum presents strong $B$ and $Q$ bands that have been assigned to $\pi \rightarrow \pi^{*}$ transitions. The $Q$ band is centered at $697 \mathrm{~nm}$ and is considerably redshifted compared to $Q$ band maximum (659 $\mathrm{nm}$ ) observed in the unsubstituted $\mathrm{LuPc}_{2}$ in chloroform solution ${ }^{32}$. This bathochromic shift is usually observed when the aromatic ring is substituted with electron withdrawing groups ${ }^{24,33}$. In addition, the substitution with eight acceptor chlorine groups caused a strong decrease of the charge transfer bands (associated with intramolecular transitions of the unpaired electron) 
that appear at $450 \mathrm{~nm}$ and $900 \mathrm{~nm}$ in unsubstituted analogues, but those were almost absent when strong withdrawing chlorine groups were present. By registering spectra at increasing concentrations $\left(8.4 \times 10^{-5}, 6.72 \times 10^{-5}, 4.2 \times 10^{-5}\right.$ and $\left.1.68 \times 10^{-5} \mathrm{~mol} \cdot \mathrm{L}^{-1}\right)$ a molar extinction coefficient of $5.9 \times 10^{4} \mathrm{M}^{-1} \cdot \mathrm{cm}^{-1}$ at $697 \mathrm{~nm}$ was obtained (spectra not shown).

The UV-Vis spectra of the LB and LS films were similar to that of the THF solution but a red shift of the $Q$ band was observed in both cases. This band appears centered at $711 \mathrm{~nm}$ for the LB film and at $709 \mathrm{~nm}$ for the LS one. The shift observed in relation to maximum absorption of the solution at $697 \mathrm{~nm}$ is characteristic of a face-to-tail stacking of the chromophores ( $J$ aggregates $)^{34}$, consistent with $\pi$-A isotherm data. In terms of film growth, the absorbance increased linearly with the number of monolayers for both LB and LS films as shown in Figures 3.3.a and 3.3.b, confirming the good quality of the transferred films. Besides the absorbance intensity for the $Q$ band, comparison of 10 layers LB and LS films indicated that a major quantity of material was transferred to the substrate in the LS film for each layer, in average. It is important to note that layers were deposited only onto one side of the substrate for LS films while layers were deposited onto both sides of the substrate for LB films. Finally, focusing on $Q$ band, the greater relative intensity of the band at higher wavelength for both films indicated the monomers were dominant in relation to dimers or higher order of aggregates of $\operatorname{LuPC}_{2} \mathrm{Cl}_{32}$.
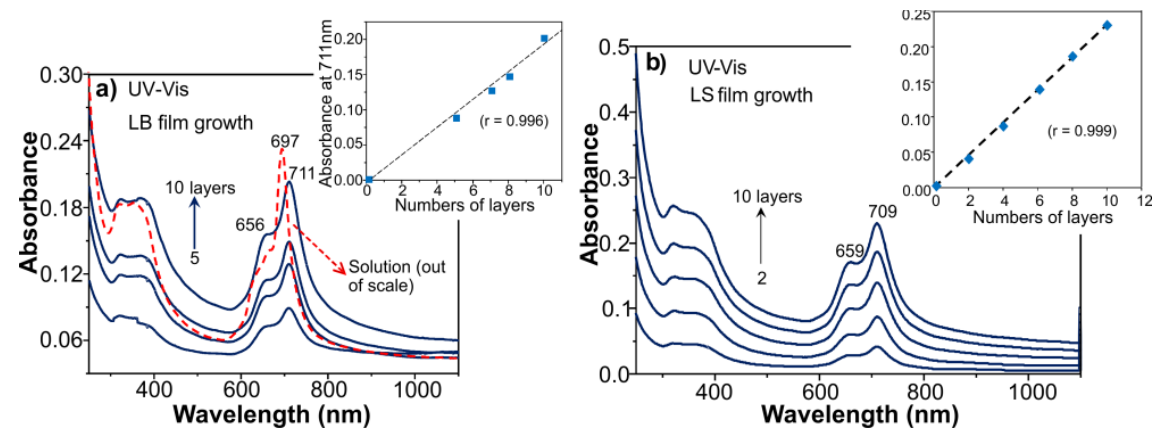
Figure 3.3. UV-Vis absorption spectra for a) LB film and b) LS film of $\mathrm{LuPc}_{2} \mathrm{Cl}_{32}$ up to 10 layers deposited onto quartz plates. The dashed red line in 3.a corresponds to the THF solution spectrum of $\mathrm{LuPc}_{2} \mathrm{Cl}_{32}$ (out of scale).

\subsection{3- LB an LS films. Molecular organization determined by FTIR}

The FTIR is a powerful tool to determine possible molecular orientation in thin films ${ }^{35}$. Therefore, FTIR spectra of LB (transmission mode) and LS films (transmission and reflection modes) films of $\mathrm{LuPc}_{2} \mathrm{Cl}_{32}$ are compared Figure 3.4. Table 3.1 shows a list of the active vibrations and their assignment in the LB and LS films ${ }^{36}$. An important point to be noticed here is that according to the surface selection rules $^{37}$ the fundamental vibrations with transition dipole parallel to the substrate surface have maximum intensity for the FTIR spectra obtained in transmission mode (incident electric field parallel to the substrate surface). In reflection mode (incident electric field polarized perpendicularly to the substrate surface), the intensities of the fundamental vibrations with dynamic dipole perpendicular to the surface have maximum intensity ${ }^{37}$.

Table 3.1. Infrared active vibrations and their assignment in the LB and LS films.

\begin{tabular}{|r|l|}
\hline Wavenumber $\left(\mathbf{c m}^{-1}\right)$ & \multicolumn{1}{|c|}{ Assignment } \\
\hline 759 & C-Cl stretching \\
\hline 932 & benzene ring \\
\hline 1091 & phthalocyanine ring breathing \\
\hline 1135 & pyrrole ring breathing \\
\hline 1205 & isoindole stretching \\
\hline 1275 & isoindole stretching \\
\hline 1305 & isoindole stretching \\
\hline 1370 & isoindole stretching \\
\hline 1385 & isoindole stretching \\
\hline 1653 & benzene stretching \\
\hline 1733 & C=O stretching (from acetate) \\
\hline
\end{tabular}


In Figures 3.4.a and 3.4.b, the FTIR spectra for the LS film in both transmission and reflection modes presented a similar profile. This indicates a non-preferential molecular arrangement or an orientation of the phthalocyanine ring forming $c a .45^{\circ}$ in relation to the substrate for LS films ${ }^{38}$. A similar profile was also observed comparing the spectra in Figures 3.4.a and 3.4.c (i.e. the FTIR spectra for LS and LB films in transmission mode) indicating that both $L S$ and $L B$ presented the $\mathrm{LuPC}_{2} \mathrm{Cl}_{32}$ structured in a similar way. Besides, all spectra were similar to that observed to $\mathrm{LuPc}_{2} \mathrm{Cl}_{32}$ in $\mathrm{KBr}$ pellet given by Gobernado-Mitre et al. ${ }^{36}$. Therefore, because the FTIR spectrum of the powder is characteristic of randomly structured system, it can be concluded that, despite LB and LS grow in a well stratified way, they presented a nonpreferential molecular arrangement.

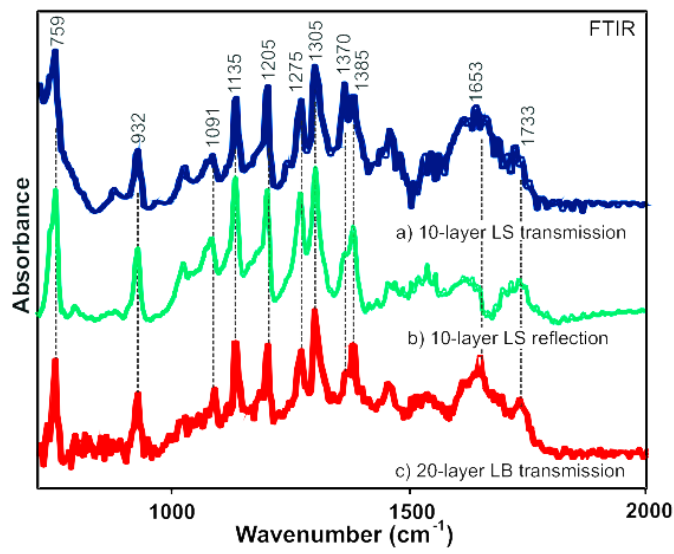

Figure 3.4. FTIR spectra in transmission mode for both a) 10 -layer LS film and c) 20-layer LB film, deposited on ZnSe and in reflection mode for b) 10-layer LS deposited on Ag mirror.

\subsection{4- Surface-Enhanced Resonance Raman Scattering (SERRS)}

The SERRS spectra of both LB and LS monolayers onto Ag island films (6 $\mathrm{nm}$ of $\mathrm{Ag}$ evaporated onto glass slides, leading to $\mathrm{Ag}$ nanoparticles) are shown in Figure 3.5.a. It was observed that the SERRS spectra for both LB and LS monolayers presented the same profile. This SERRS profile was the same shown by the $\mathrm{LuPc}_{2} \mathrm{Cl}_{32}$ powder (result not shown) and similar 
to that presented in Ref. 36. The simply enhancement of the RRS spectra without any change in the spectra profile, as the relative intensity of the bands, is a common observation for SERRS of phthalocyanines ${ }^{39}$. This absence of changes in the SERRS spectra indicated that there was no chemical interaction between molecule-metal ( $\left.\mathrm{LuPc}_{2} \mathrm{Cl}_{32}-\mathrm{Ag}\right)$ and both $\mathrm{LB}$ and LS monolayers were physisorbed on the $\mathrm{Ag}$ islands.
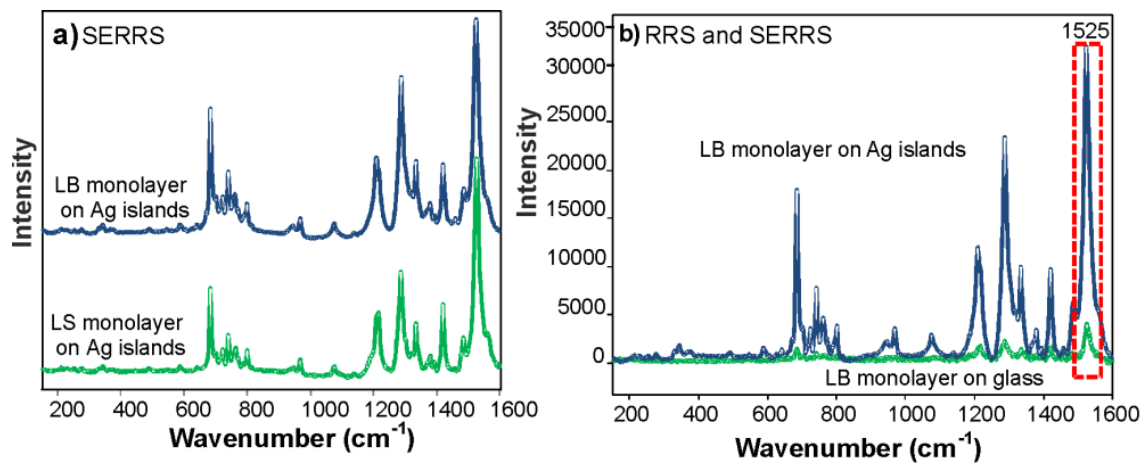

Figure 3.5. a) SERRS spectra for both $L B$ and $L S$ monolayers of $\mathrm{LuPC}_{2} \mathrm{Cl}_{32}$ onto $\mathrm{Ag}$ islands films (Ag nanoparticles). b) RRS and SERRS spectra for LB monolayers on glass and Ag islands, respectively.

The enhancement factors (EF) can be estimated for both LB and LS films considering the intensity ratio SERRS/RRS of the band at $1525 \mathrm{~cm}^{-1}$. For instance, for the LB film (Figure 3.5.b) the intensity of the SERRS band at $1525 \mathrm{~cm}^{-1}$ was $\mathrm{ca} .32,500$ counts and in the RRS the band intensity was ca. 3,500 counts (the intensity is the height from the top to the bottom of the band). Considering the intensity ratio SERRS/RRS for this band, and that the RRS spectrum was collected with a laser power 200 times higher than the SERRS spectrum, the enhancement factor was estimated to be $c a .2 \times 10^{3}$. A similar EF was observed for the LS film. These EF observed are in agreement with those found to phthalocyanine molecules $^{40,41}$ and in agreement with the model considering the electromagnetic mechanism ${ }^{35,42}$. Basically, according to the EM mechanism, the enhancement of the Raman signal was achieved by the 
localized surface plasmon resonances (LSPR), which were sustained by the Ag nanoparticles and led to the enhacement of the electric field surrounding the Ag nanoparticles ${ }^{35,42}$. Therefore, the laser line $(633 \mathrm{~nm})$ must be in resonance with the Ag plasmon absorption (necessary condition) to achieve the surface-enhanced Raman scattering (SERS). In our case, because the $633 \mathrm{~nm}$ laser line was also in resonance with the $\mathrm{LuPc}_{2} \mathrm{Cl}_{32}$ absorption (Figure 3.3.a), the resonance Raman scattering (RRS) was achieved. Therefore, when the $\mathrm{LuPc}_{2} \mathrm{Cl}_{32}$ monolayer was deposited onto the $\mathrm{Ag}$ island films and excited with the $633 \mathrm{~nm}$ laser line, a double resonance was established and the SERRS phenomenon was achieved $^{43}$.

\subsection{5- Electrochemical properties}

In order to evaluate the electrochemical behavior of the $\mathrm{LuPc}_{2} \mathrm{Cl}_{32}$ sensors, the electrodes were immersed in a $\mathrm{KCl}$ solution and cyclic voltammograms were registered from -1.0 to $+1.0 \mathrm{~V}$ at a scan rate of 0.1 $\mathrm{V} \cdot \mathrm{s}^{-1}$. Figure 3.6 shows the cyclic voltammograms of $\mathrm{LB}$ and $\mathrm{LS}$ films of $\mathrm{LuPC}_{2} \mathrm{Cl}_{32}$ deposited onto ITO glass in contact with $0.1 \mathrm{~mol} \cdot \mathrm{L}^{-1} \mathrm{KCl}$ aqueous solution. The most remarkable aspect of the cyclic voltammograms was the absence of the peaks attributed to the quasireversible processes corresponding to one electron oxidation $\mathrm{Ln}(\mathrm{III}) \mathrm{Pc}_{2} / \mathrm{Ln}(\mathrm{III}) \mathrm{Pc}_{2}{ }^{+}$and the one electron reduction $\mathrm{Ln}(\mathrm{III}) \mathrm{Pc}_{2} / \mathrm{Ln}(\mathrm{III}) \mathrm{Pc}_{2}{ }^{-}$ of the phthalocyanine ring, which are usually observed in unsubstituted $\mathrm{LnPC}_{2}{ }^{11,22,28,44}$. This absence can be explained taking into account the computed ionization potentials and the electro-affinity published for asymmetrically substituted chlorine bisphthalocyanines ${ }^{45}$. According to these data, the halogen electro-attracting inductive effect tends to stabilize the phthalocyanine frontier orbital. The presence of electron acceptor chlorine groups hinders the oxidation and reduction of the phthalocyanine ring. For this reason, the peaks corresponding to these processes were not observed in the studied range. 


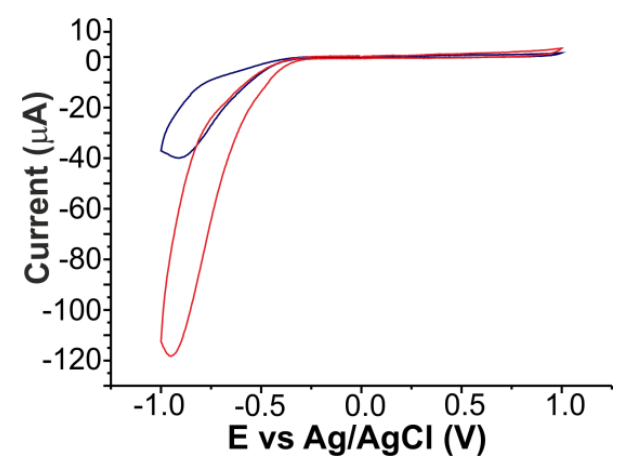

Figure 3.6. $\mathrm{CV}$ of $\mathrm{LuPC}_{2} \mathrm{Cl}_{32} \mathrm{LB}$ (10 monolayers) and LS (8 monolayers) films immersed in $0.1 \mathrm{~mol} \cdot \mathrm{L}^{-1}$. Blue line corresponds to $L B$ films and red line corresponds to LS films. Scan rate, $0.1 \mathrm{~V} \cdot \mathrm{s}^{-1}$.

Voltammograms also showed a cathodic wave at $-0.90 \mathrm{~V}$ that was caused by the decomposition of water at the electrode surface. This peak was also observed at $-1.1 \mathrm{~V}$ when using neat ITO electrodes. The shift of the potential at which decomposition of water occurs, was due to the electrocatalytic effect of the phthalocyanine layer that facilitates the reduction process. The intensity of the cathodic wave was dependent on the $\mathrm{pH}$ of the solution: it decreased when the $\mathrm{pH}$ increased (result not shown), confirming the assignment of this peak. The results obtained from LB and LS were similar and only a difference in the decomposition of water (favored at LS electrodes) was observed.

\subsection{6- Electrochemical detection of catechol}

As stated before, unsubstituted or octa-terbutyl bisphthalocyanines immobilized on inert electrode surfaces, exhibit electrocatalytic activity towards phenolic compounds ${ }^{14,15,24}$. The presence of bisphthalocyanine resulted in a decrease in the overpotential of oxidation or reduction of the target molecules and/or an increase in the intensity of the peaks observed.

In order to evaluate the electrocatalytic activity of the $\mathrm{LuPc}_{2} \mathrm{Cl}_{32}$ films towards phenols, the electrochemical response of $10^{-3} \mathrm{~mol} \cdot \mathrm{L}^{-1}$ catechol in $0.1 \mathrm{~mol} \cdot \mathrm{L}^{-1} \mathrm{KCl}$ at $\mathrm{LuPc}_{2} \mathrm{Cl}_{32}$ modified ITO electrodes was tested at a scan rate of $0.1 \mathrm{~V} \cdot \mathrm{s}^{-1}$. For comparison purposes, the cyclic voltammogram of catechol for a bare ITO electrode was also recorded 
(Figure 3.7). In good acordance with the literature, when a bare ITO glass was used as electrode, the voltammogram showed an anodic peak (at $0.55 \mathrm{~V}$ ) in the positive-going scan and a cathodic counterpart peak (at $0.22 \mathrm{~V}$ ) in the negative-going scan. These peaks correspond to the transformation of catechol to o-benzoquinone and vice-versa in a quasireversible two-electron process ${ }^{46-48}$. Under these conditions, $\Delta E$ is $0.33 \mathrm{~V}$ and peak current ratio $\left(I_{c} / l_{a}\right)$ is close to unity.

Voltammograms obtained using electrodes modified with $\mathrm{LuPc}_{2} \mathrm{Cl}_{32}$ films immersed in a catechol solution, differed significantly from voltammograms recorded using a bare ITO glass electrode. For instance, when a cast film was exposed to catechol (Figure 3.7), voltammograms showed the expected redox pair associated with the oxidation/reduction of catechol ${ }^{48}$. The cathodic peak appeared at $0.22 \mathrm{~V}$ (the same potential observed when using a bare ITO glass), whereas the anodic peak was shifted to lower potentials and appeared at $0.4 \mathrm{~V}(0.55 \mathrm{~V}$ at ITO electrode). The peak potential difference $(\Delta E)$ between anodic and cathodic peak ( $\triangle E=0.18 \mathrm{~V}$ ) was smaller than the observed for bare ITO glass $(\Delta E=0.33 \mathrm{~V})$, indicating that the reversibility of electrochemical reaction was improved in the presence of $\mathrm{LuPC}_{2} \mathrm{Cl}_{32}$. This electrocatalytic activity has been already observed in electrodes modified with unsubstituted $\mathrm{LuPc}_{2}$ where the oxidation of catechol occurs at $0.47 \mathrm{~V}$ with $\Delta E=0.30 \mathrm{~V}^{16,32}$. In this case, when the phthalocyanine ring was substituted with chlorine atoms, the shift to lower potentials was more pronounced.

It is worth to remark that the anodic peak at $0.4 \mathrm{~V}$ was accompanied by a shoulder at $0.25 \mathrm{~V}$. This splitting might be due to the existence of two types of binding sites for immobilization, giving rise to active sites with distinct electrocatalytic efficiencies. Further proofs of the existence of two types of active sites will be shown in the dynamic study of the electrodes at a different scan rates. In addition, a cathodic wave at -0.5 $\mathrm{V}$ was also observed as a result of the irreversible reduction of catechol catalyzed by the phthalocyanine. 


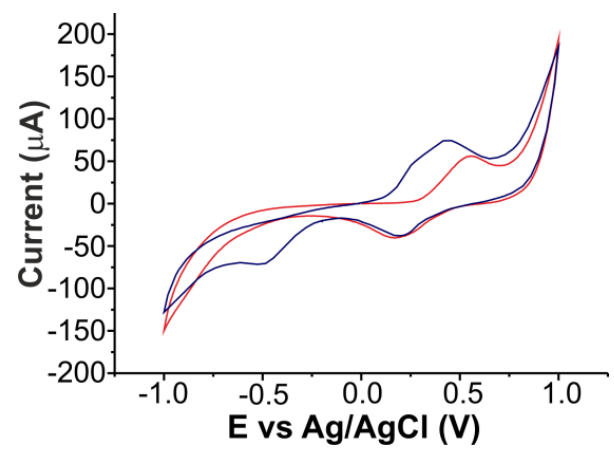

Figure 3.7. Cyclic voltammogram of $10^{-3} \mathrm{~mol} \cdot \mathrm{L}^{-1}$ catechol in the presence of 0.1 $\mathrm{mol} \cdot \mathrm{L}^{-1} \mathrm{KCl}$ at a bare ITO electrode (red line) and a cast film of $\mathrm{LuPc}_{2} \mathrm{Cl}_{32}$ (blue line). Scan rate, $0.1 \mathrm{~V} \cdot \mathrm{s}^{-1}$.

It is also important to notice that the redox peak currents of catechol increased about a $25 \%$ with respect to the intensity observed for a bare ITO glass (the increase in intensity observed in unsubstituted $\mathrm{LuPc}_{2}$ is tenfold the observed when using bare ITO glass). In summary, the excellent electrocatalytic activity of $\mathrm{LuPC}_{2} \mathrm{Cl}_{32}$ is responsible for the significantly improved electrochemical behavior of catechol at the $\mathrm{LuPC}_{2} \mathrm{Cl}_{32}$ cast film.

It is well known that the structure of the sensing layer plays a key role in the electrochemical behavior of modified electrodes. The voltammograms obtained using $\mathrm{LuPC}_{2} \mathrm{Cl}_{32}$ nanostructured films immersed in a catechol solution differed significantly from voltammograms recorded using a bare ITO glass or an ITO electrode modified with a cast film. This is illustrated in Figure 3.8 where the electrochemical responses of LB and LS films immersed in a solution of $10^{-3} \mathrm{~mol} \cdot \mathrm{L}^{-1}$ catechol (in $0.1 \mathrm{~mol} \cdot \mathrm{L}^{-1} \mathrm{KCl}$ ) are shown. 


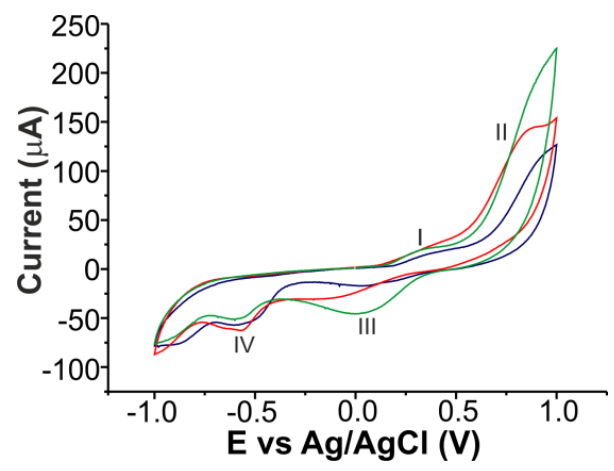

Figure 3.8. Cyclic voltammograms of $10^{-3} \mathrm{~mol} \cdot \mathrm{L}^{-1}$ catechol in the presence of 0.1 $\mathrm{mol} \cdot \mathrm{L}^{-1} \mathrm{KCl}$ at 20 monolayers LB films (green line), 10 monolayers LB (red line) and 8 monolayers $\mathrm{LS}$ (blue line) of $\mathrm{LuPc}_{2} \mathrm{Cl}_{32}$. Scan rate, $0.1 \cdot \mathrm{V} \cdot \mathrm{s}^{-1}$.

When $\mathrm{LuPC}_{2} \mathrm{Cl}_{32} \mathrm{LB}$ or LS electrodes were immersed in catechol, a set of anodic (positive) and cathodic (negative) peaks were observed. For more clarity, peaks have been numbered. The oxidation of the catechol to a quinone gave rise to a broad anodic peak on the forward scan of the cyclic voltammograms (peak I), while reduction of the quinone back to the original polyphenol produced the corresponding cathodic peak on the reverse scan (peak III). Due to the electrocatalytic activity of the $\mathrm{LuPC}_{2} \mathrm{Cl}_{32}$, peak I was displaced to $0.27 \mathrm{~V}$ for both LB and LS $(0.55 \mathrm{~V}$ when using a bare ITO glass electrode and $0.4 \mathrm{~V}$ when using a cast film). In turn, peak III was also shifted to lower potentials (at $0.1 \mathrm{~V}$ for LB, $-0.05 \mathrm{~V}$ for LS and $0.2 \mathrm{~V}$ for cast film). The anodic peak I associated with the oxidation of catechol was quite broad and by similarity with the cast film, it can be assumed that this broad peak was the wave resulting from the overlapping of redox processes at two different active sites.

An important difference between LB (or LS) and cast films is that in nanostructured films a new intense anodic wave was observed at $0.75 \mathrm{~V}$ (peak II). According to the literature, this new redox process can be associated with the polymerization of the previously oxidized cathecol ${ }^{44-}$ 49. This peak was not observed when using a $\mathrm{LuPC}_{2} \mathrm{Cl}_{32}$ cast film, indicating that the structure of the surface and the homogeneous molecular packaging of the nanostructured films facilitated the second 
oxidation. The polymeric form was reduced at potentials close to $0.2 \mathrm{~V}$. That is, in the cathodic sweep, the peak observed at $0.2 \mathrm{~V}$ (peak III) corresponded to the overlapping of the reduction of both the quinoid form and polymeric form of catechol, justifying thus the increase in intensity and in broadness with respect to the cast film. The cathodic wave at $-0.5 \mathrm{~V}$ was also observed (peak IV).

The enhanced electrocatalytic effect observed in LB and LS films can be attributed to the $\mathrm{LuPC}_{2} \mathrm{Cl}_{32}$ molecular arrangement/packing. The homogeneous layered structure provided well-defined surfaces with an increased number of active sites. The small structural differences between LB and LS films described in sections 3.3.1 to 3.3.4 justify some discrepancies in their electrochemical behavior. For instance, the oxidation and the polymerization of catechol (peaks I and II) were favored at the surface of LS films. An important difference between LB and LS films is their stability. It is well known that in chemically modified electrodes, the first cycles differ from subsequent ones. For this reason, before using the electrodes for sensing purposes, it is necessary to run several stabilization cycles. In this case it was observed that LB films were stabilized after three cycles, whereas, LS films were not stabilized until fifteen cycles were run (all the voltammograms shown in the figures correspond to stabilized signals). After stabilization, SD values (calculated from the peak I intensity values) were lower than $5 \%$ for both LB and LS films.

The thickness also influenced the electrochemical response of LB or LS films exposed to catechol (Figure 3.8). In both types of films, peaks associated with the polymerization of the catechol (peaks II and III) increased in intensity when increasing the number of monolayers. This effect can be explained by assuming that the inner layers facilitate the transfer of electrons to the ITO. In contrast, by increasing the number of monolayers the intensity of the peaks I and IV, associated exclusively with the oxidation/reduction of catechol, did not change. This means that these redox processes occur exclusively at the active sites located at the electrode surface. 


\subsection{7- Dynamic behavior}

The dynamic character of the electrode was examined by registering voltammograms at different scan rates. As observed in Figure 3.9, the intensity of the voltammograms increased with the scan rate. At high scan rates, the splitting of peak I became more evident, confirming the existence of two active sites at the film surface.

The inset of Figure 3.9 shows the linear correlation between the peak current (peak I) and the scan rate in the range 0.05-0.5 V.s ${ }^{-1}$ (Table 3.2). As shown in Figure 3.9, the intensity of peak I increased linearly with the scan rate, indicating the dominance of the surface confined processes. Under these conditions the surface coverage $(I)$ can be calculated using the Laviron equation (Equation 3.1):

\section{$I=\mathrm{nF}^{2} v \mathrm{~A} \Gamma / 4 \mathrm{RT}$ (Equation 3.1)}

Where $\mathrm{n}$ is the number of electrons, $\mathrm{F}$ the Faraday constant $\left(\mathrm{C} \cdot \mathrm{mol}^{-1}\right), v$ the scan rate $\left(\mathrm{V} \cdot \mathrm{s}^{-1}\right), \mathrm{A}$ the area of the sensor $\left(\mathrm{cm}^{2}\right), \Gamma$ the surface coverage $\left(\mathrm{mol} \cdot \mathrm{cm}^{-2}\right), \mathrm{R}$ the gas constant $\left(\mathrm{cm}^{3} \cdot \mathrm{atm} \cdot \mathrm{K}^{-1} \cdot \mathrm{mol}^{-1}\right)$ and $T$ the temperature $(\mathrm{K})$. The surface coverage of the $\mathrm{LuPc}_{2} \mathrm{Cl}_{32}$ films calculated using Equation 3.1 was $\Gamma=7.77449 \times 10^{-11} \mathrm{~mol} \cdot \mathrm{cm}^{-2}$ for the LB film and $\Gamma=1.27552 \times 10^{-10} \mathrm{~mol} \cdot \mathrm{cm}^{-2}$ for the LS film. The inherent irreproducibility of cast films did not allow calculating the surface coverage accurately. These values were higher than those obtained using a bare ITO glass electrode $\left(2.37 \times 10^{-11} \mathrm{~mol} \cdot \mathrm{cm}^{-2}\right)$ indicating that the presence of the nanostructured layer of $\mathrm{LuPc}_{2} \mathrm{Cl}_{32}$, increased the number of active sites, thus facilitating the oxidation of the catechol. 


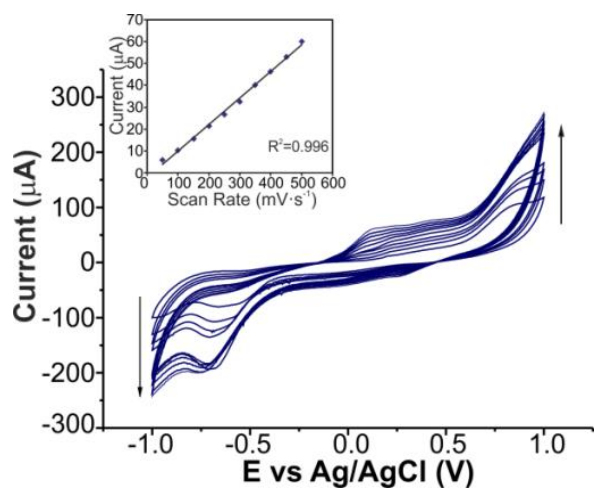

Figure 3.9. Cyclic voltammogram of a LS sensor (8 layers) registered at different scan rates from 0.05 to $0.5 \mathrm{~V} \cdot \mathrm{s}^{-1}$. The inset shows the plot of $\mathrm{I}_{\mathrm{a}} \mathrm{Vs}$. $\mathrm{V}$ (calculated for peak I). Electrolyte solution was $10^{-3} \mathrm{~mol} \cdot \mathrm{L}^{-1}$ cathecol (in $\mathrm{KCl} 0.1 \mathrm{~mol} \cdot \mathrm{L}^{-1}$ ).

Table 3.2. Slope $(m)$, coefficient of correlation $\left(R^{2}\right)$ and surface coverage $(\Gamma)$ obtained by representing the intensity of the anodic peak I and the scan rate (v).

\begin{tabular}{|c|r|c|c|}
\hline \multicolumn{1}{|c|}{ Electrode } & $\mathbf{m}$ (slope) & $\mathbf{R}^{\mathbf{2}}$ & $\Gamma\left(\mathrm{mol} \cdot \mathrm{cm}^{-2}\right.$ ) \\
\hline LuPc $_{2} \mathrm{Cl}_{32} / \mathbf{2 O L B}$ & $7 \times 10^{-5}$ & 0.995 & $7.7745 \times 10^{-11}$ \\
\hline LuPc $_{2} \mathrm{Cl}_{32} / \mathbf{8 L S}$ & $1 \times 10^{-4}$ & 0.996 & $1.2755 \times 10^{-10}$ \\
\hline
\end{tabular}

\subsection{8- Limits of detection}

The intensity of peak I was linearly dependent on the concentration of catechol in the range from $6 \times 10^{-5}$ to $5 \times 10^{-4} \mathrm{~mol} \cdot \mathrm{L}^{-1}$ as shown in Figure 3.10. The corresponding detection limits were calculated according to

the $3 \mathrm{~s}_{\mathrm{d}} / \mathrm{m}$ criterion, where $\mathrm{m}$ is the slope of the calibration graph, and $\mathrm{s}_{\mathrm{d}}$ was estimated as the standard deviation $(n=7)$ of the voltammetric signal of the electrode at the concentration level corresponding to the lowest concentration of the calibration plot. The detection limits calculated were $7.49 \times 10^{-5} \mathrm{~mol} \cdot \mathrm{L}^{-1}$ for $\mathrm{LB}$ and $8.42 \times 10^{-5} \mathrm{~mol} \cdot \mathrm{L}^{-1}$ for LS. These results demonstrate that the $\mathrm{LuPc}_{2} \mathrm{Cl}_{32}$ nanostructured films can be used to quantify the presence of catechol in the range usually present in foods. 


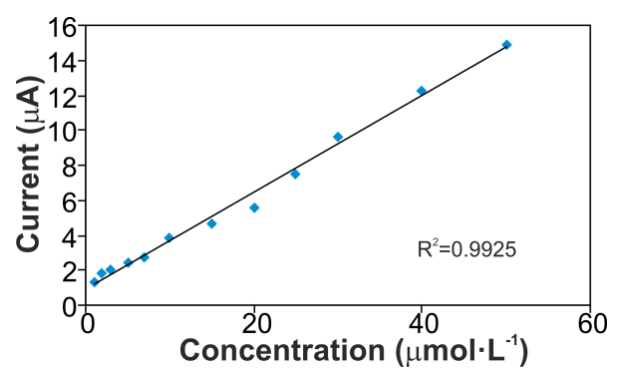

Figure 3.10. Calibration curve obtained from the LB film sensor ( 20 monolayers).

\subsection{CONCLUSIONS}

LB and LS films of bis[2,3,9,10,16,17,23,24-octachlorophthalocyaninate] lutetium(III) complex were successfully prepared forming well stratified layers. The molecular packing induced by the presence of the substituents differed from that showed by other bisphthalocyanine compounds and strongly affected the electrochemical properties of the LB and LS films when compared to $\mathrm{LuPC}_{2} \mathrm{Cl}_{32}$ cast film and bare ITO glass electrode. The electrocatalytic activity of the $\mathrm{LuPc}_{2} \mathrm{Cl}_{32}$ and the abundant binding sites for the immobilization provided by the nanostructured films are responsible for the significantly improved electrochemical behavior of catechol at the $\mathrm{LuPC}_{2} \mathrm{Cl}_{32}$ films.

The small structural difference between LB and LS films justifies some divergence in their sensing properties. For instance, the oxidation and the polymerization of catechol are favored at the surface of LS films, whereas LB films are more stable.

In summary, the electrochemical results indicate that the $\mathrm{LuPc}_{2} \mathrm{Cl}_{32} \mathrm{LB}$ and LS films modified ITO glass electrodes ca be used as catechol sensing units with good stability and detection limit around $10^{-5} \mathrm{~mol} \cdot \mathrm{L}^{-1}$. 


\section{References}

1. Jiang, J. Functional phthalocyanine molecular materials, Series: Structure and Bonding. 2010, Ed. Springer. Berlin (Germany)

2. Lever, A.B.P. J. Porphyrins Phthalocyanines. 1999, 3, 488-499.

3. Zagal, H., Griveau, S., Silva, J.F., Nyokong, T., Bedoui, F. Coord. Chem. Rev. 2010, 254, 2755-2791. 
4. Rodríguez-Méndez, M.L. Sensing properties of Phthalocyanines in Encyclopedia of Sensors, 2006, 111-134. Ed. America Scientific Publishers. California (USA)

5. Bedoui, F., Griveau, S., Nyokong, T., Appleby, A.J., Caro, C.A., M. Gulppi, M., Ochoa, G., Zagal, J.H. Phys. Chem. Chem. Phys. 2007,9, 33833396.

6. Valli, L. Adv. Col. Interf. Sci. 2005,116, 13-44.

7. Weiss, R., Fischer, J. Lanthanide Phthalocyanine Complexes in Porphyrin Handbook. 2010, 171-246. Ed. Academic Press, New York (USA).

8. Komorsky-Lovri'c, S., Quentel, F., L'Her, M., Scholz, F. J. Solid State Electrochem. 2008, 12, 165-169.

9. Bouvet, M. Radical phthalocyanines and intrinsic semiconduction, in Porphyrin Handbook, 2010, 37-104. Ed. Academic Press, New York (USA).

10. Rodríguez-Méndez, M.L., Gay, M., de Saja, J.A. J. Porphyrins Phthalocyanines. 2009, 13, 1159-1167.

11. Jiang, J.Z., Liu, R.C.W., Mak, T.C.W., Chan, T.W.D., Ng, D.K.P. Polyhedron. 1997, 16, 515-520.

12. Gay, M., Muñoz, R., de Saja, J.A., Rodriguez-Mendez, M.L. Electrochim. Acta. 2012, 68, 88-94.

13. Yilmaz, I., Nakanishi, T., Gurek, A.G., Kadish, K.M. J. Porphyrins. Phthalocyanines. 2003, 7, 227-238.

14. Gorbunova, Y., Rodríguez-Méndez, M.L., Kalashnikova, I.P., Tomilova, L., de Saja, J.A. Langmuir. 2001, 17, 5004-5010.

15. Njanja, E., Nassi, A., Ngameni, E., Elleouet, C., Quentel, F., L'Her, M. Electrochem. Commun. 2007, 9, 1695-1699. 
16. Apetrei, C., Nieto, M., Rodríguez-Méndez, M.L., de Saja, J.A. J. Porphyrins Phthalocyanines. 2011, 15, 1-10.

17. Aoki, P.H.B., Caetano, W., Volpati, D., Riul, A.,Constantino, C.J.L. J. Nanosci. Nanotechnol. 2008, 8, 4341-4318.

18. Apetrei, C., Apetrei, I., de Saja, J.A., Rodriguez-Méndez, M.L. Sensors. 2011, 11, 1328-1344.

19. Centurion, L.M.P.C., Moreira, W., Zuccolotto, V. J. Nanosci. Nanotechnol. 2012,12, 2399-2405.

20. Khaderbad, M.A., Tjoa, V., Mathews, N., Mahdu,S., Ravikan, M., Rao,V.R. Nanosci. Nantechnol. Let. 2012, 4, 743-746.

21. Narducci, D. Sci. of Advanced Mat. 2011, 3, 426-435.

22. Arrieta, A. Parra, V., Rodríguez-Méndez, M.L., de Saja, J.A. Sensors Actuat. B. 2003, 95, 357-365.

23. Fernandes, E.G.R., Brazaca, L.C., Rodríguez-Méndez, M.L., de Saja, J.A., Zucolotto, V. Biosens. Bioelectron. 2011, 26, 4715-4719.

24. Pushkarev, V.E., Shulishov, E.V., Tomilov, Y.V., Tomilova, L.G. Tetrahedron Letters. 2007, 48, 5269-5273.

25. Alessio, P., Pavinatto, F.J., Oliveira, O.N. Jr., de Saja Saez, J.A., Constantino, C.J.L., Rodriguez-Mendez, M.L. Analyst. 2010, 135, 25912599.

26. Jones, R., Hunter, R.A., Davidson, K. Thin Solid Films. 1994, 250, 249257.

27. Selektor, S.L., Shokurov, A.V., Raitman, O.A., Sheinina, L.S., Arslanov, V., Birin, K.P., Gorbunova, Y.G., Tsivadze, A.Y. Colloid Journal. 2012, 74, 334-345.

28. Rodríguez-Méndez, M.L., Aroca, R., de Saja, J.A. Chem. Mater. 1993, 5, 933-937. 
29. Gaffo, L., Constantino, C.J.L., Moreira, W.C., Aroca, R.F., Oliveira, O.N.Jr. Spectrochim. Acta-Part A. 2004, 60, 321-327.

30. Clavijo, R.E., Battisti, D., Aroca, R., Kovacs, G.J., Jennings, C.A. Langmuir. 1992, 8, 113-117.

31. Maitrot, M., Guillaud, G., Boudjema, B., Andre, J.J., Strzelecka, H., Simon, J., Even, R. Chem. Phys. Lett. 1987, 133, 59-62.

32. Gay Martin, M., Rodrıguez-Mendez, M.L., de Saja, J.A. Langmuir. 2010, 26, 19217-19224.

33. Rousseau, R., Aroca, R., Rodríguez-Méndez, M.L. J. Molecular Structure. 1995, 356, 49-62.

34. Rousseau, E., Koets, M.M., Van der Auweraer, M., De Schryver, F.C. Photochem. Photobiol. Sci. 2002, 1, 395-406.

35. Aroca, R. Surface-Enhanced Vibrational Spectroscopy. 2006, Ed. John Wiley and Sons. Hoboken, (USA).

36. Gobernado-Mitre, I., Klassen, B., Aroca, R., de Saja, J.A. J. Raman Spectroscopy. 1993, 24, 903-908.

37. Debe, M.K. Prog. Surf. Sci. 1987, 24, 1-4.

38. Alessio, P., de Oliveira, R.F., Aoki, P.H.B., Pereira, J.D.A.S., Braunger, M.L., Furini, L.N., Vieira, M., Teixeira, S.R., Job, A.E., Saenz, C.A.T., Alves, N., Olivati, C.A., Constantino, C.J.L. J. Nanosci. Nanotechnol. 2012, 12, 7010-7020.

39. Aroca, R., Kovacs, G.J., Vibrational Spectra and Structure, 1991, Ed. Elsevier, Amsterdam (Netherlands).

40. Alessio, P., Rodrıguez-Mendez, M.L., de Saja Saez, J.A., Constantino, C.J.L. Phys. Chem. Chem. Phys. 2010, 12, 3972-3983.

41. Alessio, P., de Saja Saez, J.A., Aroca, R.F., Constantino, C.J.L. Applied Spectroscopy. 2011, 65, 152-158. 
42. Le Ru, E.C., Etchegoin, P.G. Principles of Surface Enhanced Raman Spectroscopy (and Related Plasmonic Effects). 2009, Ed. Elsevier, Amsterdam (Netherlands).

43. Alessio, P., Constantino, C.J.L., Aroca, R.F., Oliveira, O.N.Jr. J. Chil. Chem. Soc. 2010, 55, 469-478.

44. Yilmaz, I., Nakanishi, T., Gurek, A., Kadish, K.M. J. Porphyrins Phthalocyanines. 2003, 7, 227-238.

45. Kahlal, S., Mentec, A., Pondaven, A., L'Her, M., Saillard, J.Y. New J. Chem. 2009, 33, 574-582.

46. Nematollahi, D., Alimoradi, M., Husainc, S.W. Electroanalysis. 2004, 16, 1359-1365.

47. Wang, G., He, X., Zhou, F., Li, Z., Fang, B., Zhang, X., Wang, L. Food Chem. 2012, 135, 446-451.

48. Makhotkina, O., Kilmartin, P.A. Anal. Chim. Acta. 2010, 668, 155-165.

49. Huang, W., Luo, S., Zhou, D., Zhang, S., Wu, K.B. Nanosci. Nanotechnol. Lett. 2013, 5, 367-371. 


\section{CHAPTER 4}

Synergistic Nanostructured Functionalised Bisphthalocyanines
Electrocatalytic

Effect

of Mixed Films Formed by Gold Nanoparticles and 

Once demonstrated the electrocatalytic effect that Langmuir-Blodgettfilms of phthalocyanines and gold nanoparticles present towards the detection of compounds with interest in the enology field, the goal of this chapter was to analyze the effect of co-depositing two electrocatalytic materials.

A new methodology has been developed to co-deposit LB films of phthalocyanines with gold nanoparticles. One of the achievement of this work was to use LB technique to modify the substrate (ITO) with polar gold nanoparticles modified. The method consisted on the insertion of the water soluble gold nanoparticles [(11-mercaptoundecyl) tetra(ethylene glycol)] (SAuNP) underneath a floating Langmuir film formed by a phthalocyanine [lutetium (III) bisphthalocyanine] (LuPc $)$ and an amphiphile [dimethyl dioctadecyl ammonium bromide] (DODAB) required to decrease the rigidity of the film. The insertion of the SAuNPs into the nanostructured $\mathrm{LuPc}_{2}: \mathrm{DODAB}$ floating film to obtain $\mathrm{LuPC}_{2}:$ DODAB/SAuNP films will be evaluated using spectroscopic and microscopic techniques. The sensing capabilities of films containing different proportions of $\mathrm{LuPc}_{2}: \mathrm{DODAB}$ and increasing amounts of SAuNPs have been studied towards hydroquinone, an antioxidant belonging to the phenols family commonly found in beverages such as teas and wines, using cyclic voltammetry (CV). The synergistic effect caused by the interaction of two electrocatalytic materials: SAuNPs and $\mathrm{LuPC}_{2}$ will be discussed. This work was carried out in collaboration with researchers from UNESP (Brazil) and has been published in Analytica Chimica Acta.

\subsection{INTRODUCTION}

Phenolic compounds are a large family of molecules which are widely distributed in plant-derived foods. They have attracted great interest due to their potential health benefits. Polyphenolic compounds also contribute to the organoleptic characteristics of foods and affect their antioxidant capacity ${ }^{1}$. The determination of phenols can be carried out using traditional techniques including spectroscopy, gas or liquid chromatography and electrochemical methods. Oxidation of phenols is 
feasible at inert electrodes (e.g. metallic or glassy carbon electrodes) $)^{2}$ and at electrodes chemically modified with a variety of materials and biomaterials ${ }^{3}$. The modification of the electrode surface with nanomaterials has demonstrated to be a good strategy to prepare sensing devices ${ }^{4,5}$. For instance, electrodes modified with gold nanoparticles (AuNPs) show unique catalytic properties that depend on the AuNP size and on the nature of the protecting groups. In addition, AuNPs provide a large surface area for the detection of analytes, leading to electrochemical sensors with lower detection limits ${ }^{6-9}$.

On the other hand, metallophthalocyanines (MPc) and their sandwich type lanthanide derivatives $\left(\mathrm{LnPC}_{2}\right)$ have demonstrated to behave as excellent sensing materials for the detection of a variety of compounds due to their well-known electrocatalytic properties, fast electron transfer and electron mediator capabilities ${ }^{10-18}$.

The design of hybrid systems combining different electrocatalytic materials is very attractive for the development of electrochemical sensors. Recently, AuNPs and phthalocyanines have been successfully combined at a sensor surface using spin coating ${ }^{19-20}$. However, the applications of these composite AuNP/MPc systems require the development of methods allowing both classes of compounds to be coimmobilized in structures with controlled distribution of the two components $^{21,22}$.

The LB technique can be an alternative to produce nanostructured multilayers where two or more compounds are co-deposited in mixed films $^{23}$. The materials used to form the films must fulfil the particular requirements of this technique. For instance, in classical LB deposition, the film-forming materials must be amphiphilic molecules (insoluble in water but soluble in organic solvents). This means that the AuNPs must be capped (e.g. with thiolate groups) which facilitate the adequate dispersion onto the water subphase ${ }^{24,25}$. In turn, to obtain phthalocyanine multilayer assemblies, it is often necessary to mix the phthalocyanines with amphiphiles such as fatty acids or phospholipids 
that induce flexibility in the monolayers facilitating the transfer to solid substrates ${ }^{15,18}$.

\subsection{MATERIALS AND METHODS}

\subsection{1- Langmuir monolayers and Langmuir-Blodgett films}

The lutetium (III) bisphthalocyaninate $\left(\mathrm{LuPC}_{2}\right)$ was synthesized and purified in the neutral radical state using a previously published method $^{27}$. (11-mercaptoundecyl)tetra(ethylene glycol) functionalized gold nanoparticles (SAuNP), dimethyldioctadecylammonium bromide

(DODAB) and all the chemicals and solvents were purchased from SigmaAldrich and Fluka.

Buffer phosphate $0.01 \mathrm{~mol} \cdot \mathrm{L}^{-1}(\mathrm{pH}$ 7.0) was prepared mixing sodium phosphate monobasic (purity $>99 \%$ ) and sodium phosphate dibasic (purity 99\%) in ultrapure water.

LB films were prepared in a KSV 2000 System Langmuir-Blodgett trough equipped with a Wilhelmy plate to measure the surface pressure versus mean molecular area $(\pi-A)$ isotherms.

Films containing $\mathrm{LuPC}_{2}$ and $\mathrm{DODAB}\left(\mathrm{LuPc}_{2}: \mathrm{DODAB}\right)$ were prepared by spreading a chloroform solution of the corresponding mixture (10:1), $(1: 1)$ or $(1: 10)\left(1 \cdot 10^{-5} \mathrm{~mol} \cdot \mathrm{L}^{-1}\right)$ onto a water subphase (ultrapure waterMillipore MilliQ kept at $20^{\circ} \mathrm{C}$ ). Then, the barriers were compressed at a speed of $10 \mathrm{~mm} \cdot \mathrm{min}^{-1}$ to register the $\pi-A$ isotherms. At a surface pressure of $35 \mathrm{mN} \cdot \mathrm{m}^{-1}, 20$ monolayers were transferred to the solid substrates by $Z$ type deposition with a transfer ratio close to 1 .

Films containing SAuNP, DODAB and $\mathrm{LuPC}_{2}\left(\mathrm{LuPC}_{2}: \mathrm{DODAB} / \mathrm{SAuNP}\right)$, were prepared from chloroform mixtures of $\operatorname{LuPc}_{2}: \operatorname{DODAB}(10: 1),(1: 1)$ and $(1: 10)$ that were spread onto the water subphase. After evaporation of the solvent, 100 or $500 \mu \mathrm{L}$ of an aqueous solution of SAuNP $(0.02 \% \mathrm{w} / \mathrm{v})$ were injected drop by drop underneath the air-water interface (before compressing the film) and adsorbed inside the floating monolayer. Floating layers of $\mathrm{LuPc}_{2}: \mathrm{DODAB} / \mathrm{SAuNP}$ were compressed and 
transferred to solid substrates using the same conditions mentioned in the previous paragraph. 20 monolayers LB films were built by $Z$ type deposition with a transfer ratio close to 1 . A scheme of the preparation method is presented in Figure 4.1. The complete list of the sensors prepared is collected in Table 4.1

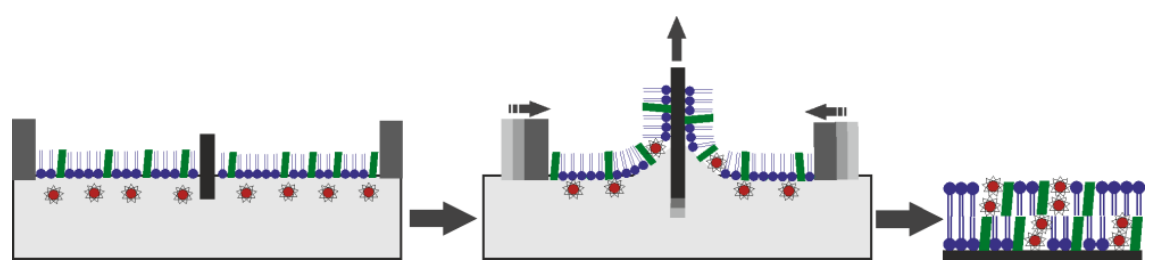

Figure 4.1. Method to prepare the LuPc 2 :DODAB/SAuNP films: SAUNP.

Table 4.1. List of the sensors prepared.

\begin{tabular}{|l|c|r|}
\hline \multicolumn{1}{|c|}{ Film } & $\begin{array}{c}\text { Proportion } \\
\text { LuPc }_{2}: \text { DODAB }\end{array}$ & $\begin{array}{c}\text { Vol. SAuNPs } \\
\text { added }(\boldsymbol{\mu L})\end{array}$ \\
\hline LuPc $_{2}$ :DODAB (10:1) & $10: 1$ & 0 \\
\hline LuPc $_{2}:$ DODAB/SAuNP (10:1/100) & $10: 1$ & 100 \\
\hline LuPc $_{2}:$ DODAB/SAuNP (10:1/500) & $10: 1$ & 500 \\
\hline LuPc $_{2}:$ DODAB (1:1) & $1: 1$ & 0 \\
\hline LuPc $_{2}:$ DODAB/SAuNP (1:1/100) & $1: 1$ & 100 \\
\hline LuPc $_{2}:$ DODAB/SAuNP (1:1/500) & $1: 1$ & 500 \\
\hline LuPc $_{2}:$ DODAB (1:10) & $1: 10$ & 0 \\
\hline LuPc $_{2}:$ DODAB/SAuNP (1:10/100) & $1: 10$ & 100 \\
\hline LuPc $_{2}:$ DODAB/SAuNP (1:10/500) & $1: 10$ & 500 \\
\hline
\end{tabular}

\subsection{2- Films characterization}

Langmuir films were analyzed by Brewster Angle Microscopy (BAM) using a KSV MicroBAM. UV-Visible absorption measurements were conducted using a Shimadzu spectrophotometer UV-1603. TEM images were recorded using a JEM -FS2200 HRP instrument. 
Raman analysis was performed in a Raman spectrometer UV-HR Lab Ram from Horiba-Jobin Ybon, equipped with a LN2-cooled chargecoupled device (CCD) detector. The excitation was carried out with different lasers, including a Nd-YAG laser (emitting at $532 \mathrm{~nm}$ ) and a HeNe laser (emitting at $633 \mathrm{~nm}$ ), with a spectral resolution of $1 \mathrm{~cm}^{-1}$. The sample was excited through the 50X optical objective of a Leica microscope. The scattered light was collected through the same optical objective (back-scattering configuration) with $c a .1 \mu \mathrm{m}$ spatial 
resolution. The excitation power on the sample surface was kept below $100 \mathrm{~kW} \cdot \mathrm{cm}^{-2}$.

The electrochemistry was carried out in an EG\&G PARC 273 potentiostat/galvanostat using a conventional three-electrode cell. The LB films were used as working electrodes. The reference electrode was $\mathrm{Ag} \mid \mathrm{AgCl} / \mathrm{KCl} 3 \mathrm{M}$ and the counter electrode was a platinum plate.

\subsection{RESULTS AND DISCUSSION}

\subsection{1- Langmuir monolayers}

The $\pi-A$ isotherms of mixtures of $\operatorname{LuPc}_{2}$ :DODAB (proportions 10:1, 1:1 and $1: 10$ ) were registered by spreading the corresponding chloroform mixture onto the water subphase and compressing the barriers at a speed of $10 \mathrm{~mm} \cdot \mathrm{min}^{-1}$ while registering the variations of the surface pressure (Figure 4.2.a). When the proportion of $\mathrm{LuPc}_{2}$ was high (10:1), the isotherms were compatible with a total miscibility of the two components. The calculated limiting area of $90 \AA^{2}$ was in agreement with the limiting area previously reported for $\mathrm{LuPc}_{2}$ and corresponds to an edge-on orientation with the Pc ring perpendicular to the water subphase ${ }^{28-30}$. When DODAB was the majoritarian component (1:10), the $\pi$-A isotherms showed a classical pattern of immiscibility consisting on two regions of different slope. At low pressures, the slope of the curve was $127 \AA^{2}$ coinciding with the limiting area registered for neat $D_{D O D A B}{ }^{31}$, whereas in the second steep rise of the surface pressure, the limiting area calculated was $90 \AA^{2}$ that coincided with the value of neat $\operatorname{LuPc}_{2}$. The $\pi-A$ isotherm of the equimolar mixture LuPc 2 :DODAB (1:1), was consistent with a miscible system and showed a large area per molecule of $240 \AA^{2}$. This expansion of the monolayer could be due to repulsive interactions between $\mathrm{LuPc}_{2}$ and DODAB or change of molecular accommodation at the surface ${ }^{32}$. 

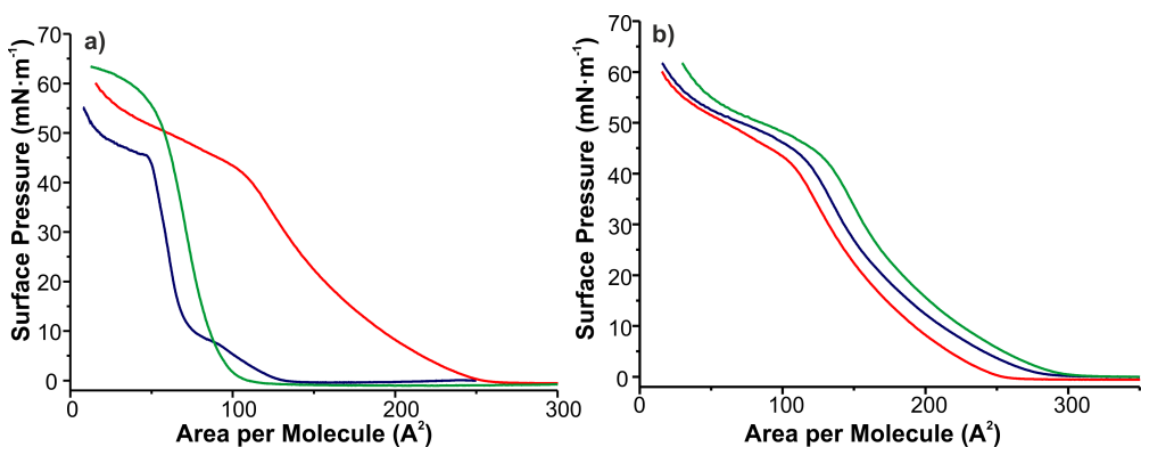

Figure 4.2. Surface pressure/Area per molecule isotherms of a) $\operatorname{LuPc}_{2}: \operatorname{DODAB}(10: 1)$ (green line), $\operatorname{LuPc}_{2}: \operatorname{DODAB}(1: 1)$ (red line) and $\operatorname{LuPc}_{2}: \mathrm{DODAB}$ (1:10) (blue line). b) LuPc 2 :DODAB (1:1) (red line); LuPc $c_{2}$ :DODAB/SAuNP (1:1/100) (blue line) and $\mathrm{LuPC}_{2}$ :DODAB/SAuNP (1:1/500) (green line).

SAuNPs were inserted in the $\operatorname{LuPc}_{2}$ :DODAB floating films by injecting the nanoparticles underneath the air-water interface. The insertion of the gold nanoparticles in the floating films was confirmed by the expansion of the area per molecule that increased with the amount of SAuNPs injected under the surface (Figure 4.2.b). The expansion of the monolayer was clear in $\mathrm{LuPC}_{2}$ :DODAB mixtures 10:1 and 1:1. In contrast, in 1:10 films (low concentration of $L\left(\mathrm{PC}_{2}\right.$ ), the insertion of SAuNP was almost negligible suggesting that the insertion of the SAuNP was mainly due to the conjugation of SAuNPs to the phthalocyanine molecules. It is also important to indicate that injecting amounts of SAuNPs higher than $500 \mu \mathrm{l}$, caused irreproducibility, probably due to the occurrence of phase segregation.

The quality of the floating films was further analyzed using Brewster Angle Microscopy (BAM). In the absence of SAuNP, Langmuir films showed highly homogeneous surfaces. Films containing SAuNP showed a granular structure as a result of the insertion of the nanoparticles in the floating film. This is illustrated in Figure 4.3 where the BAM images of $\mathrm{LuPC}_{2}:$ DODAB and $\mathrm{LuPC}_{2}$ :DODAB/SAuNP films are compared. 

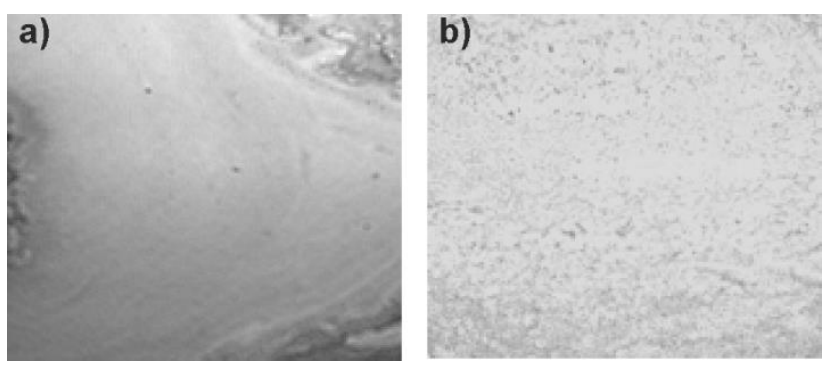

Figure 4.3. $B A M$ images of a) $\operatorname{LuPC}_{2}: \operatorname{DODAB}(1: 1)$ and b) $\operatorname{LuPC}_{2}: D O D A B / S A u N P$ $(1: 1 / 100)$.

\subsection{2- Langmuir-Blodgett films characterization}

The Langmuir films were transferred onto solid substrates. The structure of the films deposited on a copper grid coated with carbon film was examined using TEM (Figure 4.4). TEM images showed domains at micrometer scale formed by $\mathrm{LuPC}_{2}$ :DODAB. The gold cores of the nanoparticles were observed as bright spots of 3.5-5.0 nm that coincided well with the core diameter of the SAuNPs used in this work. The SAuNPs were homogeneously distributed on the surface and were preferentially distributed in the border between $\mathrm{LuPc}_{2}$ :DODAB domains.

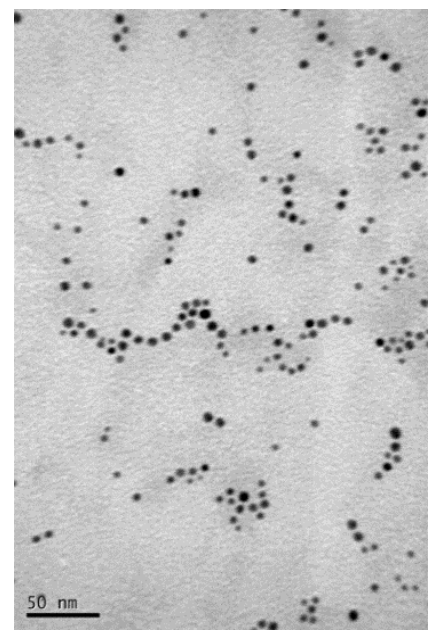

Figure 4.4. TEM image of the $\operatorname{LuPC}_{2}$ :DODAB/SAuNP (1:1/100). 
The UV-Vis absorption spectra of the $\operatorname{LuPc}_{2}$ :DODAB films deposited onto quartz substrates were characterized by a $Q$ band at $665 \mathrm{~nm}$ and a Soret band at $340 \mathrm{~nm}$ produced by $\pi-\pi *$ transitions of the phthalocyanine ring (Figure 4.5). These values were in good accordance with the results reported for $\mathrm{LuPc}_{2}$ and arachidic acid mixtures ${ }^{28}$.

The intensity of the bands increased with the proportion of $\operatorname{LuPc}_{2}(1: 10>$ 1:1 > 10:1) in accordance with the Lambert-Beer's Law. The increase in the $\mathrm{LuPC}_{2}$ proportion also caused a shift of the $Q$ band to higher wavelengths $(660 \mathrm{~nm}$ for the mixture 1:10, $665 \mathrm{~nm}$ for $1: 1$ and $675 \mathrm{~nm}$ for 10:1) indicating a higher level of aggregation and an extension of the aromaticity. The presence of $J$-aggregates in head-to-tail arrangement of transition dipoles in the LB film was responsible for this effect ${ }^{33}$. When inserting SAuNP particles in the structures, the $Q$ and Soret bands increased their intensity. This enhancement was proportional to the amount of SAuNP introduced in the films, suggesting that the amplification was caused by the interaction between the phthalocyanine and the SAuNPs (the plasmon resonance of the SAuNP overlaps with the $Q$ band of the $\operatorname{LuPc}_{2}{ }^{34}$ ). In addition, the magnification caused by the SAuNPs increased proportionally with the proportion of DODAB used. This fact could be explained taking into account that DODAB decreased the degree of aggregation of the tightly packed phthalocyanine molecules, facilitating the interaction between $\mathrm{LuPc}_{2}$ and the SAuNP.

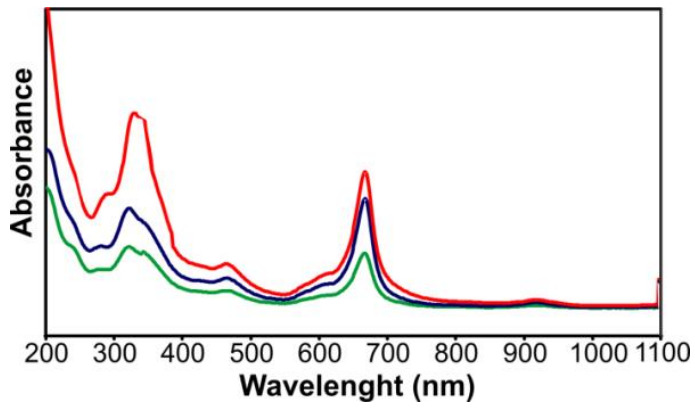

Figure 4.5. UV-Vis spectra of 20 monolayers $L B$ films of $\operatorname{LuPc}_{2}: \operatorname{DODAB}(1: 1)$ (green line), $\mathrm{LuPC}_{2}: \mathrm{DODAB} / \mathrm{SAuNP}(1: 1 / 100)$ (blue line) and $\operatorname{LuPC}_{2}$ :DODAB/SAuNP (1:1/500) (red line). 
The LB films were investigated using micro-Raman technique, which combines morphological and chemical information at micrometer scale by coupling an optical microscope to a Raman spectrograph. Raman spectra recorded with the $633 \mathrm{~nm}$ line are illustrated in Figure 4.6. Since the $\mathrm{LuPc}_{2}$ absorbs the $633 \mathrm{~nm}$ laser line used here, the Resonance Raman Scattering (RRS) should take place ${ }^{35}$.

The RRS displayed the well-known peaks corresponding to the active vibration modes of the $\mathrm{LuPc}_{2}$ where the bands in the resonance region were clearly enhanced. For this reason, the spectra were dominated by four intense bands at $676 \mathrm{~cm}^{-1}, 737 \mathrm{~cm}^{-1}, 775 \mathrm{~cm}^{-1}$ and $813 \mathrm{~cm}^{-1}$ (associated with the Pc ring) whereas, the bands at higher wavelengths (associated with the pyrrole stretching at $1300-1500 \mathrm{~cm}^{-1}$ ) were very weak. In contrast, when using the $532 \mathrm{~nm}$ laser line the bands in the $1300-1600 \mathrm{~cm}^{-1}$ region associated with the pyrrole were clearly observed $^{36}$.
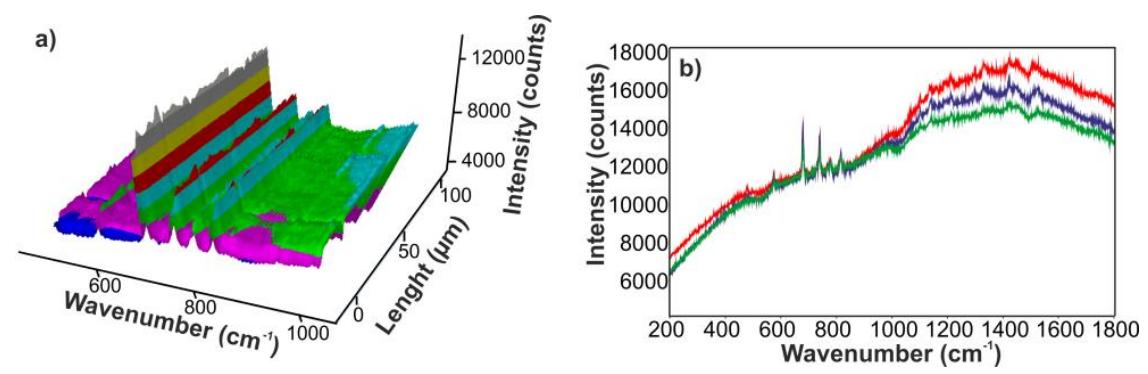

Figure 4.6. Resonant Raman Spectra registered using the $633 \mathrm{~nm}$ laser line. a) 3D line Raman mapping for a 10 monolayers LB film of LuPc 2 :DODAB/SAuNP $(1: 1 / 100)$. b) Raman spectra collected from $\operatorname{LuPC}_{2}$ :DODAB (1:1) (green line); LuPc $_{2}$ :DODAB/SAuNP (1:1/100) (blue line) and LuPc 2 :DODAB/SAuNP (1:1/500) (red line).

The Raman spectra given in Figure 4.6.a was obtained point-by-point for a line of $100 \mu \mathrm{m}$ with step of $1 \mu \mathrm{m}$ forming a line mapping. These RRS spectra revealed that the films were highly homogeneous with a regular distribution of the phthalocyanine molecules. However, as observed in Figure 4.6.b the surface-enhanced resonance Raman phenomenon 
(SERRS) $^{37}$ was not clearly observed and the presence of SAuNP only caused an increase in the fluorescence. The reason of this observation can be attributed to the small size and the functionalization of the AuNPs. It has been demonstrated that the surface plasmon resonance of small AuNPs is damped when compared to larger particles ${ }^{34,38}$. In addition, the distance dependence of the SERRS effect with the distance nanoparticle-molecule could also be the reason ${ }^{37}$.

\subsection{3- Electrochemical characterization.}

Cyclic voltammetry of indium tin oxide (ITO) electrodes modified with Langmuir-Blodgett films of $\mathrm{LuPc}_{2}: \mathrm{DODAB}$ immersed in $0.1 \mathrm{~mol} \cdot \mathrm{L}^{-1} \mathrm{KCl}$ (at a scan rate of $0.1 \mathrm{~V} \cdot \mathrm{s}^{-1}$ ) showed a quasi-reversible process with the anodic peak at $c a .0 .7 \mathrm{~V}$ and the cathodic peak at $c a .0 .5 \mathrm{~V}$. These peaks were due to the oxidation/reduction of the phthalocyanine ring $\left(\mathrm{LuPC}_{2} / \mathrm{LuPC}_{2}{ }^{+}\right)$and their intensity increased with the proportion of $\mathrm{LuPC}_{2}{ }^{39}$. The insertion of SAuNP reduced the overpotential, causing a shift of the oxidation peak to lower potential values while increasing the intensity. This is illustrated in Figures 4.7.a and 4.7.b where the voltammograms obtained from $\operatorname{LuPc}_{2}: \operatorname{DODAB}(10: 1)$ and a LuPc $_{2}$ :DODAB/SAuNPs (10:1/500) at different scan rates (from 0.01 to $1.0 \mathrm{~V} \cdot \mathrm{s}^{-1}$ ) are presented. For instance, at a scan rate of $1.0 \mathrm{~V} \cdot \mathrm{s}^{-1}$, the peak that appeared at $0.9 \mathrm{~V}$ in $\mathrm{LuPC}_{2}: \mathrm{DODAB}$ moved to $0.77 \mathrm{~V}$ in LuPc $_{2}$ :DODAB/SAuNP (10:1/500) while the intensity increased from 460 $\mu \mathrm{A}$ to $920 \mu \mathrm{A}$.

In all the LB films studied (using different proportions of $\mathrm{LuPc}_{2}: \mathrm{DODAB}$ and containing or not SAuNPs) a linear relationship was found between the peak current and the square root of scan rate $\left(v^{1 / 2}\right)$ in the range from 0.01 to $1.0 \mathrm{~V} \cdot \mathrm{s}^{-1}$ indicating a diffusion limited process (Figures 4.7.c and 4.7.d). In all cases, regression coefficients were higher than 0.994 for the oxidation peaks and higher than 0.987 for the reduction peaks.

It is worth noting that curves were steeper for the films containing SAuNPs. For instance, the slope of the curve of the LuPc $2: D O D A B(1: 1)$ was 10.5 and the slope found in $\operatorname{LuPC}_{2}$ :DODAB/SAuNP (1:1/500) was 19.3. This means that the transfer process was two times faster in the 
presence of SAuNPs. This result proved that the mixed films containing both $\mathrm{LuPC}_{2}$ and SAuNPs showed an excellent dynamic character in the redox process, and also that the charge transfer within the LB film and/or through the electrode interface was facilitated.
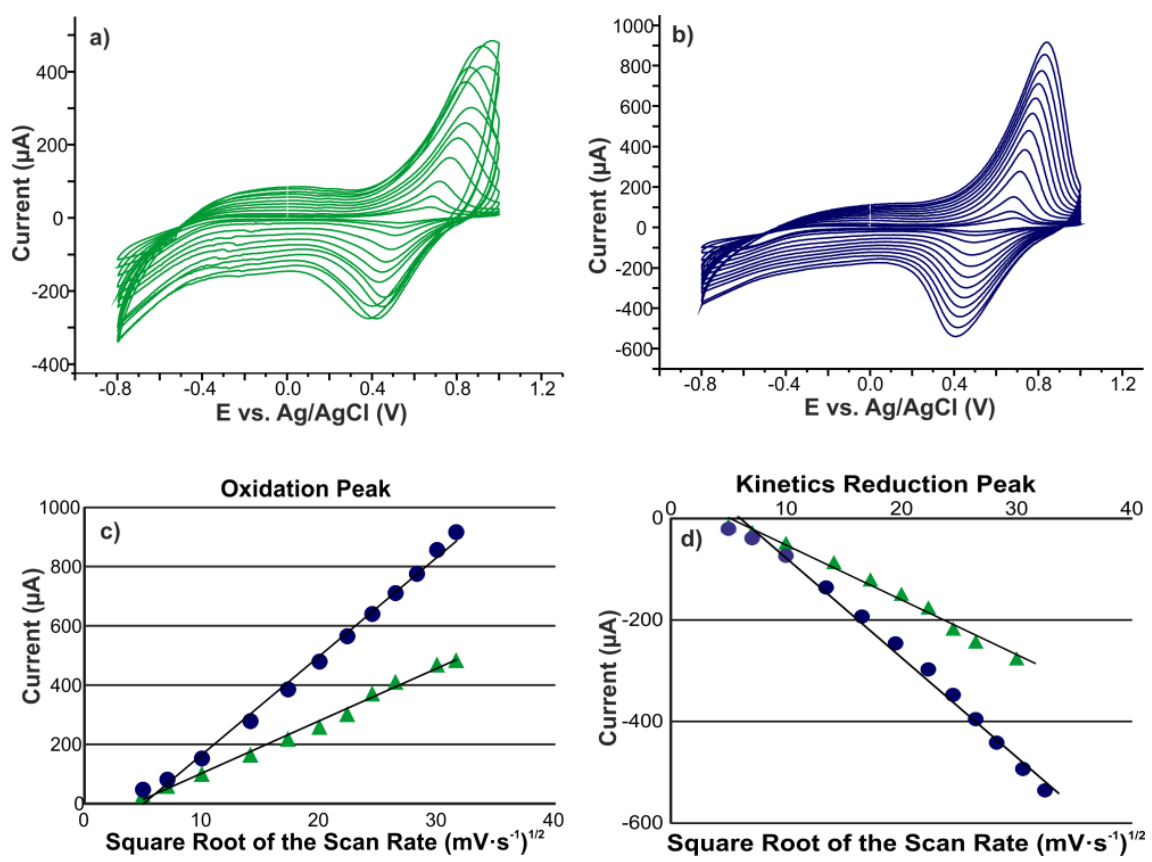

Figure 4.7. Cyclic voltammograms of a) $\operatorname{LuPc}_{2}: \operatorname{DODAB}(10: 1), \quad$ b) LuPC $_{2}: \mathrm{DODAB} / \mathrm{SAuNPs}(10: 1 / 500)$ registered at scan rates from 0.01 to $1.0 \mathrm{~V} \cdot \mathrm{s}^{-1}$, c) Plot of $I_{a}$ versus $v^{1 / 2}$ and d) Plot of $I_{c}$ versus $v^{1 / 2}$.

The oxidation and reduction of the Pc ring was counterbalanced by the diffusion of ions inside the LB films. Voltammograms carried out in electrolytes with common anions but different cations (i.e. in $\mathrm{KCl}$ and $\mathrm{MgCl}_{2}$ ) were almost identical. In contrast, when changing the anion, important changes were observed. Experiments carried out in the presence of different electrolytes (Figure 4.8) demonstrated that anions (instead of cations) diffused inside the films to maintain the electroneutrality. For this reason, voltammograms obtained in electrolytes containing a common anion were superimposable, whereas 
voltammograms obtained from solutions differing in the anion were different.

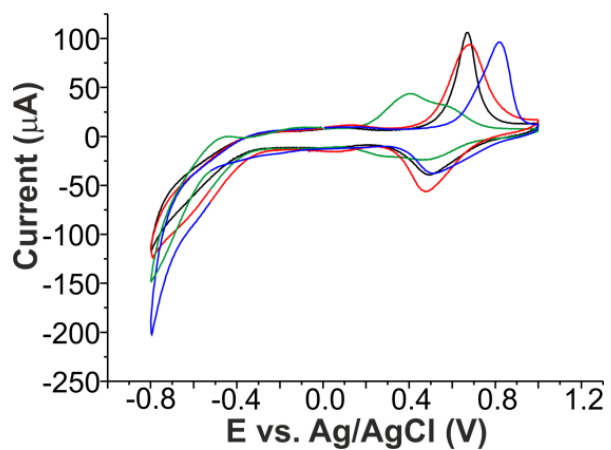

Figure 4.8. Cyclic voltammograms of $\operatorname{LuPc}_{2}$ :DODAB/SAuNP $(1: 1 / 100)$ immersed in $\mathrm{KCl}$ (black line), $\mathrm{MgCl}_{2}$ (blue line), $\mathrm{PBS}$ (green line) and $\mathrm{KClO}_{4}$ (red line).

\subsection{4- Electrocatalytic properties. Voltammetric sensors}

The electrocatalytic properties of the $\operatorname{LuPC}_{2}: D O D A B$ and $\mathrm{LuPC}_{2}: \mathrm{DODAB} / \mathrm{SAuNP}$ LB films were tested towards hydroquinone. In order to avoid the polymerization of the hydroquinone, experiments were carried out in the range $-0.5 \mathrm{~V}$ to $0.7 \mathrm{~V}$ in buffer phosphate (PBS). Under these conditions, the oxidation of the phthalocyanine was no longer observed, and the redox processes registered, correspond to the oxidation/reduction of the hydroquinone. It has to be pointed out that the response registered when using a bare ITO electrode was extremely weak and the peaks could not be clearly observed. As shown in Figure 4.9.a, LB films of $\operatorname{LuPc}_{2}: D O D A B \quad 10: 1$ and 1:1 showed electrocatalytic activity for oxidation of hydroquinone, illustrated by a large increase in the intensity of the peaks associated with the oxidation/reduction of the antioxidant and a shift of the anodic peak to lower potentials (that appear at $c a$. $0.4 \mathrm{~V}$ ). Films containing low concentrations of the bisphthalocyanine $\operatorname{LuPC}_{2}$ :DODAB (1:10) displayed a weak response similar to that observed when using a bare ITO glass electrode. For this reason, the $\operatorname{LuPc}_{2}: \operatorname{DODAB}(1: 10)$ films were not included in further studies. 
Taken into account that the electrocatalytic activity was clearly enhanced by increasing the proportion of $\mathrm{LuPc}_{2}$ in the films, such behaviour can be attributed to the interaction of the hydroquinone with $\mathrm{LuPc}_{2}{ }^{40}$.
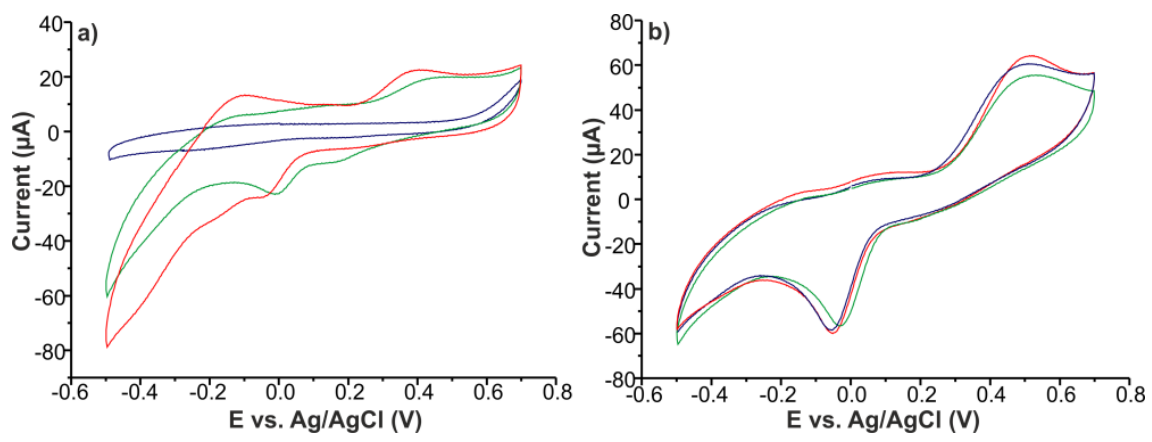

Figure 4.9. Cyclic voltammograms registered in $40 \mu \mathrm{mol} \cdot \mathrm{L}^{-1}$ of hydroquinone using: a) $\operatorname{LuPC}_{2}: \operatorname{DODAB}(10: 1)$ (green line), $\operatorname{LuPc}_{2}: \operatorname{DODAB}(1: 1)$ (red line) and $\operatorname{LuPC}_{2}: \operatorname{DODAB}(1: 10)$ (blue line). b) $\operatorname{LuPc}_{2}: \operatorname{DODAB}(1: 1)$ (green line), LuPC $_{2}$ :DODAB/SAuNPs (1:1/100) (blue line) and LuPc 2 :DODAB/SAuNPs (1:1/500) (red line). Scan rate, $0.1 \mathrm{~V} \cdot \mathrm{s}^{-1}$.

The presence of SAuNPs was found to increase the electrocatalytic efficiency of the sensors towards oxidation of hydroquinone. This increase was proportional to the concentration of SAuNPs (Figure 4.9.a). For instance, the electrocatalytic efficiency of the films was increased by $5 \%$ for LuPc $_{2}:$ DODAB/SAuNPs $(1: 1 / 100)$ and $10 \%$ for LuPC $_{2}:$ DODAB/SAuNPs $(1: 1 / 500)$ (based on the current intensity of LuPC $_{2}:$ DODAB measured at $0.4 \mathrm{~V}$ ).

The presence of SAuNPs increased the intensity of the oxidation current by creating active sites and improving the communication within the phthalocyanine films and the electrode. Similar electrocatalytic effects have been observed in electrodes covered with metallic nanoparticles and other organic materials ${ }^{41,42}$.

As shown in the previous paragraphs, the peak-to-peak separation and electron transfer kinetics of $\mathrm{LuPc}_{2}: \mathrm{DODAB} / \mathrm{SAuNP}$ modified electrodes 
changed with the amount of SAuNP inserted in the LB structure. However, it is important to notice that an excess of SAuNP (injecting more than $500 \mu \mathrm{l}$ of SAuNP under the water subphase) did not produce further improvement leading to a decrease in electrochemical sensitivity and irreproducibility.

The peak current (measured at the voltage of oxidation or reduction of hydroquinone) showed a root square dependence with the scan rate (from 0.01 to $1.0 \mathrm{~V} \cdot \mathrm{s}^{-1}$ ) which indicated diffusion controlled mechanism for the oxidation/reduction of the species in solution. As shown in Table 4.2 that collects the data corresponding to the anodic waves, the presence of SAuNPs increased the slope of the curve pointing to a favoured charge transfer process. The increase varied between $15 \%$ and $22 \%$ depending on the sensor.

Table 4.2. Slope and regression coefficient $\left(R^{2}\right)$ of the curves obtained by representing the intensity of the anodic peak of the oxidation of hydroquinone (at $0.45 \mathrm{~V}$ ) versus the square root of the scan rate (from 0.01 to $1.0 \mathrm{~V} \cdot \mathrm{s}^{-1}$ ).

\begin{tabular}{|l|c|c|}
\hline \multirow{2}{*}{ Sensor } & \multicolumn{2}{c|}{$E=\mathbf{0 . 4 5 V}$} \\
\cline { 2 - 3 } & Slope & $\mathbf{R}^{\mathbf{2}}$ \\
\hline LuPc$_{2}$ :DODAB (1:1) & 7.3847 & 0.999 \\
\hline LuPc $_{2}$ :DODAB/SAuNP (1:1/100) & 7.9500 & 0.999 \\
\hline LuPc $_{2}$ :DODAB/SAuNP (1:1/500) & 8.9535 & 0.999 \\
\hline LuPc $_{2}$ :DODAB (10:1) & 7.4009 & 0.998 \\
\hline LuPc $_{2}$ :DODAB/SAuNP (10:1/100) & 7.8023 & 0.998 \\
\hline LuPc $_{2}$ :DODAB/SAuNP (10:1/500) & 8.4641 & 0.992 \\
\hline
\end{tabular}

The intensity of the peaks associated with the phenol increased linearly with the concentration of hydroquinone in the range from $5 \mu \mathrm{mol} \cdot \mathrm{L}^{-1}$ to $150 \mu \mathrm{mol} \cdot \mathrm{L}^{-1}$ (Figure 4.10). The calibration curves were constructed by representing the intensity value of the anodic (at $c a .0 .45 \mathrm{~V}$ ) and cathodic (at ca. $-0.1 \mathrm{~V}$ ) waves versus the hydroquinone concentration. The limits of detection (LOD) were obtained according to the $3 \mathrm{~s}_{\mathrm{d}} / \mathrm{m}$ criterion, where $\mathrm{m}$ is the slope of the calibration curve, and $s_{d}$ was estimated as the standard deviation $(n=7)$ of the voltammetric signal 
registered using the blank. The LOD calculated for all the sensors prepared are collected in Table 4.3. The improvement of the sensitivity caused by the synergistic electrocatalytic effect allowed the $\mathrm{LuPC}_{2}: \mathrm{DODAB} / \mathrm{SAuNP}$ sensors to reach limits of detection in the range of $10^{-6}-10^{-7} \mathrm{~mol} \cdot \mathrm{L}^{-1}$ which are lower than those obtained for the corresponding $\mathrm{LuPC}_{2}: \mathrm{DODAB}$ electrodes. These results demonstrate that the $\mathrm{LuPc}_{2}: \mathrm{DODAB} / \mathrm{SAuNP}$ nanostructured sensors can be used to quantify the presence of hydroquinone in the range usually present in foods and even below.

The responses were highly reproducible with a coefficient of variation $(n=10)$ lower than $2.0 \%$ between similar sensors (same composition). The reproducibility intra-assay was lower than $1.0 \%$.
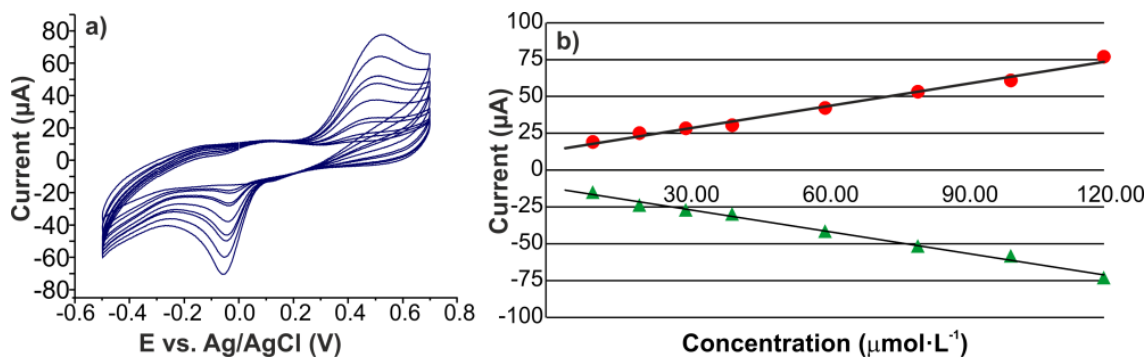

Figure 4.10. a) Response $\operatorname{LuPC}_{2}$ :DODAB/SAuNPs $1: 1 / 100$ towards hydroquinone $\left(4-150 \mu \mathrm{mol} \cdot \mathrm{L}^{-1}\right.$ in PBS). b) Plot of $\mathrm{I}_{\mathrm{a}}(\bullet)$ or $\mathrm{I}_{\mathrm{p}}(\Delta)$ versus $v^{1 / 2}$.

\subsection{CONCLUSIONS}

In this chapter, a method to prepare nanostructured electrodes of two electrocatalytic materials (functionalized AuNPs and lutetium bisphthalocyanine) using the Langmuir-Blodgett technique has been developed.

The surface pressure-mean molecular area isotherms combined with BAM images indicated that SAuNPs were adsorbed into the floating films formed by $\mathrm{LuPc}_{2}$ and DODAB. Spectroscopic and microscopic studies confirmed that homogeneous LB films can be transferred to solid substrates. 
Electrocatalytic properties of the $\operatorname{LuPc}_{2}: \mathrm{DODAB} / \mathrm{SAuNP}$ electrodes towards the detection of hydroquinone were evidenced by a decrease in the oxidation potential at which oxidation of hydroquinone takes place. It was demonstrated that the SAuNPs and $\mathrm{LuPc}_{2}$ have a synergistic effect in terms of improving electrocatalysis for the detection of hydroquinone as confirmed by the enhancement of the oxidation peak current (at 0.45 $\mathrm{V}$ ) and the reduction peak current (at $-0.01 \mathrm{~V}$ ).

Voltammetric responses were proportional to the concentration of hydroquinone between $5 \mu \mathrm{mol} \cdot \mathrm{L}^{-1}$ to $150 \mu \mathrm{mol} \cdot \mathrm{L}^{-1}$, and the limit of detection was in the range of $10^{-6}-10^{-7} \mathrm{~mol} \cdot \mathrm{L}^{-1}$ with good reproducibility. 
Table 4.3. Detection limits calculated for the detection of hydroquinone using $\mathrm{LuPC}_{2}: \mathrm{DODAB}$ and $\mathrm{LuPc}_{2}: \mathrm{DODAB} / \mathrm{SAuNP}$ nanostructured films.

\begin{tabular}{|c|c|c|c|c|c|c|c|}
\hline \multirow{4}{*}{$\begin{array}{l}\frac{1}{0} \\
\frac{0}{\pi} \\
\frac{\pi}{0} \\
\frac{0}{x}\end{array}$} & $\sum_{w}$ & กี & กี & กี & $\stackrel{\sim}{\stackrel{*}{*}}$ & $\stackrel{\infty}{+}$ & $\begin{array}{l}0 \\
0 \\
0\end{array}$ \\
\hline & 음 & \begin{tabular}{l}
\multirow{+}{*}{} \\
\multirow{2}{*}{}
\end{tabular} & $\begin{array}{l}\text { 梵 } \\
\text { ํํ } \\
\text { ○े }\end{array}$ & $\begin{array}{l}\text { ஸे } \\
\text { ஸุ } \\
0\end{array}$ & 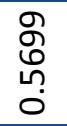 & $\begin{array}{l}\stackrel{n}{n} \\
\text { ก̊ } \\
0\end{array}$ & 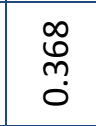 \\
\hline & $\tilde{N}^{\alpha}$ & $\begin{array}{l}\text { O } \\
\stackrel{\infty}{0} \\
0\end{array}$ & $\begin{array}{l}\text { के } \\
\text { Oे } \\
0\end{array}$ & $\begin{array}{l}\text { Oे } \\
\infty \\
\text { ọ }\end{array}$ & $\begin{array}{l}\text { กू } \\
\text { Oे }\end{array}$ & $\begin{array}{l}\infty \\
\stackrel{\infty}{\$} \\
0\end{array}$ & बू. \\
\hline & 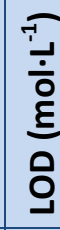 & 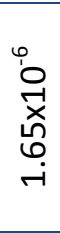 & $\begin{array}{l}\hat{i} \\
\vec{x} \\
\text { m. } \\
\sigma\end{array}$ & $\begin{array}{l}\hat{y} \\
\vec{x} \\
\stackrel{y}{m} \\
m \\
m\end{array}$ & 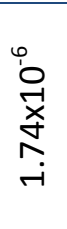 & 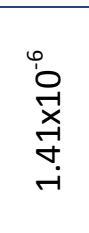 & 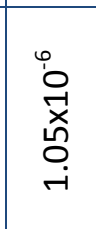 \\
\hline \multirow{4}{*}{ 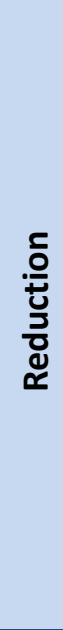 } & $\sum_{w}$ & $\begin{array}{l}n \\
0 \\
0 \\
0\end{array}$ & $\begin{array}{l}\text { ọ } \\
\text { î }\end{array}$ & $\begin{array}{l}\infty \\
0 \\
0 \\
\end{array}$ & $\begin{array}{l}\infty \\
0 \\
0\end{array}$ & $\begin{array}{l}\infty \\
0 \\
0 \\
1\end{array}$ & $\begin{array}{l}-1 \\
0 \\
0\end{array}$ \\
\hline & $\frac{\check{0}}{\frac{0}{n}}$ & $\begin{array}{l}\stackrel{\vec{N}}{\sim} \\
\stackrel{0}{0} \\
\stackrel{1}{1}\end{array}$ & $\begin{array}{l}\stackrel{\sim}{\sim} \\
\stackrel{f}{f} \\
\dot{\varphi}\end{array}$ & 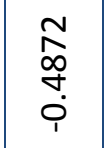 & \begin{tabular}{l}
$\stackrel{N}{N}$ \\
\multirow{+}{*}{}
\end{tabular} & $\begin{array}{l}\hat{O} \\
\text { } \\
0 \\
0\end{array}$ & 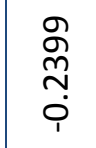 \\
\hline & $\approx$ & $\begin{array}{l}\text { @ } \\
\stackrel{2}{0} \\
0\end{array}$ & $\begin{array}{l}\text { ᄋ̆ } \\
\text { Оุ }\end{array}$ & $\begin{array}{l}m \\
\infty \\
\circ \\
0\end{array}$ & $\begin{array}{l}\text { ठั } \\
\text { О. }\end{array}$ & ڤn & $\begin{array}{l}\text { న్ } \\
\infty \\
\text { ஸे }\end{array}$ \\
\hline & 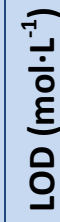 & 叒 & 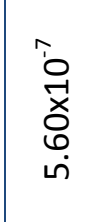 & 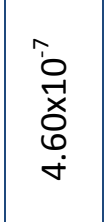 & 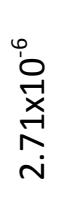 & $\begin{array}{l}0 \\
\stackrel{0}{x} \\
\stackrel{0}{\infty} \\
\stackrel{1}{n}\end{array}$ & 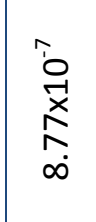 \\
\hline \multicolumn{2}{|c|}{ 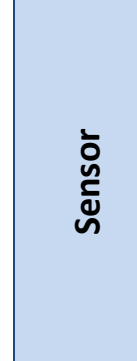 } & 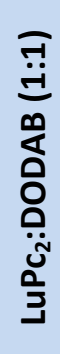 & 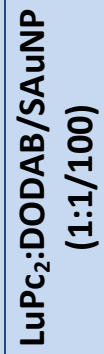 & 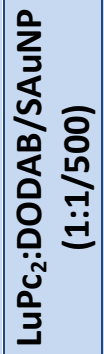 & 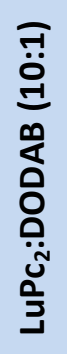 & 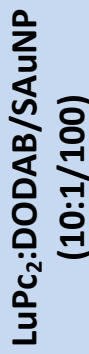 & 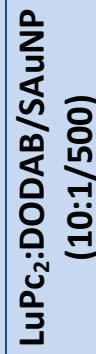 \\
\hline
\end{tabular}




\section{References}

1. Bartosz, G., Food oxidants and antioxidants: chemical, biological, and functional properties, 2013. Ed. CRC press, Florida (USA).

2. Makhotina, O., Kilmartin, P.A. Anal. Chim. Acta. 2010, 668, 155-165.

3. Prehn, R., Gonzalo-Ruiz, J., Cortina-Puig, M. Curr. Anal. Chem. 2012, 8, 472-484.

4. Narducci, D. Sci. Adv. Mat. 2011, 3, 426-435.

5. Chen, A.C., Chatterjee, S. Chem. Soc. Rev. 2013, 42, 5425-5438.

6. Campbell, F.W., Compton, R.G. Anal. Bioanal. Chem. 2010, 396, 241259.

7. Zhou, Y.G., Campbell, F.W., Belding, S.R., Compton, R.G. Chem. Phys. Lett. 2010, 497, 200-204.

8. Pena-Pereira, F., Duarte, R.M.BO., Duarte, A.C. Trends Anal. Chem. 2012, 40, 90-105.

9. Shan, X., Díez-Pérez, I., Wang, L., Wiktor, P., Gu, Y., Zhang, L., Wang, W., Lu, J., Wang, S., Gong, Q., Li, J., Tao, N. Nature Nanotech. 2012, 7, 668-672.

10. Jiang, J., Functional Phthalocyanine Molecular Materials. Series: Structure and Bonding 13, 2010. Ed. Springer, Berlin (Germany).

11. Rodriguez-Mendez, M.L. Sensing properties of phthalocyanines, in: Encyclopedia of Sensors, 2006, 111-134. Ed. America Scientific Publishers, California (USA).

12. Zagal, J.H., Griveau, S., Silva, J.F., Nyokong, T., Bedoui, F. Coord. Chem. Rev. 2010, 254, 2755-2794.

13. Bouvet, M., Gaudillat, P., Suisse, J.M. J. Porphyrins. Phthalocyanines. 2013, 17, 913-919. 
14. Sorokin, A.B., Kudrik, E.V. Catal. Today. 2011, 159, 37-46.

15. Valli, L. Adv. Colloid. Interface. Sci. 2005, 116, 13-44.

16. Rodriguez-Mendez, M.L., Gay, M., de Saja, J.A. J. Porphyrins. Phthalocyanines. 2009, 13, 1159-1167.

17. Volpati, D., Alessio, P., Zanfolim, A.A., Storti, F.C., Job, A.E., Ferreira, M., Riul, A., Oliveira, O.N.Jr., Constantino, C.J.L. J. Phys. Chem. B. 2008, $112,15275-15282$.

18. Pavinatto, F.J., Fernandez, E.G.R., Alessio, P., Constantino, C.J., de Saja, J.A., Zucollotto, V., Oliveira, O.N. Jr., Apetrei, C., Rodriguez-Mendez, M.L. J. Mat. Chem. 2010, 21, 4995-5003.

19. Nyokong, T., Antunes, E. Coord. Chem. Rev. 2013, 257, 2401-2418.

20. Chauke, V.P., Chidawanyika, W., Nyokong, T. Electroanal. 2011, 23, 487-496.

21. Hone, C., Walker, P.I., Evans-Gowing, R., Fitzgerald, S., Beeby, A., Chambrier, I., Cook, M.J., Russell, D.A. Langmuir. 2002, 18, 2985-2987.

22. Pal, M., Ganesan, V. Langmuir. 2009, 25, 13264-13272.

23. Alencar, W.S., Crespilho, F.N., Martins, M.V.A., Zucolotto, V., Oliveira, O.N.Jr., Silva, W.C. Phys. Chem. Chem. Phys. 2009, 11, 50865091.

24. Aoki, P.H.B., Alessio, P., de Saja, J.A., Constantino, C.J.L. J. Raman Spectrosc. 2010, 41, 40-48.

25. Comeau, K.D., Meli, M.V. Langmuir. 2012, 28, 377-381.

26. Deisinger, P.J., Hill, T.S., English, J.C. J. Toxicol. Environ. Health. 1996, 47, 31-46.

27. Linaje, M., Quintanilla, M.C., Gonzalez. A., Valle, J.L., Alcaide, G., Rodriguez-Mendez, M.L. Analyst. 2000, 125, 341-346. 
28. Clavijo, R.E., Battisti, D., Aroca, R., Kovacs, G.J., Jennings, C.A. Langmuir. 1992, 8, 113-117.

29. Maitrot, M., Guillaud, G., Boudjema, B., Andre, J.J., Strzelecka, H., Simon, J., Even, R. Chem. Phys. Letters. 1987, 133, 59-62.

30. Souto, J., Tomilova, L., Aroca, R., de Saja, J.A. Langmuir. 1992, 8, 942946.

31. Viseu, M.I., Gonçalves da Silva, A.M., Antunes, P., Costa, S.M.B. Langmuir. 2002, 18, 5772-5781.

32. Martin, M.T., Möbius, D. Thin Solid Films. 1996, 284-285, 663-666.

33. Rodriguez-Mendez, M.L., Gorbunova, Y., de Saja, J.A. Langmuir. 2002, 18, 9560-9565.

34. Huang, X., El-Sayed, M.A., J. Advanced. Research. 2010, 1, 13-28.

35. Moskovits, M. J. Raman Spectrosc. 2005, 36, 485-496.

36. Rodriguez-Mendez, M.L., Aroca, R. Spectrochim. Acta A. 1993, 49, 965-973.

37. Aroca, R., Pieczonka, N., Kam, A.P. J. Porphyrins Phthalocyanines. 2001, 5, 25-32.

38. Le Ru, E.C., Etchegoin, P.G., Meyer, M. J. Chem. Phys. 2006, 125, 204701.

39. Fernandes, E.G.R., Brazaca, L.C., Rodriguez-Mendez, M.L., de Saja, J.A., Zucolotto, V. Biosens. Bioelectron. 2011, 26, 4715-4719.

40. Gay Martin, M., Rodriguez-Mendez, M.L., de Saja, J.A. Langmuir. 2010, 26, 19217-19224.

41. Azad, U.P., Ganesan, V. Electroanal. 2010, 22, 575-583.

42. Pal, M., Ganesan, V. Langmuir. 2009, 25, 13264-13272. 



\section{CHAPTER 5}

Bioelectronic Tongue Based on Lipidic Nanostructured Layers Containing Phenol Oxidases and Lutetium Bisphthalocyanine for the Analysis of Grapes 

When complex samples (food and beverages) are analyze using voltammetric sensors, the responses obtained are not directly related to the concentration of a specific analyte or family of molecules. The information under the curves is associated with every redox active species present on the sample. Constructing arrays of sensors is a way to improve the electrochemical analysis. The cross-selectivity attained when more than one sensor is used on the analysis allows discriminating samples with similar characteristics (e.g. varieties of grapes, types of wines...). For this purpose an exhaustive data treatment is needed including pre-processing of the data, training of the system, prediction, validation...

In order to make sensors more specific, enzymes can be included in the sensitive layer. As stated in the introduction enzymes are proteins that catalyze specifically some reactions which involve molecules that can be bind to their active site. Phenol oxidases (tyrosinase and laccase) are a family of enzymes that catalyze reactions associated with polyphenols redox processes.

Langmuir-Blodgett (LB) technique is of special interest in the field of biosensors because it allows immobilizing the enzyme in a biomimetic environment, helping to preserve the activity of the enzyme, and coimmobilize the electron mediator.

In this work, biosensors containing phenol oxidases have been developed using LB technique. The proteins have been incorporated into LB films of arachidic acid (AA), simulating biological membranes, using lutetium bisphthalocyanine $\left(\mathrm{LuPC}_{2}\right)$ as electron mediator. Cyclic voltammetry (CV) has been applied to detect six phenolic compounds including one monophenol, three diphenols and two triphenols. The complementarity achieved by the different sensors and the electron mediator capability of the bisphthalocyanine will be discussed. In addition, this bioelectronic tongue will be employed to analyze must from different varieties of grapes and its capability of discrimination will be analyzed. These results have been published in Biosensors and Bioelectronics. 


\subsection{INTRODUCTION}

The determination of phenols, the main antioxidants in foods, has been widely investigated using traditional techniques including spectroscopy, chromatography and electrochemical methods ${ }^{1,2}$.

A promising approach in food analysis consists in the use of electronic tongues (ET) which are multisensor systems based on a number of lowselective sensors and use advanced mathematical procedures for processing the electrochemical signals, based on pattern recognition and/or multivariate data analysis ${ }^{3,4}$. Electronic tongues provide global information about the sample instead of information about specific compounds.

Electrochemical sensors are the most widely used sensing units in electronic tongues. They include potentiometric ${ }^{5}$, amperometric ${ }^{6}$, voltammetric $^{7-9}$ or impedimetric sensors ${ }^{10}$.

Arrays of voltammetric electrodes chemically modified with electroactive materials (e.g. phthalocyanines) have demonstrated to be particularly interesting for the analysis of phenolic compounds ${ }^{11-13}$. When using such electrodes, voltammograms show redox peaks produced by the electrode material and by the solution. In addition, the interactions between the electrode and the solution (i.e. electrocatalytic activity of the sensing material) produce shifts in the peak positions and changes in their intensity. In this way, each electrode produces a distinct response towards different solutions. The intrinsic complexity, richness and cross-selectivity of the signals generated by an array of voltammetric electrodes are an advantage because each curve contains large amount of information about the sample ${ }^{7,9}$. Phthalocyanines (MPc) and their sandwich type lanthanide derivatives $\left(\mathrm{LnPC}_{2}\right)$ are among the most suitable materials for electrochemical sensors due to their wellknown electrocatalytic properties ${ }^{9,13,14}$. They have demonstrated to behave as excellent modifiers for the detection of a variety of analytes including polyphenolic compounds ${ }^{11,12,15}$. Nanostructured electrochemical sensors based on phthalocyanines can be prepared using the LangmuirBlodgett (LB) technique ${ }^{16,17}$. 
On the other hand, electrochemical biosensors are an interesting alternative for the analysis of phenols due their high sensitivity and selectivity. They contain phenol oxidase enzymes such as tyrosinase or laccase combined with appropriate electron mediators such as metallic nanoparticles, graphene and conducting polymers among others ${ }^{18}$. It has been demonstrated that MPcs and $\mathrm{LnPc}_{2}$ can also be used as electron mediators in tyrosinase biosensors ${ }^{19-21}$. The LB technique is of special interest in the field of biosensors because using this method, enzymes can be immobilized in a nanostructured lipidic layer with a structure similar to that of the biological membranes. This biomimetic environment can help to preserve the functionality of the enzyme ${ }^{20-22}$. In addition, using the LB technique, the enzyme and the electron mediator can be co-inmobilized in a single sensitive layer, facilitating the electron transfer between the enzyme and the electrode.

Some attempts have been carried out to develop arrays of biosensors containing phenol oxidases for the detection of phenols (the so-called bioelectronic tongues) ${ }^{23,24}$. It has been demonstrated that arrays of biosensors combine the advantages of classical arrays of electrochemical sensors that provide global information about the sample, with the specificity of the enzyme-substrate reaction typical of biosensors.

\subsection{MATERIALS AND METHODS}

\subsection{1- Chemicals}

All chemical and solvents were of reagent grade. Deionized water (resistivity of $18.2 \mathrm{M} \Omega \cdot \mathrm{cm}^{-1}$ ) was used to prepare subphases and solutions.

Laccase, from Trametes versicolor (EC Number: 1.10.3.2, activity of 20.7 $\mathrm{U} \cdot \mathrm{mg}^{-1}$ ) and Tyrosinase (from mushroom EC 232-653-4), noted activity of $3610 \mathrm{U} \cdot \mathrm{mg}^{-1}$ were purchased from Sigma Chemical. $70 \mu \mathrm{g} \cdot \mathrm{mL}^{-1}$ solutions of tyrosinase and laccase were prepared in buffer phosphate 0.01 $\mathrm{mol} \cdot \mathrm{L}^{-1}(\mathrm{pH}=7.0)$ (PBS). 
The lutetium (III) bisphthalocyaninate $\left(\mathrm{LuPc}_{2}\right)$ was synthesized following a previously published procedure ${ }^{25}$.

\subsection{2- Langmuir and Langmuir-Blodgett films characterization}

Isotherms and LB films were prepared in a KSV 2000 Langmuir-Blodgett trough (KSV Instruments, Finland) equipped with a Wilhelmy plate to measure the surface pressure.

According to a previously published method, LB films were prepared using a PBS-NaCl subphase $\left(\mathrm{NaCl} 0.1 \mathrm{~mol} \cdot \mathrm{L}^{-1}\right.$, phosphate buffer 0.01 $\mathrm{mol} \cdot \mathrm{L}^{-1}$ of $\mathrm{pH}=7.0$ in ultrapure water) ${ }^{21}$.

Mixed films containing arachidic acid (AA) and lutetium bisphthalocyanine $\left(\mathrm{LuPC}_{2}\right)$ were prepared by spreading $250 \mu \mathrm{l}$ of a mixture 10:1 (AA/LuPc 2$)$ dissolved in chloroform $\left(1 \times 10^{-5} \mathrm{~mol} \cdot \mathrm{L}^{-1}\right)$ onto the PBS-NaCl subphase. The surface-area isotherms were measured by compressing the floating molecules at a speed of $10 \mathrm{~mm} \cdot \mathrm{min}^{-1}$.

At a surface pressure of $40 \mathrm{mN} \cdot \mathrm{m}^{-1}, 20$ monolayers were deposited onto previously cleaned ITO glass surface by $\mathrm{Y}$-type deposition with a transfer ratio close to 1 .

LB films containing enzyme, arachidic acid and lutetium bisphthalocyanine ( $\mathrm{Enz} / \mathrm{AA} / \mathrm{LuPC}_{2}$ ) were prepared in two steps. First, 10 monolayers of $\mathrm{AA} / \mathrm{LuPC}_{2}$ were deposited using the method described in the previous paragraphs. Then, 10 monolayers of $\mathrm{Enz} / \mathrm{AA} / \mathrm{LuPc}_{2}$ were deposited onto the AA/LuPc $c_{2}$ layers as follows: $250 \mu$ of the AA/LuPc solution were spread onto the PBS- $\mathrm{NaCl}$ subphase. When the solvent was evaporated, $100 \mu \mathrm{l}$ of a $70 \mu \mathrm{g} \cdot \mathrm{ml}^{-1}$ solution of the corresponding enzyme in $0.01 \mathrm{~mol} \cdot \mathrm{L}^{-1} \mathrm{PBS}$ were injected drop by drop underneath the air/liquid interface. Barriers were compressed at a speed of $10 \mathrm{~mm}$. $\mathrm{min}^{-1}$. At a surface pressure of $40 \mathrm{mN} \cdot \mathrm{m}^{-1}, 10$ monolayers of $\mathrm{Enz} / \mathrm{AA} / \mathrm{LuPC}_{2}$ were deposited onto ITO glass with a substrate speed of 3 $\mathrm{mm} \cdot \mathrm{min}^{-1}$. Films were built by $\mathrm{Y}$ type deposition with a transfer ratio close to 1 . 
After preparation, LB films of $\mathrm{Enz} / \mathrm{AA} / \mathrm{LuPc}_{2}$ were treated with glutharaldehyde to form covalent bonds between the enzymes and the amphiphilic molecules ${ }^{26}$.

Langmuir films were analyzed with Brewster Angle Microscopy (BAM) using a KSV MicroBAM.

AFM images were registered in LB films deposited onto ITO using a MultiMode Scanning Probe Microscope Model MMAFM-2 from Digital Instruments.

\subsection{3- Electrochemical measurements}

The electrochemical measurements were carried out in an EG\&G PARSTAT 2273 potentiostat/galvanostat using a conventional threeelectrode cell. The LB films were used as working electrode. The reference electrode was $\mathrm{Ag} \mid \mathrm{AgCl} / \mathrm{KCl} 3 \mathrm{M}$ and the counter electrode was a platinum plate. Cyclic voltammograms were registered at a sweep rate of $0.1 \mathrm{~V} \cdot \mathrm{s}^{-1}$.

\subsection{4- Phenols and grapes}

$10^{-3} \mathrm{~mol} \cdot \mathrm{L}^{-1}$ stock solutions of phenolic compounds including one monophenol (vanillic acid), two orto-diphenols (catechol and caffeic acid), one para-diphenol (hydroquinone) and two triphenols (gallic acid and pyrogallol) were prepared by solving the corresponding compound in PBS. Solutions with lower concentration were prepared by dilution.

Grapes of five different varieties (Tempranillo, Garnacha, CabernetSauvignon, Prieto Picudo and Mencía) were harvested in 2012 in the Castilla y León region (Spain) by the Agrotechnological Institute of the regional Government (ITACYL), and by a cellar of the region (Bodega Cooperativa de Cigales). The Enological Centre of Castilla y León carried out the chemical analysis including the Total Polyphenol Index (TPI) following international regulations ${ }^{27}$.

\subsection{5- Statistical analysis. Data treatment}

A non-supervised multivariate method, Principal Component Analysis (PCA), was used to analyze the voltammetric curves and to evaluate the 
capability of discrimination of the array of sensors. The voltammetric curves were mathematically pre-processed. After normalization a windowed slicing method was used to reduce the number of data per sample ${ }^{28}$. Using this method, 10 parameters per curve were obtained and used as a data source for statistical analysis. All computations and chemometric analysis were carried out using the software Matlab v5.3.

\subsection{RESULTS AND DISCUSSION}

\subsection{1- Langmuir monolayers and Langmuir-Blodgett films}

The isotherm of $\mathrm{AA} / \mathrm{LuPC}_{2}$ registered in PBS- $\mathrm{NaCl}$ subphase is shown in Figure 5.1.a. The limiting area calculated from the slope of the curve was $37 \AA^{2}$. This value corresponds to an edge-on orientation with the Pc ring tilted and assembled with the main molecular axis parallel to the water subphase (lying flat they should occupy an area approximately $20 \AA \times 20$ $\AA)^{29}$.

Tyrosinase and laccase could be effectively adsorbed into the noncompressed $\mathrm{AA} / \mathrm{LuPC}_{2}$ films as demonstrated by the increase in the surface pressure that occurred upon injection of the enzymes underneath the air/liquid interface. In the case of tyrosinase, a constant

and progressive increase in the surface pressure was observed. After 45 minutes (when the surface pressure reached a value of $c a .0 .35 \mathrm{mN} \cdot \mathrm{m}^{-1}$ ) a plateau was attained. The changes in pressure due to the incorporation of laccase to the non-compressed film followed a different kinetics. The increase in the surface pressure started 30 minutes after the injection and reached a plateau 30 minutes later at $0.40 \mathrm{mN} \cdot \mathrm{m}^{-1}$ (total time for saturation was 60 minutes). Once the surface pressure was stabilized, the floating films were compressed at a constant speed of $10 \mathrm{~mm} \cdot \mathrm{min}^{-1}$. Under these conditions reproducible isotherms were obtained (Figure 5.1.a).

The shapes of these isotherms differed from that of $A A / L u P c_{2}$. The formation of the bidimensional solids started at higher areas per molecule and the limiting areas per molecule were larger than the 
values observed for the $\mathrm{AA} / \mathrm{LuPc}_{2}$ Langmuir film, confirming the adsorption of the enzymes into the films. The different areas per molecule observed for Tyr/AA/LuPc $2\left(51 \mathrm{mN} \cdot \mathrm{m}^{-1}\right)$ and $\mathrm{Lac} / \mathrm{AA} / \mathrm{LuPc}_{2}(47$ $\mathrm{mN} \cdot \mathrm{m}^{-1}$ ), can be attributed to the different size and molecular weight of both enzymes (120 kDa for tyrosinase and 50-100 kDa for laccase).

The adsorption of the enzyme into the floating films was also confirmed by the dependence of the limiting area with the time elapsed between the injection of the enzyme and the beginning of the compression. This is also illustrated in Figure 5.1.a, where isotherms registered by waiting 30 and 60 minutes between the injection of the enzyme and the beginning of the compression are compared. In the case of $\mathrm{Tyr} / \mathrm{AA} / \mathrm{LuPC}_{2}$, the limiting area increased with the time elapsed after injection (from 0 to 30 minutes), but isotherms registered after waiting 30 or 60 minutes were almost identical. The variation was dramatic for the $\mathrm{Lac} / \mathrm{AA} / \mathrm{LuPC}_{2}$. This result is in good accordance with the different adsorption kinetics mentioned in the previous paragraphs.

Compression-expansion cycles were also studied. Upon decompression, $\mathrm{AA} / \mathrm{LuPC}_{2}$ floating monolayers showed a certain hysteresis, but successive compression-expansion cycles where highly reproducible (Figure 5.1.b). Hysteresis was also observed in monolayers containing tyrosinase (Figure 5.1.c) or laccase (Figure 5.1.d). The isotherms of the decompression were similar to those of $A A / L_{u P c_{2}}$ film, pointing to desorption of the enzyme during the expansion cycle. During the second cycle, Tyr/AA/LuPc ${ }_{2}$ film recovered the original shape, but the second compression of $\mathrm{Lac} / \mathrm{AA} / \mathrm{LuPC}_{2}$ was similar to the isotherm of the $\mathrm{AA} / \mathrm{LuPC}_{2}$ film. This means that after desorption, tyrosinase could be partially reinserted, whereas laccase could not be readsorbed into the film. It can be concluded that the insertion of laccase into the floating film is more difficult than the insertion of tyrosinase. This could seem surprising because the size of tyrosinase is considerably larger than that of laccase. However, the hydrophobic environment provided by the floating film is more favorable for the tyrosinase which is a 
transmembrane protein and only a small part of the enzyme extends in the cytoplasmic hydrophilic environment.
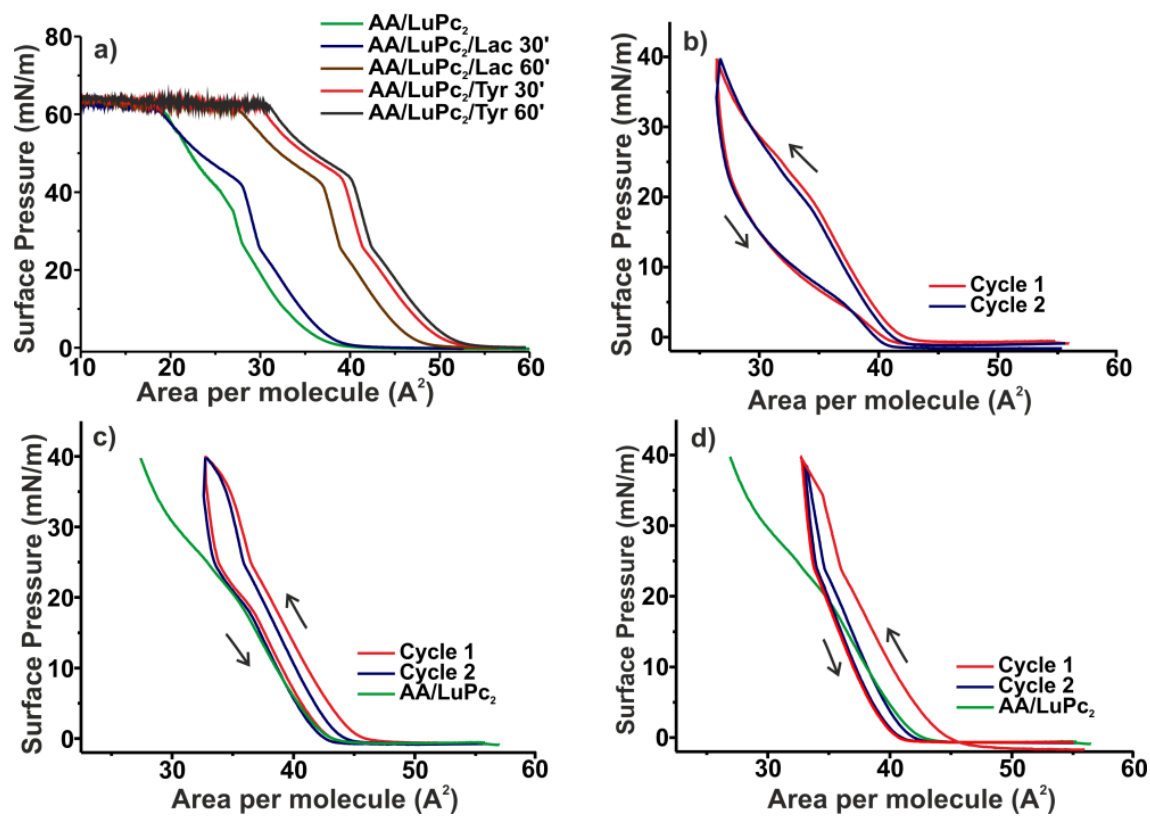

Figure 5.1. a) Pressure Area isotherms registered in a PBS- $\mathrm{NaCl}$ subphase after different waiting times. Compression-expansion cycles of b) $A A / L \mathrm{Pc}_{2}, c$ ) $\mathrm{Tyr} / \mathrm{AA} / \mathrm{LuPc}_{2}$ and d) Lac/AA/LuPc 2.

The quality of the floating films was further analyzed with Brewster Angle Microscopy (BAM). The homogeneity of the Langmuir films containing tyrosinase or laccase was similar to that of the AA/LuPc $c_{2}$ films (Figure 5.2).

In order to visualize the topography of the LB films, AFM was employed. As presented in Figure 5.2.a, AA/LuPC $\mathrm{C}_{2}$ films showed a homogeneous and smooth surface. Regarding Enz/AA/LuPc 2 films, immobilized enzymes were clearly observed showing their characteristic cloud-like morphology (Figure 5.2.b). The enzymes were well and evenly distributed on the surface of the electrode, and no large aggregates were formed. 

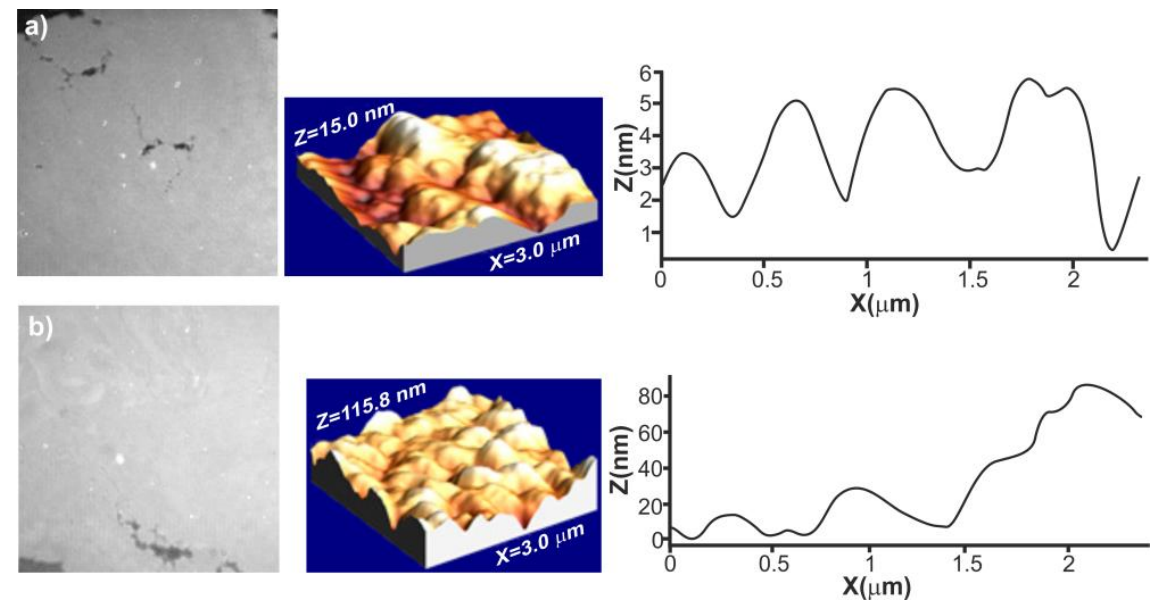

Figure 5.2. $B A M$ images, $A F M$ images and roughness profile of the sensors a) $\mathrm{AA} / \mathrm{LuPC}_{2}$ and $\mathrm{b}$ ) $\mathrm{Lac} / \mathrm{AA} / \mathrm{LuPC}_{2}$ films.

\subsection{2- Electrochemical response towards phenols}

The voltammetric responses of the array formed by three electrodes $\left(\mathrm{AA} / \mathrm{LuPc}_{2}, \mathrm{Tyr} / \mathrm{AA} / \mathrm{LuPC}_{2}\right.$ and $\left.\mathrm{Lac} / \mathrm{AA} / \mathrm{LuPC}_{2}\right)$ towards six phenolic compounds $\left(40 \mu \mathrm{mol} \cdot \mathrm{L}^{-1}\right)$ are shown in Figure 5.3. The responses were highly reproducible with a coefficient of variation $(n=10)$ lower than $1.5 \%$ (calculated from the peaks associated with antioxidants) and lower than $0.75 \%$ (calculated from the peaks associated with $\mathrm{LuPc}_{2}$ ). The reproducibility between different sensors, containing the same enzyme, immersed in the same solution was always lower than $1.75 \%$.

The electrochemical response of $\mathrm{AA} / \mathrm{LuPc}_{2}$ nanostructured films towards phenols (represented in Figure 5.3 as green lines) showed a quasireversible and intense redox pair associated with the $\mathrm{LuPc}_{2}{ }^{-} / \mathrm{LuPC}_{2}{ }^{0}$ process at $c a$. $E_{1 / 2}=-0.15 \mathrm{~V}$. However, due to the interaction with phenols, this peak appeared at different positions and showed diverse intensities depending on the antioxidant analyzed. Voltammograms also showed redox processes arisen from the oxidation/reduction of phenols. The position and intensity of such peaks depended on the type of phenol and were in good accordance with previously published results ${ }^{21,30}$. 
Taking into acount that oxidation of phenols barely takes place at bare ITO electrodes and considering that when using a carbon paste electrode the oxidation occurs at higher potentials than those reported here ${ }^{30}$, it can be confirmed that the $\mathrm{AA} / \mathrm{LuPC}_{2}$ sensor reduced the overpotential and improved the reversibility, validating the electrocatalytic behavior of the $\mathrm{LuPc}_{2}$. For instance, the oxidation of catechol in carbon paste electrode ocurred at $0.5 \mathrm{~V}$ and the reduction in the reverse scan appeared at $0.05 \mathrm{~V}\left(\Delta \mathrm{E}_{1 / 2}=0.45 \mathrm{~V}\right)$. When using $\mathrm{AA} / \mathrm{LuPC}_{2}$ sensor, the oxidation of the phenol appeared at $0.4 \mathrm{~V}$ and the cathodic wave at $0.15 \mathrm{~V}(\Delta \mathrm{E}=0.25 \mathrm{~V})$. The intensity of the peaks was also clearly increased.

One of the objectives of this chapter was to improve the selectivity of the sensors by introducing enzymes in biomimetic layers containing $\mathrm{LuPC}_{2}$ as electron mediator ${ }^{19,26,27}$. Two phenol oxidases (tyrosinase and laccase) were selected. Tyrosinase oxidizes monophenols and odiphenols to the corresponding quinone, whereas laccase catalyzes the oxidation of a larger variety of aromatic compounds such as substituted mono- and polyphenols ${ }^{31}$.

Using this strategy, Tyr/AA/LuPc 2 and $\mathrm{Lac} / \mathrm{AA} / \mathrm{LuPc}_{2}$ sensors were prepared and their response towards phenols was analyzed in terms of sensitivity and cross-selectivity. The results are shown in Figure 5.3 ( Tyr/AA/LuPc 2 responses are represented as blue lines and $\mathrm{Lac} / \mathrm{AA} / \mathrm{LuPC}_{2}$ as red lines). When biosensors containing tyrosinase or laccase are immersed in a phenolic solution, the phenol is enzymatically oxidized to the corresponding quinone (no need of external voltage). When the voltage was biased to positive values, an anodic peak at $c a .0 .5 \mathrm{~V}$ was observed. This peak corresponded to the electrochemical oxidation of the phenol to the quinoid form. During the reverse scan, both the enzymatically and the electrochemically formed o-quinone molecules were reduced simultaneously at ca. $-0.2 \mathrm{~V}$. This concurrent reduction explains why this peak was more intense in $\mathrm{Enz} / \mathrm{AA} / \mathrm{LuPc}_{2}$ than in $A A / L u P c_{2}$ sensors. Moreover, the enzymatic processes were favored by 
the presence of the $\mathrm{LuPc}_{2}$, which acted as electron mediator, producing signal amplification.

Unexpectedly, the presence of the enzyme also increased the intensity of the peaks associated with the oxidation/reduction of the phthalocyanine ring (at $c a .-0.2 \mathrm{~V}$ ). These changes confirmed the interaction between the phthalocyanine and the enzyme and the subsequent electrocatalytic effect.

The most remarkable conclusion that can be extracted from Figure 5.3 is the important degree of cross-selectivity attained by the array of sensors. Significant differences were observed in the responses of $\mathrm{Tyr} / \mathrm{AA} / \mathrm{LuPC}_{2}$ and $\mathrm{Lac} / \mathrm{Tyr} / \mathrm{LuPc}_{2}$ that come from their different specificity.

For instance, as both enzymes react with monophenols, their response towards vanillic acid was similar. Catechol is an o-diphenol and consequently the response shown by tyrosinase was clearly more intense than the response observed for laccase. Moreover, the electrochemical oxidation of catechol occurred at lower potentials in $\mathrm{Tyr} / \mathrm{AA} / \mathrm{LuPc}_{2}(0.38 \mathrm{~V})$ than in Lac/AA/LuPc $2(0.62 \mathrm{~V})$. Caffeic acid is also an o-diphenol, but the presence of substituents in the benzene ring changes the polarity and the size of the substrate, modifying the interaction with the active site of the tyrosinase. A similar argument applies for hydroquinone, a $p$-diphenol that shows higher affinity towards laccase. 

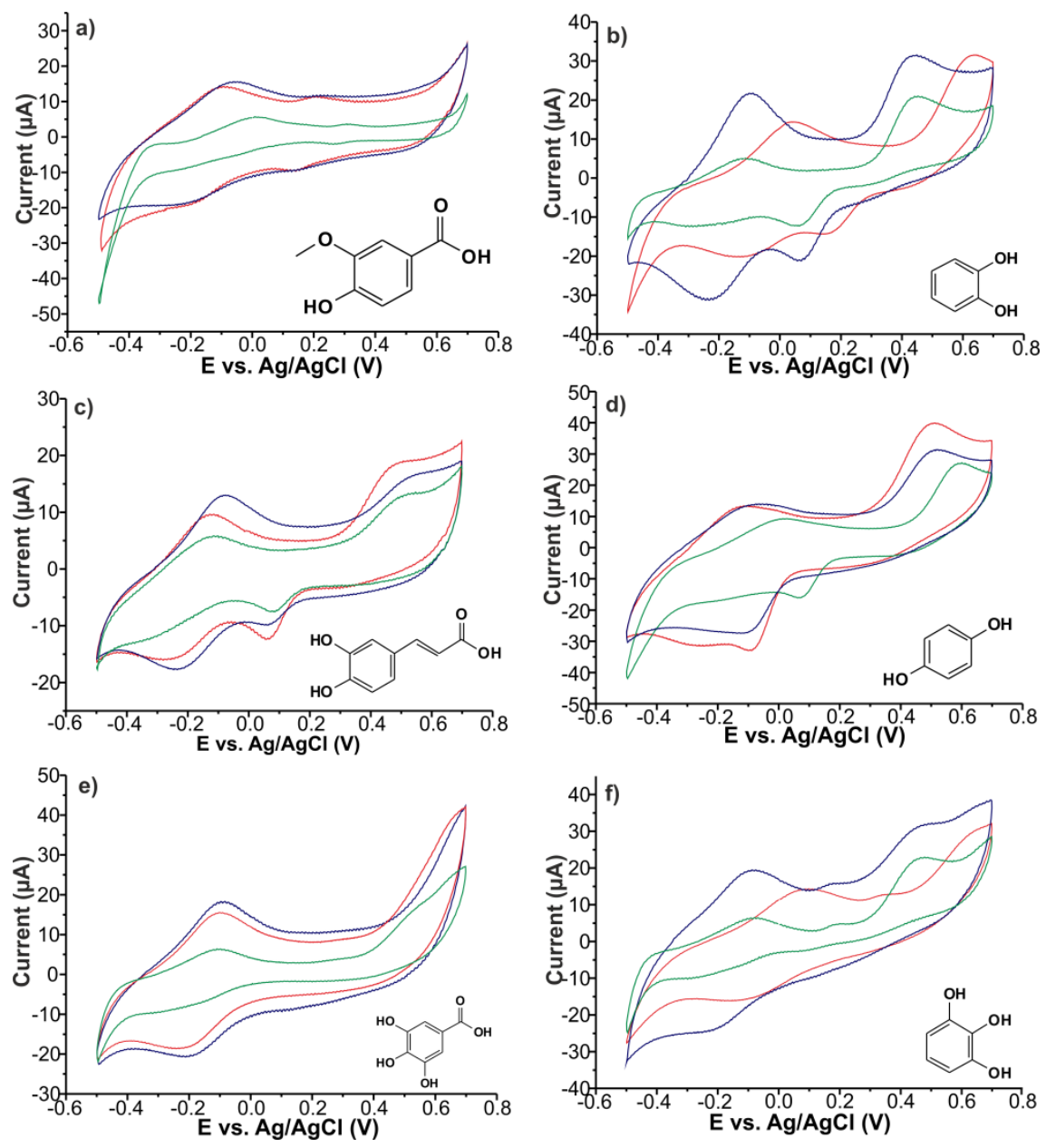

Figure 5.3. Cyclic voltammograms of $A A / L u P c_{2}$ (green line), Tyr/AA/LuPc $c_{2}$ (blue line) and $\mathrm{Lac} / \mathrm{AA} / \mathrm{LuPC}_{2}$ (red line) immersed in $40 \mu \mathrm{mol} \cdot \mathrm{L}^{-1} \mathrm{PBS}$ solutions of a) vanillic acid, b) catechol, c) caffeic acid, d) hydroquinone, e) gallic acid and f) pyrogallol.

The triphenols tested, gallic acid and pyrogallol, showed completely different responses towards Tyr/AA/LuPc 2 and $\mathrm{Lac} / \mathrm{AA} / \mathrm{LuPC}_{2}$. Gallic acid is a substituted triphenol and according to the results obtained, its affinity towards tyrosinase and laccase is not good because enzymatic activity was not observed. In the case of pyrogallol, the first cycle was clearly different from the signals obtained in the subsequent ones which 
were reproducible and similar to those obtained when the electrodes were immersed in catechol. The reason is that the oxidation of pyrogallol occurs in two steps: during the first cycle, the quinoid form is obtained and during the second cycle, the redox properties of the oquinone are observed. This behavior also explains that sensors modified with tyrosinase or laccase provided different responses, due to their different affinity towards o-diphenols.

The detection limits (LOD) were determined by measuring the responses of the sensors towards phenol solutions with concentrations ranging from 4 to $150 \mu \mathrm{mol} \cdot \mathrm{L}^{-1}$. The peaks associated with phenols were clearly identified by the progressive increase in their intensity. The detection limit were statistically calculated using $L O D=3 s_{d} / m$, where $s_{d}$ is the standard deviation of the blank at the potential measured and $m$ is the slope of the calibration curve. Peak positions, LOD and regression coefficients are shown in Table 5.1. The LOD found in Enz/AA/LuPc were at least one order of magnitude lower than those found in $\mathrm{AA} / \mathrm{LuPc}_{2}$. They were in the range of those published for tyrosinase biosensors containing other electron mediators ${ }^{32}$.

The dynamic behavior was examined by analyzing the effect of the sweep rate (from 0.025 to $0.2 \mathrm{~V} \cdot \mathrm{s}^{-1}$ ) on the intensity of the voltammetric responses. The experiments were carried out in $100 \mu \mathrm{mol} \cdot \mathrm{L}^{-1}$ phenolic solutions. A clear dependence of the intensity of the peaks with the square root of the sweep rate could be noticed for all the phenols and sensors analyzed (Figure 5.4). It is worthily noting that in the case of the $\mathrm{Enz} / \mathrm{AA} / \mathrm{LuPC}_{2}$ films, the linear relationship between the peak current and the square root of the scan rate was approximately 5 times faster than the value found in the $A A / L u P C_{2}$ electrode. This result indicates that the charge transfer within the LB film and/or through the electrode interface was facilitated and this improvement should be related to the enzymatic activity.

Table 5.1. Detection limits calculated from the peaks associated with phenols redox processes. 


\begin{tabular}{|c|c|c|c|c|c|c|}
\hline Sensor & $E_{a}(V)$ & $\operatorname{LD}\left(\mathrm{mol}^{-\mathrm{L}^{-1}}\right)$ & $\mathbf{R}^{2}$ & $E_{c}(V)$ & $\mathrm{LD}\left(\mathrm{mol} \cdot \mathrm{L}^{-1}\right)$ & $R^{2}$ \\
\hline \multicolumn{7}{|c|}{ Vanillic Acid } \\
\hline $\mathrm{AA} / \mathrm{LuPc}_{2}$ & 0.200 & $1.33 \times 10^{-4}$ & 0.921 & 0.100 & $6.59 \times 10^{-5}$ & 0.921 \\
\hline Lac/AA/LuPc 2 & 0.200 & $5.10 \times 10^{-6}$ & 0.975 & 0.110 & $4.06 \times 10^{-6}$ & 0.976 \\
\hline Tyr/AA/LuPc 2 & 0.200 & $7.69 \times 10^{-6}$ & 0.962 & 0.100 & $5.45 \times 10^{-6}$ & 0.975 \\
\hline \multicolumn{7}{|c|}{ Catechol } \\
\hline $\mathrm{AA} / \mathrm{LuPc}_{2}$ & 0.528 & $4.28 \times 10^{-6}$ & 0.992 & 0.083 & $3.04 \times 10^{-6}$ & 0.994 \\
\hline Lac/AA/LuPc ${ }_{2}$ & 0.550 & $4.59 \times 10^{-7}$ & 0.990 & 0.065 & $4.88 \times 10^{-7}$ & 0.992 \\
\hline Tyr/AA/LuPc 2 & 0.600 & $4.81 \times 10^{-7}$ & 0.992 & 0.060 & $5.18 \times 10^{-7}$ & 0.997 \\
\hline \multicolumn{7}{|c|}{ Caffeic Acid } \\
\hline $\mathrm{AA} / \mathrm{LuPC}_{2}$ & 0.450 & $4.19 \times 10^{-6}$ & 0.997 & 0.100 & $3.45 \times 10^{-6}$ & 0.997 \\
\hline Lac/AA/LuPc ${ }_{2}$ & 0.520 & $5.89 \times 10^{-7}$ & 0.990 & 0.054 & $7.74 \times 10^{-7}$ & 0.981 \\
\hline Tyr/AA/LuPc 2 & 0.500 & $5.73 \times 10^{-7}$ & 0.997 & 0.060 & $6.23 \times 10^{-7}$ & 0.996 \\
\hline \multicolumn{7}{|c|}{ Hydroquinone } \\
\hline $\mathrm{AA} / \mathrm{LuPc}_{2}$ & 0.600 & $3.34 \times 10^{-6}$ & 0.988 & 0.058 & $3.38 \times 10^{-6}$ & 0.989 \\
\hline Lac/AA/LuPc 2 & 0.550 & $5.18 \times 10^{-7}$ & 0.976 & -0.090 & $5.42 \times 10^{-6}$ & 0.972 \\
\hline Tyr/AA/LuPc 2 & 0.600 & $5.94 \times 10^{-7}$ & 0.995 & -0.100 & $6.40 \times 10^{-7}$ & 0.995 \\
\hline \multicolumn{7}{|c|}{ Gallic Acid } \\
\hline $\mathrm{AA} / \mathrm{LuPc}_{2}$ & 0.698 & $3.69 \times 10^{-6}$ & 0.992 & & & \\
\hline Lac/AA/LuPc 2 & 0.699 & $4.10 \times 10^{-8}$ & 0.991 & & & \\
\hline Tyr/AA/LuPc 2 & 0.700 & $4.97 \times 10^{-7}$ & 0.985 & & & \\
\hline \multicolumn{7}{|c|}{ Pyrogallol } \\
\hline $\mathrm{AA} / \mathrm{LuPc}_{2}$ & 0.250 & $2.66 \times 10^{-5}$ & 0.991 & 0.528 & $2.14 \times 10^{-6}$ & 0.989 \\
\hline Lac/AA/LuPc ${ }_{2}$ & 0.360 & $1.87 \times 10^{-6}$ & 0.998 & 0.699 & $3.05 \times 10^{-7}$ & 0.998 \\
\hline Tyr/AA/LuPc 2 & 0.200 & $3.41 \times 10^{-6}$ & 0.992 & 0.500 & $4.51 \times 10^{-7}$ & 0.992 \\
\hline
\end{tabular}

a) Kinetics Oxidation Peak

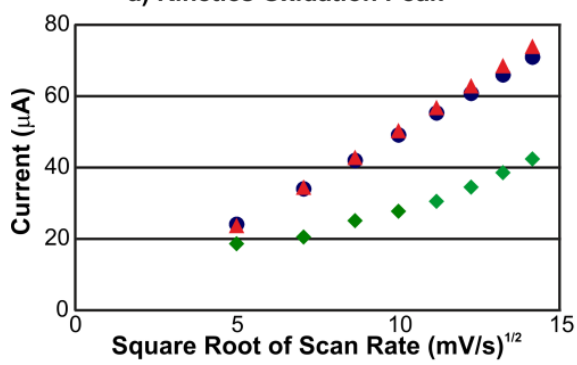

b) Kinetics Reduction Peak

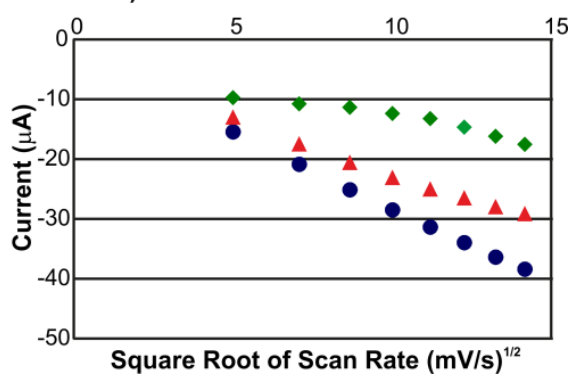


Figure 5.4. Correlation between the intensity of a) anodic and b) cathodic peaks versus the square root of the scan rate $\left(v^{1 / 2}\right):(\bullet) \mathrm{AA} / \mathrm{LuPc}_{2},(\bullet) \mathrm{Tyr} / \mathrm{AA} / \mathrm{LuPC}_{2}$ and $(\Delta) \mathrm{Lac} / \mathrm{AA} / \mathrm{LuPC}_{2}$, immersed in caffeic acid $100 \mu \mathrm{mol} \cdot \mathrm{L}^{-1}$.

\subsection{3- Array of sensors. Discrimination of phenolic compounds}

The intrinsic complexity and cross-selectivity of the signals generated by the array of voltammetric electrodes could be used to discriminate the phenols using Principal Component Analysis (PCA). The high amount of information displayed by the voltammograms, makes difficult the data analysis, increasing the processing time. A pre-treatment method of the voltammetric curves has been developed in our laboratory that allows reducing the number of variables to a few representative values ${ }^{13,28}$. As a result of the calculations, 10 input variables were extracted for each voltammetric curve and used for PCA calculations. As shown in PCA scores plot (Figure 5.5.a) PC1, PC2 and PC3 explained 98\% of the total variance between the samples. The separated clusters indicated that the six phenols could be clearly discriminated. The graph could be divided into three regions corresponding to the chemical structure of the studied phenols: the monophenol (vanillic acid) appeared in the region of positive PC1. The three diphenols (catechol, caffeic acid and hydroquinone) appeared in the left part of the graph in the negative PC1 region. Finally, gallic acid and pyrogalloll (triphenols) were located in the middle region of PC1 and PC2 but in positive PC3 values.

Figure 5.5.b shows the contribution of the variables (10 kernels per sensor) in a two-dimensional PCA loading plot. As observed in the figure, all the variables used in the PCA analysis showed high loading parameters for a particular principal component, indicating a positive influence in the discrimination process. Moreover, Figure 5.5.b shows that the variables associated with each sensor appear in different regions of the plot. 

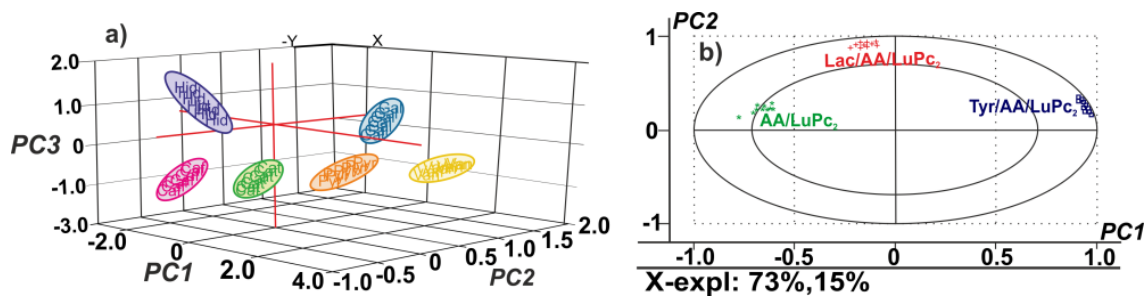

Figure 5.5. a) PCA scores plot of the considered phenols. Yellow- Vanillic acid, Purple- Hydroquinone, Pink- Caffeic acid, Green- Catechol, Orange- Pyrogallol and Blue- Gallic acid. b) Corresponding loadings plot in terms of PC1 versus PC2.

\subsection{4- Array of sensors. Response towards grapes}

The array of sensors and biosensors described in the previous sections was exposed to musts prepared from grapes of different varieties (diluted $50 \%$ in water). Voltammograms were dominated by the redox response of the phenolic groups present in musts that appeared as anodic peaks in the 0.4-0.8 $\mathrm{V}$ region, and the corresponding cathodic waves in the $0.35 \mathrm{~V}$ region. The intensities and positions of those peaks were related to the total polyphenol index (TPI) measured by chemical methods that, in turn, depended on the grape variety. The responses were highly reproducible with a coefficient of variation $(n=7)$ always lower than $4.5 \%$. Obviously in such a complex media, the peaks were broader than in the phenolic solutions and a variety of other small and not well-defined peaks were observed. In summary, each electrode provided a different response towards the same must sample and an important degree of cross-selectivity was attained.
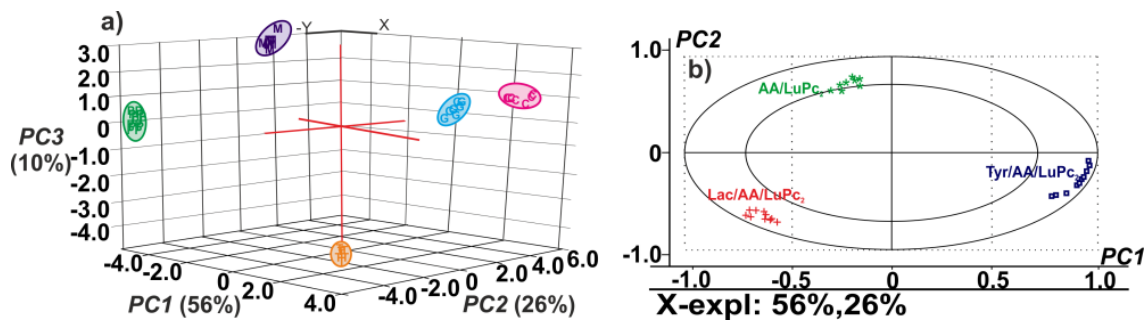
Figure 5.6. a) PCA scores plot of the different varieties of grapes: T-Tempranillo (orange), G-Garnacha (blue), C-Cabernet-Sauvignon (pink), M-Mencía (purple) and PP-Prieto Picudo (green). b) Corresponding loadings plot in terms of PC1 versus PC2.

As observed in the PCA scores plot, the array was able to discriminate grapes according to the grape variety (Figure 5.6.a). PC1, PC2 and PC3 explained $92 \%$ of the total variance between musts. The position of the clusters was related to the chemical composition of the grape juices. The third Principal Component PC3, was responsible of the discrimination of the samples according to their Total Polyphenol Index: The must obtained from the variety Mencia (TPI of 12) appeared in the top part of the graph in the PC3 positive values, whereas the must obtained from Tempranillo (TPI of 20) was located in the lower part of the figure. Musts obtained from Garnacha, Cabernet-Sauvignon and Prieto Picudo grapes which have an intermediate TPI value (TPI of 15), appeared in the middle region. Also in the case of musts, the loading plot confirmed the complementarity of the sensors forming the array (Figure 5.6.b).

\subsection{CONCLUSIONS}

A bioelectronic tongue formed by three sensors based on LangmuirBlodgett films of AA containing Tyr or Lac and using $\mathrm{LuPC}_{2}$ as electron mediator was constructed. The increase in the area per molecule observed in the surface pressure-area isotherms and the AFM images indicated that enzymes were imbibed in the floating monolayer formed by $\mathrm{LuPC}_{2}$ and $\mathrm{AA}$ with different kinetics. The hydrophobic environment provided by the floating film was more favorable for the tyrosinase which is a transmembrane protein.

The electrochemical responses of the sensors towards phenolic compounds (mono, di and triphenols) depended on the nature of the enzymes and on their different enzymatic specificity. The biomimetic environment improved the dynamic behavior and the detection limits which were in the range of $10^{-7}$ and $10^{-8} \mathrm{~mol} \cdot \mathrm{L}^{-1}$. 
The bioelectronic tongue was able to discriminate phenols according to their chemical nature. In addition, the system was able to discriminate musts according to their Total Polyphenol Index. The loading plots confirmed the excellent complementarity of the sensors forming the array.

It has been demonstrated that the proposed array of sensors combines the advantages of classical phthalocyanine based-sensors that provide global information about the sample, with the specificity of the enzymesubstrate reaction typical of biosensors. For this reason, the selectivity of the multisensor system and its capability of discrimination were clearly improved when biosensors containing Tyr and Lac were included in the array.

The high functionality of the enzyme obtained using a biomimetic immobilization method, the selectivity afforded by enzyme catalysis and the signal enhancement caused by the $\mathrm{LuPc}_{2}$ mediator make this bioelectronic tongue attractive for the analysis of grapes.

\section{References}

1. Mello, L.D., Del Río, D., Costa, L.G., Lean, M.E.J., Crozier, A. Nutr. Metab. Cardiovasc. Dis. 2010, 20, 1-6.

2. Bartosz, G. Food oxidants and antioxidants: chemical, biological, and functional properties (chemical \& functional properties of food components), 2013, CRC press, Florida (USA). 
3. Vlasov, Y., Legin, A., Rudnitskaya, A., Di Natale, C., D'Amico, A. Pure Appl. Chem. 2005, 77, 1965-1983.

4. Tahara, Y., Toko, K. IEEE Sens. J. 2013, 13, 3001-3011.

5. Ciosek, P., Wroblewski, W. Sensors. 2011, 11, 4688-4701.

6. Scampicchio, M., Ballabio, D., Arecchi, A., Cosio, S.M., Mannino, S. Electrochim. Acta. 2008, 163, 11-21.

7. Winquist, F., Olsson, J., Eriksson, M. Anal. Chim. Acta. 2011, 10, 192197.

8. Escobar, J.D., Alcaniz, M., Masot, R., Fuentes, A., Bataller, R., Soto, J., Barat, J.M. Food Chem. 2013, 138, 814-820.

9. Rodriguez-Mendez, M.L., Parra, V., Apetrei, C., Gay, M., Prieto, N., de Saja, J.A. Microchim. Acta. 2008, 163, 23-31.

10. Cabral, F.P.A., Bergamo, B.B., Dantas, C.A.R., Riul, A., Giacometti, J.A. Rev. Sci. Instrum. 2009, 80, 026107-026107-3

11. Gay, M., Muñoz, R., De Saja, J.A., Rodriguez-Mendez, M.L. Electrochim. Acta. 2012, 68, 88-94.

12. Ceto, X., Gutierrez, J.M., Gutierrez, M., Céspedes, F., Capdevila, J., Mínguez, S., Jimenez-Jorquera, C., del Valle, M. Anal. Chim. Acta. 2012, 732, 172-179.

13. Zagal, J.H., Griveau, S., Silva, J.F., Nyokong, T., Bedioui, F. Coord. Chem. Rev. 2010, 254, 2755-2794.

14. Bouvet, M., Gaudillat, P., Suisse, J.M. J. Porphyrins Phthalocyanines. 2013, 17, 913-919.

15. Matemadombo, F., Apetrei, C., Nyokong, T., Rodriguez-Mendez, M.L., de Saja, J.A. Sensors. Actuat. B. 2012, 457, 166-167. 
16. Arrieta, A., Rodriguez-Mendez, M.L., de Saja, J.A. Sensors Actuat. B. 2003, 95, 357-365.

17. Volpati, D., Alessio, P., Zanfolim, A.A., Storti, F.C., Job, A.E., Ferreira, M., Riul, A., Oliveira, O.N.Jr., Constantino, C.J.L. J. Phys. Chem. B. 2008, $112,15275-15282$.

18. Karim, F., Fakhruddin, A. N. M. Rev. Environ. Sci. Biotechnol. 2012, 11, 261-274.

19 Yin, H.S., Zhou, Y.L., Xu, J., Ai, S.Y., Cui, L., Zhu, L.S. Anal.Chim.Acta. 2010, 659, 144-150.

20. Fernandes, E.G.R., Brazaca, L.C., Rodriguez-Mendez, M.L., de Saja, J.A., Zucolotto, V. Biosens Bioelectron. 2011, 26, 4715-4719.

21. Apetrei, C., Alessio, P., Constantino, C.J.L., De Saja, J.A., RodriguezMendez, M.L., Pavinatto, F.J., Fernandes, E.G., Zucolotto, V., Oliveira, O.N. Jr. Biosens. Bioelectron. 2011, 26, 2513-2519.

22. Soloducho, J., Cabaj, J., Swist, A. Sensors. 2009, 9, 7733-7752.

23. Ceto, X., Cespedes, F., Pividori, M.I., Gutierrez, J.M., del Valle, M. Analyst. 2012, 137, 349-356.

24. Ghasemi-Varnamkhasti, M., Rodriguez-Mendez, M.L., Mohtasebi, S.S., Apetrei, C., Lozano, J., Ahmadi, H., Razavi, S.H., de Saja, J.A. Food Control. 2012, 25, 216-224.

25. Linaje, M., Quintanilla, M.C., Gonzalez, A., del Valle, J.L., Alcaide, G., Rodriguez- Mendez, M.L. The Analyst. 2000, 125, 341-346.

26. Pavinatto, F.J., Fernandez, E.G.R., Alessio, P., Constantino, C.J.L., de Saja, J.A., Zucolotto, V., Oliveira, O.N.Jr., Apetrei, C., Rodriguez-Mendez, M.L. J. Mater. Chem. 2011, 21, 4995-5003.

27. OIV. Compendium of International Methods of Analysis of Wines and Musts, 2013, vol.2. 
28. Parra, V., Hernando, T., Rodríguez-Méndez, M.L., de Saja, J.A. Electrochim. Acta. 2004, 49, 5177-5185.

29. Casili, S., De Luca, M.A., Apetrei, C., Parra, V., Arrieta, A., Valli, L., Jiang, J., Rodriguez-Mendez,M.L., de Saja J.A. App. Surf. Sci. 2005, 246, 304-313.

30. Makhotina, O., Kilmartin, P.A. Anal. Chim. Acta. 2010, 668, 155-165.

31. Cortina-Puig, M., Noguer, T., Marty, J.L., Calas-Blanchard, C. Electrochemical Biosensors as a Tool for the Determination of Phenolic Compounds and Antioxidant Capacity in Foods and Beverages. In Biosensors in Food processing, safety and quality control, 2011, 257-272. Ed. CRC Press. Boca Raton, London (UK).

32. Tang, L., Zhou, Y.Y., Zeng, G.M., Li, Z., Liu, Y.Y., Zhang, Y., Chen, G.Q., Yang, G.D., Lei, X.X., Wu, M.S. Analyst. 2013, 138, 3552-3560. 



\section{CHAPTER 6}

Array of Biosensors for Discrimination of Grapes According to Grape Variety, Vintage and Ripeness 

During the ripening process is necessary to monitor not only polyphenolic content but also sugar concentration in the berries. Sugar content is one of the most important parameters analyzed by the winemaking industry as it is directly related to the alcohol degree of the wine.

There are two kinds of sugar mainly present in the grapes, D-glucose and $D$-fructose. Their ratio during the ripening process varies however when the berries are ripe the ratio is close to the unity.

Due to the excellent performance of the bioelectronic tongue containing phenol oxidases we decided to incorporate to the array new enzymes devoted to the analysis of these two molecules (glucose oxidase and Dfructose dehydrogenase). The methodology needed to be adapted in order to deposit the films containing the new enzymes. This bioelectronic tongue has been applied to discriminate musts prepared from different varieties of grapes, grapes harvested in two different vintages and to monitor the ripening of grapes from veraison to harvest.

In this chapter, the multisensory system formed by four LB films containing two phenol oxidases (tyrosinase and laccase) and two biosensors dedicated to the detection of sugars (glucose oxidase and Dfructose dehydrogenase) have been developed. The capability of discrimination of the array will be evaluated using Principal Component Analysis (PCA). The correlation of the responses with the phenolic and sugar content of the grapes analyzed by classical chemical methods will be evaluated using Partial Least Squares (PLS-1). This work has been submitted to Analytica Chimica Acta.

\subsection{INTRODUCTION}

The quality of the grapes is typically established on the basis of their phenolic and sugar content ${ }^{1,2}$. Sugar content is the parameter usually used to monitor the maturity of grapes because it is directly associated with the alcohol degree of the final product. Phenols are a large group of metabolites with a direct influence on the organoleptic characteristics of 
wine ${ }^{3}$. There is an increasing interest to detect the phenolic maturity of grapes, a parameter that would be crucial to decide when to harvest.

Sugar and phenolic content of wines and musts are usually analyzed using optical, spectroscopic or electrochemical methods ${ }^{4}$. Electrochemical biosensors can be an alternative to classical methods due to their high specificity, low detection limits, rapid response and possibility of miniaturization ${ }^{5,6}$.

A large variety of biosensors dedicated to the detection and quantification of phenols has been developed. Those sensors contain phenol oxidases such as tyrosinase, laccase or horseradish peroxidase ${ }^{7}$. Similarly, many efforts have been carried out to develop biosensors devoted to the detection of sugars using glucose oxidase $e^{8,9}$. Biosensors containing other enzymes such as fructose dehydrogenase have been studied in lesser extent ${ }^{10,11}$.

The immobilization of the enzyme onto the substrate is a key step in the development of efficient biosensors with high enzymatic activity ${ }^{12}$. Classical immobilization strategies include adsorption on a substrate ${ }^{13}$, immobilization in a carbon paste or PVC matrix ${ }^{14,15}$, entrapment in a polymeric matrix ${ }^{16}$, covalent binding ${ }^{17}$, cross-linking $^{18}$ or encapsulation on liposomes among many others ${ }^{19}$. The advances in Nanoscience and Nanotechnology provide alternative methods to immobilize biomolecules preserving their activity more efficiently. Layer by layer $(\mathrm{LbL})^{20-22}$ and Langmuir-Blodgett $(\mathrm{LB})^{23-25}$ are two examples of these techniques. The advantages of $L b L$ and $L B$ films are directly associated with the control of the thickness and the possibility of tuning the molecular architectures. Moreover, these techniques allow preparing sensors where the enzymes are adsorbed in biomimetic lipidic layers formed by fatty acids or phospholipids (similar to membrane cells) via $\mathrm{COOH}$ group interaction. This biomimetic environment contributes to the preservation of the enzymatic conformation. This strategy has been successfully used to prepare glucose oxidase ${ }^{26}$ and tyrosinase biosensors $^{27}$. LB technique can also be advantageous because the 
electron mediator can be co-immobilized with the enzyme in the lipidic layer, facilitating the electron transfer process ${ }^{27-29}$.

During the last years, multisensory systems combined with appropriate pattern recognition software (electronic tongues) have been developed and applied to analyze complex liquids ${ }^{30,31}$. They have been successfully used for the discrimination and classification of wines according to their grape variety, type of ageing or adulteration ${ }^{32-34}$ and grapes ${ }^{35}$.

It has been claimed that arrays formed by biosensors can be advantageous because they combine the advantages of classical arrays of electrochemical sensors (that provide global information about the sample) with the specificity of the enzyme-substrate reaction typical of biosensors. In spite of their good capability to discriminate wines or beers, bioelectronic tongues have rarely been used to obtain specific information about the composition of the samples ${ }^{14,36,37}$.

\subsection{MATERIALS AND METHODS}

\subsection{1- Chemicals}

Laccase (Lac), from Trametes versicolor (EC Number: 1.10.3.2, activity of plus of $20.7 \mathrm{U} \cdot \mathrm{mg}^{-1}$ ), Tyrosinase (Tyr) from Mushroom (EC Number 1 1.14.18.1, activity of $3610 \mathrm{U} \cdot \mathrm{mg}^{-1}$ ), Glucose oxidase (GOx) from Aspergillus Niger, type VII (EC Number: 1.1.3.4, activity plus 100000 $\mathrm{U} \cdot \mathrm{mg}^{-1}$ ) and D-Fructose Dehydrogenase (FDH) from Gluconobacter Industrius (EC Number:1.1.99.11, activity of 400-1,200 U.mg-1 ${ }^{-1}$ ) were purchased from Sigma Chemical Co. (USA). $70 \mu \mathrm{g} \cdot \mathrm{mL}^{-1}$ solutions of the enzymes were prepared in phosphate buffer $0.01 \mathrm{~mol} \cdot \mathrm{L}^{-1}(\mathrm{pH}=7.0)(\mathrm{PBS})$.

All chemical and solvents (Sigma Chemical Ltd.) were of reagent grade and used as supplied. Deionized water was obtained from a Millipore purifier $\left(18.2 \mathrm{M} \Omega \cdot \mathrm{cm}^{-1}\right)$.

The lutetium (III) bisphthalocyaninate $\left(\mathrm{LuPC}_{2}\right)$ was synthesized and purified in the neutral radical state following a previously published procedure $^{38}$. 


\subsection{2- Grape samples}

Five varieties of grapes (Tempranillo, Garnacha, Cabernet-Sauvignon, Prieto Picudo and Mencía) were selected and harvested in Castilla y León region (Spain). Grapes were harvested from the same cultivar in two consecutive vintages (2012 and 2013). In addition, during the year 2013, grapes of the variety Tempranillo were collected periodically in order to monitor the ripening. Sample 1 corresponded to grapes collected during the veraison (change of the grape color from green to red). Then, samples were collected on a weekly basis (Samples 2 to 5). To obtain the musts, 300 grams of each type of grape were crushed using standard procedures. Chemical analyses were carried out following international regulations ${ }^{4}$. Parameters measured included classical chemical markers of the sugar content (degree brix, density, sugars, grade (16.8), grade (17.5)), markers of the polyphenolic content (Total Polyphenol Index, TPI) and indicators of the acidity $(\mathrm{pH}$, total acidity, malic acid, tartaric acid).

\subsection{3- Langmuir-Blodgett films}

LB sensors containing enzyme (Enz), fatty acid (arachidic acid, AA) and the electron mediator (lutetium bisphthalocyanine, $\mathrm{LuPC}_{2}$ ) (Enz/AA/LuPc $)_{2}$ ), were fabricated using a KSV 2000 trough (KSV Instruments, Finland). Films of $\mathrm{Tyr} / \mathrm{AA} / \mathrm{LuPC}_{2}$ and $\mathrm{Lac} / \mathrm{AA} / \mathrm{LuPC}_{2}$ were prepared using the conditions previously described ${ }^{33}$. LB film sensors based on FDH and GOx are reported here for the first time and preparation conditions were established in order to maximize the insertion of the enzyme into the floating film.

GOx and FDH films were prepared at pH 4.5 using a phosphate buffered saline (PBS-NaCl) subphase $\left(\mathrm{NaCl} 0.1 \mathrm{~mol} \cdot \mathrm{L}^{-1}\right.$, phosphate buffer $0.01 \mathrm{~mol}$. $\mathrm{L}^{-1}, \mathrm{pH}=4.5$ ). The Langmuir monolayers at the air/water interface were characterized by surface pressure versus mean molecular area $(\pi-A)$ isotherms at $21^{\circ} \mathrm{C}$ by spreading $100 \mu \mathrm{l}$ of a chloroform AA/LuPc$c_{2}$ mixture $(10: 1)$ onto the subphase. Once the solvent was evaporated, $40 \mu \mathrm{l}$ of a $70 \mu \mathrm{g} \cdot \mathrm{ml}^{-1}$ solution of the corresponding enzyme (GOx or FDH) in 0.01 $\mathrm{mol} \cdot \mathrm{L}^{-1}$ PBS $(\mathrm{pH}=4.5)$ were injected drop by drop underneath the 
air/liquid interface. The enzymes were then adsorbed inside the floating film for one hour. Barriers were compressed at a speed of $5 \mathrm{~mm} \cdot \mathrm{min}^{-1}$.

$\mathrm{Enz} / \mathrm{AA} / \mathrm{LuPC}_{2}$ transferred to ITO glass at a surface pressure of $40 \mathrm{mN} \cdot \mathrm{m}^{-1}$ by Y-type deposition with a transfer ratio close to 1 with a substrate speed of $3 \mathrm{~mm} \cdot \mathrm{min}^{-1}$. Finally, the $\mathrm{Enz} / \mathrm{AA} / \mathrm{LuPC}_{2} \mathrm{LB}$ films were treated with glutaraldehyde $(2.5 \% \mathrm{w} / \mathrm{v}$ in PBS).

Brewster Angle Microscope (BAM) images were registered using a KSV/Nima MicroBAM

\subsection{4- Electrochemical measurements}

Biosensors were used as working electrode, the reference electrode was $\mathrm{Ag} \mid \mathrm{AgCl} / \mathrm{KCl} 3 \mathrm{M}$ and the counter electrode was a platinum plate. The potentiostat was an EG\&G PARSTAT 2273 potentiostat/galvanostat. Cyclic voltammograms were registered at a sweep rate of $0.1 \mathrm{~V} \cdot \mathrm{s}^{-1}$ from $-0.8 \mathrm{~V}$ to $+1.0 \mathrm{~V}$. In order to facilitate the diffusion of ions and to reduce the complexity of the sample, musts were diluted $50 \%$ in water.

\subsection{5- Statistical analysis.}

Curves were pre-processed a data reduction technique based on "kernels" ${ }^{39}$. The voltammogram curve is multiplied by 10 smooth, bellshaped windowing functions defined as Equation 6.1:

$$
K_{i}\left(V_{j}\right)=\frac{1}{1+\left(\frac{V_{j}-c_{i}}{a_{i}}\right)^{2 b_{i}}} \quad \text { (Equation 6.1) }
$$

Where $a_{i}, b_{i}$ and $c_{i}$ define the width, shape and center of the different windowing functions $\mathrm{K}_{\mathrm{i}}$. Subsequently, data were integrated with respect to voltage. After compression, each voltammogram has been reduced to a vector of 10 variables which were used as input data source for statistical analysis.

A non-supervised multivariate method, Principal Component Analysis (PCA), was used to evaluate the capability of discrimination of the system. Partial Least Squares (PLS-1) method was used to establish 
correlations between the signals produced by the array of biosensors and the results obtained by means of chemical methods. Chemometric analyses were carried out using the software Matlab v5.3. (The Mathworks Inc., Natick, MA, USA).

\subsection{RESULTS AND DISCUSSION}

\subsection{1- Characterization of Langmuir films}

The first step was to develop a method to prepare GOx/AA/LuPc $\mathrm{C}_{2}$ and $\mathrm{FDH} / \mathrm{AA} / \mathrm{LuPC}_{2} \mathrm{LB}$ films. For this purpose, Surface pressure/Area $(\pi / \mathrm{A})$ isotherms of the $\mathrm{Enz} / \mathrm{AA} / \mathrm{LuPC}_{2}$ systems were registered. Figure 6.1 shows the isotherms registered for the four sensing layers included in the array. The isotherm obtained from the mixture of the lipid and the electron mediator $\left(\mathrm{AA} / \mathrm{LuPC}_{2}\right)$ has been included in the graph for comparison purposes.

The limiting area obtained from the mixture $A A / L u \mathrm{Pc}_{2}$ was $37 \AA^{2}$. As expected, the incorporation of enzymes produced the expansion of the isotherms to higher areas per molecule

The limiting area per molecule values obtained for GOx/AA/LuPc $\mathrm{C}_{2}$ and $\mathrm{FDH} / \mathrm{AA} / \mathrm{LuPc}_{2}$, with values of $63 \mathrm{mN} \cdot \mathrm{m}^{-1}$ and $60 \mathrm{mN} \cdot \mathrm{m}^{-1}$ respectively, were clearly higher than those observed in phenol oxidases $\left(47 \mathrm{mN} \cdot \mathrm{m}^{-1}\right.$ for $\mathrm{Lac} / \mathrm{AA} / \mathrm{LuPc}_{2}$ and $51 \mathrm{mN} \cdot \mathrm{m}^{-1}$ for Tyr/AA/LuPc$c_{2}$ ). This indicated that enzymes were adsorbed in the amphiphilic monolayer. The large values observed in GOx and FDH can be due to an enhanced adsorption of the enzyme into the $A A$ environment caused by more favorable hydrophobic-hydrophilic interactions between the enzymes and the floating $\mathrm{AA} / \mathrm{LuPc}_{2}$ film. The differences in molecular weight of the enzymes must also have an important effect (120-133 KDa for Tyr, 50$100 \mathrm{KDa}$ for Lac, $160 \mathrm{KDa}$ for GOx, $150 \mathrm{KDa}$ for FDH). In fact, GOx and $\mathrm{FDH}$ which present the higher molecular weights also showed the larger areas per molecule.

In order to better understand the intermolecular interactions inside the floating films, compression-expansion cycles were analyzed (Figure 6.1.b 
and 6.1.c). Under these conditions, the behavior of GOx and FDH enzymes was different from the behavior shown by phenol oxidases which are desorbed during the expansion cycle $^{40}$. In the case of $\mathrm{GOx} / \mathrm{AA} / \mathrm{LuPc}_{2}$ and $\mathrm{FDH} / \mathrm{AA} / \mathrm{LuPc}_{2}$ the limiting area per molecule obtained after decompression was only slightly smaller than the value observed in the first compression. During the second compression, the area per molecule values were only slightly smaller than those registered in the first compression. Therefore, only a small amount of GOx or FDH was desorbed from the film during the expansion. In addition, a large part of this desorbed enzyme was readsorbed during the second compression. Because GOx and FDH were not completely expelled from the film during decompression and were easily readsorbed, it can be concluded that the interactions with the AA/LuPc film were stronger than in the case of Tyr and Lac, justifying the larger area per molecule observed.

The homogeneity of the floating films was analyzed using Brewster Angle Microscopy (BAM) (Figure 6.1.b and 6.1.c inset). Good quality surfaces were observed for all the films analyzed. BAM images also showed a clear increase in the roughness of the film (with respect to the $\mathrm{AA} / \mathrm{LuPc}_{2}$ film). This increase was particularly evident in $\mathrm{GOx} / \mathrm{AA} / \mathrm{LuPc}_{2}$ films that could be associated with the high affinity of the enzyme towards the lipidic layer. 

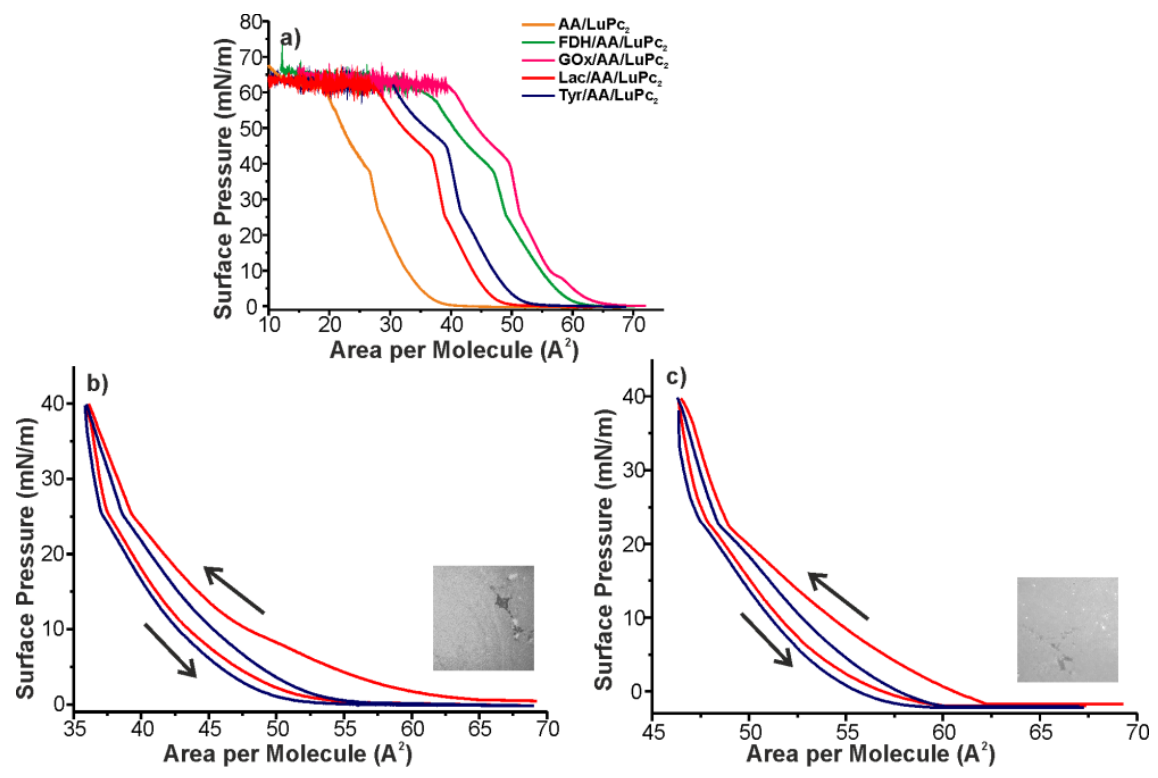

Figure 6.1. a)Pressure area isotherms registered in $\mathrm{PBS}-\mathrm{NaCl}$ subphase for $\mathrm{AA} / \mathrm{LuPC}_{2}$ and $\mathrm{Enz} / \mathrm{AA} / \mathrm{LuPc}_{2}$ films where $\mathrm{Enz}$ is Tyrosinase (Tyr), Laccase (Lac), Glucose oxidase (GOx) and D-Fructose dehydrogenase (FDH). b) Compressionexpansion cycles of $\mathrm{GOx} / \mathrm{AA} / \mathrm{LuPC}_{2}$ and c) Compression-expansion cycles of $\mathrm{FDH} / \mathrm{AA} / \mathrm{LuPC}_{2}$. First cycle (red line), second cycle (blue line). Inset show BAM images.

\subsection{2- Discrimination of musts obtained from different varieties of grapes harvested in two consecutive vintages}

The array formed by four biosensors was used to analyze musts prepared from five varieties of grapes (Tempranillo, Garnacha, Cabernet-Sauvignon, Prieto Picudo and Mencía) harvested in two different vintages (2012 and 2103) from the same cultivar.

The response of the array is illustrated in Figure 6.2 for Prieto Picudo variety. The peaks related to the antioxidants appeared as anodic waves in the 0.5-1.0 V region with the corresponding cathodic peaks at $c a$. 0.6 $\mathrm{V}$. The peaks associated with sugars appeared at negative potentials ( $c a$. $-0.2 \mathrm{~V}$ ). Due to the complexity of the media, the peaks were wider than those observed in standard aqueous solutions ${ }^{41}$. Each electrode provided a different response towards the same must sample and the 
positions and the intensity of the peaks changed with the grape variety. Moreover, voltammograms could detect small differences from one vintage to another; however, the general behavior of grapes of the same variety was maintained.

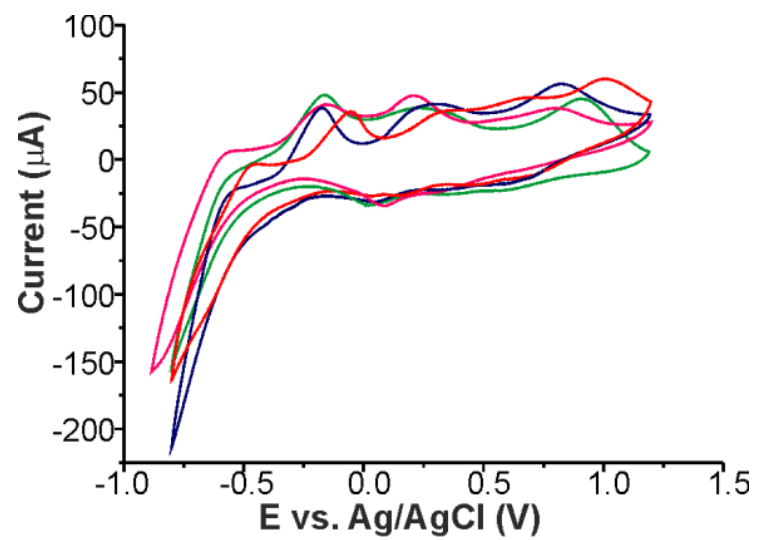

Figure 6.2. Voltammetric responses of the four sensors towards must prepared from the grape variety Prieto Picudo harvested in 2012. Glucose oxidase (pink line), Laccase (red line), D-Fructose dehydrogenase (green line) and Tyrosinase (blue line).

When PCA was carried out in musts obtained from grapes of different varieties (harvested in 2012), the scores plot showed that the array was able to discriminate musts according to the type of grape. The three first components explained $c a$. $97 \%$ of the total information of the system.

The experiment was repeated in the vintage 2013 and the results were similar. Moreover, PCA was carried out merging in the same matrix the responses obtained in both 2012 and 2013 (Figure 6.3). Grapes were discriminated according to their variety. Samples collected in different vintages could be clearly distinguished but appeared close one to each other in the scores plot. This result indicates that the bioelectronic tongue provides similar results than classical chemical analyses that clearly establish that varietal qualities are maintained from one year to another. 


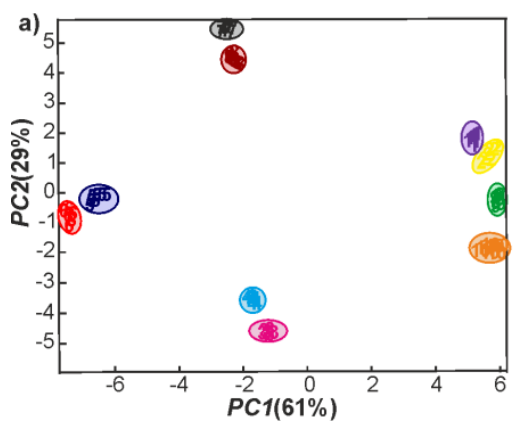

b)

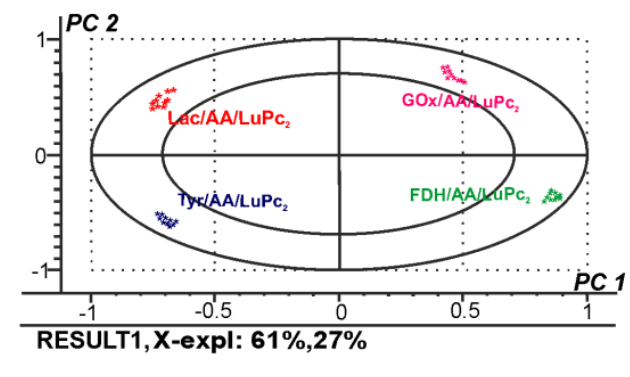

Figure 6.3. a) PCA scores plot and b) loading plot illustrating the discrimination capability of the bioelectronic tongue exposed to must prepared from the same five varieties harvested in two vintages (2012 and 2013): 1-Cabernet-Sauvignon 2012 (purple), 2-Cabernet-Sauvignon 2013 (yellow), 3-Garnacha 2012 (pink), 4Garnacha 2013 (light blue), 5-Mencía 2012 (dark blue), 6-Mencía 2013 (red), 7Tempranillo 2012 (black), 8-Tempranillo 2013 (brown), 9-Prieto Picudo 2012 (green), 10-Prieto Picudo 2013 (orange).

The position of the clusters was directly related to the chemical composition of the grapes. For this reason, the must prepared from Mencía variety, with the lowest concentration of sugar (average of 215 $\mathrm{g} \cdot \mathrm{L}^{-1}$ ) and TPI (average of 12), was located in the left side of the diagram whereas, samples from Tempranillo variety with the highest sugar content (average of $238.2 \mathrm{~g} \cdot \mathrm{L}^{-1}$ ) and TPI (average of 20) were located in the top part of the figure. Musts obtained from Garnacha, CabernetSauvignon and Prieto Picudo grapes with intermediate values of sugar (220-230 g. $\mathrm{L}^{-1}$ ) and TPI (TPI of 15), appeared far apart from the rest. $\mathrm{pH}$ seems to play an important role in the response of the array: Tempranillo and Mencía samples showed the highest pHs (4.18 and 4.17 respectively) and were located far from Prieto Picudo (3.7) and Cabernet-Sauvignon (3.8). Finally, Garnacha which showed the lowest $\mathrm{pH}$ (3.4) was clearly discriminated from the rest.

Figure 6.3.b shows the contribution of the variables (10 kernels per sensor) in the PCA loading plot. The loadings of each sensor were located in a different quadrant and showed values close to 1 . This is important because each one of the four sensors forming the array 
contributes in an important manner to the discrimination process. This also evidences the high cross-selectivity attained by the four biosensors.

\subsection{3- Monitoring the grape ripeness by means of the bioelectronic tongue}

The bioelectronic tongue was used to analyze grapes harvested from the veraison to ripening in a weekly basis during five weeks (variety Tempranillo, vintage 2013). Sample 1 was collected during the veraison (change of the grape color from green to red). Samples 2-5 were harvested in subsequent weeks. Sample number 4 corresponded to the optimal date of harvesting predicted by chemical parameters. Sample 5 corresponded to over-ripened grapes.

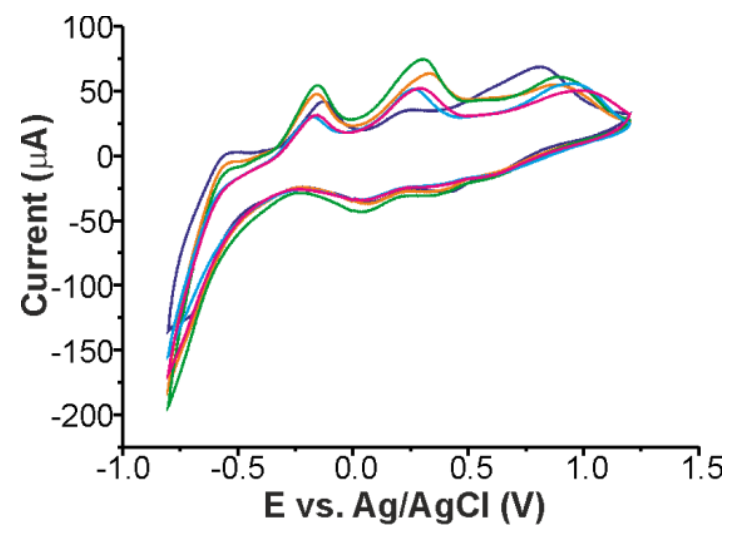

Figure 6.4. Response of the $\mathrm{Tyr} / \mathrm{AA} / \mathrm{LuPc}_{2}$ towards all the samples of Tempranillo harvested weekly from veraison to over-ripeness (vintage 2013). First week (dark blue line), second week (orange line), third week (green line), fourth week (light blue line) and fifth week (pink line).

Figure 6.4 illustrates how voltammograms changed with the ripening using a tyrosinase electrode. The anodic peak at $c a .0 .7 \mathrm{~V}$ associated with polyphenols shifted to higher potentials whereas the peaks at $c a$. $0.4 \mathrm{~V}$ and $-0.1 \mathrm{~V}$ increased their intensity progressively from weeks 1 to 3. Suddenly, in week 4 (the optimal date as indicated by classical techniques) the intensity decreased and was maintained in over-ripened grapes collected in week 5 . These changes are in good agreement with 
changes in the phenolic maturation measured by chemical methods which indicate that the development of phenolic maturation in the late stage of ripening produces a notorious increase near the harvest ${ }^{42}$. Similar results were obtained with biosensors modified with laccase. In turn, sensors modified with glucose oxidase could follow the increase in the sugar content by showing an increase in the intensity of the cathodic peak at $-0.2 \mathrm{~V}$.

PCA showed a clear discrimination of the samples collected during the progression of maturing. (Figure 6.5). Clusters corresponding to samples harvested in successive weeks from veraison to ripening (samples 1 to 4 ) were located in a clockwise order. Grapes collected one week after the optimal maturity (sample 5), did not follow the same trend than the others.

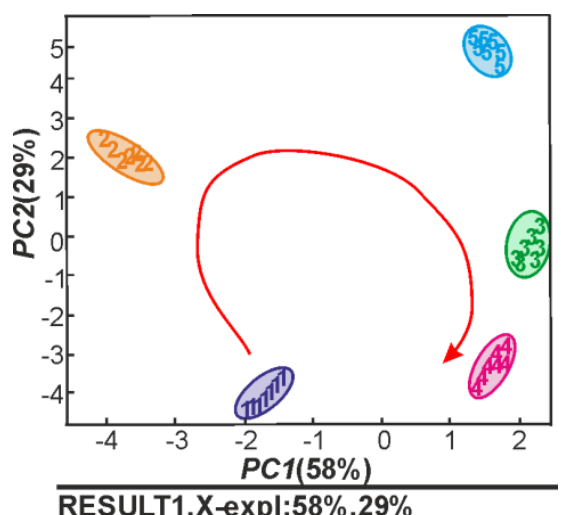

Figure 6.5. PCA scores plot illustrating the discrimination capability of the bioelectronic tongue exposed to must prepared from Tempranillo samples harvested in 2013 weekly from 1-first week (veraison), 2-second week, 3-third week, 4-fourth week (harvest), 5-fith week (over-ripe).

\subsubsection{Multiparametric correlations between the bioelectronic tongue and the classical chemical analysis}

Table 6.1 shows the statistical parameters for the PLS-1 regression models correlating the output of the array with the chemical parameters. 
Table 6.1. Results of the PLS-1 analysis. ${ }^{a}$ Root Mean Square Error of Calibration; ${ }^{b}$ Root Mean Square Error of Prediction. ${ }^{\mathrm{c} S q u a r e}$ correlation coefficient in calibration. ${ }^{d}$ Square correlation coefficient in prediction. ${ }^{\mathrm{e}}$ Latent variables.

\begin{tabular}{|l|r|r|c|c|c|}
\hline Parameter & RMSEC $^{\mathbf{a}}$ & RMESP $^{\mathbf{b}}$ & $\mathbf{R}_{\mathbf{C}}{ }^{\mathbf{c}}$ & $\mathbf{R}_{\mathbf{P}}{ }^{\mathbf{d}}$ & $\mathbf{L V}^{\mathbf{e}}$ \\
\hline Degree brix & 0.254 & 0.307 & 0.987 & 0.982 & 3 \\
\hline Density & 0.003 & 0.005 & 0.904 & 0.732 & 2 \\
\hline Sugars & 0.801 & 1.298 & 0.902 & 0.729 & 2 \\
\hline Grade (16.8) & 0.475 & 0.770 & 0.902 & 0.729 & 2 \\
\hline Grade (17.5) & 0.458 & 0.738 & 0.900 & 0.725 & 2 \\
\hline pH & 0.058 & 0.070 & 0.982 & 0.974 & 3 \\
\hline Total acidity & 0.047 & 0.059 & 0.995 & 0.992 & 3 \\
\hline Malic acid & 0.209 & 0.246 & 0.927 & 0.897 & 3 \\
\hline Tartaric acid & 0.126 & 0.143 & 0.996 & 0.994 & 3 \\
\hline TPI & 0.593 & 0.677 & 0.973 & 0.965 & 3 \\
\hline
\end{tabular}

Excellent correlations were found for all the parameters related to the sugar (sugar, degree brix, grade and density) and in particular with the degree Brix which is commonly used to evaluate the quality of grapes. Also good correlations were found with TPI. These good correlations can be attributed to the excellent performance of the enzymes imbibed in the LB films. It is also worthy to notice the good correlations found with parameters related to the $\mathrm{pH}(\mathrm{pH}$, Total acidity, Malic and Tartaric acid). This can be explained by the influence of the $\mathrm{pH}$ in the enzymatic activity.

\subsection{CONCLUSIONS}

A bioelectronic tongue formed by four voltammetric biosensors based on LB films containing GOx, FDH, Tyr and $\mathrm{Lac} \mathrm{LuPC}_{2}$ as electron mediator and AA as lipid, was developed. The increase in the area per molecule observed in the surface pressure-area isotherms confirms that enzymes were imbibed inside the floating monolayer formed by $\mathrm{LuPC}_{2}$ and $\mathrm{AA}$.

The array of biosensors was able to discriminate five varieties of grapes according to their sugar and phenolic composition. The system was more sensitive to the differences caused by the variety of grape than to 
the changes caused by weather conditions from vintage to vintage. It was also able to monitor the ripening of grapes from veraison to harvesting and could be used to predict the appropriate date to harvest.

The loading plot confirmed the excellent complementarity of the biosensors. Moreover, PLS-1 showed exceptional correlations with all the chemical parameters directly related to phenols and sugar concentration. 


\section{References}

1. Boulton, R. Am. J. Enol. Vitic. 2001, 52, 67-87.

2. Glories, Y. Progrès Agricole et Viticole. 2001, 118, 347-350.

3. Sun, B.S., Pinto, T., Leandro, M.C., Ricardo-Da-Silva, J.M., Spranger, M.I. Am. J. Enol. Vitic. 1999, 50, 179-184.

4. OIV, Compendium of international methods of analysis of wines and musts. Vol. 2, 2013.

5. Sassolas, A., Blum, L.J., Leca-Bouvier, B.D. Biotechnol. Adv. 2012, 30, 489-511.

6. Thevenot, D.R., Toth, K., Durst, R.A., Wilson, G.S. Biosens. Bioelectron. 2001, 16, 121-31.

7. Fahmida, K., Fakhruddin, A.N.M. Rev. Environ. Sci. Biotech. 2012, 11, 261-274.

8. Nouira, W., Maaref, A., Elaissari, H., Vocanson, F., Siadat, M., JaffrezicRenault, N. Mater. Sci. Eng. C. 2013, 33, 298-303.

9. Kamyabi, M.A., Hajari, N., Turner, A.P.F., Tiwari, A. Talanta. 2013, 116, 801-808.

10. Antiochina, R., Vinci, G., Gorton, L. Food Chem. 2013, 140, 742-747.

11. Damar, K., Demirkol, D.O. Talanta. 2011, 87, 67-73.

12. Goto, T.E., Lopez, R.F., Oliveira, O.N., Caseli, L. Langmuir. 2010, 26, 11135-11139.

13. Moyo, M., Okonkwo, J. Sensors Actuat. B. 2014, 193, 515-521.

14. Cetó, X, Capdevilla, J., Mínguez, S., del Valle, M. Food Res. Int. 2014, $55,455-461$. 
15. Apetrei, I.M., Rodriguez-Mendez, M.L., Apetrei, C., de Saja, J.A. Sensors Actuat. B. 2013, 177, 138-144.

16. Mariani, A.M., Natoli, M.E., Kofinas, P. Biotechnol. Bioeng. 2013, 10, 2994-3002.

17. Dong, J., Liu, T., Meng, X., Zhu, J., Hang, K., Ai, S., Cui, S. J. Solid State Electrochem. 2012, 16, 3783-3790.

18. Vicentini, F. C., Janegitz, B. C., Brett, C. M. A., Fatibello-Filho, O. Sensors Actuat. B. 2013, 188, 1101-1108.

19. Guan, H., Liu, X., Wang, W. J. Solid State Electrochem. 2013, 17, 2887-2893.

20. Ho, M.L., Wang, J.C., Wang, T.Y., Lin, C.Y., Zhu, J.F., Chen, Y.A., Chen, T.C. Sens. Actuators B. 2014, 190, 479-485.

21. dos Santos, V., dos Santos, M., de Jesus, C.G., Fujiwara, S.T., Garcia, J.R., Pessoa, C.A., Wohrath, K. Int. J. Electrochem. Sci. 2013, 8, 1060110620.

22. Fernandes, E.G.R., Brazaca, L.C., Rodriguez-Mendez, M.L., de Saja, J.A., Zucolotto, V. Biosens. Bioelectron. 2011, 26, 4715-4719.

23. Cabaj, J., Soloducho, J., Nowakowska-Oleksy, A. Sensors Actuat. B. 2010, 143, 508-515.

24. Zanon, N.C.M., Oliveira Jr, O.N., Caseli, L. J. Colloid Interface Sci. 2012, 373, 69-74.

25. Challier, L., Gal, F., Carrot, G., Perez, H., Noel, V. Electrochem. Commun. 2013, 28, 118-121.

26. Wang, K.H., Syu, M.J., Chang, C.H., Lee, Y.L. Sensors Actuat. B. 2012, 164, 29-36. 
27. Pavinatto, F.J., Fernandes, E.G.R., Alessio, P., Constantino, C.J.L., de Saja, J.A., Zucolotto, V., Apetrei, C., Oliveira Jr, O.N., Rodriguez-Mendez, M.L. J. Mat. Chem. 2011, 21, 4995-5003.

28. Alessio, P., Pavinatto, F.J., Oliveira Jr, O.N., de Saja, J.A., Constantino, C.J.L., Rodriguez-Mendez, M.L. Analyst. 2010, 135, 2591-2599.

29. Zagal, J.H., Griveau, S., Ozoemena, K.I., Nyokong, T., Bedioui, F. Nanosci. Nanotechnol. J. 2009, 9, 2201-2214.

30. Sliwinska, M., Wisniewska, P., Dymerski, T., Namiesnik, J., Wardenci, W. J. Agric. Food. Chem. 2014, 62, 1423-1448.

31. Smyth, H., Cozzoino, D. Chem. Rev. 2013, 113, 1429-1440.

32. Gay, M., Apetrei, C., Nevares, I., del Alamo, M., Zurro, J., Prieto, N., de Saja, J.A., Rodriguez-Mendez, M.L. Electrochim. Acta. 2010, 55, 67826788.

33. Apetrei, C., Apetrei, I.M., Nevares, I., del Alamo, M., Parra, V., Rodriguez-Mendez, M.L., de Saja, J.A. Electrochim. Acta. 2007, 52, 25882594.

34. Prieto, N., Gay, M., Vidal, S., Aagaard, O., de Saja, J.A., RodriguezMendez, M.L. Food Chem. 2011, 129, 589-594.

35. Moreno-Codinachs, L., Kloock, J.P., Schöning, M.J., Baldi, A., Ipatov, A., Bratov, A., Jiménez-Jorquera, C. Analyst. 2008, 133, 1440-1448.

36. Ghasemi-Varnamkhasti, M., Rodriguez-Mendez, M.L., Mohtasebi, S.S., Apetrei, C., Lozano, J., Ahmadi, H., Razavi, S.H., de Saja, J.A. Food Control. 2012, 25, 216-224.

37. Medina-Plaza, C., Revilla, G., Munoz, R., Fernandez-Escudero, J.A., Barajas, E., Medrano, G., de Saja, J.A., Rodriguez-Mendez, M.L. J. Porphyrins Phthalocyanines. 2014, 18, 76-86. 
38. Linaje, M., Quintanilla, M.C., del Valle, J.L., Alcaide, G., RodriguezMendez, M.L. Analyst. 2000, 125, 341-346.

39. Parra, V., Hernando, T., Rodriguez-Mendez, M.L., de Saja, J.A. Electrochim. Acta. 2004, 28, 5177-5185.

40. Medina-Plaza, C., de Saja, J.A., Rodriguez-Mendez, M.L. Biosens. Bioelectron. 2014, 57, 276-283.

41. Zhang, H., Meng, Z., Wang, Q., Zheng, J. Sensors Actuat. B. 2011, 158, 23-27.

42. Ribéreau-Gayon, P., Glories, Y., Maujean, A., Dubourdieu, D. Handbook of enology. Vol. 2. The chemistry of wine stabilization and treatments. 2000. Ed. John Wiley \& Sons, Chichester (England). 
Electrochemical Characterization of Dilithium Phthalocyanine Carbonaceous Electrodes 

Despite the excellent performance of nanostructured (bio)sensors, classical techniques were used to obtain cheaper sensors that could be easily applied in the industrial environment.

Carbon Paste Electrode (CPE) technique is an easy and fast method to obtain voltammetric sensors. These sensors consist on a composite made mixing carbonaceous powder with a binder packed into a plastic tube using a metallic copper wire as electrical contact. One of the advantages of these sensors is that they can be used several times (i.e. the surface can be polished regenerating the electrode).

The modification of this kind of sensors is done by mixing the modifier with the carbonaceous material and the binder in the desire proportion or using casting method. Different types of carbonaceous materials can also be used as a matrix (microspheres, graphite powder, carbon black, nanotubes...).

In this chapter, carbon paste electrodes of dilithium phthalocyanine $\left(\mathrm{Li}_{2} \mathrm{Pc}\right)$ have been prepared using different carbonaceous materials: graphite, carbon microspheres and multiwall carbon nanotubes (MWCNT). Microspheres present the advantage of their high specific surface and porous structure whereas carbon nanotubes are excellent candidates for the fabrication of electrochemical sensors because of their electrical conductivity, large surface area and ability to reduce overpotentials. The electrochemical reduction/oxidation behaviors of the sensors in a variety of simple electrolytes will be studied in detail analyzing the influence of the anions, cations and the $\mathrm{pH}$ of the solution. The possibility of using the $\mathrm{Li}_{2} \mathrm{Pc}$ as sensitive material and their electrocatalytic properties towards citric acid will be analyzed. The synergistic effect of MWCNT and $\mathrm{Li}_{2} \mathrm{Pc}$ will be evaluated. The results presented in this chapter have been published in Journal of Phthalocyanines and Porphyrins.

\subsection{INTRODUCTION}

Phthalocyanines can be immobilized on inert electrode surfaces such as graphite, carbon, ITO glass, or gold and exhibit electrocatalytic activity 
for a variety of reactions ${ }^{1-4}$. These metal complexes act as mediators by lowering the overpotential of oxidation or reduction of the target molecules or increasing the intensity of the peaks observed. Therefore, phthalocyanine sensors have been applied in amperometric, voltammetric or potentiometric electrocatalytic determination of many organic and inorganic compounds.

Their catalytic action can be described in terms of chemical structure and chemical and physical properties. Their reactive centers are clearly identified and their reactivity can be modulated by changing the nature of the central metal or by modifying the structure of the macrocyclic ligand $d^{2,5,6}$.

The number of works published using phthalocyanines as sensitive materials for electrochemical sensors is quite large and include a variety of phthalocyanine derivatives (e.g. central metal ions, substituents), electrode designs, preparation techniques and target molecules ${ }^{5,6}$. Metallophthalocyanine complexes (MPc) where the phthalocyanine ring (in oxidation state -2 ) is coordinated to a range of transition metal ions (in oxidation state +2 ) have been widely studied. Other families of phthalocyanines have been studied in lesser extent. For instance, some works have been dedicated to electrochemical sensors based on lanthanoid bisphthalocyanines which are sandwich type compounds with free radical character and ring oxidation state $-1.5^{7-10}$.

The dilithium complex $\left(\mathrm{Li}_{2} \mathrm{Pc}\right)$ is an example of a different class of phthalocyanine derivative, where the $\mathrm{Pc}$ ring is coordinated to two lithium ions ${ }^{11}$. Both cations cannot be accommodated in the center of the cavity and thus the lithium atoms are projected out of the plane of the phthalocyanine ring. Dilithium phthalocyanine possess mixed electronic-ionic conductivity due to overlap of $\pi-\pi$ orbitals (electronic) and mobility of $\mathrm{Li}^{+}$ion (ionic) in a channel formed due to stacking of the macromolecules ${ }^{12}$. The electrochemical oxidation of the dilithium phthalocyanine, produces the lithium complex (LiPc) (ring oxidation state -1$)$ that can be considered the simplest representative of the radical phthalocyanines ${ }^{11,13-15}$. As during oxidation lithium ions are 
liberated, these molecules have been used to prepare electrodes for solid state batteries ${ }^{13}$. Such electrodes have been prepared by electrodeposition $^{16}$ or by Langmuir-Blodgett technique ${ }^{12}$. In spite of these interesting electrochemical and conducting properties that make $\mathrm{Li}_{2} \mathrm{Pc}$ a good candidate as electrode modifier, electrochemical sensors based on $\mathrm{Li}_{2} \mathrm{Pc}$ have not been yet developed.

Electrochemical sensors based on phthalocyanines can be prepared using a variety of techniques that include polymerization ${ }^{17}$, sol-gel ${ }^{18}$, Langmuir-Blodgett ${ }^{4,19}$ or Layer by Layer ${ }^{20,21}$ among others. One of the classical methods to prepare electrodes based on phthalocyanines is the carbon paste technique (CPE) in which the phthalocyanine is mixed with a carbonaceous material and a binder to form a paste. In addition, different types of carbonaceous materials can be used to prepare the paste $^{22}$ that include graphite, microspheres or carbon nanotubes among others ${ }^{23-36}$.

\subsection{MATERIALS AND METHODS}

\subsection{1- Chemicals}

All reagents, including $\mathrm{Li}_{2} \mathrm{Pc}$, were of high purity and used without further purification (Sigma-Aldrich). Solutions were prepared using deionized water $(18.3 \mathrm{M} \Omega \cdot \mathrm{cm}$ resistivity), Milli-Q, Millipore. Carbonaceous materials used for the preparation of the CPE electrodes were: Graphite powder (High purity Ultracarbon ${ }^{\circledR}$, Ultra F purity. Bay City, MI, USA), carbon microspheres (from sigradur G HTW, Thierhaupten, Germany) and carbon nanotubes (multi wall nanotubes, Nanoledge Inc., Boncherville, Quebec, Canada). Carbon paste electrodes containing $\mathrm{Li}_{2} \mathrm{Pc}$ were prepared by mixing the carbonaceous material, the dilithium phthalocyanine $(15 \%, w / w)$ and Nujol (Fluka) as binder of the composite mixture ${ }^{34}$. Three types of electrodes were prepared using different carbonaceous materials: graphite powder was used to prepare classical graphite based carbon paste electrodes ( $\left.\mathrm{Li}_{2} \mathrm{Pc} / \mathrm{G}-\mathrm{CPE}\right)$, microspheres were used to prepare electrodes with high surface to volume ratio $\left(\mathrm{Li}_{2} \mathrm{Pc} / \mathrm{ME}-\mathrm{CPE}\right)$ and multiwall carbon nanotubes were used to prepare electrodes that combine two electrocatalysts, $\mathrm{Li}_{2} \mathrm{Pc}$ and 
MWCNT ( $\left.L i_{2} P c / M W C N T-C P E\right)$. Pastes were packed into the body of a $1 \mathrm{~mL}$ PVC (polyvinyl chloride) syringe and compressed. A metallic copper wire was used as electrical contact.

\subsection{2- Equipment}

Electrochemical experiments were performed using a three electrode system with $\mathrm{Ag} \mid \mathrm{AgCl} / \mathrm{KCl} 3 \mathrm{M}$ reference electrode, $1 \mathrm{~cm}^{2}$ platinum counter electrode and the corresponding CPE as working electrode. The potentiostat used was an EG\&G PARC, Model 2273 potentiostat/galvanostat (Princeton Applied Research Corp.). Temperature control at $25^{\circ} \mathrm{C}$ was achieved using a circulating bath (Neslab).

\subsection{RESULTS AND DISCUSSION}

\subsection{1- Electrochemical characterization}

Electrochemical studies were carried out in $\mathrm{KCl} 0.1 \mathrm{~mol} \cdot \mathrm{L}^{-1}$. Figure 7.1 shows the cyclic voltammetric (CV) curves from $-1.0 \mathrm{~V}$ to $+1.0 \mathrm{~V}$ at 0.1 $\mathrm{V} \cdot \mathrm{s}^{-1}$ for $\mathrm{Li}_{2} \mathrm{Pc}$ carbonaceous electrodes prepared using graphite (Figure 7.1.a), microspheres (Figure 7.1.b) and nanotubes (Figure 7.1.c). The electrode prepared with graphite $\left(\mathrm{Li}_{2} \mathrm{Pc} / \mathrm{G}-\mathrm{CPE}\right)$ showed a quasireversible redox process at $\mathrm{E}_{1 / 2}=-0.04 \mathrm{~V}$ with a peak separation $(\Delta \mathrm{E}) c a$. $0.52 \mathrm{~V}$. According to literature, this redox process is assigned to phthalocyanine ring oxidation/reduction (from $\mathrm{Pc}^{2-}$ to $\mathrm{Pc}^{-}$) that gives rise to the LiPc radical species ${ }^{35}$. The responses were highly stable and the electrodes could be cycled up to 100 cycles without important changes in the responses. Only a slight decrease of the intensity of the peaks was observed (about $5 \%$ for 100 cycles).

Electrodes prepared with microspheres ( $\left.\mathrm{Li}_{2} \mathrm{Pc} / \mathrm{ME}-\mathrm{CPE}\right)$ (Figure 7.1.b) and nanotubes ( $\mathrm{Li}_{2} \mathrm{Pc} / \mathrm{MWCNT}-\mathrm{CPE}$ ) (Figure 7.1.C) showed a similar behavior, but molecular aggregation of phthalocyanines influenced strongly the electrochemical responses. The use of carbon forms with higher active surface (as microspheres) caused a decrease of the separation between the anodic and the cathodic waves $(\triangle \mathrm{E}=0.504 \mathrm{~V})$. This decrease was clearly more marked when using MWCNT as 
carbonaceous material $(\Delta \mathrm{E}=0.426 \mathrm{~V})$. This seems to indicate that the electrochemical oxidation of the $\mathrm{Li}_{2} \mathrm{Pc}$ was facilitated in the presence of MWCNT due to the $\pi-\pi$ interactions with the carbon nanotubes that promoted the charge transfer through the electrode interface and/or the charge transport within the film confirming the electrocatalytic effect of nanotubes. In contrast, MWCNT made difficult the reduction process, probable due to the strong interaction between the nanotubes and the radical species formed upon oxidation (LiPC).
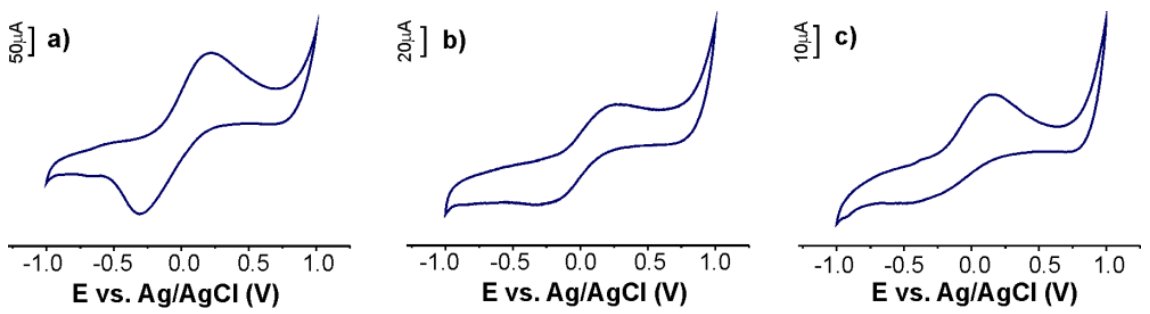

Figure 7.1. Cyclic voltammograms of $\mathrm{Li}_{2} \mathrm{Pc} C P E$ electrodes prepared using: a) graphite, b) microspheres and c) MWCNT as carbonaceous material in $0.1 \mathrm{~mol}$. $\mathrm{L}^{-1} \mathrm{KCl}$. Scan rate, $0.1 \mathrm{~V} \cdot \mathrm{s}^{-1}$

The dynamic character of the electrode process was further examined by registering voltammograms at different scan rates (Figure 7.2). In all three electrodes the intensity of the peaks depended linearly with the square root of the scan rate indicating a diffusion controlled process in accordance with the Randles-Sevcik equation (Equation 7.1).

$$
I=2.687 \times 10^{5} n^{3 / 2} v^{1 / 2} D^{1 / 2} \mathrm{AC} \text { (Equation 7.1) }
$$

Where $I$ is the anodic peak current $(A), n$ is the number of electrons involved in the redox process, $v$ is the scan rate $\left(V \cdot s^{-1}\right), D$ is the diffusion coefficient $\left(\mathrm{cm}^{2} \cdot \mathrm{s}^{-1}\right), A$ is the electrode surface area $\left(\mathrm{cm}^{2}\right)$, and $C$ is the concentration $\left(\mathrm{mol} \cdot \mathrm{L}^{-1}\right)$.

This Nerstian behavior was in good accordance with data obtained using other radical phthalocyanine-CPE sensors ${ }^{23}$. Table 7.1 shows the values of the slope of the curves obtained by representing the intensity of the 
anodic peaks versus the square root of the scan rate. As observed in the table, the slope of the curve obtained when using MWCNT was approximately one order of magnitude higher than $\mathrm{Li}_{2} \mathrm{Pc} / \mathrm{G}-\mathrm{CPE}$ and $\mathrm{Li}_{2} \mathrm{Pc} / \mathrm{ME}-\mathrm{CPE}$ electrodes, suggesting a faster response. From the slope of $I$ versus $v^{1 / 2}$ plot, the diffusion coefficient $D$ (i.e. ions diffusing inside/outside the film to maintain the electroneutrality) could be calculated (Table 7.1). Again, the diffusion coefficient obtained for $\mathrm{Li}_{2} \mathrm{Pc}$ immobilized in carbon nanotubes is higher than the value obtained using other carbonaceous forms.

Table 7.1. Slope $(m)$, coefficient of correlation $\left(R^{2}\right)$ and diffusion coefficients (D) obtained by representing the intensity of the anodic peak versus the square root of the scan rate.

\begin{tabular}{|l|r|c|c|}
\hline \multicolumn{1}{|c|}{ Electrode } & $\mathbf{m}$ (slope) & $\mathbf{R}^{2}$ & $\mathbf{D}\left(\mathbf{c m}^{2} \cdot \mathbf{s}^{-1}\right.$ ) \\
\hline $\mathrm{Li}_{2} \mathrm{Pc} / \mathrm{G}-\mathrm{CPE}$ & $4 \times 10^{-5}$ & 0.9606 & $8.94 \times 10^{-7}$ \\
\hline $\mathrm{Li}_{2} \mathrm{Pc} / \mathrm{ME}-\mathrm{CPE}$ & $3 \times 10^{-5}$ & 0.9936 & $5.03 \times 10^{-7}$ \\
\hline $\mathrm{Li}_{2} \mathrm{Pc} / \mathrm{MWCNT}-\mathrm{CPE}$ & $1 \times 10^{-4}$ & 0.9928 & $3.02 \times 10^{-6}$ \\
\hline
\end{tabular}

It is worthily noting that although $\mathrm{Li}_{2} \mathrm{Pc} / \mathrm{MWCNT}-\mathrm{CPE}$ also showed a Nerstian behavior, voltammograms registered at high scan rates appeared tilted approaching progressively to an ohmic conduction. Lithium phthalocyanine (LiPc) possesses mixed electronic-ionic conductivity due to overlap of $\pi-\pi$ orbitals (electronic) and mobility of $\mathrm{Li}^{+}$ion (ionic) in a channel formed due to stacking of the macromolecules ${ }^{12}$. The formation of the conductive LiPc free radical and the liberation of $\mathrm{Li}^{+}$ions that were trapped at the cavities of the MWCNT electrodes can be responsible of this increase of the ohmic behavior.

Another interesting observation was that at high scan rates, the shapes of voltammogramms registered using graphite or microspheres were different from those obtained at low scan rates and a small second peak at lower potentials is observed/anodic wave at ca. $-0.2 \mathrm{~V}$. According to the literature, this second peak could be attributed to the oxidation of $\mathrm{Li}_{2} \mathrm{Pc}$ to the free radical of phthalocyanine $\mathrm{H}(\mathrm{Pc})^{35}$. That is, from the same starting material (the $\mathrm{Li}_{2} \mathrm{Pc}$ ), two different products can be obtained 
depending on the oxidation conditions. Usually, electrochemical oxidation produces the radical lithium salt (LiPc), but under certain conditions (usually chemical oxidation), the free metal HPc (where Pc is the radical anion $\mathrm{Pc}^{-}$) can also be obtained. In our case, high scan rates could favor this new pathway.
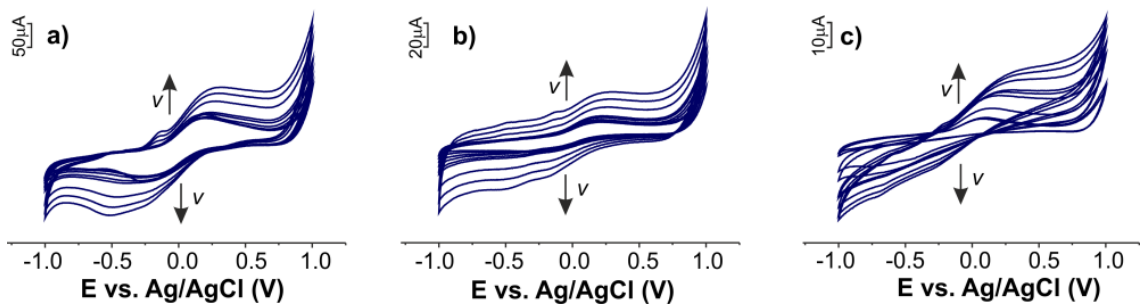

Figure 7.2. Cyclic voltammograms of a) $\left.\mathrm{Li}_{2} \mathrm{Pc} / \mathrm{G}-\mathrm{CCE}, \mathrm{b}\right) \mathrm{Li}_{2} \mathrm{Pc} / \mathrm{ME}-\mathrm{CPE}$ and $\mathrm{c}$ ) $\mathrm{Li}_{2} \mathrm{PC} / \mathrm{MWCNT}-\mathrm{CPE}$ in $0.1 \mathrm{~mol} \cdot \mathrm{L}^{-1} \mathrm{KCl}$ at scan rates from $0.050-0.200 \mathrm{~V} \cdot \mathrm{s}^{-1}$.

In order to understand the electron transfer behavior of the chemically modified electrodes, electrochemical measurements on $\mathrm{Li}_{2} \mathrm{Pc} / \mathrm{G}-\mathrm{CPE}$, $\mathrm{Li}_{2} \mathrm{Pc} / \mathrm{ME}-\mathrm{CPE}, \mathrm{Li}_{2} \mathrm{Pc} / \mathrm{MWCNT}-\mathrm{CPE}$ in presence of ferrocyanide were carried out. The $\left[\mathrm{Fe}(\mathrm{CN})_{6}\right]^{3-} /\left[\mathrm{Fe}(\mathrm{CN})_{6}\right]^{4-}$ couple was used to characterize the active surface (i.e. number of active sites or blocking ability of surfaces). Results are shown in Figure 7.3.
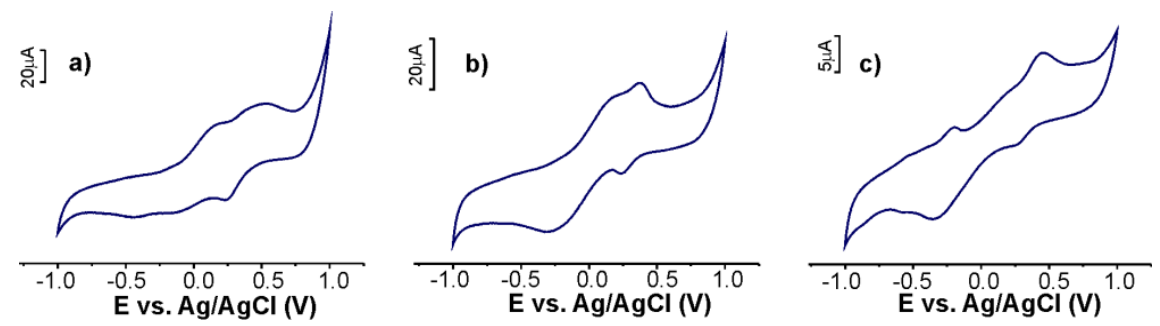

Figure 7.3. Cyclic voltammograms of a) $\left.\mathrm{Li}_{2} \mathrm{Pc} / \mathrm{G}-\mathrm{CCE}, \mathrm{b}\right) \mathrm{Li}_{2} \mathrm{Pc} / \mathrm{ME}-\mathrm{CPE}$ and c) $\mathrm{Li}_{2} \mathrm{Pc} / \mathrm{MWCNT}-\mathrm{CPE}$, in $10^{-3} \mathrm{~mol} \cdot \mathrm{L}^{-1}\left[\mathrm{Fe}(\mathrm{CN})_{6}\right]^{3-} /\left[\mathrm{Fe}(\mathrm{CN})_{6}\right]^{4-}$ in $0.1 \mathrm{~mol} \cdot \mathrm{L}^{-1} \mathrm{KCl}$. Scan rate, $0.1 \mathrm{~V} \cdot \mathrm{s}^{-1}$.

Voltammograms obtained from electrodes prepared with graphite and microspheres showed two redox pairs associated with both $\mathrm{Li}_{2} \mathrm{Pc} / \mathrm{LiPc}$ 
couple (at $\mathrm{E}_{1 / 2} c a .0 .1 \mathrm{~V}$ ) and ferrocyanide/ferricyanide couple (at $c a$. $0.45 \mathrm{~V})$. Peaks were broad and somehow overlapped. In contrast, when MWCNT were used, peaks were well separated and the peak related to the $\mathrm{Li}_{2} \mathrm{Pc}$ appeared shifted to lower potentials (i.e. anodic wave that appeared at $+0.2 \mathrm{~V}$ in $\mathrm{KCl}$ shifted to $-0.1 \mathrm{~V}$ ). The most interesting feature was that the intensity of the ferrocyanide increased drastically in the presence of the MWCNT, indicating that the number of active sites was amplified. The active area calculated from voltammograms registered at different scan rates (0.050 to $\left.1.0 \mathrm{~V} \cdot \mathrm{s}^{-1}\right)$ according to the Randles-Sevcik equation (taking into account that the diffusion coefficient for $10^{-3} \mathrm{~mol}$. $\mathrm{L}^{-1}$ ferrocyanide is $7.26 \times 10^{-6} \mathrm{~cm}^{2} \cdot \mathrm{s}^{-1}$ in $1.0 \mathrm{~mol} \cdot \mathrm{L}^{-1} \mathrm{KCl}$ solution) was similar for graphite and microspheres $\left(0.159 \mathrm{~cm}^{2}\right)$ whereas, for the MWCNT electrode the calculated active area was $0.25 \mathrm{~cm}^{2}$.

The voltammetric response relied on the transfer of counterions between the electrolyte and the bulk of these materials in response to the electron-transfer processes associated with their oxidation and reduction. In order to evaluate the influence of the electrolyte in the electrochemical comportment, carbonaceous electrodes were also immersed in solutions containing different electrolytes.

\subsection{2- Analysis of simple electrolytes}

The role of protons was studied by immersing the electrodes in $\mathrm{HCl}$. The cyclic voltammogram of the $\mathrm{Li}_{2} \mathrm{Pc} / \mathrm{MWCNT}$-CPE electrode in $10^{-4} \mathrm{~mol} \cdot \mathrm{L}^{-1}$ $\mathrm{HCl}(\mathrm{pH}=3)$ is shown in Figure 7.4. In the presence of protons, the three electrodes showed two anodic waves of similar intensity at ca. $-0.2 \mathrm{~V}$ and $+0.25 \mathrm{~V}$. The cathodic wave contained a small peak at $+0.05 \mathrm{~V}$ and a broad and intense peak at $-0.6 \mathrm{~V}$. These two redox processes could be due to the formation of a protonated species in $\mathrm{HCl}$ that has also been described in other radical species ${ }^{9}$. This protonated ring can be oxidized at lower potentials than the neutral $\mathrm{Li}_{2} \mathrm{Pc}$. 


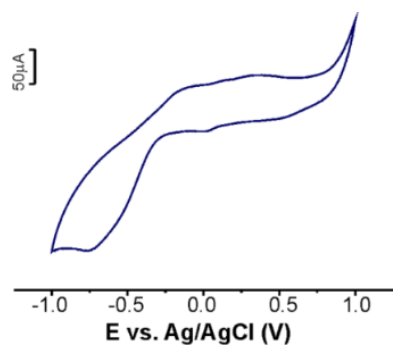

Figure 7.4. Cyclic voltammograms of $\mathrm{Li}_{2} \mathrm{Pc} / \mathrm{ME}-\mathrm{CPE}$ in $0.1 \mathrm{~mol} \cdot \mathrm{L}^{-1} \mathrm{HCl}$. Scan rate, $0.1 \mathrm{~V} \cdot \mathrm{s}^{-1}$.

As previously established, the electrochemical oxidation of the dilithium salt of phthalocyanine produces de monolithium radical derivative LiPc, (that possess mixed electronic-ionic conductivity) with liberation of $\mathrm{Li}^{+}$ ions ${ }^{17}$. Due to the important role of $\mathrm{Li}^{+}$ion in the ionic conductivity of $\mathrm{Li}_{2} \mathrm{Pc}$, the electrochemical behavior of these electrodes was tested in a $\mathrm{LiClO}_{4}$ solution. As shown in Figure 7.5, the presence of $\mathrm{Li}^{+}$ions produced two effects in the voltammograms. The first effect was an increase in the separation between the anodic and cathodic waves of the redox pair $\mathrm{Li}_{2} \mathrm{Pc} / \mathrm{LiPc}$ while voltammograms became tilted and showed an increased ohmic behavior. This might be the result of an increase in their conductivity through the easier transfer of the $\mathrm{Li}^{+}$ions in the presence of lithium in the solution. In addition, the IR drop for electrolyte motion in carbon pores affected the double-layer formation mechanism, in which the charge stored is recognized to be distributed. The second effect was that the intensity of the peaks decreased upon successive cycling, indicating that the active sites are progressively blocked. This decrease was dependent on the surface area of the carbonaceous materials and followed the trend $\mathrm{Li}_{2} \mathrm{Pc} / \mathrm{G}-\mathrm{CPE}>\mathrm{Li}_{2} \mathrm{Pc} / \mathrm{ME}-\mathrm{CPE}>\mathrm{Li}{ }_{2} \mathrm{Pc} / \mathrm{MWCNT}-\mathrm{CPE}$. That is, in MWCNT this effect was almost negligible. 

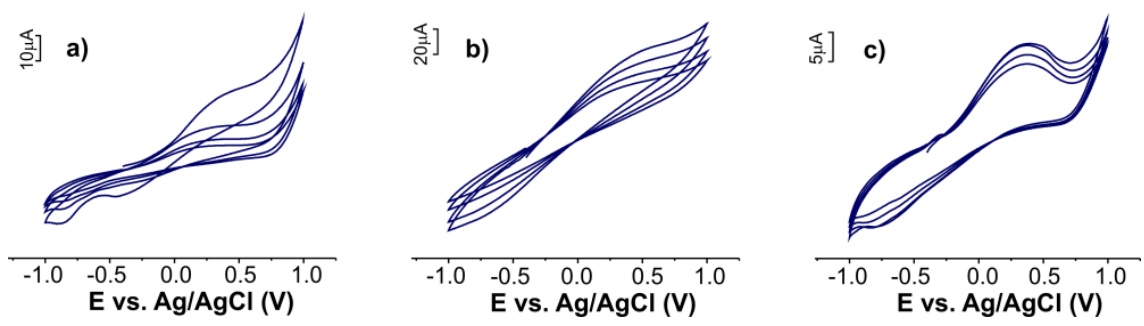

Figure 7.5. Cyclic voltammograms of $\mathrm{Li}_{2} \mathrm{Pc} C P E$ electrodes prepared using: a) graphite, b) microspheres and c) MWCNT as carbonaceous material in $0.1 \mathrm{~mol}$. $\mathrm{L}^{-1} \mathrm{LiClO}_{4}$. Scan rate, $0.1 \mathrm{~V} \cdot \mathrm{s}^{-1}$.

When using $\mathrm{NH}_{4} \mathrm{OH}$ as electrolyte, the responses were highly similar to those obtained in $\mathrm{LiClO}_{4}$. The cyclic voltammograms also became tilted and pointed at each end and the intensity changed almost linearly with potential over a very wide range (Figure 7.6). But in this case, all modified electrodes showed improved stability and the blocking effect was almost unexistent. These results indicate that $\mathrm{NH}_{4}{ }^{+}$ions can also participate in the ions motion inside the electrodes and to the double layer formation, but the basic environment prevents the blocking of the active sites.

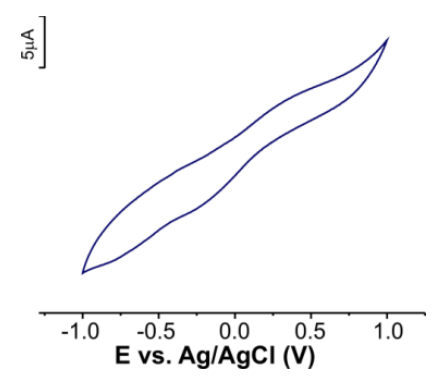

Figure 7.6. Cyclic voltammograms of $\mathrm{Li}_{2} \mathrm{Pc} / \mathrm{ME}-\mathrm{CPE}$ electrodes in $0.1 \mathrm{~mol} \cdot \mathrm{L}^{-1}$ $\mathrm{NH}_{4} \mathrm{OH}$. Scan rate, $0.1 \mathrm{~V} \cdot \mathrm{s}^{-1}$.

\subsection{3- Analysis of citric acid}

Finally, the response of the electrodes towards an antioxidant of interest in the food industry such as citric acid was tested (Figure 7.7). Voltammograms showed peaks of two different origins: peaks associated with the oxidation-reduction of the citric acid present in the 
solution and transient responses related to the electrode material $\left(\mathrm{Li}_{2} \mathrm{Pc}\right)$. But, the important issue is that the interactions that occur between the electrode and the citric acid can improve the electrochemical signals.

In all three electrodes, the electrocatalytic behavior of $\mathrm{Li}_{2} \mathrm{Pc}$ caused a decrease in the oxidation potential of the citric acid that using a bare electrode appeared at $0.62 \mathrm{~V}$, but shifted to lower potentials in the presence of $\mathrm{Li}_{2} \mathrm{Pc}\left(0.57 \mathrm{~V}\right.$ in $\mathrm{Li}_{2} \mathrm{Pc} / \mathrm{G}-\mathrm{CPE}, 0.50 \mathrm{~V}$ in $\mathrm{Li}_{2} \mathrm{Pc} / \mathrm{ME}-\mathrm{CPE}$ and 0.45 $\mathrm{V}$ in $\mathrm{Li}_{2} \mathrm{Pc} / \mathrm{MWCNT}$-CPE). In addition, the anodic peak associated with the $\mathrm{Li}_{2} \mathrm{Pc}$ also appeared at lower potentials $(-0.07 \mathrm{~V})$.
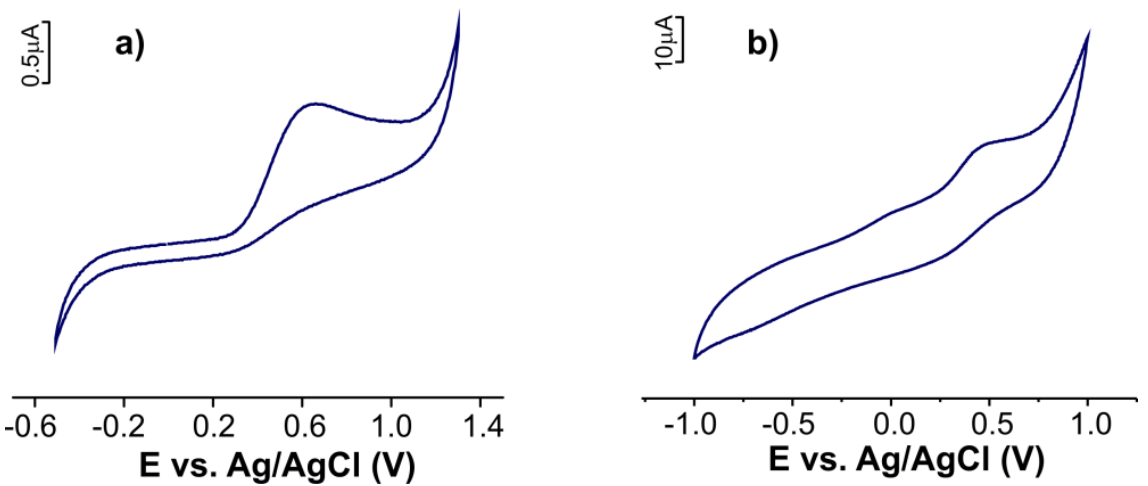

Figure 7.7. Cyclic voltammograms of a) bare MWCNT-CPE and b) $\mathrm{Li}_{2} \mathrm{Pc} / \mathrm{MWCNT}$ $\mathrm{CPE}$ electrodes in $0.4 \times 10^{-4} \mathrm{~mol} \cdot \mathrm{L}^{-1}$ citric acid. Scan rate, $0.1 \mathrm{~V} \cdot \mathrm{s}^{-1}$.

Catalysis was also evidenced by the enhancement of the oxidation peak current, ( 10 fold compared to the bare MWCNT electrodes). The charge passed under the curve was larger for MWCNT than for microspheres or graphite. This result indicates that carbon nanotubes facilitated the charge transfer through the electrode interface and/or the charge transport within the film. The strong electrocatalytic effect observed in the $\mathrm{Li}_{2} \mathrm{Pc} / \mathrm{MWCNT}$-CPE immersed in citric acid can be attributed to the synergistic effect between MWCNT and $\mathrm{Li}_{2} \mathrm{Pc}$ that improves electrocatalysis for the detection of citric acid. This is illustrated in Figure 
7.7 where the response of a bare MWCNT-CPE and a Li $\mathrm{i}_{2} \mathrm{Pc} / \mathrm{MWCNT}-\mathrm{CPE}$ towards citric acid are shown.

\subsection{CONCLUSIONS}

The electrochemical behavior of carbonaceous electrodes of dilithium phthalocyanine prepared using graphite, carbon microspheres and multiwall carbon nanotubes, was analyzed. The three carbonaceous materials were adequate for the immobilization of $\mathrm{Li}_{2} \mathrm{Pc}$ and showed distinct electrochemical behaviors that were related to the nature of the carbon material. The electrode formed by combining MWCNT and the $\mathrm{Li}_{2} \mathrm{Pc}$ showed a higher diffusion coefficient and an increased number of active sites. The electrochemical response registered in different electrolytic solutions was found to be largely dependent on the nature of the ions present in the solution. In the presence of protons, the electrodes showed two anodic waves produced by the protonation of the $\mathrm{Pc}$ ring, whereas the presence of $\mathrm{LiClO}_{4}$ or $\mathrm{NH}_{4} \mathrm{OH}$ promoted the mobility of lithium ions increasing the ohmic conduction. The electrodes were also used to detect citric acid, an antioxidant of interest in the food industry. It was demonstrated that the electrocatalytic properties of the $\mathrm{Li}_{2} \mathrm{Pc}$ facilitate the oxidation of the citric acid. The simultaneous use of two electrocatalysts MWCNT and $\mathrm{Li}_{2} \mathrm{Pc}$ produce a synergic effect that improves the electrocatalytic effect. 


\section{References}

1. Jiang, J. Functional Phthalocyanine Molecular Materials. Series: Structure and Bonding 135, 2010. Ed. Springer, Berlin (Germany).

2. Zagal, J.H., Griveau, S., Silva, J.F., Nyokong, T., Bedioui, F. Coord. Chem. Rev. 2010, 254, 2755-2791.

3. Rodriguez-Mendez M.L. Sensing properties of Phthalocyanines in Encyclopedia of Sensors. 2006, 111-134. Ed. American Scientific Publishers, California (USA).

4. Valli, L. Adv. Col. Interf. Sci. 2005, 116, 13-44.

5. Lever A.B.P. J. Porphyrins Phthalocyanines. 1999, 3, 488-499.

6. Bedioui, F., Griveau, S., Nyokong, T., Appleby, A.J., Caro, C.A., Gulppi, M., Ochoa, G., Zagal, J.H. Phys. Chem. Chem. Phys. 2007, 9, 3383-3396.

7. Weiss, R., Fischer, J. Lanthanide phthalocyanine complexes in The Porphyrin Handbook, 2003, 171-246. Ed. Academic Press, New York (USA).

8. Rodríguez-Méndez, M.L., Gay, M., de Saja J.A. J. Porphyrins Phthalocyanines. 2009, 13, 1159-1167.

9. Gay, M., Muñoz, R., de Saja, J.A., Rodriguez-Mendez, M.L. Electrochim. Acta. 2012, 68, 88-94.

10. Parra, V., Hernando, T., Rodríguez-Méndez, M.L. de Saja, J.A. Electrochim. Acta. 2004, 49, 5177-5185.

11. Bouvet, M. Radical Phthalocyanines and Intrinsic Semiconduction in Porphyrin Handbook. 2003, 37-104. Ed. Academic Press, New York (USA).

12. Xiang, H.Q., Tanaka, K., Takahara, A., Kajiyama, T. Langmuir. 2002, $18,2223-2228$. 
13. Scanlon, L.G., Lucente, L.R., Feld, W.A., Sandi, G., Balbuena, P.B., Alonso, P.R., Turner, A. J. Electrochem. Soc. 2004, 151, A1338-A1343.

14. Deng, X., Porter III, W.W., Vaid, T.P. Polyhedron. 2005, 24, 30043011.

15. Turek, P., Petit, P., Andre, J.J., Simon, J., Even, R., Boudjema, B., Guillaud, G., Maitrot, M. J. Am. Chem. Soc. 1987, 109, 5119-5122.

16. Ilangovan, G., Zweier, J.L., Kuppusamy, P. J. Phys. Chem. 2000, 104, 4047-4059.

17. Griveau, S., Gulppi, M., Pavez, J., Zagal, J.H., Bedioui, F. Electroanal. 2003, 15, 779-785.

18. Guo, Y., Guadalupe, A.R. Sensors Actuat. B. 1998, 46, 213-219.

19. Gorbunova, Y., Rodríguez-Méndez, M.L., Kalashnikova, I.P., Tomilova, L., de Saja, J.A. Langmuir. 2001, 17, 5004-5010.

20. Demel, J., Lang, K. Eur. J. Inorg. Chem. 2012, 32, 5154-5164.

21. Volpati, D., Alessio, P., Zanfolim, A.A., Storti, F.C., Job, A.E., Ferreira, M., Riul Jr., A., Oliveira, O.N.Jr., Constantino C.J.L. J. Phys. Chem. B. 2008, $112,15275-15282$.

22. Svancara, I., Vytras, K., Barek, J., Zima, J. Crit. Rev. Anal. Chem. 2001, 31, 311-345.

23. Apetrei, C., Apetrei, I.M., de Saja, J.A., Rodriguez-Méndez, M.L. Sensors. 2011, 11, 1328-1344.

24.Ruiz-Morales, J.C., Canales-Vázquez, J., Marrero-López, D., Savvin, S.N., Nunez, P., Dos Santos-García, A.J., Sánchez-Bautista, C., PeñaMartínez, J. Carbon. 2010, 48, 3964-3967.

25. Jacobs, .CB., Peairs, M.J., Venton, B.J. Anal. Chim. Acta. 2010, 662, 105-127. 
26. Mamuru, S.A., Ozoemena, K.I., Fukuda, T., Kobayashi, N., Nyokong, T. Electrochim. Acta. 2010, 55, 6367-6375.

27. Chen, Y., Lin, Y., Liu, Y., Doyle, J., He, N., Zhuang, X.D., Bai, J.R., Blau W.J. J. Nanosci. Nanotech. 2007, 7, 1268-1283.

28. Bandaru, P.R. J. Nanosci. Nanotech. 2007, 7, 1239-1267.

29. Inagaki, M., Kaneko, K., Nishizawa, T. Carbon. 2004, 42, 1401-1417.

30. Zagal, J.H., Griveau, S., Ozoemena, K., Nyokong, T. Bedioui, F. J. Nanosci Nanotech. 2009, 9, 2201-2214.

31. Ozoemena, K.I., Nyokong, T., Knosi, D., Chambrier, I., Coock, M.J. Electrochim. Acta. 2007, 52, 4132-4143.

32. Apetrei, C., Nieto, M., Rodríguez-Méndez, M.L., de Saja, J.A. J. Porphyrins Phthalocyanines. 2011, 15, 908-917.

33. Khene, S. Nyokong, T. Electroanalysis. 2011, 23, 1901-1911.

34. Rodríguez-Méndez, M.L., Gay, M., Apetrei, C., de Saja, J.A. Electrochim. Acta. 2009, 54, 7033-7041.

35. Sugimoto, H., Higashi, T., Mori, M. J. Chem. Soc., Chem. Commun. $1983,11,622-623$. 



\section{CHAPTER 8}

Electronic Tongue Formed by Sensors and Biosensors Containing Phthalocyanines as Electron Mediators. Application to the Analysis of Red Grapes. 

Based on the good performance of carbon paste electrodes containing phthalocyanines and their excellent electron mediator behavior, the aim of this chapter was to develop a hybrid multisensor system combining voltammetric sensors and biosensors and to evaluate its capability to discriminate musts prepared from different varieties of grapes according to their polyphenol and sugar content.

As stated in the previous chapter, phthalocyanines are mixed with the carbonaceous material and the binder, forming the matrix of the sensor. In order to prepare biosensors, enzymes need to be included in the system. In this case, the technique used to immobilize the enzyme was drop casting followed by a cross-linking process.

As the goal of the work was to analyze musts, enzymes devoted to the analysis of phenols and sugars were included in the array.

In this chapter, three different arrays of sensors have been developed and combined: an array of sensors based on phthalocyanines (MPc-CPE) and two arrays of biosensors based on tyrosinase and glucose oxidase: (MPc-Tyr-CPE and MPc-GOx-CPE respectively) in which phthalocyanines are used as electron mediators.

The sensors have been immersed in model solutions of phenols (catechol) and sugars (glucose) and the responses have been evaluated. Then, the array has been used to analyze musts prepared from different varieties of grapes. The capability of discrimination of the sensor array will be investigated using Principal Component Analysis (PCA). This work has been published in Journal of Porphyrins and Phthalocyanines.

\subsection{INTRODUCTION}

During the last years efforts have been made to develop a new type of instrument for the analysis of liquids, the electronic tongue $(E T)^{1-4}$. According to the IUPAC, an ET is a multisensor system formed by an array of low-selective sensors combined with advanced mathematical procedures for signal processing based on pattern recognition and/or multivariate data analysis ${ }^{5}$. These instruments provide global 
information about the sample instead of giving information of particular constituents. Due to this holistic approach, ETs are particularly interesting for the analysis of complex liquids such as wines ${ }^{6-9}$. Most of the works in the field of electronic tongues involve signal generation from electrochemical sensors including potentiometric, impedimetric or voltammetric sensors $^{9-12}$.

In the last years, our group has developed an ET based on voltammetric sensors chemically modified with phthalocyanines (MPc) ${ }^{7,13-15}$. Sensors based on phthalocyanines show interesting sensing properties due to their rich electrochemical and electrocatalytic behavior, and because their properties can be tuned by chemical modification ${ }^{16-19}$. In addition, sensors can be prepared using a variety of approaches that include simple methods such as carbon paste technique or more sophisticated methods that produce nanostructured devices ${ }^{11,13,20}$.

The voltammetric signals obtained from electrodes modified with phthalocyanines show redox peaks associated with the studied solution (as in classical metallic or carbonaceous electrodes), but in the modified electrodes, the position and intensity of such redox processes are modulated by the interaction between the solution and the phthalocyanine (i.e. by the electrocatalytic behavior of the phthalocyanine $)^{18}$. Phthalocyanines have also demonstrated their ability to act as electron mediators in voltammetric biosensors. In such devices, phthalocyanines are used to facilitate the electron transfer between the enzyme (e.g. tyrosinase) and the electrode surface ${ }^{21-22}$.

Arrays of sensors prepared from different phthalocyanine molecules have shown a high degree of cross-selectivity and have been successfully used to analyze model solutions of basic tastes and other complex liquids of industrial interest such as wines ${ }^{4,7,14-15}$.

The cross-selectivity of a multisensor system could be improved by constructing hybrid arrays combining low-specific sensors, with biosensors containing enzymes selective to specific compounds of interest. This can be of particular importance in the field of viticulture 
and enology where the content of certain compounds is directly related to the quality of wines and also to the quality of grapes from which wines are prepared ${ }^{23,24}$. For instance, the quality of grapes is usually established by measuring their sugar content and acidity. In addition, it is becoming evident that the quality of grapes is also closely associated with other parameters such as their phenolic composition ${ }^{25,26}$.

\subsection{MATERIALS AND METHODS}

\subsection{1- Grape samples}

Grapes of five different varieties were harvested in 2012 in Valladolid region (Spain). The varieties included were Tempranillo, Garnacha, Cabernet-Sauvignon, Prieto Picudo and Mencía. Samples were selected and harvested by the ITACYL and Bodega Cooperativa de Cigales (Spain). The Enological Centre of Castilla y León carried out the chemical analysis of the grapes and prepared the corresponding musts. Grapes were analyzed following international regulations ${ }^{27}$.The results are collected in Table 8.1.

\subsection{2- Reagents and solutions}

All reagents were of high purity and used without further purification (Sigma-Aldrich). All solutions were prepared with deionized water (18.2 $\mathrm{M} \Omega \cdot \mathrm{cm}^{-1}$ resistivity, Milli-Q, Millipore). A $70 \mu \mathrm{g} \cdot \mathrm{mL}^{-1}$ solution of enzymes (tyrosinase and glucose oxidase) in buffer phosphate $0.01 \mathrm{~mol} \cdot \mathrm{L}^{-1}(\mathrm{pH}$ 7.0) was used for the enzyme immobilization. $10^{-3} \mathrm{~mol} \cdot \mathrm{L}^{-1}$ solutions of catechol and glucose were prepared in buffer phsophate $(\mathrm{pH} \mathrm{7.0)}$ and buffer citrate $(\mathrm{pH} 3.1)$.

Cobalt (II), copper (II) and zinc (II) phthalocyaninates (CoPc, CuPc, ZnPc) were purchased from Sigma Aldrich. The lutetium (III) bisphthalocyaninate $\left(\mathrm{LuPC}_{2}\right)$ was synthesized and purified in its neutral radical state following previously published procedures ${ }^{28}$. 


\subsection{3- Preparation of the electrodes}

8.2.3.1- Array of sensors formed by Carbon Paste Electrodes (CPE) modified with phthalocyanines (MPC-CPE)

An array formed by five CPE electrodes was prepared. It was formed by three electrodes modified with metalophthalocyanines including CoPc (CoPc-CPE), CuPc (CuPc-CPE), ZnPc (ZnPc-CPE), one electrode modified with $\mathrm{LuPC}_{2}$ ( $\left.\mathrm{LuPC}_{2}-\mathrm{CPE}\right)$ and one unmodified carbon paste electrode (CCPE). CPEs were prepared as previously reported by mixing graphite powder and the corresponding phthalocyanine ( $15 \%, w / w)$. Nujol was used as binder of the composite mixture. Pastes were packed into the body of a $1 \mathrm{~mL}$ plastic syringe and compressed. A metallic copper wire was used as a contact ${ }^{29}$.

Table 8.1. Results of chemical analysis of the grapes.

\begin{tabular}{|c|c|c|c|c|c|}
\hline 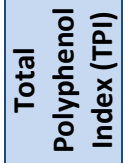 & ̊ి & $\stackrel{\stackrel{\sim}{\sim}}{ }$ & Э & $\stackrel{\sim}{\sim}$ & $\stackrel{\sim}{\sim}$ \\
\hline 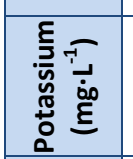 & $\underset{7}{\stackrel{?}{f}}$ & 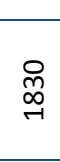 & 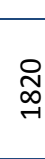 & 号 & 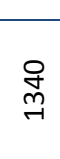 \\
\hline 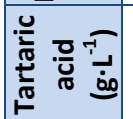 & 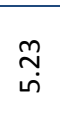 & 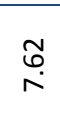 & O̊ & $\begin{array}{c}\infty \\
\stackrel{\infty}{m}\end{array}$ & $\begin{array}{l}\hat{\infty} \\
0 \\
0\end{array}$ \\
\hline$\frac{u}{\pi}$ & $\stackrel{m}{i}$ & $\begin{array}{c}\infty \\
\infty \\
0 \\
0\end{array}$ & $\stackrel{n}{n}$ & $\stackrel{\infty}{\stackrel{\infty}{\sim}}$ & $\stackrel{n}{\stackrel{n}{0}}$ \\
\hline
\end{tabular}




\begin{tabular}{|c|c|c|c|c|c|}
\hline 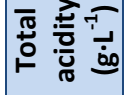 & $\underset{+}{\stackrel{+}{+}}$ & 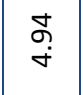 & $\underset{\sim}{\stackrel{\sim}{*}}$ & $\stackrel{\infty}{\stackrel{\infty}{m}}$ & $\stackrel{\hat{m}}{\dot{r}}$ \\
\hline 즘 & 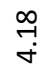 & 足 & $\underset{+}{\stackrel{\gamma}{\sigma}}$ & $\stackrel{\vec{T}}{m}$ & $\stackrel{\stackrel{\sim}{\sim}}{\dot{m}}$ \\
\hline 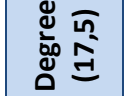 & $\begin{array}{l}\stackrel{8}{6} \\
\dot{m} \\
\rightarrow\end{array}$ & $\stackrel{\stackrel{n}{\sim}}{\stackrel{m}{\rightarrow}}$ & 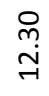 & $\begin{array}{l}\stackrel{8}{0} \\
\stackrel{-}{-1}\end{array}$ & $\begin{array}{l}8 \\
\dot{m} \\
\stackrel{-1}{ }\end{array}$ \\
\hline 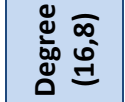 & $\stackrel{\stackrel{n}{\sim}}{\stackrel{+}{\sim}}$ & $\begin{array}{l}\ddot{\varphi} \\
\ddot{m} \\
\stackrel{\sim}{1}\end{array}$ & $\begin{array}{l}\stackrel{0}{2} \\
\stackrel{\sim}{r}\end{array}$ & $\begin{array}{l}8 \\
\stackrel{-}{-}\end{array}$ & $\begin{array}{l}\text { ஸे } \\
\stackrel{n}{\sim}\end{array}$ \\
\hline مَّ & $\stackrel{\sim}{\infty}$ & Фั & $\underset{\sim}{\stackrel{\infty}{\sim}}$ & 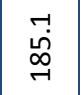 & 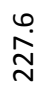 \\
\hline 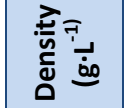 & $\begin{array}{l}\infty \\
\stackrel{0}{8} \\
\stackrel{8}{0}\end{array}$ & 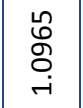 & $\begin{array}{l}\text { ஜ } \\
\text { Oे } \\
-1\end{array}$ & $\begin{array}{l}\text { ò } \\
\text { م̦ } \\
\text { - }\end{array}$ & 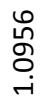 \\
\hline$\stackrel{x}{\frac{x}{0}}$ & $\stackrel{\circ}{\stackrel{\sim}{\sim}}$ & $\stackrel{m}{\sim}$ & $\stackrel{\circ}{\mathbb{N}}$ & ণे & $\stackrel{-1}{\stackrel{\sim}{N}}$ \\
\hline 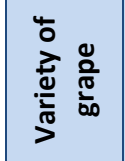 & 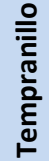 & 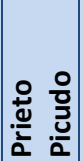 & $\frac{\frac{\pi}{4}}{\stackrel{\frac{C}{0}}{2}}$ & 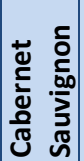 & 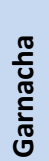 \\
\hline
\end{tabular}

8.2.3.2- Array of biosensors formed by CPE electrodes modified with phthalocyanines and tyrosinase (MPC-Tyr-CPE)

Five CPE sensors modified with phthalocyanines were prepared as described in the previous paragraph. The enzyme, tyrosinase (Tyr), was then immobilized on the surface of those electrodes using the drop casting technique followed by cross-linking. For this purpose $10 \mu \mathrm{L}$ of $0.01 \mathrm{~mol} \cdot \mathrm{L}^{-1}$ phosphate buffer ( $\mathrm{pH} 7.0$ ) containing $70 \mu \mathrm{g} \cdot \mathrm{mL}^{-1}$ of enzyme, were deposited onto the electrode surface. After drying at room temperature for 45 minutes, the biosensors were placed in a saturated glutaraldehyde vapor for 30 minutes and dried in air for 15 minutes at room temperature. The biosensors were then rinsed with phosphate buffer to remove any unbound enzyme and stored at $4^{\circ} \mathrm{C}$. Using this method, five biosensors were prepared (C-Tyr-CPE; CoPc-Tyr-CPE, CUPcTyr-CPE, ZnPc-Tyr-CPE and LuPc $2-T y r-C P E)^{30}$. 
8.2.3.3- Array of biosensors formed by CPE electrodes modified with phthalocyanines and glucose oxidase (MPC-GOX-CPE)

Five CPE sensors modified with phthalocyanines were prepared as described in previous paragraphs but in this case, $10 \mu \mathrm{L}$ of $0.01 \mathrm{~mol} \cdot \mathrm{L}^{-1}$ phosphate buffer $\left(\mathrm{pH} 7.0\right.$ ) containing $70 \mu \mathrm{g} \cdot \mathrm{mL}^{-1}$ of glucose oxidase (GOx), was immobilized on the surface of those electrodes using the drop casting technique followed by the cross-linking above described. Using this method, five biosensors were prepared (C-GOx-CPE; CoPcGOx-CPE, CuPc-GOx-CPE, ZnPc-GOx-CPE and $\mathrm{LuPc}_{2}-\mathrm{GOx}-\mathrm{CPE}$ ).

\subsubsection{4-Electrochemical measurements and data analysis}

Electrochemical experiments were performed using a three electrode system with $\mathrm{Ag} \mid \mathrm{AgCl} / 3 \mathrm{M}$ as reference electrode, $1 \mathrm{~cm}^{2}$ platinum plate as counter electrode and a sensor or a biosensor as working electrode (the sensors forming the array were polarized sequentially). The potentiostat used was an EG\&G PARC, Model 273 potentiostat/galvanostat (Princeton Applied Research Corp). Voltammograms were carried out at a scan rate of $0.1 \mathrm{~V} \cdot \mathrm{s}^{-1}$ and the working range was adapted to the nature of each class of electrodes. Seven repetitions per sample were measured. In order to reduce the high dimensionality of the recorded signals (samples $\times$ sensors $\times$ potentials), a pre-processing stage was required. For this, a feature extraction tool based on "bell-shapedwindowing" curves called "kernels" was used to compress the information from the original signals and to extract meaningful data from the readings $\mathrm{s}^{31,32}$. Then, the obtained coefficients (10 coefficients per curve) were used as the input variables for Principal Component Analysis (PCA) used for recognition of sample patterns and dis(similarities) between varieties of grapes.

\subsection{RESULTS AND DISCUSSION}

As stated in the introduction section, the quality of grapes is mainly related to their sugar concentration and their polyphenolic content. For this reason, an array of CPE sensors combined with two arrays of CPE biosensors purposely dedicated to detect the sugar and polyphenolic content of grapes has been developed. 
In a first step of this chapter, the response of the three arrays (MPc-CPE sensors, MPc-Tyr-CPE biosensors modified with tyrosinase and MPcGOx-CPE biosensors modified with glucose oxidase) were tested separately using two model solutions: $10^{-3} \mathrm{~mol} \cdot \mathrm{L}^{-1}$ glucose solution to evaluate the capability of the sensors to detect sugars and $10^{-3} \mathrm{~mol} \cdot \mathrm{L}^{-1}$ catechol solution to evaluate the capability to detect phenols. The responses of the three arrays versus catechol and glucose were also used to evaluate the electrocatalytic properties of the different phthalocyanines and their capabilities as electron mediators. Once characterized, the three arrays were exposed to musts prepared from grapes of different varieties. Finally, the three arrays were combined and the capability of the hybrid array formed by sensors and biosensors was evaluated.

\subsection{1- Response of the array of CPE sensors modified with phthalocyanines (MPc-CPE)}

The response of the bare C-CPE electrode towards $10^{-3} \mathrm{~mol} \cdot \mathrm{L}^{-1}$ catechol in buffer phosphate $(\mathrm{pH} 7.0)$ showed the expected anodic $(0.5 \mathrm{~V})$ and cathodic $(0.05 \mathrm{~V})$ waves associated with the oxidation of the 0 dihydroquinone to benzoquinone $\left(\Delta \mathrm{E}_{1 / 2}=0.45 \mathrm{~V}\right.$ ) (Figure 8.1). CoPc-CPE, CUPc-CPE and ZnPc-CPE showed a similar response than C-CPE however, the intensity of the redox peaks related to the phenol increased their intensity (from $4 \mu \mathrm{A}$ in C-CPE to ca. 13-15 $\mu \mathrm{A}$ in CoPc, CuPc and ZnPc). Notice that in the case of the CoPc-CPE electrode, a peak due to the oxidation of Co was also clearly observed at $0.2 \mathrm{~V}$. The most important electrocatalytic effect was observed when using the $\mathrm{LuPc}_{2}-\mathrm{CPE}$ sensor. The anodic peak produced by the oxidation of the phenol appeared shifted to lower potentials (observed at $0.4 \mathrm{~V}$ instead of $0.5 \mathrm{~V}$ ) and the cathodic wave was at $0.15 \mathrm{~V}(\Delta \mathrm{E}=0.25 \mathrm{~V})$. According to these results it can be confirmed that in the $\mathrm{LuPc}_{2}$-CPE sensor the overpotential is reduced and the reversibility is clearly improved. It is also important to remark that the redox activity of the $\mathrm{LuPc}_{2}$ associated with $\mathrm{LuPc}_{2} / \mathrm{LuPc}_{2}$ was observed at $-0.2 \mathrm{~V}$ (anodic) and $-0.4 \mathrm{~V}$ (cathodic). 

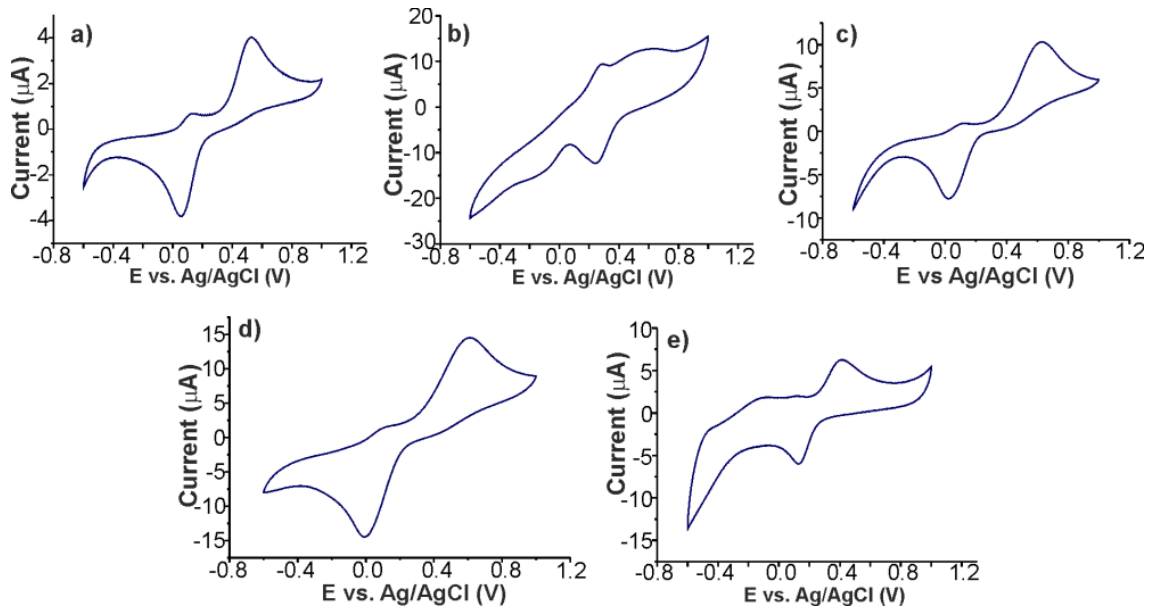

Figure 8.1. Response of CPE electrodes modified with phthalocyanines to $10^{-3} \mathrm{~mol} \cdot \mathrm{L}^{-1}$ catechol in buffer phosphate ( $\mathrm{pH} \mathrm{7.0)}$. a) bare C-CPE, b) CoPc-CPE, c) CuPc-CPE, d) $\mathrm{Zn}-\mathrm{CPE}$ and e) $\mathrm{LUPC}_{2}-\mathrm{CPE}$. Scan rate, $0.1 \mathrm{~V} \cdot \mathrm{s}^{-1}$.

CPE sensors modified with phthalocyanines were also used to detect glucose. It is well known that glucose is difficult to detect using noncatalytic electrodes, because the oxidation of glucose to gluconic acid requires large overpotentials ${ }^{33}$. This is the reason why the C-CPE electrode could not detect the presence of glucose and the voltammograms were characterized by a complete absence of peaks. When using CPE chemically modified with ZnPc-CPE or CUPC-CPE the response towards glucose was weak and only one small cathodic wave was observed at ca. - $0.5 \vee$ (Figure 8.2.a). In contrast, when electrodes chemically modified with CoPc-CPE and $\mathrm{LuPc}_{2}$-CPE were tested, a drastic increase in the cathodic response at $c a$. $-0.8 \mathrm{~V}$ was observed (from -10 $\mu \mathrm{A}$ in $\mathrm{C}-\mathrm{CPE}$ and $\mathrm{ZnPc}-\mathrm{CPE}$, to $-50,-55 \mu \mathrm{A}$ in CoPc-CPE and $\mathrm{LuPc}_{2}-\mathrm{CPE}$ ) (Figure 8.2.b). 

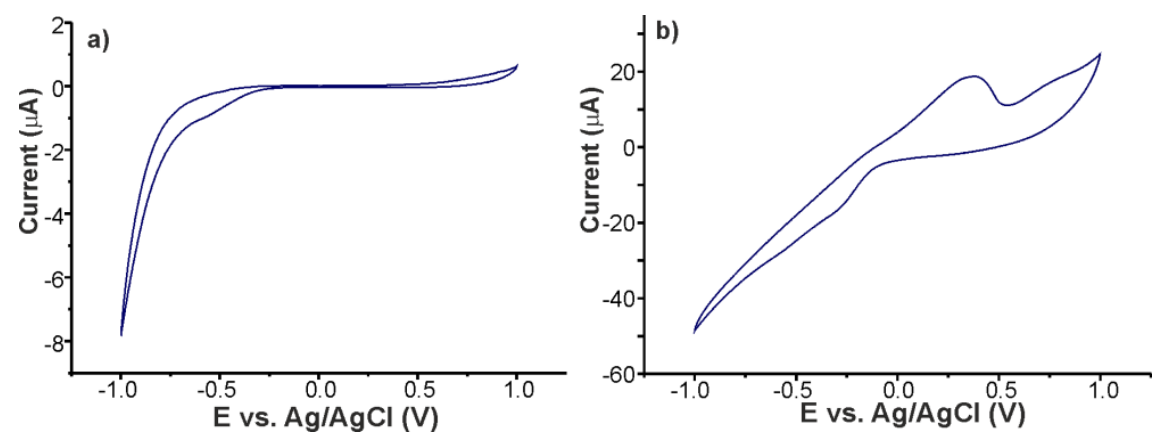

Figure 8.2. Response of CPE electrodes modified with phthalocyanines to $10^{-3}$ $\mathrm{mol} \cdot \mathrm{L}^{-1}$ glucose in buffer phosphate $(\mathrm{pH} \mathrm{7.0)}$ a) $\mathrm{ZnPc}-\mathrm{CPE}$ and b) CoPc-CPE. Scan rate, $0.1 \mathrm{~V} \cdot \mathrm{s}^{-1}$.

According to these results, it can be concluded that the chemical structure of the phthalocyanine plays a critical role in detection of catechol and glucose. It is particularly remarkable that CoPc and $\mathrm{LuPc}_{2}$ (which have redox reactivity in the working range) show enhanced electrocatalytic properties facilitating the electrochemical oxidation/reduction of both catechol and glucose.

Taking into account that grapes and musts obtained from the berries have a $\mathrm{pH}$ close to 3.5 , the response of the CPE sensors modified with phthalocyanines towards catechol and glucose was also tested at an acidic $\mathrm{pH}$ obtained from a buffer citrate $(\mathrm{pH} 3.1)$. The effect of the acidic $\mathrm{pH}$ is illustrated in Figure 8.3 where the responses of the $\mathrm{LuPc}_{2}-\mathrm{CPE}$ towards catechol and glucose at pH 7.0 and at pH 3.1 are shown.

It is well known that $\mathrm{pH}$ affects the electrochemical response of phenols and when decreasing the $\mathrm{pH}$, the oxidation of phenols occurs at higher potentials $^{34,35}$. This effect was also observed in our phthalocyaninebased electrodes (Figure 8.3.a). Moreover, at pH 3.1 the intensity of the voltammograms increased drastically. This increase in the sensitivity could be due to the protonation of the phthalocyanine molecule and can be a good advantage in the detection of phenols in musts. 
The effect of the $\mathrm{pH}$ in the detection of glucose was the opposite and the intensity of the peaks decreased at pH 3.1 (Figure 8.3.b). This result is in accordance with previously published results that conclude that gluconic acid in its free form reversibly inhibits the oxidation process in acidic media ${ }^{36}$. Nevertheless, the inhibition is only partial and the intensity of the signals is good enough for applications in the field of wines and musts.
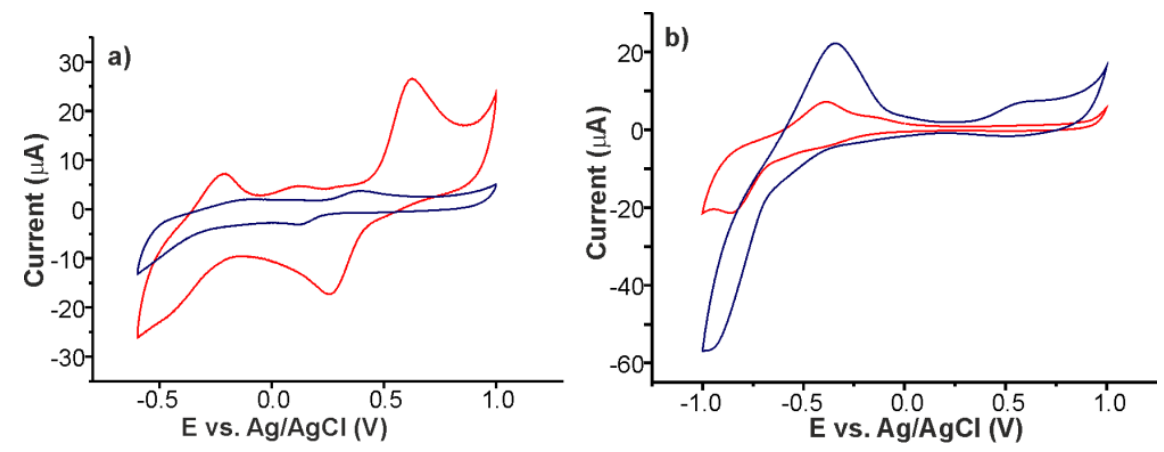

Figure 8.3. Cyclic voltammograms of $\mathrm{LuPC}_{2}$-CPE electrodes immersed in a) $10^{-3}$ $\mathrm{mol} \cdot \mathrm{L}^{-1}$ catechol and b) $10^{-3} \mathrm{~mol} \cdot \mathrm{L}^{-1}$ glucose. Blue lines correspond to measurements in buffer phosphate $(\mathrm{pH}$ 7.0) and red lines correspond to measurements registered in buffer citrate $(\mathrm{pH} 3.1)$. Scan rate, $0.1 \mathrm{~V} \cdot \mathrm{s}^{-1}$.

\subsection{2- Response of the array of biosensors formed by CPEs modified with phthalocyanines and tyrosinase (MPc-Tyr-CPE)}

In order to improve the selectivity of the electronic tongue towards polyphenols, an array formed by biosensors containing tyrosinase was prepared. Tyrosinase is involved in the oxidation of diphenols to the corresponding quinoid form. Then, the formed benzoquinone can be reduced electrochemically at the electrode surface. Phthalocyanines used as electron mediators can facilitate the transfer of electrons from the enzyme to the electrode, improving the performance of the biosensors $^{21,22,37}$.

The response of the array MPc-Tyr-CPE electrodes towards catechol is illustrated in Figure 8.4. The influence of the $\mathrm{pH}$ in the response is also illustrated in the figure. 
In all MPc-Tyr-CPE electrodes, voltamograms registered at $\mathrm{pH}$ 7.0, showed the electrochemical reduction of the previously formed benzoquinone in the $-0.4 \mathrm{~V}$ region (Figure 8.4.a). The reduction of the quinone to the phenolic form, shifted to lower potentials in the presence of phthalocyanines (results not shown). It is particularly remarkable the shift observed in CoPc-Tyr-CPE and $\mathrm{LuPC}_{2}$-Tyr-CPE where this process occured at $c a .0 .0 \mathrm{~V}$. The electrochemical behavior of these two electrodes was also different from the rest, because redox processes of the phthalocyanines which occur in the working range $\left(\mathrm{Co}^{\prime} / \mathrm{Co}^{\prime \prime}\right.$ and $\left.\mathrm{LuPc}_{2}{ }^{-} / \mathrm{LuPc}_{2}\right)$ can facilitate the electron transfer to the electrode.

The $\mathrm{pH}$ of a solution has several effects on the structure and activity of enzymes. The optimal $\mathrm{pH}$ for tyrosinase is about $6-7^{37}$. The acidic $\mathrm{pH}$ of grapes and musts (close to 3.5 ) could inhibit the enzymatic activity. In Figure 8.4.a and 8.4.b the voltammograms of the C-Tyr-CPE biosensor towards catechol dissolved in buffer phosphate $(\mathrm{pH} 7.0)$ and in buffer citrate $(\mathrm{pH}$ 3.1) are compared. The enzymatic reduction of the benzoquinone shifted from $-0.35 \mathrm{~V}$ at $\mathrm{pH} 7$ to $+0.17 \mathrm{~V}$ at $\mathrm{pH} 3.1$ while the intensity of the signal decreased. The most remarkable difference is that at $\mathrm{pH} 3.1$, a new peak was observed at $c a .0 .8 \mathrm{~V}$. The acidity dissociation constants (pKa) for catechol are both above $\mathrm{pH} \mathrm{7,} \mathrm{but} \mathrm{the} \mathrm{pKa} \mathrm{for} \mathrm{the}$ catechol radical is close to $4^{38}$. Thus, the $\mathrm{pH}$ can affect the dissociation state and hence the electroxidation/reduction mechanism of the catechol, facilitating the electrochemical oxidation at $0.8 \mathrm{~V}$.

As shown in Figure 8.4.c-f, similar trends were observed in all the MPcTyr-CPE sensors immersed in catechol solved in citric acid (pH 3.1). 

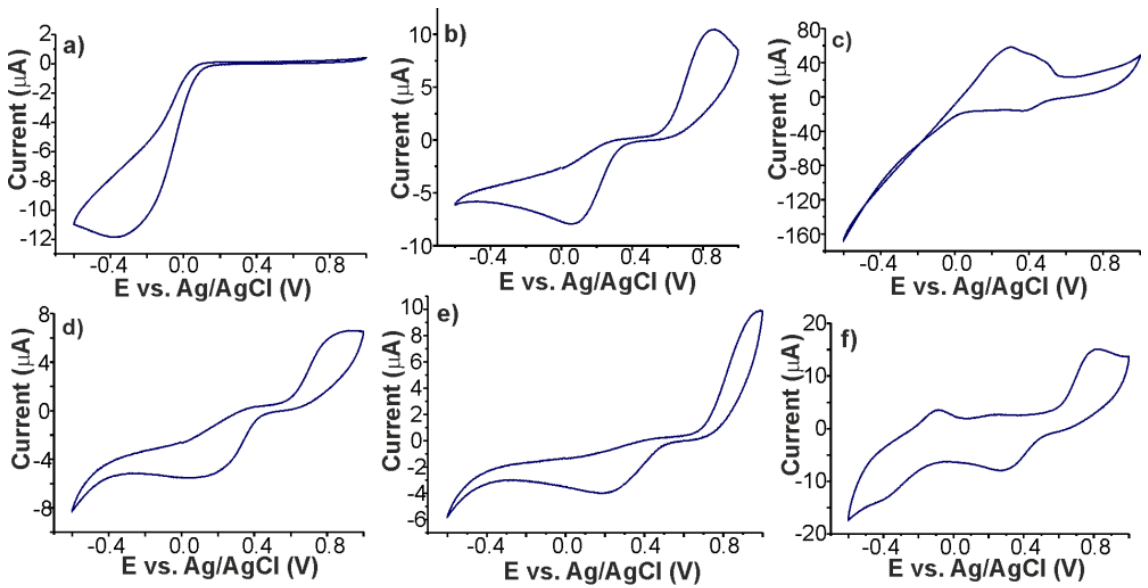

Figure 8.4. Response of CPE electrodes modified with phthalocyanines and tyrosinase towards $10^{-3} \mathrm{~mol} \cdot \mathrm{L}^{-1}$ catechol. a) C-Tyr-CPE in buffer phosphate $(\mathrm{pH}$ 7.0), b) C-Tyr-CPE in buffer citrate (pH 3.1), c) CoPc-Tyr-CPE in buffer citrate (pH 3.1), d) CuPc-Tyr-CPE in buffer citrate (pH 3.1), e) ZnPc-Tyr-CPE in buffer citrate $(\mathrm{pH} 3.1)$ and f) $\mathrm{LuPC}_{2}-\mathrm{Ty}$-CPE in buffer citrate $(\mathrm{pH} 3.1)$. Scan rate, $0.1 \mathrm{~V} \cdot \mathrm{s}^{-1}$.

8.3.3- Response of the array of biosensors formed by CPEs modified with phthalocyanines and glucose oxidase (MPc-GOxCPE)

With the aim of increasing the selectivity towards glucose, a third array formed by biosensors containing glucose oxidase was prepared. In electrochemical biosensors based on the glucose oxidase, the enzymatic oxidation of glucose produces gluconic acid and hydrogen peroxide with consumption of oxygen ${ }^{39}$. The reduced glucose oxidase is not able to transfer electrons to conventional electrodes because the distance between its redox centers and the electrode surface exceeds the distance across which electrons are transferred at sufficient rates. Therefore, electrical communication between the redox centers of this enzyme and electrodes require the presence of electron mediators. A suitable mediator for the GOx enzyme must have a more positive redox potential than the redox potential of the coenzyme FAD (ca. $-0.4 \mathrm{~V}$ versus $\mathrm{Ag} / \mathrm{AgCl})^{40}$. It has been reported that some phthalocyanines such as CoPc can act as electron mediators of the GOx enzyme ${ }^{41}$. In this work, 
the electron mediator properties of $\mathrm{CoPc}, \mathrm{CuPc}, \mathrm{ZnPc}$ and $\mathrm{LuPc}_{2}$ have been analyzed and compared.

At pH 7.0 (buffer phosphate), the presence of phthalocyanines increased the intensity of the response towards glucose with respect to the signal obtained using an electron mediator free electrode. This is illustrated in Figure 8.5.a where the responses of the phthalocyanine-free C-GOx-CPE electrode and CuPc-GOx-CPE and ZnPc-GOx-CPE electrodes are compared. However, as shown in Figure 8.5.b, the difference between the response of an electrode modified with both phthalocyanine and GOx and one electrode modified only with a phthalocyanine is not so dramatic.
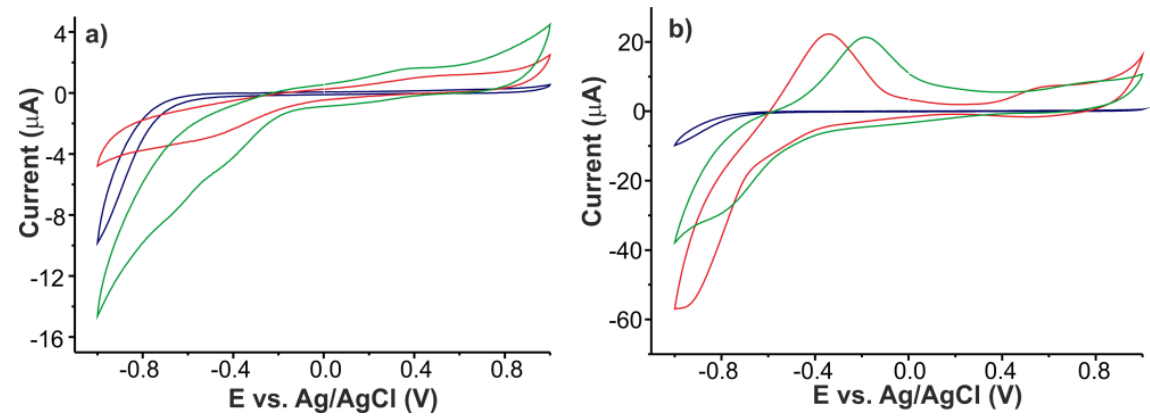

Figure 8.5. a) Voltammetric response of CPE electrodes modified with phthalocyanines and glucose oxidase towards glucose $10^{-3} \mathrm{~mol} \cdot \mathrm{L}^{-1}$ in buffer phosphate ( $\mathrm{pH} 7.0$ ), C-GOx-CPE (blue line), CuPc-GOx-CPE (red line) and ZnPcGOx-CPE (green line). b) Cyclic voltammograms of C-GOx-CPE (blue line), $\mathrm{LuPC}_{2}-$ $\mathrm{CPE}$ (red line) and $\mathrm{LuPC}_{2}-\mathrm{GOX}-\mathrm{CPE}$ (green line) immersed in glucose $10^{-3} \mathrm{~mol} \cdot \mathrm{L}^{-1}$ in buffer phosphate $(\mathrm{pH} 7.0)$. Scan rate, $0.1 \mathrm{~V} \cdot \mathrm{s}^{-1}$.

On the other hand, the optimal pH for glucose oxidase is 5.5 with broad range $4-7$. Surprisingly, the voltammograms registered in buffer citrate at $\mathrm{pH} 3.1$ (closest to the $\mathrm{pH}$ found in wines and musts) showed a clear increase in the intensity of the responses, that was particularly noticeable for the $\mathrm{LuPc}_{2}-\mathrm{GOX}$-CPE (Figure 8.6). This enhancement can be the result of the protonation of the phthalocyanine ring that modifies 
the electrochemical properties of the phthalocyanines ${ }^{13,29}$ improving their electron mediator activity.

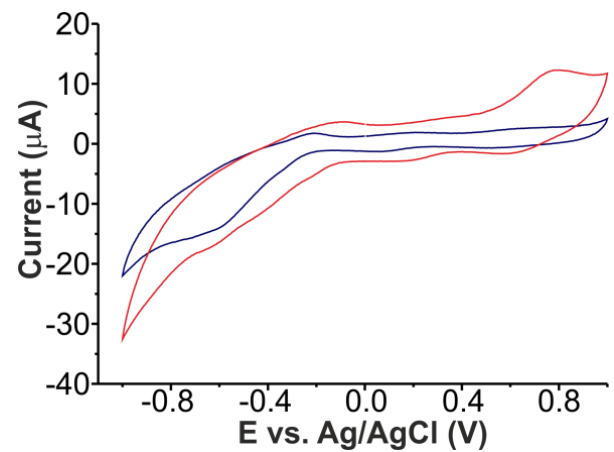

Figure 8.6. Response of $\mathrm{LuPc}_{2}-\mathrm{CPE}$ (blue line) and $\mathrm{LuPc}_{2}-\mathrm{GOx}-\mathrm{CPE}$ (red line) to $10^{-3} \mathrm{~mol} \cdot \mathrm{L}^{-1}$ glucose in buffer citrate $(\mathrm{pH} 3.1)$. Scan rate, $0.1 \mathrm{~V} \cdot \mathrm{s}^{-1}$.

\subsection{4- Response towards musts}

The sensors and biosensors described in the previous sections were exposed to musts prepared from grapes of different varieties. In order to decrease the complexity of the samples, musts were diluted $50 \%$ in water (Figure 8.7). Voltammograms were dominated by the redox response of the phenolic groups present in musts that appeared as anodic peaks in the 0.4-0.8 $\mathrm{V}$ region and the corresponding cathodic waves in the $0.35 \mathrm{~V}$ region. Obviously, in such a complex media, the peaks were broader than in the corresponding model solutions and a variety of other small and not well-defined peaks were observed. In all cases, a cathodic peak in the $-0.5 \mathrm{~V}$ region was also observed that could be associated with the glucose but also with the presence of protons.

The intensity and position of the peaks depended on the nature of the phthalocyanine used as modifier. As expected, in the case of sensors modified with CoPc and $\mathrm{LuPc}_{2}$ the peaks increased their intensity and shifted to lower potentials.

The presence of tyrosinase or glucose oxidase also introduced important modifications in the electrochemical responses. The intensities and 
positions of the peaks were related to the total polyphenols index and the content of glucose measured by chemical methods that in turn depend on the grape variety (Table 8.1).

In summary, each electrode provided a different response towards the same must sample and an important degree of cross-selectivity was attained.
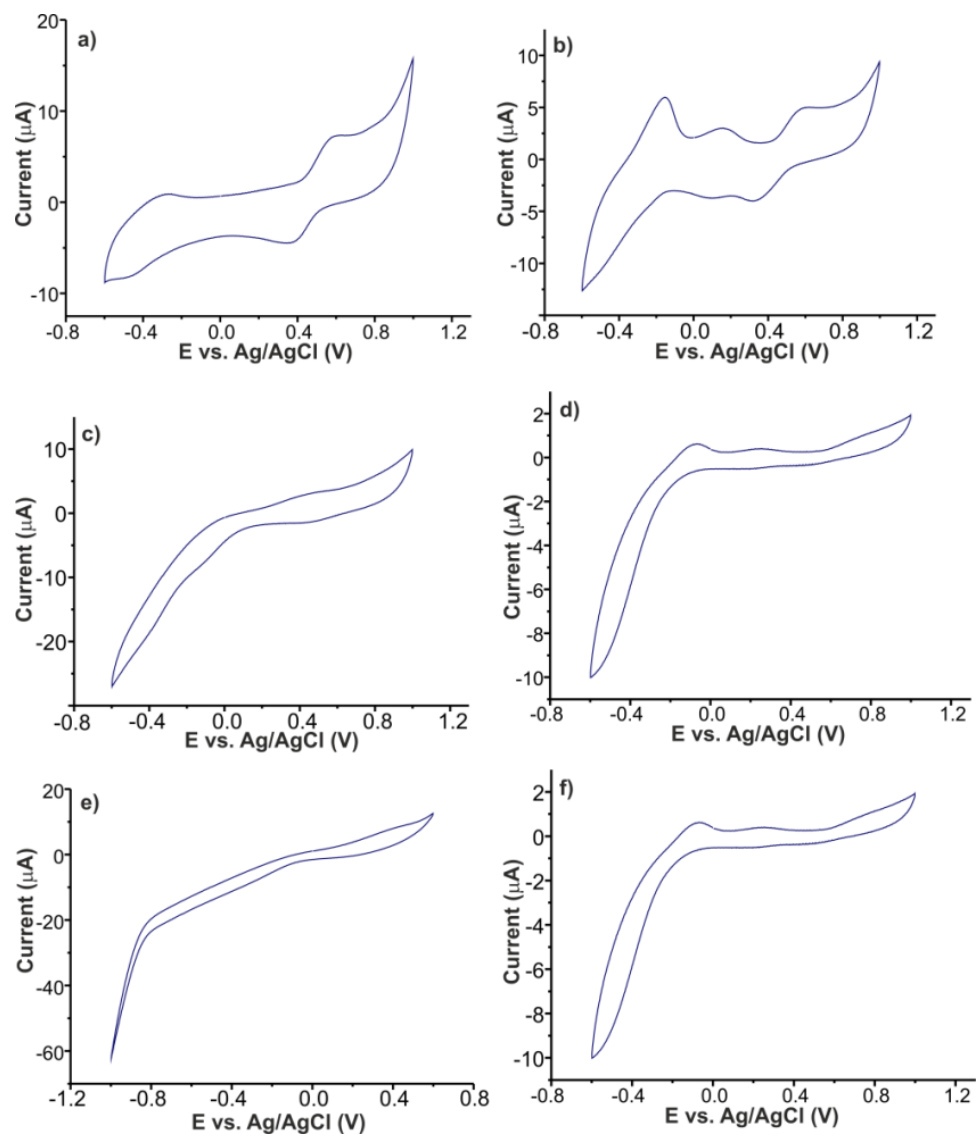

Figure 8.7. Response of CPE electrodes modified with phthalocyanines towards Garnacha must diluted $50 \%$ in water. a) CoPc-CPE, b) LuPc 2 -CPE, c) CoPc-TyrCPE, d) $\mathrm{LuPC}_{2}-\mathrm{Tyr}-\mathrm{CPE}$, e) CoPc-GOx-CPE and f) $\mathrm{LuPC}_{2}-\mathrm{GOx}-\mathrm{CPE}$. Scan rate, 0.1 $\mathrm{V} \cdot \mathrm{s}^{-1}$. 


\subsection{5- Data treatment}

As demonstrated in the above sections, the CPE sensors and biosensors showed complex voltammograms which contain information about the musts. For this reason, voltammograms can be used to discriminate must samples using Principal Component Analysis (PCA $)^{15,29,43}$.

In order to evaluate the capability of the three arrays to discriminate the variety of grapes, they were immersed in each must and 7 replicas of each sample were registered. Then, voltammograms were pre-treated to decrease the number of variables used in the PCA calculations by means of the kernel method. The 10 values obtained from each voltammogram were scaled between the maximum and minimum values to discard range current effects and standardized (i.e. mean value $=0$, standard deviation $=1$ ) to build the matrix used for the pattern recognition techniques.

The three arrays were able to discriminate the five musts. This is illustrated in Figure 8.8 where PCA scores plot and loadings plot corresponding to the musts analyzed with the array of MPc-Tyr-CPE is shown. As observed in the scores plot (Figure 8.8.a), the percentage of variance explained using two principal components was $97.28 \%$, that is, almost the total information of the model was contained in two principal components. The array discriminated the musts according to their polyphenol content. For this reason Tempranillo must which has the highest TPI (see Table 8.1) appears on the right side of the graph, in the positive PC1, far apart from the rest of the musts, whereas, Mencia must that presents the lowest TPI content, appears at negative PC1 on the left side of the diagram. Prieto Picudo, Garnacha and Cabernet-Sauvignon musts, appeared close one to each other because they have a similar polyphenolic content (TPI=15). As observed in Figure 8.8.b where the loading plot is presented, the loadings provided by each sensor (ten kernels per sensor) appear in different regions of the loading plots confirming that the central metal ion coordinated to the phthalocyanine ring plays an important role in the selectivity of the sensors. This result demonstrates that sensors based on different phthalocyanines provide 
complementary information and show an important degree of cross selectivity. Similar results were obtained when using the array of MPcGOx-CPE biosensors where the array discriminates according to the sugar content.

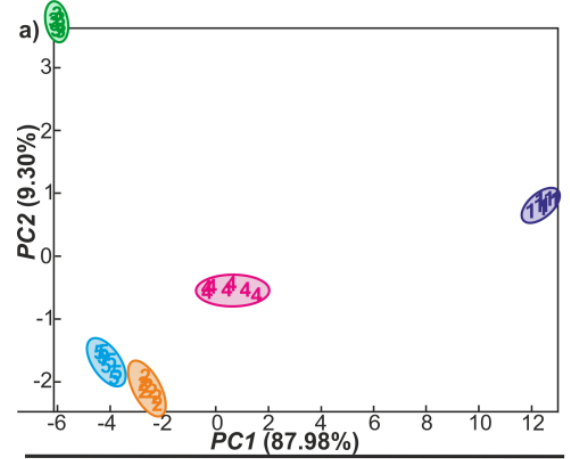

RESULT1,X-expl:87.98\%,9.30\%

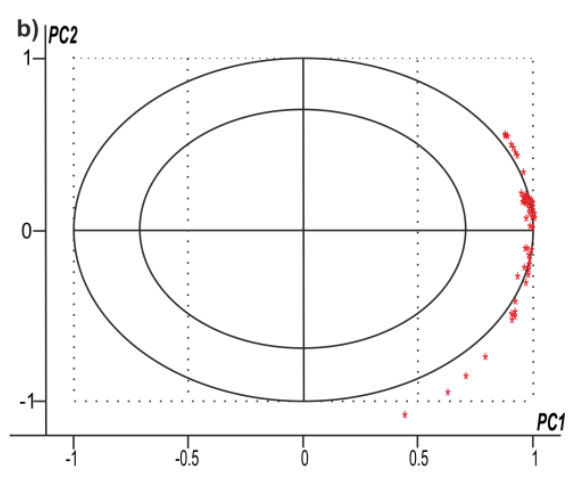

Figure 8.8. a) PCA scores plot corresponding to the classification of the musts. Analysis performed using the CPE modified with phthalocyanines and tyrosinase. 1-Tempranillo, 2-Prieto Picudo, 3-Mencía, 4-Cabernet-Sauvignon and 5-Garnacha. b) Loading plot of the PCA (ten variables were extracted per sensor using the kernel method).

Finally, the three arrays of MPc-CPE, MPc-Tyr-CPE and MPc-GOx-CPE were combined in a single multisensory system and the PCA was performed. The results are shown in Figure 8.9 where the PCA scores plot and loading plot are presented. In this case, due to the increase in the number of sensors (and variables) the three principal components bring a noticeable amount of information. The first principal component (PC1) explains the $54.16 \%$ of the information, the second principal component (PC2) the $25.92 \%$ and the third one (PC3) the $9.46 \%$.

As observed in the figure, when using the complete set of sensors a better discrimination is achieved and all the musts appear well separated. The combined array containing non specific MPc-CPE sensors with biosensors sensitive to polyphenols (MPc-Tyr-CPE) and glucose (MPc-GOx-CPE) provided a specific signature for each must that allowed discriminating the samples according to the variety of grape. It is also 
remarkable that sensors forming the array had an excellent complementarity as observed in the loading plot (Figure 8.9.b).

Although the system provides global information about the sample, it is important to notice that some correlations with the composition can be found in the PCA. For instance, the must prepared from grapes of Tempranillo variety appears on the left and up side of the graph, well apart from the rest of the musts. This result is in good accordance with the results obtained by means of chemical analysis shown in Table 8.1, where it can be observed that the grapes of the variety Tempranillo have a TPI and a glucose content (and a Brix degree) clearly higher than the levels observed in the other musts. Musts prepared from Mencia, Prieto Picudo and Cabernet appear in the bottom part of the graph, indicating that their TPI and Brix degree is lower. As the quality of the grapes (and of the corresponding musts) depends on the TPI and the sugar content, this result indicates that our bioelectronic tongue could be an interesting instrument to evaluate the quality of berries.
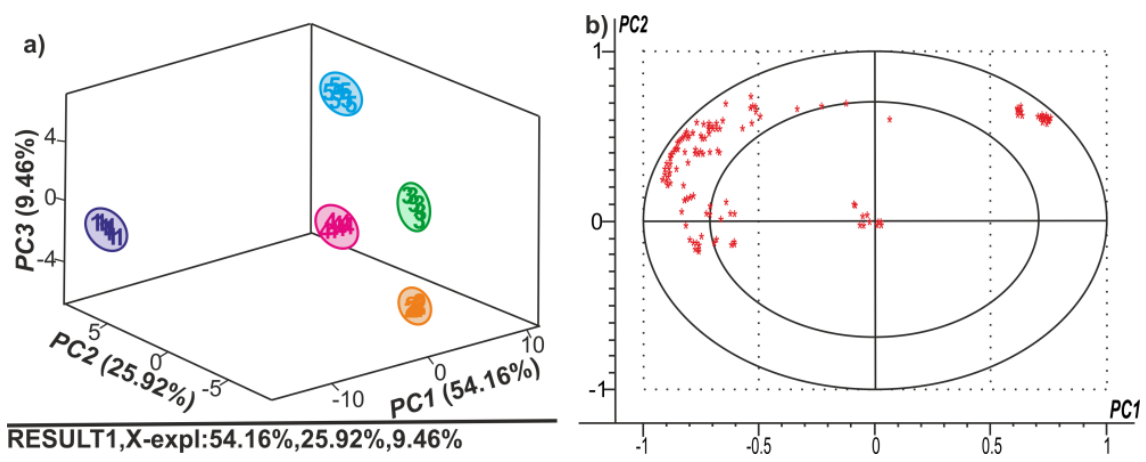

Figure 8.9. a) PCA scores plot and b) loading plots (ten variables were extracted per sensor using the kernel method) corresponding to the classification of the musts. Analysis performed using the array formed by the CPE modified with phthalocyanines, CPE modified with phthalocyanines and tyrosinase and CPE modified with phthalocyanines and glucose. 1-Tempranillo, 2-Prieto Picudo, 3Mencía, 4-Cabernet-Sauvignon and 5-Garnacha. 


\subsection{CONCLUSIONS}

An electronic tongue based on voltammetric sensors and biosensors containing phthalocyanines has been developed and used to discriminate musts prepared from different varieties of grapes.

The important degree of cross-selectivity of the MPc-CPE array towards catechol and glucose was related to the electrocatalytic properties of the phthalocyanines used. It was demonstrated that the electrocatalytic effect of CoPc and $\mathrm{LuPc}_{2}$ towards catechol and glucose was superior to the observed in $\mathrm{ZnPc}$ and CuPc. In addition, the performance of the arrays of biosensors modified with tyrosinase and glucose oxidase (MPcTyr-CPE and MPc-GOx-CPE) was also improved in the presence of phthalocyanines as electron mediators.

The electrochemical responses towards musts were associated with the content of polyphenols and glucose of the samples. A multivariate data treatment was carried out to explore the capability of discrimination of the array. PCA showed a good discrimination according to the composition of the musts in terms of polyphenolic content and sugar concentration. The capability of discrimination of the system was improved by combining the MPc-CPE sensors, the MPc-Tyr-CPE and MPc-GOx-CPE biosensors to form an array of sensors with high crossselectivity. These results confirm the possibility of using this new array of sensors to study the quality of grapes.

In summary, this multisensor system containing sensors and biosensors could give the classical global information about the characteristics of the samples plus complementary information about sugars or polyphenolic content that could help to decide important issues such as the retail price (marked by the quality) or the appropriate harvesting date. 


\section{References}

1. Winquist, F. Microchim. Acta. 2008, 163, 3-10.

2. Riul, A.Jr., Dantas, C.A.R., Miyazaki, C.M., Oliveira, O.N.Jr. Analyst. 2010, 135, 2481-2495.

3. Del Valle, M. Electroanal. 2010, 22, 1539-1555.

4. Rodríguez-Méndez, M.L., Parra, V., Apetrei, C., Villanueva, S., Gay, M., Prieto, N., Martínez, J., de Saja, J.A. Microchim. Acta. 2008, 163, 23-31.

5. Vlasov, Y., Legin, A., Rudnitskaya, A., Di Natale, C. D'Amico, A. Pure Appl. Chem. 2005, 77, 1965-1983.

6. Cetó, X., Gutiérrez, J.M., Moreno-Barón, L., Alegret, S. del Valle, M. Electroanal. 2011, 23, 72-78.

7. Gay, M., Apetrei, C., Nevares, I., del Alamo, M., Zurro, J., Prieto, N., de Saja, J.A., Rodriguez-Mendez, M.L. Electrochim. Acta. 2010, 55, 67826788.

8. Rudnitskaya, A., Rocha, S.M., Legin, A., Pereira, V., Marques, J.C. Anal. Chim. Acta. 2010, 662, 82-89.

9. Moreno i Codinachs, L., Kloock, J.P., Schöning, M.J., Baldi, A., Ipatov, A., Bratov, A. Jimenez-Jorquera, C. Analyst. 2008, 133, 1440-1448.

10. Ciosek, P., Wróblewski, W. Sensors. 2011, 11, 4688-4701.

11. Furini, L.N., Feitosa, E., Alessio, P., Shimabukuro, M.H., Riul, A.Jr., Constantino, C.J.L. Mater. Sci. Eng., C. 2013, 33, 2937-2946.

12.Winquist, F., Olsson, J., Eriksson, M. Anal. Chim. Acta. 2011, 683, 192197.

13. Apetrei, C., Nieto, M., Rodriguez-Mendez, M.L., de Saja, J.A. J. Porphyrins Phthalocyanines. 2011, 15, 1-10. 
14. Apetrei, I.M., Rodriguez-Mendez, M.L., Apetrei, C., Nevares, I., del Alamo, M., de Saja, J.A. Food Res. Int. 2012, 45, 244-249.

15. Apetrei, C., Apetrei, I., Nevares, I., del Alamo, M., Parra, V., Rodriguez-Mendez, M.L., de Saja, J.A. Electrochim. Acta. 2007, 52, 25882594.

16. Zagal, J.H., Griveau, S., Silva, J.F., Nyokong, T., Bediou, F. Coordin. Chem. Rev. 2010, 254, 2755-2791.

17. Gay, M., Rodriguez-Mendez, M.L., de Saja, J.A. Langmuir. 2010, 26, 19217-19224.

18. Rodriguez-Mendez, M.L., Gay, M. de Saja, J.A. J. Porphyrins Phthalocyanines. 2009, 13, 1159-1167.

19. Zagal, J.H., Griveau S, Santander-Nelli M and Bedioui F. J. Porphyrins Phthalocyanines. 2012, 16, 713-740.

20. Selektor, S.L., Shokurov, A.V., Raitman, O.A., Sheinina, L.S., Arslanov, V.V., Birin, K.P., Gorbunova, Y.G., Tsivadze, A.Y. Colloid J. 2012, 74, 334345.

21. Apetrei, C., Alessio, P., Constantino, C.J.L., de Saja, J.A., RodriguezMendez, M.L., Pavinatto, F.J., Fernandes, E.G., Zucolotto, V., Oliveira, O.N.Jr. Biosens. Bioelectron. 2011, 26, 2513-2519.

22. Pavinatto, F.J., Fernandes, E.G.R., Alesio, P., Constantino, C.J.L., de Saja, J.A., Zucolotto, V., Apetrei, C., Oliveira, O.N.Jr., Rodriguez-Mendez, M.L. J. Mater. Chem. 2011, 21, 4995-5003.

23. Riberéau-Gayon, P., Glories, Y., Maujean, A., Dubordieu, D. Compuestos fenólicos. Tratado de enología. Química del vino, estabilización y tratamientos. Vol 2, 1999. Ed. Mundi-prensa. Madrid (Spain)

24. Revilla, E., Alonso, E., Kovac, V. Wine: Nutritional and Therapeutic Benefits. The content of catechin and procyanidins in grapes and wines 
as affected by agroecological factors and technological practices. 1997, Ed. American Chemical Society. Washington DC (USA)

25. Boulton, R. Am. J. Enol. Vitic. 2001, 52, 67-87.

26. Glories, Y. Caracterisatión du potentiel phenolique : adaptation de la vinification. Progrès Agricole et Viticole. Vol.118. 2001, 347-350.

27. Compendium of International Methods of Analysis of Wines and Musts. Vol. 2. OIV, 2013. Paris (France).

28. Linaje, M., Quintanilla, M.C., Gonzalez, A., del Valle, J.L., Alcaide, G. Rodriguez-Mendez, M.L. Analyst. 2000, 125, 341-346.

29. Rodriguez-Mendez, M.L., Gay, M., Apetrei, C., de Saja, J.A. Electrochim. Acta. 2009, 54, 7033-7041.

30. Li, Y.G., Zhou, Y.X., Feng, J.L., Jiang, Z.H., Ma, L.R. Anal.Chim.Acta. 1999, 382, 277-282.

31. Cetó, X., Céspedes, F., del Valle, M. Microchim. Acta. 2013, 180, 319330.

32. Parra, V., Hernando, T., Rodriguez-Mendez, M.L., de Saja, J.A. Electrochim. Acta. 2004, 49, 5177-5185.

33. Park, S., Boo, H., Chung, T.D. Anal. Chim. Acta. 2006, 556, 46-57.

34. Martinez, S., Valek, L., Petrovic, Z., Metikos-Hukovic, M., Piljac, J. J. Electroanal. Chem. 2005, 548, 92-99.

35. Kilmartin, P.A., Zou, H., Waterhouse, A.L. Am. J. Enology and Viticulture. 2002, 53, 294-302.

36. Abbadi, A., Makkee, M., Visscher, W., van Veen, J.A.R., van Bekkum H. J. Carbohyd. Chem. 1993, 12, 573-587.

37. Yin, H.S., Zhou, Y.L., Ai, S.Y. J. Electroanal. Chem. 2009, 626, 80-88. 
38. Chang, T.S. Int. J. of Mol. Sci. 2009, 10, 2440-2475.

39. Scheweigert, N., Zehnder, A.J.B., Rik, I.L. Environ. Microbiol. 2001, 3, 81-91.

40. Degani, Y., Heller, A. J. Phys. Chem. 1987, 91, 1285-1289.

41. Harper, A., Anderson, M.R. Sensors. 2010, 10, 8248-8274.

42. Wang K, Xu JJ and Chen HY, Biosens. Bioelectron. 2005, 20, 13881396.

43. Apetri, C., Rodriguez-Mendez, M.L., de Saja, J.A. Electrochim.Acta. 2008, 53, 5867-5872. 



\section{CHAPTER 9}

The Advantages of Disposable Screen-Printed Biosensors in a Bioelectronic Tongue for the Analysis of Grapes 

Despite the good results obtained with the previous sensors either nanostructured or CPE, the use of liquid electrochemical cells and heavy potentiostast restrict their use to the laboratory. It would be desirable to develop a portable multisensor system using disposable electrodes that could be used in the vineyard.

Screen Printed Electrodes (SPE) are a good option for this kind of system as they are low cost, disposable and portable. They include the reference electrode, the counter electrode and the working electrodes according to the design needed on the same device. The working electrode can be made of a wide variety of materials including glassy carbon, platinum, gold and nanoparticles. In addition, they can be easily modify by means of casting technique and allow user to work with a small amount of sample.

The aim of this chapter was to develop a bioelectronic tongue, based on an array of disposable SPEs dedicated to the analysis of grapes. For this purpose, six SPE sensors made with different materials (M-SPE) have been selected, including three classical electrode materials: graphite (CSPE), platinum (Pt-SPE) and gold (Au-SPE), two nanostructured electrocatalytic materials: graphene (GPH-SPE) and nickel oxide nanoparticles (NiONP-SPE) and material with well-known electron mediator properties: Prussian Blue (PB-SPE). Then, glucose oxidase (GOx) or Tyrosinase (Tyr) have been immobilized on the surface of the M-SPE electrodes to obtain M-GOx-SPE and M-Tyr-SPE biosensors that could provide information about the glucose and phenol content respectively. The discriminatory capability of the sensor array will be investigated using Principal Component Analysis (PCA). This research has been published in LWT-Food Science and Technology.

\subsection{INTRODUCTION}

The use of accurate techniques for the analysis of grapes is an important need in the wine sector. As stated in previous chapters, glucose and polyphenols are among the analytes that need to be monitored and measured in order to guarantee the maturity of the grapes and the quality of the final product. In the laboratory, the 
assessment of grape maturity is performed by analyzing representative samples by standard analytical techniques such as spectroscopy, chromatography (to measure phenols) or refractometry (to measure the sugar content in ${ }^{\circ}$ Brix $)^{1}$. In the last few years, a variety of sensors dedicated to the grape analysis have been developed. Most of them are fiber-optic fluorescence sensors that measure the levels of anthocyanins and chlorophy $\mathrm{I}^{2}$, or near-infrared optical sensors that can assess the sugar content $\left({ }^{\circ} \mathrm{Brix}\right)^{3}$. Electrochemical glucose and polyphenol biosensors are a powerful alternative for monitoring such compounds due to their specificity, high sensitivity and short response time ${ }^{4-6}$.

Typical enzymatic electrodes, based on glucose oxidase (or tyrosinase), undergo several electrochemical steps which produce a measurable current that is linearly related to the glucose (or polyphenol) content. In order to improve the electron transfer, electron mediators must be included in the sensor ${ }^{4,6-8}$. Nanotechnology has opened up new opportunities to obtain more efficient electron mediators, such as metal nanoparticles or nanocarbons (e.g. carbon nanotubes or graphene) $)^{5,9}$.

The analysis of complex mixtures such as wines or musts will be improved by using the so-called electronic tongues (ET), a new class of instruments that provide global information about the sample, instead of information about specific compounds. There have been a range of portable electronic tongues which have been produced based on a numerous core sensing technologies including mass, optic, electrical or electrochemical transduction ${ }^{10-16}$. Arrays of electrochemical sensors have been successfully used to discriminate between wines with different organoleptic characteristics ${ }^{17-25}$ or grapes with different qualities ${ }^{26,27}$. It has also been established that arrays combining sensors and biosensors can be advantageous, as they bring together both the benefits of classical arrays of electrochemical sensors (which provide global information about the sample) with the specificity of the enzymesubstrate reaction typical of biosensors ${ }^{27-29}$

In spite of the good results obtained with electronic and bioelectronic tongues, the use of liquid electrochemical cells and heavy potentiostats, 
the high cost of the sensors and the need for periodic calibration restrict their use to the laboratory. It would be desirable to develop multisensor systems using disposable electrodes that could be used in the vineyard block.

During recent years, the screen-printing (thick film) technology, applied to sensor and biosensor construction, has been considerably improved. Screen-printed electrodes (SPEs) are in fact simple to prepare, rapid and versatile, and this technology also appears to be the most economical. Their low cost makes possible to use them as disposable electrodes. SPE containing a serigraphied pseudo-reference $\mathrm{Ag} / \mathrm{AgCl}$ electrode, a counter electrode and a working electrode in the same device, can be prepared using a variety of modifiers that include metals, metal oxides, nanocarbons, nanoparticles, phthalocyanines, conducting polymers, or prussian blue among many others ${ }^{30}$. Moreover, enzymes can be immobilized on modified screen-printed electrodes to take advantage of the electron mediator properties of many of these materials for biosensing.

The aim of this chapter is to develop a bioelectronic tongue, based on an array of disposable screen-printed electrodes, dedicated to the analysis of grapes. For this purpose, six SPE sensors, modified with different materials (M-SPE) will be selected including three classical electrode materials: graphite (C-SPE), platinum (Pt-SPE) and gold (Au-SPE), two nanostructured electrocatalytic materials: graphene (GPH-SPE) and nickel oxide nanoparticles (NiONP-SPE) and materials with well-known electron mediator properties: Prussian Blue (PB-SPE). Then, glucose oxidase (GOx) or Tyrosinase (Tyr) will be immobilized on the surface of

\subsection{MATERIALS AND METHODS}

\subsection{1- Chemicals}

All chemicals and solvents were purchased from Sigma-Aldrich. Solvents were of reagent grade and used as supplied. Deionized water was obtained from a Millipore purifier, with a resistivity of $18.2 \mathrm{M} \Omega \cdot \mathrm{cm}$. 
Glucose oxidase (GOx), from Aspergillus Niger, type VII (activity plus $0.001 \mathrm{~kat} \cdot \mathrm{mg}^{-1}$ ), and Tyrosinase (Tyr) from Mushroom (activity of $6 \times 10^{-5}$ kat $\left.\cdot \mathrm{mg}^{-1}\right)$, were purchased from Sigma Chemical Co. (USA).

\subsection{2- Grape samples}

Samples of five varieties of red grapes (Tempranillo, Garnacha, Cabernet-Sauvignon, Prieto Picudo and Mencía) were harvested in September 2013. For each variety, berries were collected in the vineyards of 'Bodega Cooperativa de Cigales' and of 'Instituto Tecnologico Agrario de Castilla y León', both located in Valladolid area (Spain). To obtain the musts, 200 berries were crushed manually. For each variety of grapes, this process was carried out by septuplicate, giving a total of 35 samples. The musts were analyzed after separation from the seeds and the peel. The Oenological Center of Castilla y León carried out the chemical analysis of the grapes following international regulations ${ }^{31}$. Parameters analyzed included the chemical indicators of the sugar concentration ( ${ }^{\circ} \mathrm{Brix}$ ) and of the polyphenolic content (Total Polyphenol Index: TPI). Total acidity (expressed as $\mathrm{g} \cdot \mathrm{L}^{-1}$ of tartaric acid) and $\mathrm{pH}$ were also analyzed, due to the influence of the $\mathrm{pH}$ and the ionic strength in the enzymatic activity. The results are collected in Table 9.1. 
Table 9.1. Results of the chemical analysis of grapes carried out by traditional chemical methods (seven replicas).

\begin{tabular}{|l|c|c|r|r|}
\hline \multicolumn{1}{|c|}{ Grape Variety } & ${ }^{\circ}$ Brix & $\mathbf{p H}$ & $\begin{array}{c}\text { Total Acidity } \\
\left(\mathbf{g} \cdot \mathbf{L}^{-1} \text { ) }\right.\end{array}$ & $\begin{array}{c}\text { Total Polyphenol } \\
\text { Index }\end{array}$ \\
\hline Prieto Picudo & $23 \pm 2$ & $3.61 \pm 0.08$ & $4.8 \pm 0.2$ & $15 \pm 3$ \\
\hline Mencia & $21 \pm 2$ & $4.18 \pm 0.08$ & $4.3 \pm 0.2$ & $13 \pm 3$ \\
\hline Tempranillo & $24 \pm 2$ & $4.20 \pm 0.08$ & $4.1 \pm 0.2$ & $21 \pm 4$ \\
\hline Cabernet-Sauvignon & $23 \pm 2$ & $3.65 \pm 0.08$ & $4.1 \pm 0.2$ & $16 \pm 3$ \\
\hline Garnacha & $23 \pm 2$ & $3.39 \pm 0.08$ & $4.4 \pm 0.2$ & $15 \pm 3$ \\
\hline
\end{tabular}

\subsection{3- Screen-printed electrodes and biosensors}

Six screen-printed electrodes modified with different materials (M-SPE), purchased from Dropsens (www.dropsens.com) were used as substrates for the deposition of enzymes. Each sensor device contained a serigraphied pseudo-reference $\mathrm{Ag} / \mathrm{AgCl}$ electrode (RE), a counter electrode ( $\mathrm{C}$ or $\mathrm{Pt}$ ) (CE) and a working electrode. As observed in Table 9.2, the modifiers covering the working electrode of the M-SPE devices included carbon $(C)$, platinum $(P t)$, gold $(A u)$, graphene $(G P H)$, nickel oxide nanoparticles (NiONP) and Prussian blue (PB).

The six screen-printed electrodes were modified with GOx or Tyr using the drop casting technique followed by cross-linking. For this purpose, $10 \mu \mathrm{l}$ of a $70 \mu \mathrm{g} \cdot \mathrm{L}^{-1}$ solution of the corresponding enzyme in $0.01 \mathrm{~mol} \cdot \mathrm{L}^{-1}$ phosphate buffer ( $\mathrm{pH}$ 7.0) were placed onto the working electrode surface. After drying at room temperature for 30 minutes, cross linking was carried out by exposing the modified working electrode to glutaraldehyde vapors (20 g. $\mathrm{L}^{-1}$ water solution) for 20 minutes. Throughout the process, CE and RE were protected with a mask to avoid contamination by the enzyme or the glutaraldehyde. Using this method, six GOx-based (M-GOx-SPE) and six Tyr-based (M-Tyr-SPE) biosensors were prepared (Table 9.2). 
Table 9.2. List of the screen printed electrodes and acronyms used in this work.

\begin{tabular}{|c|c|c|c|c|c|c|}
\hline 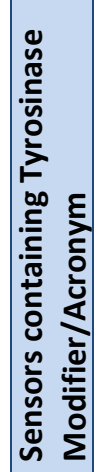 & 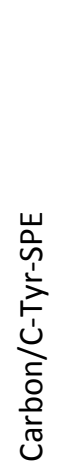 & 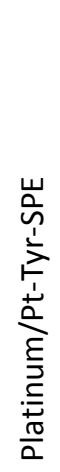 & 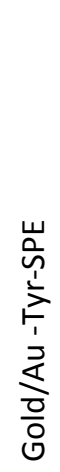 & 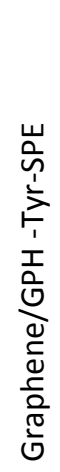 & 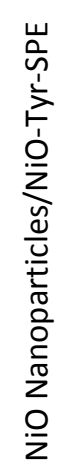 & 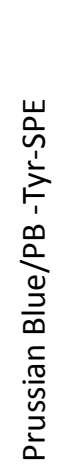 \\
\hline 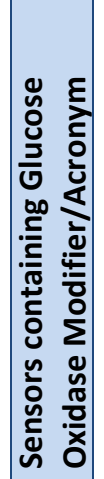 & 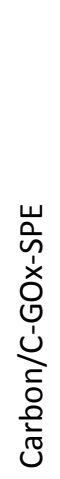 & 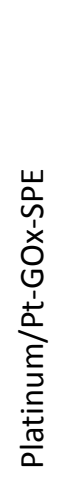 & 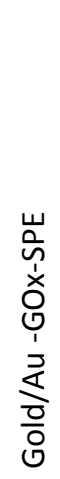 & 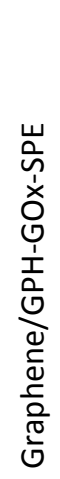 & 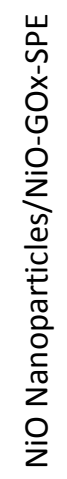 & 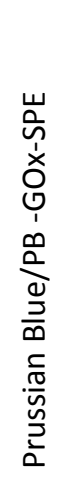 \\
\hline 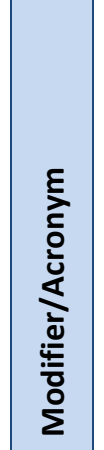 & 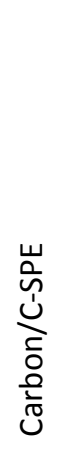 & 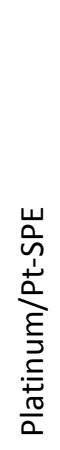 & $\begin{array}{l}\text { 山े } \\
\overline{1} \\
\frac{1}{\Delta} \\
\frac{1}{0} \\
\frac{0}{0} \\
0\end{array}$ & 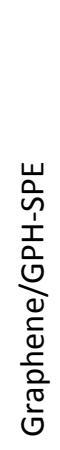 & 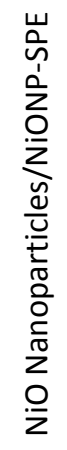 & 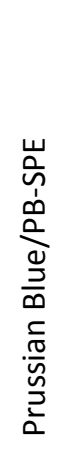 \\
\hline 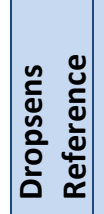 & 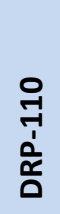 & 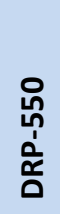 & 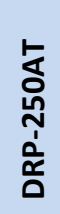 & 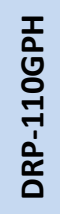 & 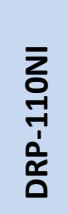 & 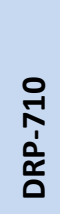 \\
\hline
\end{tabular}




\subsection{4- Electrochemical measurements}

Electrochemical measurements were carried out in a portable (weight under $1 \mathrm{~g}$ ) potentiostat SSTAT 400 (from Dropsens). Cyclic voltammograms were registered from $-0.6 \mathrm{~V}$ to $+1.0 \mathrm{~V}$ at a sweep rate of $0.05 \mathrm{~V} \cdot \mathrm{s}^{-1}$. The applied potential was measured versus the screenprinted internal silver pseudo-reference electrode. Sensors were immersed in the solution and polarized sequentially. The electrochemical experiments were performed at a controlled temperature of $21^{\circ} \mathrm{C}$. After each measurement, sensors were discarded and replaced by a new sensor and musts were measured randomly.

\subsection{5- Statistical analysis}

Curves were pre-processed through the adaptation to our case of a data reduction technique based on predefined response "bell-shapedwindowing" curves called "kernels" ${ }^{23}$. It is based on a compression method $^{32}$. The voltammogram curve is multiplied by 10 smooth bellshaped windowing functions defined as (Equation 9.1)

$$
K_{i}\left(V_{j}\right)=\frac{1}{1+\left(\frac{V_{j}-c_{i}}{a_{i}}\right)^{2 b_{i}}} \text { (Equation 9.1) }
$$

Where $a_{i}, b_{i}$ and $c_{i}$ define the width, the shape and the center of the different windowing functions $\mathrm{K}_{\mathrm{i}}$. Subsequently, data were integrated with respect to voltage. After compression, each voltammogram has been reduced to a vector of 10 variables.

Using this method, ten variables per curve were obtained which were used as the input data source for statistical analysis. In previous works, it has been demonstrated that this method provides similar results to other pre-treatment processes such as the wavelet transformation $(\mathrm{WT})^{18}$ or genetic algorithms ${ }^{33}$.

A non-supervised multivariate method, the Principal Component Analysis (PCA), was used to analyze the voltammetric curves and to evaluate the discrimination capability of the system. Partial Least 
Squares (PLS-1) regression models were built to predict the phenolic and the sugar content of the musts.

All computations and chemometric analysis were carried out using the software Matlab v5.3. (The Mathworks Inc., Natick, MA, USA) and Unscrambler (Camo).

\subsection{RESULTS AND DISCUSSION}

\subsection{1- Measurements in glucose and catechol}

As a preliminary experiment, the electrochemical response of screenprinted sensors immersed in $0.01 \mathrm{~mol} \cdot \mathrm{L}^{-1}$ phosphate buffer was analyzed. As expected, C-SPE, GPH-SPE and NiONP-SPE sensors did not show any redox peak within the studied range. Pt-SPE and Au-SPE showed the usual peaks related to the oxidation/reduction of water and those associated with the adsorption of oxidized species to the surface. Finally, PB-SPE showed the redox peaks of the hexacyanoferrate ion ${ }^{34}$.

The effect of the electrode modification with GOx on the oxidation of glucose at the SPE surface and the role of the six materials used as electron mediators was evaluated by performing voltammetric experiments. Figure 9.1 compares the cyclic voltammograms of the $\mathrm{M}$ SPE and M-GOX-SPE electrodes in the presence of $0.01 \mathrm{~mol} \cdot \mathrm{L}^{-1}$ glucose in phosphate buffer.

The responses of C-SPE, Pt-SPE and Au-SPE were similar to those of the electrodes modified with the enzyme (C-GOx-SPE, Pt-GOx-SPE and AuGOx-SPE). The only noticeable differences were small increases in the background currents in M-GOx-SPE and a slight increase in the current intensity at potentials related to the electrochemical reactivity of $\mathrm{H}_{2} \mathrm{O}_{2}$ (at $-0.4 \mathrm{~V}$ and lower). The curves obtained with GPH-GOX-SPE, NiONPGOx-SPE and PB-GOx-SPE showed a clear increase in the current intensities of the whole curves, demonstrating that graphene, nickel oxide nanoparticles and Prussian blue were excellent electron mediators. It is important to remark that Prussian blue was particularly effective in enhancing the sensitivity towards glucose. The good electro- 
catalytic activity of such modifiers was in good agreement with results described in the literature using other types of electrodes ${ }^{9,34,35}$.
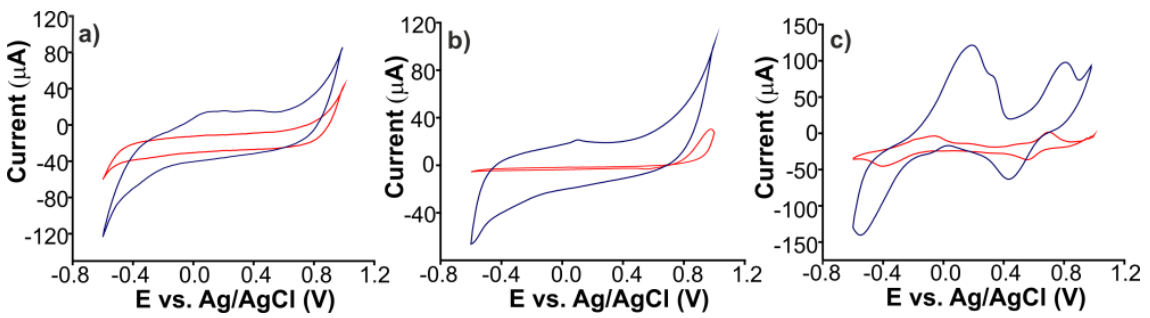

Figure 9.1. Voltammetric response towards $0.01 \mathrm{~mol} \cdot \mathrm{L}^{-1}$ glucose in $0.01 \mathrm{~mol} \cdot \mathrm{L}^{-1}$ phosphate buffer ( $\mathrm{pH}$ 7.0) of screen printed electrodes modified with a) graphene, b) nickel oxide nanoparticles and c) Prussian blue. Red lines correspond to M-CPEs response and blue lines correspond to M-GOx-CPE curves. Scan rate, $0.05 \mathrm{~V} \cdot \mathrm{s}^{-1}$.

The electrochemical response of the M-SPE and M-Tyr-SPE sensors towards phenols was evaluated by registering the cyclic voltammograms in a $0.01 \mathrm{~mol} \cdot \mathrm{L}^{-1}$ catechol solution (in $0.01 \mathrm{~mol} \cdot \mathrm{L}^{-1}$ phosphate buffer $\mathrm{pH}$ 7.0). In all M-SPE sensors, the oxidation of catechol to the quinoid form was observed at ca. $0.8 \mathrm{~V}$. This peak was accompanied by a peak at ca. $-0.2 \mathrm{~V}$ produced by the reverse reaction ${ }^{36}$. Only small differences in the position and intensities of the peaks were observed from one electrode to another. According to this, none of the modifiers tested showed a particularly intense electro-catalytic effect towards catechol.

When electrodes were covered with tyrosinase, the electrochemical response of C-Tyr-SPE, Pt-Tyr-SPE and Au-Tyr-SPE were almost identical to the responses observed in the absence of tyrosinase. In contrast, GPH-Tyr-SPE, NiO-Tyr-SPE and PB-Tyr-SPE produced a shift of the anodic peak to lower values (from $0.8 \mathrm{~V}$ to $0.65 \mathrm{~V}$ ). This effect was accompanied by a moderate increase in the intensity of the cathodic peak at $-0.2 \mathrm{~V}$ due to the reduction of the quinone derivative formed as a result of the enzymatic oxidation of catechol by the immobilized tyrosinase (Figure 9.2). 


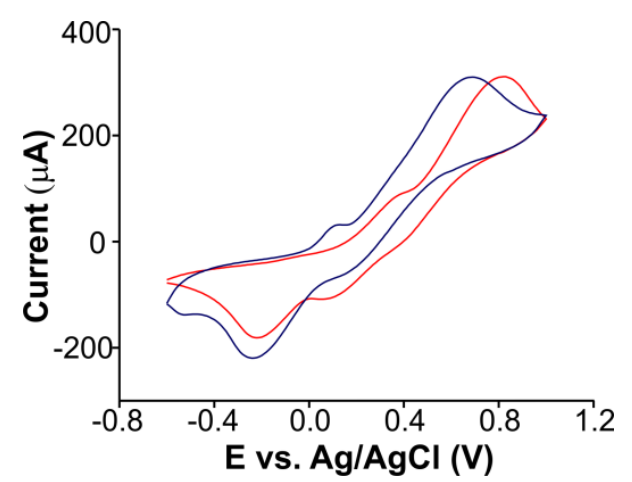

Figure 9.2. Cyclic voltammograms registered using screen printed electrodes modified with nickel oxide nanoparticles (red line) and nickel oxide nanoparticles-tyrosinase (blue line) immersed in $0.01 \mathrm{~mol} \cdot \mathrm{L}^{-1}$ catechol in 0.01 $\mathrm{mol} \cdot \mathrm{L}^{-1}$ phosphate buffer $\left(\mathrm{pH}\right.$ 7.0). Scan rate $0.05 \mathrm{~V} \cdot \mathrm{s}^{-1}$.

\subsection{2- Measurements in musts. Optimization of the experimental conditions}

As will be shown below, voltammograms registered by immersing the SPE electrodes in musts showed rich voltammograms where peaks produced by components with redox activity present in the sample (e.g. phenols, or sugars) and peaks related to the electrode modifier (e.g. Prussian blue) could be observed.

Unfortunately, preliminary experiments using M-SPE sensors demonstrated that the direct analysis of non-diluted musts produced irreproducible responses. The fact that the first cycle is always different from the rest has to be taken into account because, during this cycle, a flux of ions diffusing inside/outside the film is established. This cycle was always discarded. Upon successive cycling, a progressive decrease in the intensity of the signals was observed, with a coefficient of variation (CV) always higher than $30 \%$ (Figure 9.3.a). This was due to the existence of proteins in suspension or the presence of other materials, such as sugars, that could adhere to the electrode surface. Moreover, the direct contact between the solution and the pseudo reference $\mathrm{Ag} / \mathrm{AgCl}$ electrode could also be a source of irreproducibility. 
A 1:2 dilution with water or with $0.01 \mathrm{~mol} \cdot \mathrm{L}^{-1}$ phosphate buffer drastically improved the repeatability, and the coefficients of variation were within the range of $8-16 \%$ in M-SPE sensors not modified with enzymes (Figure 9.3.b). The variability was lower than $10 \%$ in sensors covered with enzymes.
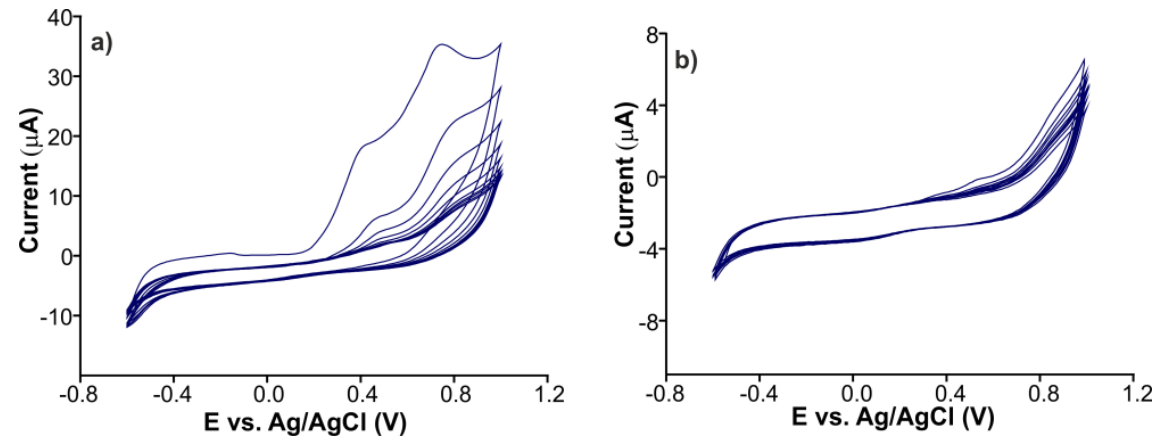

Figure 9.3. Cyclic voltammograms registered using a screen printed electrode modified with nickel oxide nanoparticles immersed in a must obtained from grapes of Cabernet-Sauvignon variety a) undiluted sample and b) must diluted 1:2 in $0.01 \mathrm{~mol} \cdot \mathrm{L}^{-1}$ phosphate buffer. Graphs correspond to 10 successive cycles.

In most of the cases, a 1:2 dilution with $0.01 \mathrm{~mol} \cdot \mathrm{L}^{-1}$ phosphate buffer produced voltammograms with a higher intensity than dilution with water. However, the degree of amplification was dependent on the nature of the electrode. This is illustrated in Figure 9.4, where a clear increase in the intensity was observed when using GPH-Tyr-SPE whereas the amplification was almost negligible when using a NiONP-Tyr-SPE electrode. The reasons for the amplification are not clear, but this phenomenon could be related to the increase in the $\mathrm{pH}$ produced by the phosphate buffer. 

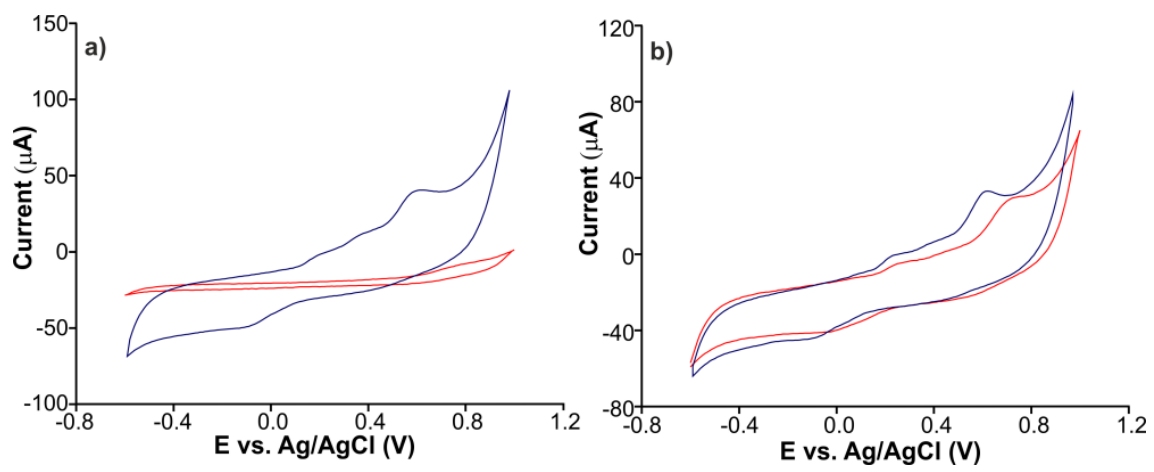

Figure 9.4. Voltammetric responses of screen printed electrode modified with a) graphene-tyrosinase and b) nickel oxide nanoparticles-tyrosinase immersed in a must obtained from grapes of Tempranillo variety. Red lines correspond to must diluted $1: 2$ in water and blue lines to must diluted in $0.01 \mathrm{~mol} \cdot \mathrm{L}^{-1}$ phosphate buffer.

Regarding the lifetime, it is worth mentioning that M-SPE electrodes decreased their intensity smoothly over 50 cycles. In contrast, M-GOxSPE or M-Tyr-SPE decreased their intensity progressively over ca. 10-15 cycles. After the $10-15^{\text {th }}$ cycle, erratic behavior was observed and these electrodes should be discarded. According to this, each sensor was used to analyze one must sample.

Once the experimental conditions were established, the array of sensors was used to analyze musts of five different grape varieties.

As mentioned in previous paragraphs the sensors developed here provide complex voltammetric responses due to voltammetric curves take into account every electro-active compound present in wines or musts (e.g. polyphenols or sugars). In addition, the interaction between the electro-catalytic material and the analytes increase the crossselectivity of the sensors improving the performance of the array. Finally, the modification with enzymes and the enzyme-electron mediator interaction introduce certain selectivity to the array.

For these reasons, each electrode showed a distinct response towards the musts analyzed, depending on the chemical composition of the 
working electrode. In all the M-SPE sensors, the oxidation peak of phenols present in the musts was observed to be within the 0.5-0.8 V region as a broad anodic wave (Figure 9.5). Different intensities were observed depending on the nature of the working electrode.

When the electrodes were covered with GOx (Figure 9.5 blue lines), a clear increase in the intensity of the curves was observed when the electron mediator was NiONP or PB, confirming the excellent electron mediator properties of nickel oxide nanoparticles and Prussian blue for GOx. The electro-catalytic effect was not observed in C-GOx-SPE, PtGOx-SPE, Au-GOx-SPE or GPH-GOx-SPE.
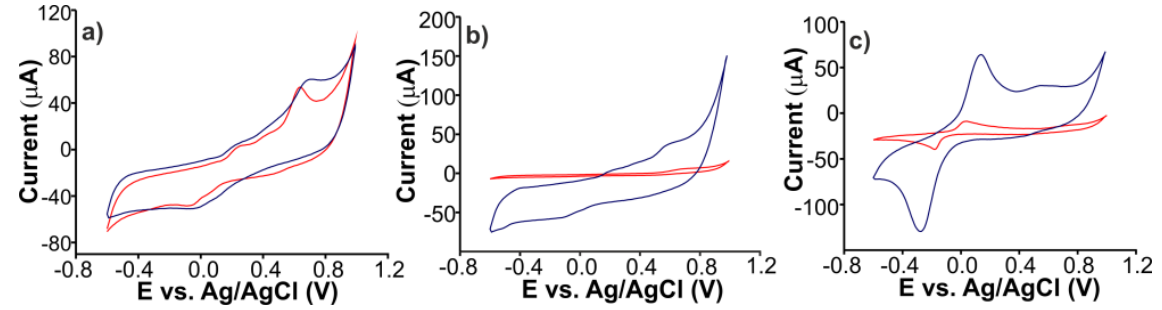

Figure 9.5. Voltammetric response towards must elaborated from t Tempranillo variety diluted $1: 2$ in $0.01 \mathrm{~mol} \cdot \mathrm{L}^{-1}$ phosphate buffer $(\mathrm{pH} 7.0)$ of screen printed electrodes modified with a) graphene, b) nickel oxide and c) Prussian blue. Red lines correspond to M-CPEs response and blue lines correspond to M-GOx-CPE curves. Scan rate, $0.05 \mathrm{~V} \cdot \mathrm{s}^{-1}$.

The NiONP-Tyr-SPE and PB-Tyr-SPE biosensors also furnished substantially larger signals than NiONP-SPE or PB-SPE analogues reflecting the electro-catalytic activity of NiONP and PB for Tyrosinase (Figure 9.6). This enhancement was particularly noticeable in the case of the NiONP electrodes, demonstrating the excellent characteristics of NiONP as electrode material in the construction of electro-chemical enzyme sensors for the detection of phenolic compounds. 

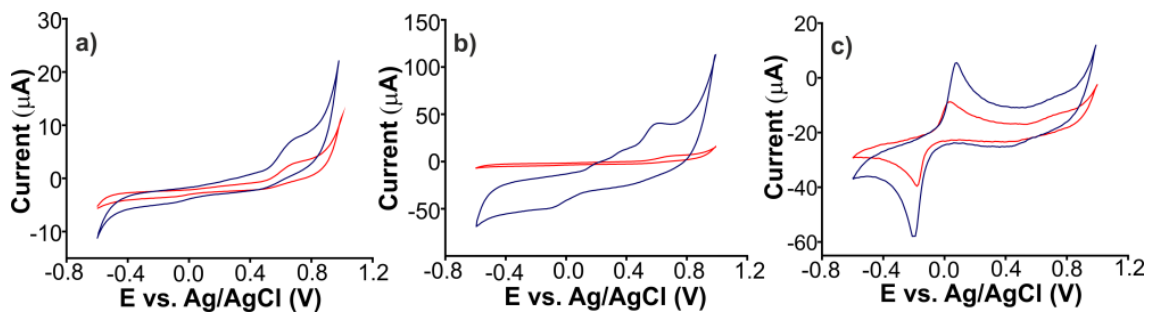

Figure 9.6. Voltammetric response towards must elaborated from Tempranillo variety diluted $1: 2$ in $0.01 \mathrm{~mol} \cdot \mathrm{L}^{-1}$ phosphate buffer $(\mathrm{pH} 7.0)$ of screen printed electrodes modified with a) carbon, b) nickel oxide nanoparticles and c) Prussian blue. Red lines correspond to M-CPEs response and blue lines correspond to $\mathrm{M}-\mathrm{Ty}$ r-CPE curves. Scan rate, $0.05 \mathrm{~V} \cdot \mathrm{s}^{-1}$.

As voltammetric responses depend on the chemical composition of the studied solution and each variety of berries presents its own content in sugars and phenols, the same sensor provided different responses towards different musts. This is illustrated in Figure 9.7 where the response of the PB-Tyr-SPE immersed in different musts is shown.

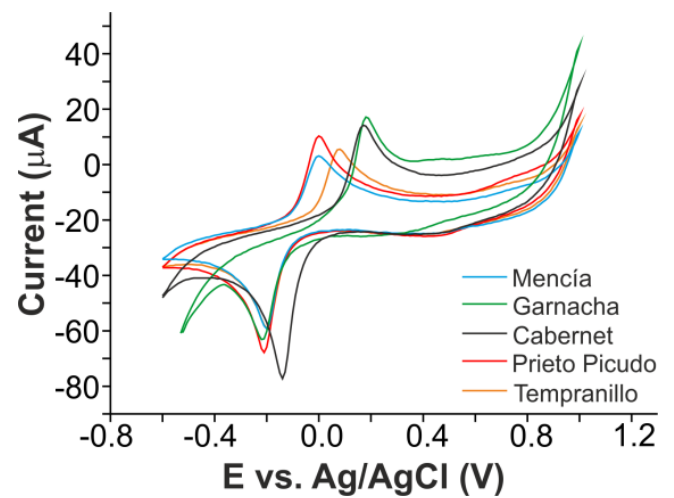

Figure 9.7. Cyclic voltammograms registered using a screen printed electrode modified with Prussian Blue-tyrosinase immersed in five musts prepared from different grape varieties. 


\subsection{3- Bioelectronic tongue. Statistical analysis}

As demonstrated in the previous section, the screen-printed electrodes were sensitive to the chemical compounds present in musts. In addition, the chosen electron mediators showed different electro-catalytic behaviors. According to these results, the electrodes provided distinct responses when immersed in different musts, showing an important degree of cross-selectivity.

Principal Component Analysis (PCA) was performed using the signals obtained separately from the arrays of M-SPE (Figure 9.8.a), M-GOx-SPE (Figure 9.8.b), and M-Tyr-SPE electrodes (Figure 9.8.c). Notice that each array is formed by 6 sensors (number of variables in each case is 6 sensors $\times 10$ kernels). As observed in the figure, the third principal component also brought an important amount of information. This result is usually found in voltammetric systems ${ }^{17,18,33}$ and is the consequence of the large amount of information contained under the voltammetric curves.
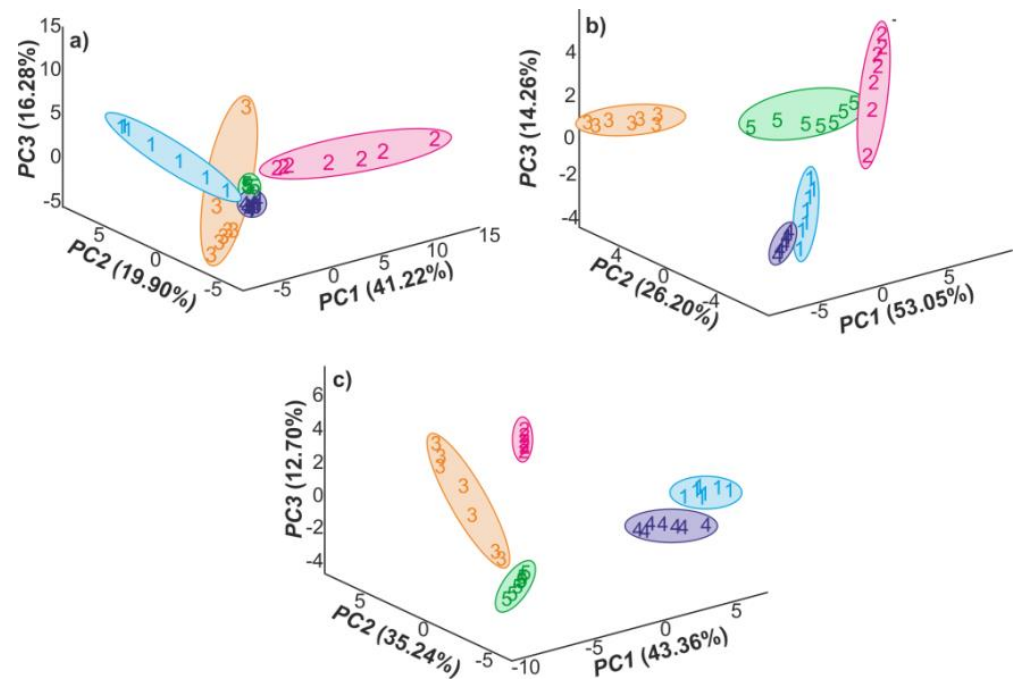

Figure 9.8. Principal Component Analysis scores plot using arrays of a) screen printed electrodes, b) screen printed electrodes modified with glucose oxidase and c) screen printed electrodes modified with tyrosinase. Must samples are 1: Prieto Picudo; 2: Mencía; 3: Tempranillo; 4: Cabernet-Sauvignon; and 5: Garnacha. 
After testing the arrays separately, the multisensor systems were merged to obtain an array that can discriminate musts according to the sugar and phenolic content simultaneously. The combination of M-GOxSPE and M-Tyr-SPE considerably improved the discrimination capability. This is illustrated in Figure 9.9.a where the scores plot, calculated when using the combined biosensor array, is shown. As observed, using the mixed array, a clear separation between the five musts studied was attained. The positions of the clusters are related to sugar and phenolic content. For instance, the Tempranillo variety which has the higher ${ }^{\circ} \mathrm{Brix}$ and IPT appears apart from the rest in the negative region of PC1 and the positive region of PC2. Prieto Picudo, Cabernet-Sauvignon and Garnacha which have intermediate values of ${ }^{\circ}$ Brix and IPT appear in the middle of PC1, while Mencía which presents the lowest values appears in the negative region of PC1. It has to be noted that the cluster of the Garnacha variety (which has similar values of IPT and ${ }^{\circ}$ Brix to Prieto Picudo and Cabernet-Sauvignon) appears well separated from the cluster corresponding to the other two varieties, instead of being located in the same region. This can be attributed to the low $\mathrm{pH}$ values of the must obtained from this grape which can cause important differences in the enzymatic activity. It is also worth mentioning that including the set of M-SPE sensors in the array did not significantly improve the discrimination capability of the system.

Figure 9.9.b shows the loading plots obtained by using the hybrid array formed by six M-GOx-SPE and six M-Tyr-SPE sensors (12 sensors $\times 10$ kernels per sensor). As observed in the figure, biosensors have different loadings, indicating that they provide complementary information.

The system developed showed almost the same discrimination capability as other arrays based on more complex sensors with a high degree of cross-selectivity. 

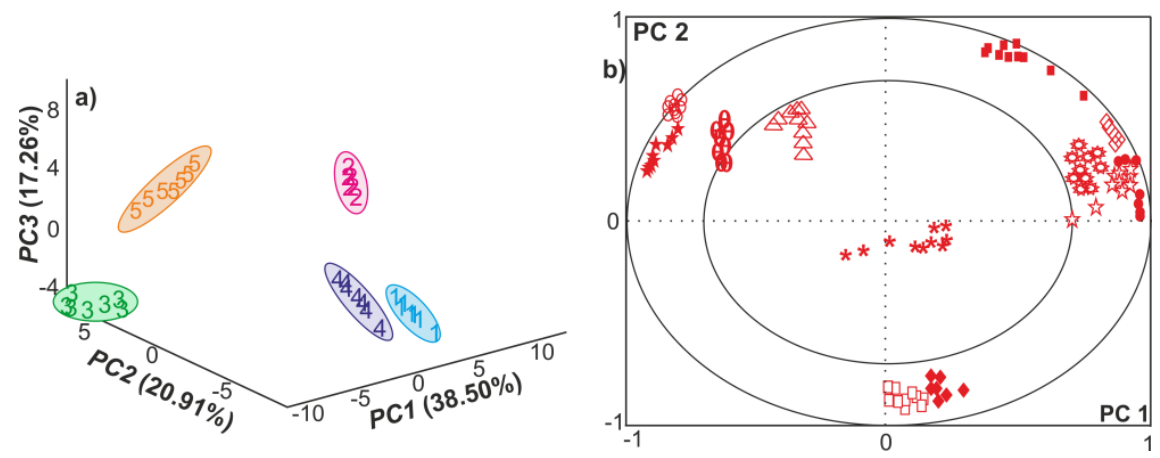

Figure 9.9. Principal Component Analysis calculated using an array formed by six screen printed electrodes modified with glucose oxidase and six screen printed electrodes modified with tyrosinase immersed in musts of different varieties. a) Scores plot (must samples are 1: Prieto Picudo; 2: Mencía; 3: Tempranillo; 4: Cabernet-Sauvignon; and 5: Garnacha). b) Loadings plot (sensors are labeled as: $\bigcirc$ Graphene-Tyrosinase, $\star$ Graphene-Glucose oxidase, $\theta$ platinum-Glucose oxidase, $\Delta$ Carbon-Tyrosinase, *Gold-Glucose oxidase, $\square$ Platinum-Tyrosinase, Nickel Oxide Nanoparticles-Tyrosinase, CarbonGlucose oxidase, Nickel Oxide Nanoparticles-Glucose oxidase, Prussian Blue-Glucose oxidase, $\diamond$ Gold-Tyrosinase, Prusian Blue-Tyrosinase).

The PLS model was developed in the PLS-1 mode. In order to select the number of factors, a cross-validation method leaving out one sample at a time, was used. Given the set of 35 calibration voltammograms, the PLS-1 calibration on 34 calibration curves was performed and using this calibration, the concentration of the compounds in the sample left out during calibration was predicted. This process was repeated 35 times until each calibration sample had been left out once. The concentration of each sample was then predicted and compared with the known concentration of the reference sample.

The values of the root mean square error of calibration (RMSEC), which is an estimate of the absolute error of calibration and the values of the root mean square of the prediction (RMSEP) and the squared correlation coefficients $\left(R^{2}\right)$ obtained when plots of measured versus predicted concentration are summarized in Table 9.3. Results indicated that the optimized PLS-1 model allows us to assess simultaneously the IPT and ${ }^{\circ}$ Brix in grape juices. 
Table 9.3. Statistical parameters obtained for the Partial Least Squares regression model established between the chemical parameters and the

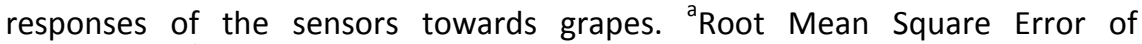

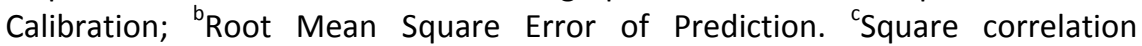
coefficient in calibration. ${ }^{\mathrm{d}}$ Square correlation coefficient in prediction; ${ }^{\mathrm{e}}$ Latent variables.

\begin{tabular}{|l|r|r|c|c|r|}
\hline Parameter & RMSEC $^{\mathbf{a}}$ & RMESP $^{\mathbf{b}}$ & $\mathbf{R}_{\mathbf{C}}{ }^{\mathbf{c}}$ & $\mathbf{R}_{\mathbf{P}}{ }^{\mathbf{d}}$ & LV $^{\mathbf{e}}$ \\
\hline${ }^{\mathbf{B}}$ Brix & 0.957 & 5.4211 & 0.943 & 6.1827 & 3 \\
\hline Total Polyphenol Index & 0.982 & 0.4932 & 0.913 & 1.2976 & 5 \\
\hline
\end{tabular}

\subsection{CONCLUSIONS}

A multisensor system was obtained by using screen-printed electrodes modified with carbon, platinum, gold, graphene, nickel oxide nanoparticles and Prussian blue and covered with glucose oxidase or tyrosinase. The voltammetric responses towards glucose and catechol demonstrated that each screen-printed material shows a different electro-catalytic and electron mediator activity, producing a variety of responses. The electrochemical signals of musts consisted of complex voltammetric curves bearing information associated with the phenolic and sugar content of the grapes. In addition, the interactions between the electrode and the solution (e.g. the $\mathrm{pH}$ affecting the enzymatic activity, or the electro-catalytic activity of the modifiers) increased the cross-selectivity of the sensors.

A clear discrimination of the samples was attained by using the hybrid array formed by glucose oxidase and tyrosinase based sensors, combined with PCA.

The enhanced electrochemical reactivity of the M-GOx-SPE and M-TyrSPE electrodes (particularly when using Prussian Blue and nickel oxide nanoparticles), and the variety of responses obtained when electrodes were immersed in musts, make these modified screen-printed electrodes attractive to form an array of sensors.

The system developed showed almost the same discrimination capability as other arrays based on more complex sensors. Due to the limited 
repeatability of the serigraphied electrodes, each sensor could only be used to analyze one sample. However, the lower price, ease of use and portability of the modified screen-printed electrode system makes the bioelectronic tongue developed here a possible alternative tool to analyze simultaneously sugar and phenols in situ in the vineyard block. However, further work is needed to reduce the number of sensors, so the system could be used more easily in a non-laboratory environment. There is also a need to extend the study to grapes with different degree of maturity. 


\section{References}

1. Blouin, J., Guimberteau, G. Maturation et maturité des raisins. 2000.

Ed. Féret. Bordeaux (France).

2 Ghozlen, N.B., Cerovic, Z.G., Germain,C., Toutain, S., Latouche, G. Sensors, 2010, 10, 10040-10068.

3. Herrera, J., Guesalaga, A., Agosin, E. Meas. Sci. Technol. 2003, 14, 689697.

4. Barroso, M.F., De los Santos Alvarez, N., Delerue-Matos, C., Oliveira, M.B.P.P. Biosens. Bioelectron. 2011, 30, 1-12.

5. Carralero Sanz, V., Mena, M.L., González-Cortés, A., Yáñez-Sedeño, P., Pingarrón, J.M. Anal. Chim. Acta. 2005, 528, 1-8.

6. Wang, J. Chem. Rev. 2008, 108, 814-825.

7. Chaubey, A., Malhotra, B. D. Biosens. Bioelectron. 2002, 17, 441-456.

8. Ricci, F., Amine, A., Palleschi, G., Moscone, D. Biosens. Bioelectron. 2003, 18, 165-174.

9. Rahman, Md. M., Ahammad, A. J. S., Jin, J., Ahn, S.J., Lee, J.J. Sensors. 2010, 10, 4855-4886.

10. Baldwin, E.A., Bai, J., Plotto, A., Dea, S. Sensors. 2011, 11, 4744-4766.

11. Haddi, Z., Mabrouk, S., Bougrini, M., Tahri, K., Sghaier, K., Barhoumi, H.,El Bari, N., Maaref, A., Jaffrezic-Renault, N., Bouchikhi, B. Food Chem. 2014, 150, 246-253.

12. Riul Jr., A., Dantas, C. A. R., Miyazaki, C. M., Oliveira Jr., O. N. Analyst, 2010, 135, 2481-2495.

13. Rodriguez-Mendez, M. L., Medina, C., de Saja, J.A., Apetrei, C., Muñoz, R. (2012). Sensor arrays based on phthalocyanines: new developments on nanostructured and biomimetic electrochemical 
sensors, in Multisensor systems for chemical analysis: materials and sensors. 2012, 70-109. Ed. Pan Stanford Publishing, Inc (Singapore).

14. Sghaier, K., Barhoumi, H., Maaref, A., Siadat, M., Jaffrezic-Renault, N. Sensor Letters. 2009, 7, 683-688.

15. Sliwinska, M., Wisniewska, P., Dymerski, T., Namiesnik, J., Wardencki, W. J. Agric. Food Chem. 2014, 62, 1423-1448.

16. Smyth, H., Cozzolino, D. Chem. Rev. 2013, 113, 1429-1440.

17. Apetrei, I.M., Rodríguez-Méndez, M.L., Apetrei, C., Nevares, I., del Alamo, M., de Saja, J.A. Food Res. Int. 2012, 45, 244-249.

18. Cetó, X., Apetrei, C., Del Valle, M., Rodríguez-Méndez, M.L. Electrochim. Acta. 2014, 120, 180-186.

19. Cetó, X., Gutiérrez, J. M., Gutiérrez, M., Céspedes, F., Capdevila, J., Mínguez, S., Jiménez-Jorquera, C., del Valle, M. Anal. Chim. Acta. 2012, 732, 172-179.

20. Gay, M., Apetrei, C., Nevares, I., Del Alamo, M., Zurro, J., Prieto, N., de Saja, J.A., Rodriguez-Mendez, M.L. Electrochim. Acta. 2010, 55, 67826788.

21. Gil-Sánchez, L., Soto, J., Martínez-Máñez, R., Garcia-Breijo, E., Ibáñez, J., Llobet, E. Sensors Actuat. A. 2011, 171, 152-158.

22. Gutiérrez, M., Domingo, C., Vila-Planas, J., Ipatov, A., Capdevila, F., Demming, S., Büttgenbach, S., Llobera, A., Jiménez-Jorquera, C. Sensors Actuat. B. 2011, 156, 695-702.

23. Parra, V., Hernando, T., Rodríguez-Méndez, M.L., de Saja, J.A. Electrochim. Acta. 2004, 49, 5177-5185.

24. Rodríguez-Méndez, M.L., Apetrei, C., Gay, M., Medina-Plaza, C., De Saja, J.A., Vidal, S., Aagaard, O., Wirth, J., Cheynier, V. Food Chem. 2014, 155, 91-97. 
25. Zeravik, J., Hlavacek, A., Lacina, K., Skládal, P. Electroanal. 2009, 21, 2509-2520.

26. Gutiérrez, J.M., Moreno-Barón, L., Pividori, M.I., Alegret, S., del Valle, M. Microchim. Acta, 2010, 169, 261-268.

27 Moreno i Codinachs, L., Kloock, J.P., Schöning, M. J., Baldi, A., Ipatov, A., Bratov, A., Jiménez-Jorquera, C. Analyst, 2008, 133, 1440-1448.

28. Medina-Plaza, C., De Saja, J.A., Rodríguez-Méndez, M.L. Biosens. Bioelectron. 2014, 57, 276-283.

29. Medina-Plaza, C., Revilla, G., Muñoz, R., Fernández-Escudero, J.A., Barajas, E., Medrano, G., De Saja, J.A., Rodríguez-Méndez, M.L. J. Porphyrins Phthalocyanines. 2014, 18, 76-86.

30. Metters, J.P., Kadara, R.O., Banks, C.E. Analyst. 2011, 136, 10671076.

31. OIV. Compendium of international methods of analysis of wines and musts. Vol. 2. Organisation Internationale de la Vigne et du Vin. 2013. Paris (France).

32. Gutiérrez-Osuna, R., Nagle, H.T. IEEE Trans. Syst. Man. Cybern. BCybern. 1999, 29, 626-632.

33. Prieto, N., Oliveri, P., Leardi, R., Gay, M., Apetrei, C., RodriguezMendez, M.L., de Saja, J.A. Sensors Actuat. B. 2013, 183, 52-57.

34. To Thi Kim, L., Gabrielli, C., Perrot, H., Garcia-Jareno, J., Vicente, F. Electrochim. Acta. 2012, 84, 35-48.

35. Valentini, F., Carbone, M., Palleschi, G. Anal. Bioanal. Chem. 2013, 405, 3449-3474.

36. Matemadombo, F., Apetrei, C., Nyokong, T., Rodríguez-Méndez, M.L., de Saja, J. A. Sensors Actuat. B. 2012, 166-167, 457-466. 


\section{CHAPTER 10}

Nanoscale Au-In Alloy-Oxide Core-Shell Particles as Electrocatalysts for Efficient Hydroquinone Detection 

Despite the health benefits and antioxidant properties present on phenols, they can also occur as a hazardous byproduct of different industries.

Hydroquinone $(\mathrm{HQ})$ is used as a developing agent in black-and-white photography, lithography and x-ray films. It is also used as an intermediate to produce antioxidants for rubber. It is added to a number of industrial monomers to inhibit polymerization during shipping, storage, and processing. $\mathrm{HQ}$ is on the Hazardous Substance List because it is regulated by Occupational Safety and Health Administration (OSHA).

This chapter was develop in the collaboration with Dr. Eli Sutter at Brookhaven National Lab (NY,USA). The group of Dr. Eli Sutter focuses its research on new nanomaterials with energy and environmental applications. This collaboration led to new voltammetric sensors applied to detect $\mathrm{HQ}$ with environmental purposes.

For this goal, voltammetric sensors of high-surface area $A u_{x} I_{1-x}$ coreshell nanostructures will be studied. $A u_{x} I_{1-x}$ with different alloy composition, $x$, were prepared by room temperature oxidation of Au-In alloys. Au-In core-shell nanoparticles have been characterized by XPS, EDS, TEM and SEM and used to modify standard indium tin oxide (ITO) electrodes and investigate the electrocatalytic properties towards the oxidation of hydroquinone in aqueous solutions. The electrocatalytic effect, the influence of Au:In ratio on the electrochemical analysis and the dynamic behavior of the sensors will be discussed. This research has been published on Journal of Physical Chemistry- $C$.

\subsection{INTRODUCTION}

Phenolic compounds are a large family of molecules, which have attracted great interest in the food industry due to their antioxidant capacity and potential health benefits ${ }^{1}$.On the negative side, phenolic compounds occur as byproducts of a variety of industries and are ubiquitous in the environment. They are classified as hazardous materials and are particularly toxic to the environment. Hydroquinone $(\mathrm{HQ})$ is one example of this broader class of phenolic compounds that is 
important in a number of biological processes, as well as in industrial products including dyes, cosmetics, pesticides, paper manufacturing, and photographic developers ${ }^{2}$. The detection and assessment of hydroquinone can be carried out using traditional techniques such as fluorescence $^{3}$, chemiluminescence ${ }^{4}$ and high performance liquid chromatography (HPLC) $)^{5}$ among others. Compared to these methods that require complex instrumentation, electrochemical methods could provide compact and relatively inexpensive setups with fast response for real-time analysis in the field. Conventional (e.g. metallic or glassy carbon) electrodes however, are not suitable for the detection of phenols due to their poor electrochemical response ${ }^{6}$. One possible strategy for preparing efficient sensing devices is the modification of the electrode surface with nanomaterials. Electrodes modified with metal nanoparticles are very promising as they show unique electronic and catalytic properties ${ }^{7}$. Au nanoparticles, among other noble metals, have demonstrated electrocatalytic enhancement in various processes: fuel cells $^{8,9}$, sensors ${ }^{10,11}$, food analysis ${ }^{12,13}$ and photovoltaic devices ${ }^{14,15}$. Au nanoclusters provide even higher catalytic activity ${ }^{16}$ as well as other benefits, for instance stabilization against dissolution under potential cycling regimes of oxygen-reduction fuel-cell electrocatalysts ${ }^{17}$. Small Au nanoparticles and nanoclusters require complicated synthesis and are hard to stabilize in their active configuration, as they sinter easily and their catalytic properties degrade as a result of the size increase. Recently, a simple approach for the formation of stable Au-based catalysts, in which the active sites are small gold clusters anchored in an amorphous Au-In oxide matrix, has been developed. Au-In alloy nanoparticles prepared by metal evaporation (or other methods) transform into metal alloy-oxide core-shell structures during oxidation at room temperature ${ }^{18}$. Auln alloy nanoparticles terminated by goldcontaining oxide shells were found to be active in the conversion of $\mathrm{CO}$ and $\mathrm{O}_{2}$ to $\mathrm{CO}_{2}$ near room temperature, as well as stable against sintering up to high temperatures $\left(>300^{\circ} \mathrm{C}\right.$ ), and thus show promising properties for heterogeneous catalysis. 


\subsection{MATERIALS AND METHODS}

\subsection{1- Synthesis of $A u_{x} I_{1-x}$ alloy nanoparticles}

Bimetallic Au-In alloy nanoparticles with different compositions were formed by sequential room-temperature magnetron sputtering of controlled amounts of $\mathrm{Au}$ and In onto different substrates: indium tin oxide (ITO) electrodes (for electrocatalytic measurements), as well as $\mathrm{Ge}$ (111), amorphous carbon and few-layer graphene membranes supported on standard transmission electron microscopy (TEM) grids for materials characterization. Pure In and $A u$ nanoparticles for control experiments were prepared by sputtering of only In and $\mathrm{Au}$, respectively, under the same conditions. Different compositions of the Au-In alloy in the nanostructures were obtained by depositing a fixed amount of $\mathrm{Au}$ ( $2 \mathrm{~nm}$ equivalent thickness), followed by sputtering of different amounts of In to obtain the desired composition. The asdeposited nanoparticle ensembles were exposed to ambient conditions after removal from the growth reactor, which led to their oxidation in air and formation of mixed oxide shells encapsulating the bimetallic alloy cores $^{18-20}$.

\subsection{2- Characterization of Au-In alloy nanoparticles}

The morphology and composition of the nanoparticles were investigated by TEM in a JEOL 2100F field-emission microscope equipped with energy dispersive X-ray spectroscopy (EDS) instrument, in scanning TEM mode (beam size: $2 \AA$ ). Laboratory X-ray photoelectron spectroscopy (XPS) spectra on nanoparticle ensembles deposited on $\mathrm{Ge}(111)$ were acquired at room temperature using a Specs Phoibos 100 MCD hemispherical analyzer, using excitation by $\mathrm{Al} \mathrm{K} \alpha(\mathrm{hv}=1486.6 \mathrm{eV})$ radiation at $300 \mathrm{~W}$ (10 $\mathrm{keV} ; 30 \mathrm{~mA}$ ). XPS spectra were acquired with pass energy of $25 \mathrm{eV}$ and energy step of $0.05 \mathrm{eV}$. The base pressure in the analysis chamber was in the range of $(2-6) \times 10^{-9}$ Torr. The $C$ 1s binding energy $(284.8 \mathrm{eV}$ ) was used as binding energy reference. To determine the composition in the outermost surface layer, low-energy ion-scattering spectroscopy (ISS) measurements were carried out in a ultrahigh vacuum (UHV) system 
with $(1-3) \times 10^{-10}$ Torr base pressure, using $2 \mathrm{keV}$ He ions (Specs IQE 12/38 ion source).

\subsection{3-Electrochemical characterization}

Cyclic voltammetry (CV) of ITO electrodes modified with Au-In alloyoxide core-shell nanoparticles, prepared as described above, was carried out in an Autolab PGSTAT128N potentiostat-galvanostat using a threeelectrode cell. $\mathrm{Ag} \mid \mathrm{AgCl} / \mathrm{KCl} 3 \mathrm{M}$ was used as reference electrode and the counter electrode was a platinum plate. ITO glasses covered with Au-In nanostructures with different compositions were used as working electrode. Experiments were carried out in the bias range from -0.8 to $1.0 \mathrm{~V}$ using $\mathrm{KCl} \quad 0.1 \mathrm{~mol} \cdot \mathrm{L}^{-1}$ as supporting electrolyte in which hydroquinone $(\mathrm{HQ})$ was dissolved to obtain a final concentration of $10^{-3}$ $\mathrm{mol} \cdot \mathrm{L}^{-1}$. The scan rate used in $\mathrm{CV}$ was $0.1 \mathrm{~V} \cdot \mathrm{s}^{-1}$, with the influence of the scan rate analyzed in the range from 0.025 to $0.5 \mathrm{~V} \cdot \mathrm{s}^{-1}$.

\subsection{RESULTS AND DISCUSSION}

\subsection{1- Structural characterization}

Figure 10.1 summarizes the structure and morphology of nanostructured $A u_{x} I_{1-x}$ alloys with different compositions, produced by sequential vacuum deposition of $\mathrm{Au}$ and $\mathrm{In}$, as well as pure $\mathrm{Au}$ nanoparticles. The TEM images showed that magnetron sputtering yielded discrete $\mathrm{Au}$ nanoparticles with a large variety of sizes (Figure 10.1.a), while the typical morphology obtained for a wide composition range $\mathrm{Au}$-In bimetallic alloys following room-temperature oxidation in air (Figure 10.1.b-d) are elongated, meandering nanostructures and nanoparticles exhibiting a high-surface area morphology. The TEM images also showed the partial dewetting of the Au-In alloy into stripes, between which the amorphous $C$ support is exposed. High resolution TEM (Figure 10.1.b-d, insets) showed that the meandering nanostructures consist of a crystalline core with darker contrast and interspersed areas with brighter contrast that stem from the amorphous oxide shells, similar to earlier observations ${ }^{18}$. Scanning electron microscopy (SEM) investigation on ITO electrodes and crystalline Ge substrates confirmed that the Au-In nanostructures have the same 
morphology, independent of the support. The surface coverage increased with the increase of In content, both because the amount of deposited metal was larger and because the resulting oxides were thicker (Figures 10.2.b and 10.2.c). Experimental electron diffraction patterns for the four different samples (Figure 10.1.a'- $d^{\prime}$ ) were compared to simulated diffraction patterns for $\mathrm{Au}$, orthorhombic $\mathrm{Au}_{3} \mathrm{In}^{21}$, and cubic Auln ${ }_{2}^{22}$ structures and confirmed the crystal structure and composition of the cores. Crystallographic studies of bulk $A u_{0.5} I_{0.5}$ found that it adopts a pseudo-orthorhombic structure ${ }^{23}$, however, the atomic positions have not been reported to date, so we could not simulate the diffraction pattern (DP) for this composition.
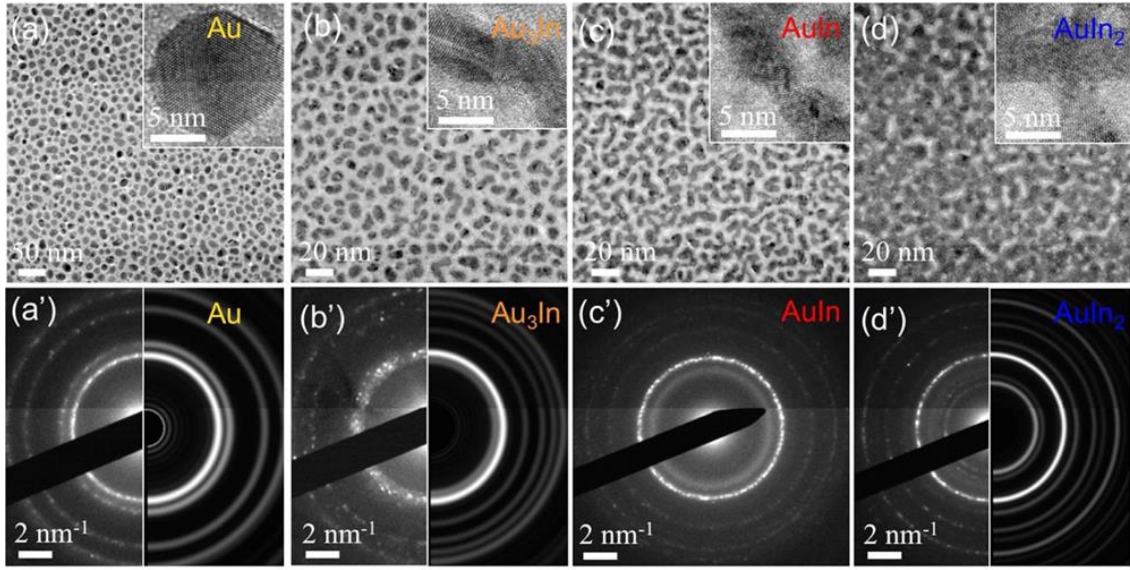

Figure 10.1. Overview TEM images of the characteristic structure of a) Au and Au-In samples with different compositions, b) $\left.\mathrm{Au}_{3} \mathrm{In}, \mathrm{c}\right)$ Auln and d) $\mathrm{AuIn}_{2}$ prepared by magnetron sputtering. High-resolution TEM images showing details of the crystalline $\mathrm{Au}$ nanoparticles and $\mathrm{Au}-\mathrm{In}$ nanostructures terminated by amorphous surface oxides are shown in the insets of figures a-d. $a^{\prime}-d^{\prime}$ Electron diffraction patterns from the nanostructures in figures a-d taken with a $150 \mathrm{~nm}$ aperture. The experimental diffraction patterns shown in the left half are compared to simulated diffraction patterns (right half) calculated using the software package JEMS for nanoparticles with $\mathrm{Au}$, orthorhombic $\mathrm{Au}_{3} \ln ^{21}$ and cubic Auln ${ }_{2}^{22}$ structures. 
The $A u_{0.5} I_{0.5}$ nanostructures were identified unambiguously from the EDS and XPS measurements (Figures 10.2 and 10.3). It is worth noting that the structures with $A u_{0.5} I_{0.5}$ composition showed distinct DP from the DPs of other alloys, which confirmed that $A u_{0.5} \ln _{0.5}$ represents a distinct crystalline phase and can be used for the identification of this alloy as well.

EDS measurements were used to confirm the different compositions of the nanostructures depending on the amounts of $A u$ and In deposited. Figure 10.2.a shows characteristic EDS spectra from $\mathrm{Au}_{3} \mathrm{ln}, \mathrm{Auln}$, and Auln $_{2}$ nanostructures. The spectra confirmed the alloying of the sequentially deposited metals at room temperature ${ }^{18,24}$. Following air exposure, amorphous oxide shells that contain both Au and In covered the surface of the Au-In alloy nanostructures (Figure 10.2.b). Analysis of the TEM images (Figure 10.2.c) showed that the thickness of the oxide shells depends on the composition of the initial Au-In alloy: $1.0 \pm 0.4 \mathrm{~nm}$ for $\mathrm{Au}_{3} \mathrm{In}, 1.8 \pm 0.8 \mathrm{~nm}$ for Auln, and $2.8 \pm 1.2 \mathrm{~nm}$ for $\mathrm{Auln}_{2}$ nanostructures. This trend in the oxidation rate with alloy composition is the same as the one established for discrete Au-In particles ${ }^{18}$. The amorphous mixed oxide forming on the surface of the particles during room temperature oxidation in air scales with In content, i.e. the oxide shells are thicker for In-rich nanoparticles.
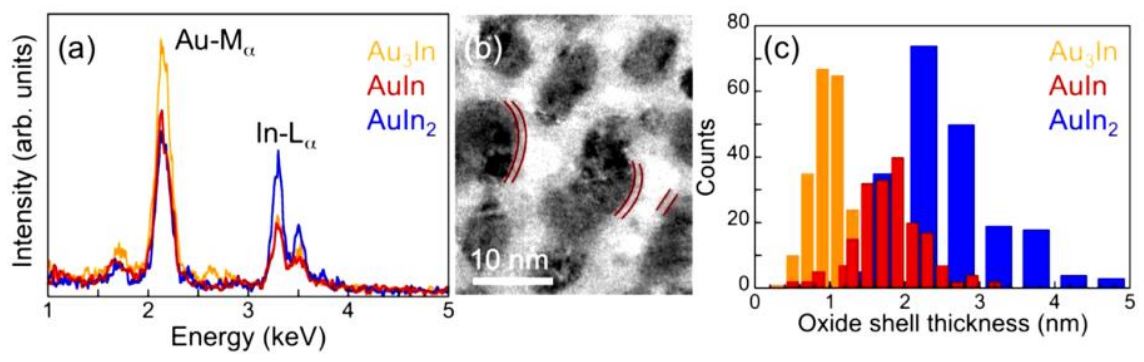

Figure 10.2. a) EDS spectra from Au-In nanostructures with different alloy compositions $\left(\mathrm{Au}_{3} \mathrm{In}, \mathrm{Auln}, \mathrm{Auln} \mathrm{n}_{2}\right)$. b) High-resolution TEM image showing detail of the crystalline Auln nanostructures terminated by an amorphous surface oxide after exposure to air at room temperature. c) Thickness distribution of the amorphous oxide shells formed after oxidation in air for 28 days for three different as-deposited alloy compositions. 
Core-shell $A u_{x} \mathrm{In}_{1-\mathrm{x}}$ oxide nanostructures were further investigated using XPS to determine the composition and chemical environment, and ISS to identify the elements in the outermost layer of the oxide shell. Both investigations were performed on oxidized nanostructures on $\mathrm{Ge}$ support. XPS (in conjunction with TEM) was used to monitor the thickening of the oxide on the surface until the oxide reached its limiting thickness, identified by the absence of further changes in the XPS spectra. For the Au-In alloys investigated here, this limit was reached after 21 days in air. XPS on all $\mathrm{Au}_{3} \mathrm{In}$, Auln and $\mathrm{Auln}_{2}$ nanostructures revealed the presence of $A u, I n$, and $O$. The $A u 4 f$ and $\ln 3 d$ XPS spectra for these three alloy compositions together with reference spectra for a $2 \mathrm{~nm}$ Au film and pure $\ln _{2} \mathrm{O}_{3}$ nanoparticles (on $\mathrm{Ge}$ ) are shown in Figures 10.3.a and 10.3.b, respectively. As expected, the Au $4 \mathrm{f}$ spectra of the oxidized alloys were shifted to higher binding energy compared to the $\mathrm{Au}$ reference and the observed shifts increased with increasing In content, in good agreement with previous results on Au-In alloys ${ }^{25}$. The In $3 \mathrm{~d}$ peaks for the three alloys were also shifted compared to the spectrum of pure $\ln _{2} \mathrm{O}_{3}$ nanoparticles.
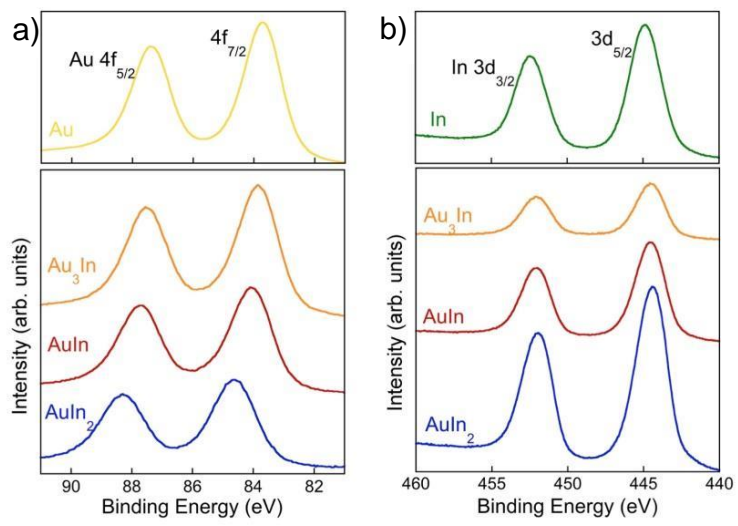

Figure 10.3. a) X-ray photoelectron spectra of the Au $4 \mathrm{f}$ core levels of the composite Au-In-amorphous oxide core-shell nanostructures compared to a reference spectrum of Au nanoparticles. b) X-ray photoelectron spectra of the In $3 \mathrm{~d}$ core levels from the nanostructures compared to a reference sample of $\mathrm{In}_{2} \mathrm{O}_{3}$ nanoparticles on $\mathrm{Ge}$ substrate. 
Because of the high energy of the exciting photons from a laboratory XPS source, the kinetic energy of the Au $4 f$ and In $3 d$ photoelectrons is high, which translates into a large escape depth. As a result the XPS measurements probed both the alloy core and the mixed oxide shell of the nanostructures and were of limited use for characterizing the nearsurface composition of the Au-In oxide structures, which is key to their electrocatalytic properties. Thus, ISS was used to determine the constituents of the surface of oxidized Au-In alloy nanoparticles (Figure 10.4.c-e), with a bulk Ge crystal (with native oxide, Figure 10.4.a), Au film on Ge (Figure 10.4.b), and $\ln _{2} \mathrm{O}_{3}$ nanoparticles on Ge (Figure 10.4.f) serving as reference samples.

ISS on the nanostructured Au-In oxide samples showed the presence of $\mathrm{Au}, \mathrm{In}, \mathrm{Ge}$, and $\mathrm{O}$ in the surface layer (Figure 10.4.c-e). This confirmed that all oxidized $\mathrm{Au}-\mathrm{In}$ nanostructures contain Au at the surface of their oxide shells. The Ge signal stemed from the exposed substrate between the nanoparticles. In the alloy nanostructures with higher In content (i.e. larger overall coverage of deposited metal) the Ge peak was not well resolved because of the small remaining area of the bare support in these samples (Figure 10.1.d). These samples have the thickest oxide shells (Figure 10.2.c), which contribute to the almost complete shielding of the substrate from the incoming He ions. The (Au:In) peak ratios in samples with different In content showed a clear trend in Au content, which follow the composition of the initial Au-In alloy: the oxide surface of particles with $\mathrm{Au}_{3} \mathrm{In}$ cores contains significantly more $\mathrm{Au}(\mathrm{Au}: \mathrm{In}=0.79$ ) than that of particles with Auln cores (Au: $\ln =0.22$ ), which again is larger than that of particles with Auln $_{2}$ cores (Au:In $=0.11$ ). From the ISS measurements, it can be concluded that the outermost atomic layer of the amorphous oxide shells contains $\mathrm{Au}, \mathrm{In}$ and $\mathrm{O}$. The amount of $\mathrm{Au}$ exposed at the oxide surface is not fixed, but can be varied by adjusting the Au concentration in the initial Au-In binary alloy. This provided access to working electrodes with systematically different concentrations of near-surface $\mathrm{Au}$, stabilized on the amorphous Au-In oxide shells, for electrochemical characterization. 


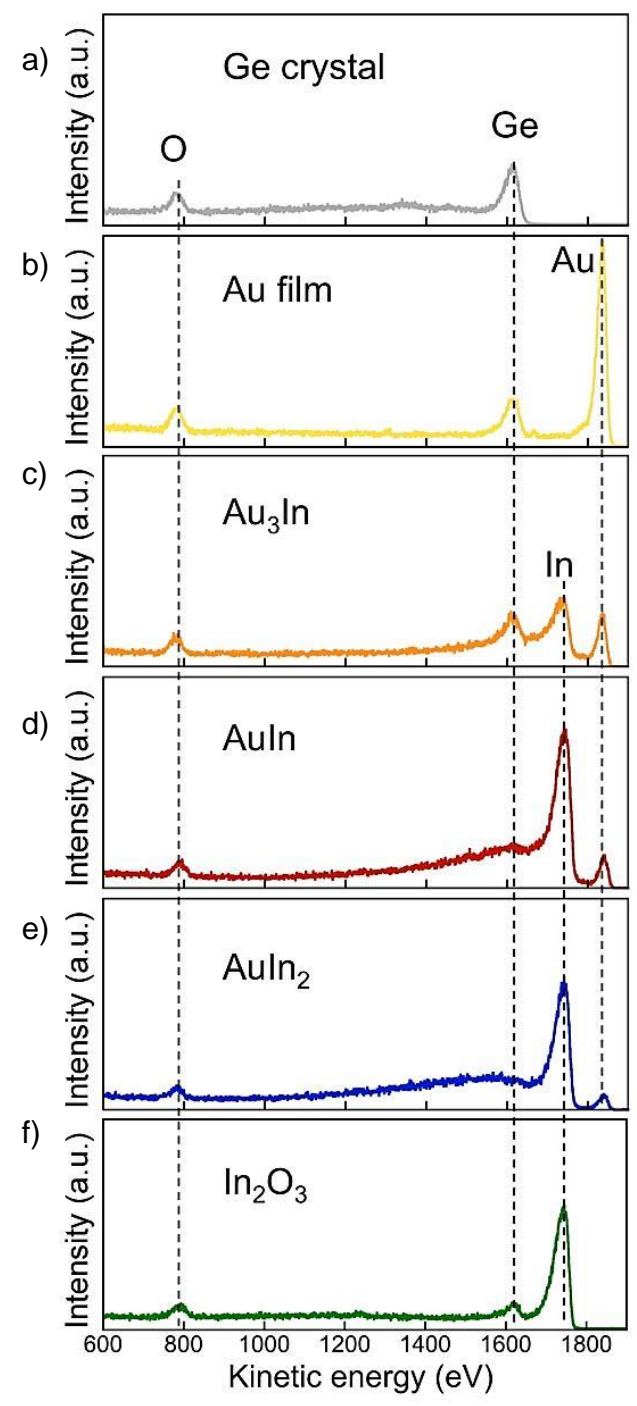

Figure 10.4. Ion scattering spectra of: a) Reference Ge wafer, used as a substrate for the nanostructures, b) Reference Au film, c) $\mathrm{Au}_{3} \mathrm{In}$, d) Auln, e) Auln $n_{2}$-amorphous Au-In oxide core-shell nanostructures and f) crystalline $\ln _{2} \mathrm{O}_{3}$ nanoparticles.

\subsection{2- Electrocatalytic properties}

The electrocatalytic properties of the Au-In alloy nanostructures for the detection of $\mathrm{HQ}$ were measured in aqueous solutions containing $10^{-3}$ 
$\mathrm{mol} \cdot \mathrm{L}^{-1} \mathrm{HQ}$. This particular concentration was chosen to facilitate comparison with other means of detection, as it is the one usually targeted for $\mathrm{HQ}$ detection. Cyclic voltammograms were measured using ITO electrodes modified with the core-shell nanostructures with different (Au:In) ratios. Reference voltammograms were recorded for unmodified ITO and bulk Au electrodes, as well as working electrodes modified with Au nanoparticles. According to the literature, in aqueous solution with neutral $\mathrm{pH}$ and using carbon electrodes, parahydroquinones undergo a two-electron single-step oxidation ${ }^{26}$ that appears as a broad and irreversible anodic peak in the 0.7-1.0 $\mathrm{V}$ region. The characteristic voltammograms registered using unmodified ITO-onglass electrodes, bulk gold and Au nanoparticle-modified ITO electrodes are compared in Figure 10.5.a. The voltammograms measured with unmodified ITO and ITO modified with the Au-In nanostructures as the working electrode are shown in Figure 10.5.b. In Figure 10.5, all voltammograms are shown on the same scale to allow direct comparison of the currents. In Figure 10.6, the voltammograms registered with the different electrodes are shown on different scales, so that their details can be clearly seen. The characteristic voltammogram registered using unmodified ITO the working electrode, is shown in Figures 10.5.a (black curve) and 10.6.a. Starting at $0.75 \mathrm{~V}$, a small increase in the current was observed, indicating that with an unmodified ITO working electrode HQ oxidation starts at high voltages, probably due to the difficulty of the electron transfer to the ITO glass. Thus, unmodified ITO electrodes are not suitable for the detection of HQ. 

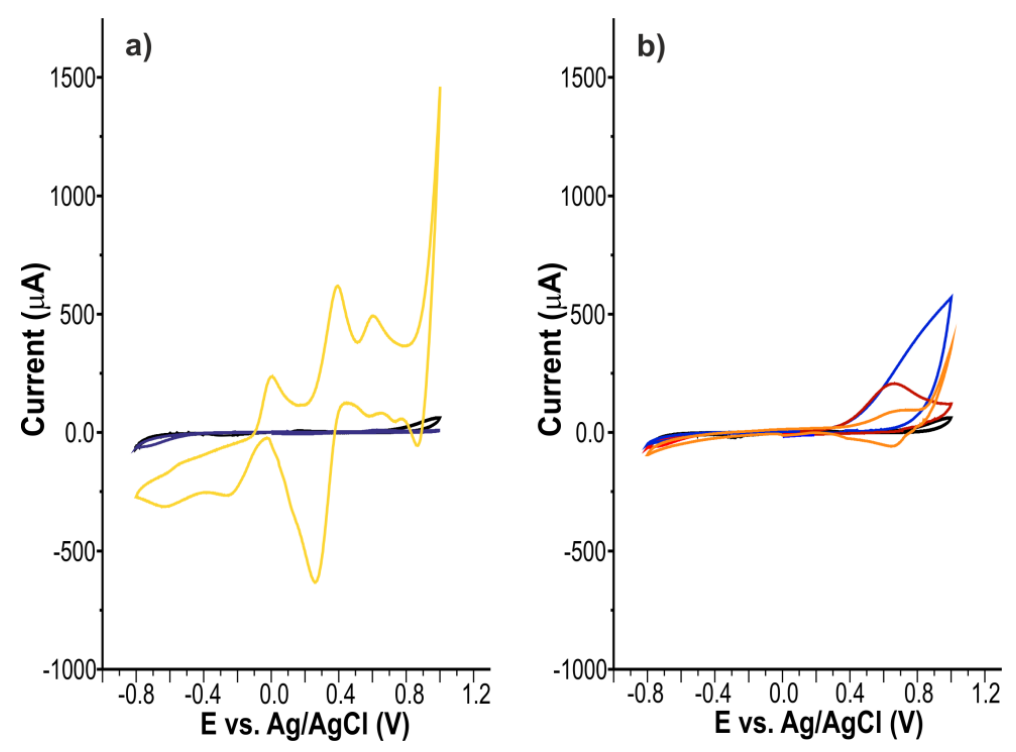

Figure 10.5. Cyclic voltammograms of a) ITO (black), bulk Au electrodes (dark blue) and Au nanoparticle modified ITO electrodes (yellow curve) and b) ITO (black) and electrodes modified with Auln ${ }_{2}$ (blue), Auln (red) and $\mathrm{Au}_{3} \mathrm{In}$ (orange) core-amorphous mixed oxide shell nanostructures immersed in an aqueous $\mathrm{HQ}$ solution $\left(10^{-3} \mathrm{~mol} \cdot \mathrm{L}^{-1}\right)$. Scan rate, $0.1 \mathrm{~V} \cdot \mathrm{s}^{-1}$.

The voltammogram recorded with a bulk gold working electrode is shown in Figure 10.5.a (dark blue curve) and 10.6.b. The entire curve presented very low intensity. Despite the low overall intensity, the voltammogram (Figure 10.6.b) showed a well-defined redox pair at $\sim 0.7$ $\mathrm{V}$ and $\sim 0.2 \mathrm{~V}$ (labeled $\mathrm{I}_{\mathrm{a}}$ and $\mathrm{I}_{\mathrm{c}}$ ), respectively. This redox process is associated with the two-electron (reduction-) oxidation process of the quinone-hydroquinone couple in buffered aqueous media ${ }^{26}$ that can be written as: $\mathrm{QH}_{2} \rightarrow \mathrm{Q}+2 \mathrm{H}^{+}+2 \mathrm{e}^{-}$.<smiles>C=CC#C[14CH2][14CH2]C1C(C)=C(C)C(=O)C(C)=C1C</smiles>

Scheme 10.1. Two-electron two-proton reduction of quinone in aqueous buffer. 
For the bulk Au electrode, several additional peaks were observed as well. The most important is the redox pair III, which is related to a weak dimerization process of the quinoid form. Notice that peak $\mathrm{III}_{\mathrm{a}}$ can be clearly observed, whereas peak $\mathrm{III}_{\mathrm{c}}$ overlaps with peak $\mathrm{I}_{\mathrm{c}}$. In addition, several cathodic peaks arising from redox processes associated with adsorbates on the gold surface (usually $-\mathrm{OH}$ of the solvent linked to the gold surface) were detected ${ }^{27}$. Importantly the current densities recorded with the bulk Au electrode were very low, rendering it almost inert and not suitable to efficiently detect the oxidation of $\mathrm{HQ}$.

The coverage of the ITO/glass electrodes with nanoparticles induced new reaction mechanisms leading to significant changes in the cyclic voltammograms. The voltammograms registered using ITO/glass electrodes with Au nanoparticles with broad distribution of sizes in the range between 1 and $20 \mathrm{~nm}$, (Figures 10.5.a (yellow curve) and 10.6.c), were characterized by a drastic increase in intensity. In addition, the presence of gold nanoparticles changes the mechanism of oxidation and the HQ molecules undergo a two-step one-electron oxidation. This led to a new peak $\left(\mathrm{II}_{\mathrm{a}}\right)$ which was clearly observed at $\sim 0.0 \mathrm{~V}$ corresponding to the first one-electron oxidation, while the second one-electron oxidation corresponded to peak $\mathrm{I}_{\mathrm{a}}$. In this case, the number of dimers was higher justifying the change in the relative intensities $\mathrm{I}_{\mathrm{a}} / \mathrm{III}_{\mathrm{a}}$. Other cathodic peaks observed were related to the redox process associated with adsorbates on the gold surface, similar to the bulk Au electrode. The current densities were large, thus, there is high electrocatalytic activity stemming from the $\mathrm{Au}$ nanoparticles. However, the $\mathrm{CV}$ was quite complicated due to the activation of several processes such as HQ oxidation, dimerization, etc.

Results for ITO working electrodes modified with Au-In nanostructures with bimetallic core and oxide shell are discussed in the following paragraphs. A characteristic voltammogram recorded with a working electrode modified by oxidized Aul $\mathrm{n}_{2}$ is shown in Figures 10.5.b (blue line) and 10.d. The voltammogram was rather simple. The onset of the 
oxidation peak was shifted by $\sim 0.3 \mathrm{~V}$ to lower potential compared to the ITO electrode, and the increase of the current was much larger.

The changes in the voltammograms were even more pronounced for ITO electrodes modified with Auln core-oxide shell nanoparticles (Figures 10.5.b and 10.6.e). Here the onset of oxidation was again shifted to lower potentials, similar to the Auln $\mathrm{n}_{2}$ modified electrode. In addition, a well-defined peak with an onset at $0.25 \mathrm{~V}$ and maximum at $\sim 0.55 \mathrm{~V}$ was observed. This behavior is consistent with the two-electron oxidation of quinone-hydroquinone couples in buffered aqueous medium ${ }^{28}$.
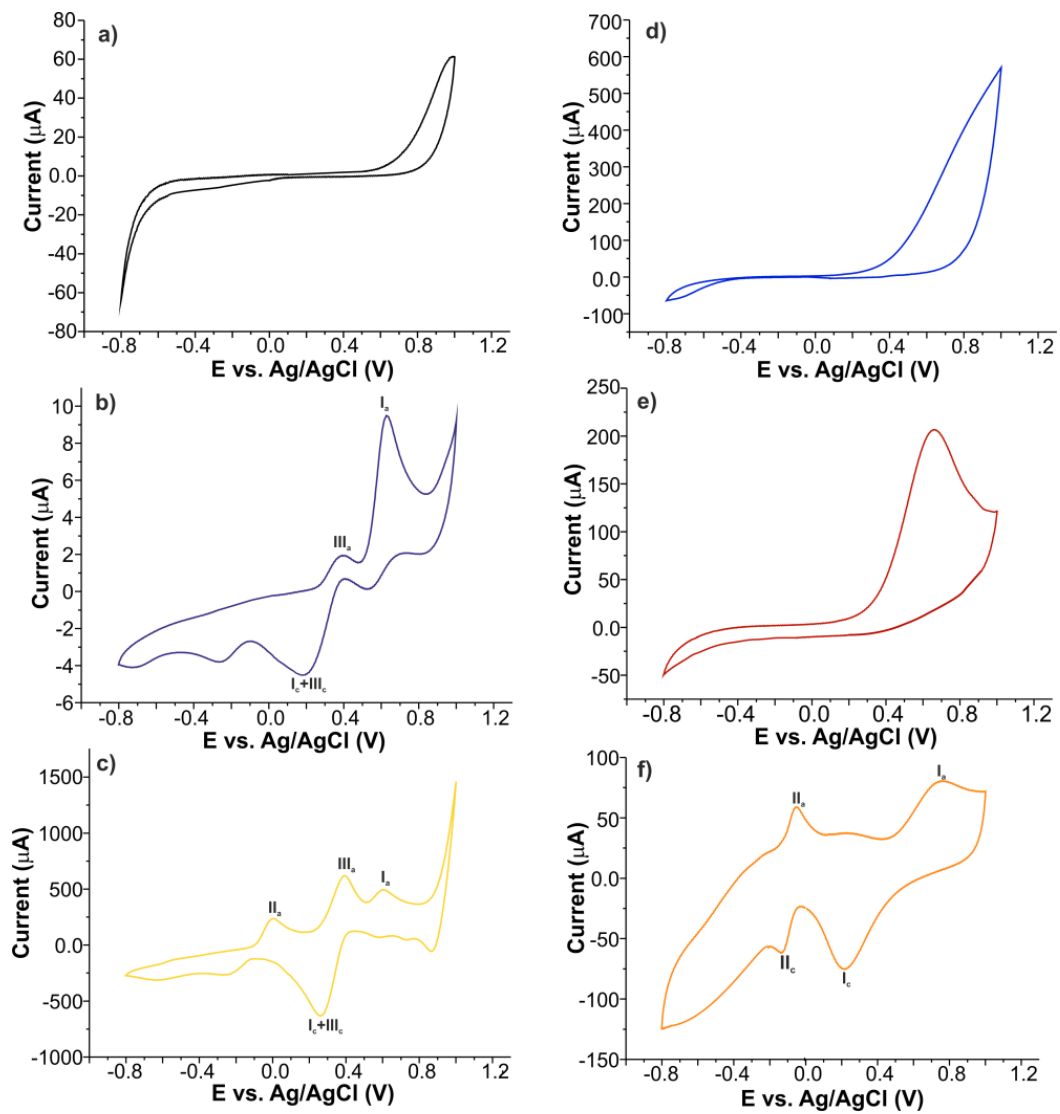

Figure 10.6. Cyclic voltammograms of a)ITO, b) bulk $\mathrm{Au}$ electrodes and electrodes modified with c) Au nanoparticles, d) Auln 2 , e) Auln and f) $\mathrm{Au}_{3} \mathrm{In}$ coreamorphous-mixed-oxide-shell nanostructures immersed in $\mathrm{HQ}\left(10^{-3} \mathrm{~mol} \cdot \mathrm{L}^{-1}\right)$. Scan rate, $0.1 \mathrm{~V} \cdot \mathrm{s}^{-1}$. 
On the extreme Au-rich side, finally, ITO electrodes modified with oxidized $\mathrm{Au}_{3} \mathrm{In}$ core-shell nanoparticles produced a fundamentally different response. Two separate anodic waves $\mathrm{I}_{\mathrm{a}}$ and $\mathrm{I}_{\mathrm{a}}$ accompanied by their corresponding reduction peaks $I_{c}$ and $I_{c}$ were observed (Figures 10.5.b and 10.6.f). This behavior is consistent with two successive oneelectron oxidation steps (Scheme 10.2) in which the first step is completely reversible, leading to the formation of semiquinone, and the second quasi-reversible step gives rise to the quinone. Such a behavior has previously been reported in aprotic solvents ${ }^{29}$, but this is the first time that this two-step oxidation process has been found in aqueous media.

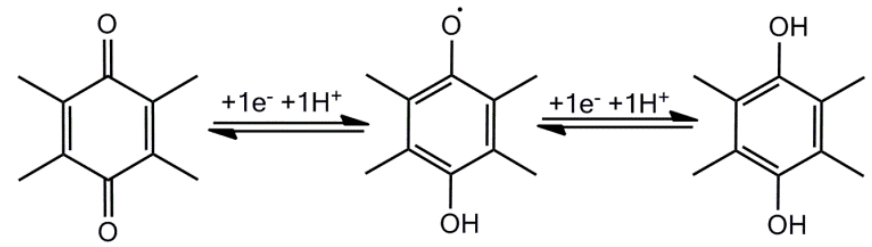

Scheme 10.2. Two-electron two-step one-electron oxidation of quinone in aqueous buffer.

From the above results, it can be concluded that Au-In core-shell nanoparticles showed clear electrocatalytic effects that depend on the $\mathrm{Au} / \mathrm{In}$ ratio of the initial alloy, which in turn determines the amount of Au stabilized in the near surface area of the oxide on the surface of these nanostructures. ITO working electrodes modified with nanoparticles with moderate Au content (Auln $\mathrm{n}_{2}$ and Auln) caused a shift of the oxidation peak to lower potentials (i.e. facilitated the oxidation) and showed much higher activity than unmodified ITO electrodes. Importantly for the detection of $\mathrm{HQ}$, the electrocatalytic (reduction-) oxidation of $\mathrm{HQ}$ on these electrodes follows a single pathway, the twoelectron oxidation of the quinone-hydroquinone couple. This contrasts with the behavior of Au nanoparticle modified ITO electrodes, which also showed large current densities (i.e. high activity) but were not selective to a single reaction mechanism and instead showed a number 
of concurrent processes. Au-rich $\mathrm{Au}_{3}$ In nanoparticle electrodes not only facilitated the oxidation but also provided a different pathway, a twosteps mechanism involving two successive one-electron oxidation steps, to the oxidation of $\mathrm{HQ}$. In general, dimerization and polymerization are avoided when Au-In nanoparticles are used as working electrodes, showing more stables responses and clearer curves. Finally, it is worth to point that $\mathrm{Au} / \mathrm{In}$ ratio influenced the intensity of the responses. The intensity of the oxidation peaks was higher when the mechanism was a two-electron process, and the intensity was much higher at low $\mathrm{Au}$ content.

\subsection{3- Dynamic behavior}

The influence of the scan rate on the peak height was also investigated in the $0.025-0.500 \mathrm{~V} \cdot \mathrm{s}^{-1}$ range. The redox peak currents increased progressively with the scan rate (Figure 10.7.a). The intensity of the peak current (measured at the voltage of oxidation or reduction of $\mathrm{HQ}$ ) scaled with the square root of the scan rate (Figure 10.7.b), which indicates a diffusion controlled mechanism for the oxidation/reduction of the antioxidant. This indicates that the high surface area of the nanostructured electrode material facilitates a rapid electron transfer between electrode surface and the analyte.

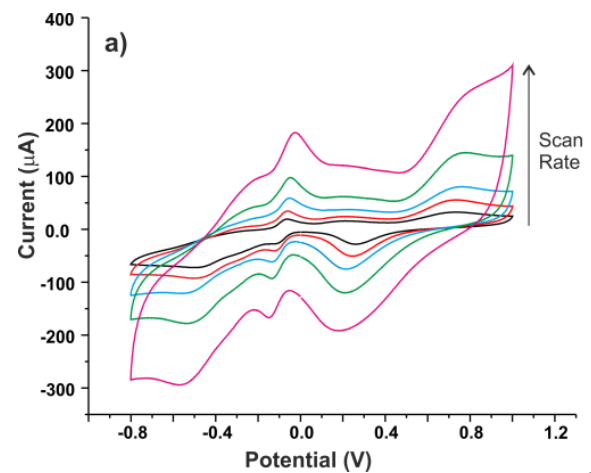

\section{b)}

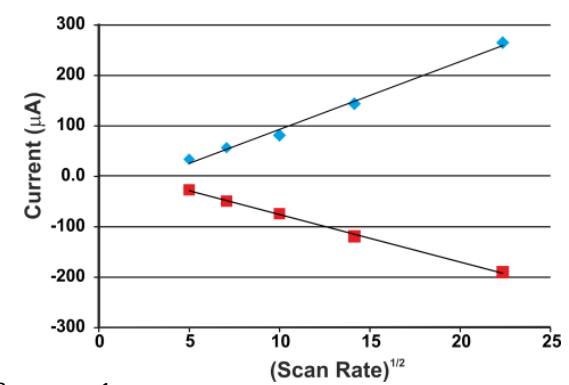

Figure 10.7. a) CVs obtained for $\mathrm{HQ}\left(10^{-3} \mathrm{~mol} \cdot \mathrm{L}^{-1}\right)$ at $\mathrm{Au}_{3} \mathrm{ln}$ modified electrode at different scan rates $\left(0.025-0.5 \mathrm{~V} \cdot \mathrm{s}^{-1}\right)$. b) Plot of peak current, measured at the voltage of oxidation ( $\bullet$ ) or reduction ( $\nabla$ ) of hydroquinone, as a function of (scan rate $)^{1 / 2}$. 
The slopes obtained of the peak current versus (scan rate) ${ }^{1 / 2}$ characteristics for the oxidation peak were different for the different alloys (Table 10.1). A higher value of the slope indicates faster charge transfer. The highest value was found for Auln nanoparticles, indicating that Auln modified working electrodes were most effective in facilitating the electrode-to-analyte charge transfer.

Table 10.1. Slope and regression coefficient of linear fits of the intensity of the anodic and cathodic peaks of the hydroquinone redox process as a function of the square root of the scan rate (between $0.025-0.5 \mathrm{~V} \cdot \mathrm{s}^{-1}$ ).

\begin{tabular}{|l|r|r|r|r|}
\hline \multirow{2}{*}{ Sensor } & \multicolumn{2}{|c|}{ Slope $\left(\boldsymbol{\mu} \mathbf{A} \cdot(\mathbf{m V} \cdot \mathbf{s})^{-1 / 2}\right)$} & \multicolumn{2}{|c|}{$\mathbf{R}^{\mathbf{2}}$} \\
\cline { 2 - 5 } & Oxidation & Reduction & Oxidation & Reduction \\
\hline Auln & 2.4 & - & 0.993 & - \\
\hline $\mathrm{Auln}_{\mathrm{yyyy}}$ & 55.0 & - & 0.994 & - \\
\hline $\mathrm{Au}_{\mathbf{3}} \mathrm{In}$ & 13.4 & 9.4 & 0.992 & 0.998 \\
\hline
\end{tabular}

\subsection{4- Limits of detection}

The effect of the concentration of $\mathrm{HQ}$ in the response of the sensors was investigated in the range $10^{-5}$ to $10^{-3} \mathrm{~mol} \cdot \mathrm{L}^{-1}$. The sensitivity was obtained from the slope of the graph. The corresponding Limits of Detection (LOD) were calculated according to the $3 \mathrm{~s}_{\mathrm{d}} / \mathrm{m}$ criterion where $\mathrm{m}$ was the slope of the calibration graph, and $s_{d}$ was estimated as the standard deviation $(n=5)$ of the signals at the concentration level corresponding to the lowest concentration of the calibration plot. Results are shown in Table 10.2.

Table 10.2. Sensitivity and LOD towards HQ for ITO working electrodes modified with different oxidized Au-In nanostructures, compared to AuNP and Au bulk electrodes. Relative standard deviation: $1.8 \%\left(\mathrm{Au}_{3} \mathrm{In}\right)$ and 7-8\% (Auln, Au NPs, bulk $\mathrm{Au}$ )

\begin{tabular}{|l|r|r|r|r|r|}
\hline & \multicolumn{1}{|c|}{ Auln $_{\mathbf{2}}$} & \multicolumn{1}{c|}{ Auln } & \multicolumn{1}{c|}{$\mathrm{Au}_{\mathbf{3}}$ In } & \multicolumn{1}{c|}{ AuNPS } & \multicolumn{1}{c|}{ Au bulk } \\
\hline Sensitivity & - & 0.201 & 0.075 & 0.487 & 0.005 \\
\hline LOD $\left(\mathrm{mol}^{-\mathrm{L}^{-1}}\right.$ ) & - & $1.33 \times 10^{-5}$ & $3.57 \times 10^{-5}$ & $5.49 \times 10^{-6}$ & $5.05 \times 10^{-4}$ \\
\hline
\end{tabular}


The LODs decreased when increasing the amount of Au exposed on the amorphous oxide surface. The LODs were determined to be in the range of $10^{-5}-10^{-6} \mathrm{~mol} \cdot \mathrm{L}^{-1}$ and were lower than those obtained using bulk Au. However, it is important to notice that Auln $\mathrm{n}_{2}$ cores did not show good electrocatalytic properties, and peaks associated to $\mathrm{HQ}$ shifted to even higher potentials when increasing the concentration of antioxidant. For this reason, the limit of detection could not be calculated accurately for Auln ${ }_{2}$ films.

To establish the reproducibility of the measurements with the different electrodes the determination of $10^{-3} \mathrm{~mol} \cdot \mathrm{L}^{-1} \mathrm{HQ}$ was repeated six times. The first cycle was always different from the rest of the scans and was discarded. This behavior is typically observed in chemically modified electrodes and is due to the diffusion of ions inside/outside the films. In the case of $\mathrm{Au}_{3} \mathrm{In}$, subsequent cycles achieved a good reproducibility with a relative standard deviation (RSD) of $1.8 \%$. In the rest of the films studied the intensity of the signals decreased progressively and the RSD calculated was in the range of $7-8 \%$.

\subsection{CONCLUSIONS}

Oxidized Au-In core-shell nanoparticles with different compositions were investigated as electrocatalysts for the (reduction-) oxidation of $\mathrm{HQ}$. The nanoparticles were characterized by TEM, XPS and ISS measurements and these combined measurements demonstrated that the amorphous mixed oxide shells formed on the Au-In nanoparticles with different alloy compositions had different amount of $\mathrm{Au}$ and In on the surface. ITO electrodes modified with oxidized Au-In core-shell nanostructures present different electrocatalytic activity depending on the amount of Au stabilized on their surfaces. Nanoparticles with Auln $n_{2}$ and Auln core surrounded by oxide shells produced a displacement of the onset of the peak to lower potentials, whereas $\mathrm{Au}_{3}$ In samples caused two separate anodic peaks with their corresponding cathodic waves. It can be concluded that among the investigated alloy compositions the oxidized Auln core-shell nanoparticles promise the best performance for the analysis of antioxidants due to the excellent range where the redox 
peaks are detected, the excellent definition of the redox peaks with high intensity, and enhancement of the charge transfer. 


\section{References}

1. Vauzour, D., Rodriguez-Mateos, A., Corona, G., Oruna-Concha, M.J., Spencer, J.P.E. Nutrients. 2010, 2, 1106-1131.

2. Zhang, F., Li, M.A., Li, W.Q., Feng, C.P., Jin, Y.X., Guo, X., Cui, J.G. Chem. Eng. J. 2011, 175, 349-355.

3. Pistonesi, M.F., Di Nezio, M.S., Centurion, M., Palomeque, M.E., Lista, A.G., Band, B.S.F. Talanta. 2006, 69, 1265-1268.

4. Cui, H., Zhang, Q.L., Myint, A., Ge, X.W., Liu, L.J. J. Photoch. Photobio. A. 2006, 181, 238-245.

5. Liu, C., Wang, J., Yang, Y.L. Anal. Methods-UK. 2014, 6, 6038-6043.

6. Sakthinathan, S., Palanisamy, S., Chen, S.M., Wu, P.S., Yao, L., Lou, B.S. Int. J. Electrochem. Sci. 2015, 10, 3319-3328.

7. Campbell, F.W., Compton, R.G. Anal. Bioanal. Chem. 2010, 396, 241259.

8. Kuralkar, M., Ingle, A., Gaikwad, S., Gade, A., Rai, M. IET Nanobiotechnology [Online], 2015, 66-70. http://digitallibrary.theiet.org/content/journals/10.1049/iet-nbt.2014.0004.

9. Kilic, M.S., Korkut, S., Hazer, B., Erhan, E. Biosens. Bioelectron. 2014, 61, 500-505.

10. Zhao, Z., Zhang, M., Li, Y., Cheng, S., Chen, X., Wang, J. Anal. Lett. 2015, 48, 1437-1453.

11. Medina-Plaza, C., Furini, L.N., Constantino, C.J.L., de Saja, J.A., Rodriguez-Mendez, M.L. Anal. Chim. Acta. 2014, 851, 95-102.

12. Lin, X., Ni, Y., Li, S., Kokot, S. Analyst. 2012, 137, 2086-2094.

13. Medina-Plaza, C., García-Cabezón, C., García-Hernández, C., Bramorski, C., Blanco-Val, Y., Martín-Pedrosa, F., Kawai, T., de Saja, J. A., Rodríguez-Méndez, M. L. Anal. Chim. Acta. 2015, 853, 572-578. 
14. Chuang, M.K., Lin, S.W., Chen, F.C., Chu, C.W., Hsu, C.S. Nanoscale. 2014, 6, 1573-1579.

15. Vijayakumar, C., Balan, B., Saeki, A., Tsuda, T., Kuwabata, S., Seki, S. J. Phys. Chem. C. 2012, 116, 17343-17350.

16. Corma, A., Concepción, P., Boronat, M., Sabater, M. J., Navas, J., Yacaman, M.J., Larios, E., Posadas, A., López-Quintela, M.A., Buceta, D., Mendoza, E., Guilera, G., Mayoral, A. Nat. Chem. 2013, 5, 775-781.

17. Zhang, J., Sasaki, K., Sutter, E., Adzic, R.R. Science. 2007, 315, 220222.

18. Sutter, E.A., Tong, X., Jungjohann, K., Sutter, P.W. P. Natl. Acad. Sci. USA. 2013, 110, 10519-10524.

19. Sutter, E., Sutter, P. J. Phys. Chem. C. 2012, 116, 20574-20578.

20. Robinson, M.C., Slavin, A.J. Phys. Rev. B. 1996, 54, 14087-14092.

21. Jayne, D.T., Fatemi, N.S., Weizer, V.G. J. Vac. Sci. Tech. A 1991, 9, 1410-1415.

22. Bailey, S.I., Ritchie, I.M. Electrochim. Acta. 1985, 30, 3-12.

23. Deplanche, K., Merroun, M.L., Casadesus, M., Tran, D.T., Mikheenko, I.P., Bennett, J.A., Zhu, J., Jones, I.P., Attard, G.A., Wood, J., SelenskaPobell, S., Macaskie, L.E. J. R. Soc. Interface. 2012, 9, 1705-1712.

24. Guin, P.S., Das, S., Mandal, P.C. Int. J. Electrochem. 2011, 2011, 22.

25. Gupta, N., Linschitz, H. J. Am. Chem. Soc. 1997, 119, 6384-6391. 


\section{CHAPTER 11}

Final Conclusions 

According to the objectives stablished and the results obtained, the conclusions reached during the elaboration of this thesis are the following:

1- Voltammetric sensors and biosensors have been desingned and developed using different techniques and electrocatalytic materials. They have been successfully used to the analysis of diverse analytes present in musts such antioxidants (catechol, hydroquinone...), organic acids and sugars.

a) Functionalized ( $n$-dodecanethiol) gold nanoparticles sensors were successfully developed by Langmuir-Blodgett technique. The modified electrodes showed an enhancement in the sensitivity towards organic and phenolic acids (malic, tartaric, lactic, gallic and cafeic), an increase in the current and a shift of the potential in the less positive direction, compared to an ITO bare electrode. Efficient catalytic activity was also observed in mixtures of tartaric/caffeic acid, being the electrode able to provide simultaneous information about the concentrations of both analytes without any interference.

b) Lutetium Bis-Octachloro-Phthalocyanate sensors were developed by Langmuir Blodgett and Lagmuir-Schaefer techniques. The nanostructure of the films is responsible of the improved electrochemical behavior towards the analysis of catechol when compared with cast film. The sensors presented good stability and sensitivity reaching limits of detection around $10^{-5} \mathrm{~mol} \cdot \mathrm{L}^{-1}$.

c) Two electrocatalytic materials (functionalized gold nanoparticles and lutetium bisphthalocyanine) were deposited onto ITO glass using Langmuir-Blodgett technique. Synergistic electrocatalytic effect was observed towards the analysis of hydroquinone, getting an increase in the current and limits of detection in the order of $10^{-7} \mathrm{~mol}$. $\mathrm{L}^{-1}$.

d) Carbon paste electrodes of dilithium phthalocyanine were prepared using different carbonaceous materials (graphite, carbon 
microspheres and multiwall carbon nanotubes). The electrochemical response of the electrode was found to be dependent on the nature of the matrix. The electrodes were used to analyze citric acid facilitating the oxidation of the analyte. Synergistic effect was also found when $\mathrm{MWCNT}$ and $\mathrm{LiPc}_{2}$ were used, improving the electrocatalytic activity.

e) Au-In alloy-oxide core-shell particles prepared by magnetron sputtering showed electrocatalitic effect towards the detection of hydroquinone. The electrocatalytic activity and the mechanism of the redox process depended on the amount of Au stabilized on the surface. Limits of detection in the order of $10^{-5}-10^{-6} \mathrm{~mol} \cdot \mathrm{L}^{-1}$ were reached.

2- Arrays of sensors and biosensors have been applied to the discrimination of musts from different varities of grapes. In order to get information about the behavior of the electrodes, model solutions were analyzed previously to the samples.

a) An electronic tongue formed by sensors and biosensors containing different metallophthalocyanines and enzymes (tyrosinase and glucose oxidase) was developed using carbon paste technique. The response was found to be dependent on the nature of the phthalocyanine and improved by the presence of the enzymes. The array was applied to analyze musts of different varieties of red grapes and its capability of discrimination was evidenced using Principal Component Analysis. The selectivity of the multisensor system and its capability of discrimination were clearly improved when biosensors were included in the array.

b) Commercial screen-printed electrodes were modified with enzymes (tyrosinase and glucose oxidase) in order to obtain a multisensory system devoted to the discrimination of red grapes varieties. The sensors presented different electron mediators: carbon, platinum, Prussian blue, gold, graphene and nickel oxide nanoparticles. The hybrid array was able to discriminate samples from different varieties of grapes as shown by Principal Component Analysis. The results obtained presented good correlation with ${ }^{\circ}$ Brix and Total 
Polyphenol Index analyzed by traditional methods. The advantages of this hybrid electronic tongue are the lower price of the sensors, easy use and portability of the system.

c) A bioelectronic tongue formed by nanostructured biosensors containing phenol oxidases (laccase and tyrosinase) was developed using Langmuir-Blodgett technique. Lutetium bisphthalocyanine was used as electron mediator and arachidic acid as a lipid in order to mimic cell membranes. Biomimetic structure improved enzymes performance allowing getting limits of detection around $10^{-8} \mathrm{~mol} \cdot \mathrm{L}^{-1}$. The array was able to discriminate model solutions of phenols according to the number of phenolic groups present on their structure and musts from different varieties of grapes according to their total polyphenolic content as demonstrated by Principal Component Analysis.

3- A bioelectronic tongue containing enzymes devoted to the detection of phenols (tyrosinase and laccase) and sugars (glucose oxidase and D-fructose dehydrogenase) was employed to monitor the ripening process of the grapes.

a) Enzymes were imbibed in a biomimetic environment using Langmuir-Blodgett technique to increase their performance. Lutetium bisphtalocyanine was employed as electron mediator to improve the electron transfer within the electrode.

b) Musts from different varieties of red grapes were discriminated using the bioarray of sensors. The scores plot obtained using Principal Component Analysis places the must on the basis of the phenolic content and sugar concentration. In addition, when samples of the same variety and harvested in different vintages were analyzed the system was able to discriminate them according to the variety and the vintage.

c) The bioelectronic tongue was used to analyze grapes harvested from the veraison to over-ripening in a weekly basis. Principal Component Analysis showed a clear discrimination of the samples 
collected during the progression of ripening being able to follow the maturing process.

d) The results obtained using the array of biosensors were correlated to the traditional chemical parameters by means of Partial Least Square-1 obtaining excellent correlations for all parameters related to sugar and phenolic content. 
RESUMEN EN ESPAÑOL 



\section{1- INTRODUCCIÓN}

El sector de agroalimentación constituye una de las bases más importantes de la economía de Castilla y León, originando un cuarto de la producción industrial de la región. La industria enológica es uno de los sectores más tradicionales e importantes de Castilla y León donde el vino de calidad es considerado patrimonio cultural y gastronómico.

En los últimos años el sector enológico has sido confirmado como una de las partes más dinámicas en el sector agroalimentario en Castilla y León. La región presenta más de 75000 hectáreas de viñedos con más de 5750 trabajadores. Tiene 530 bodegas que producen más de 200 millones de litros de vino al año. La región presenta diez denominaciones de origen y el $86 \%$ de los viñedos están dedicados a estos signos de calidad. En 2013, el valor económico de este sector alcanzó los 738 millones de euros, siendo 134 generados por la exportación.

Los principales objetivos de las tecnologías llevadas a cabo durante el proceso de obtención del vino están centrados en una extracción efectiva de los compuestos fenólicos que son los responsables del color, sabor y aromas de los vinos y el control de la fermentación del azúcar que está directamente relacionado con el grado alcohólico del producto final.

Como materia prima de la industria enológica la calidad de las uvas debe ser controlada, ya que ésta influye directamente en la calidad del vino. Para obtener uvas con las mejores características es necesario controlar, no sólo la uva madura sino también el proceso de maduración de la misma.

Tradicionalmente el control de la maduración de la uva se lleva a cabo mediante la evaluación de una serie de correlaciones teóricas denominadas "índices de maduración" consistentes en ciertas formulaciones matemáticas propuestas para estimar el punto óptimo de maduración de la uva. 
Los índices de maduración externos se basan en el análisis organoléptico de las bayas, determinando características propias de la maduración como el color del grano y el peso del racimo mientras que, los índices de maduración químicos se basan en la determinación analítica de los compuestos más característicos que aumentan o disminuyen en el proceso de maduración como la acidez o la concentración de azúcares. El método de cata complementa los análisis físico-químicos que tradicionalmente se llevan a cabo (contenido fenólico, grado, azúcares, acidez, etc.) mediante métodos espectroscópicos, ópticos o electroquímicos.

Existe una necesidad de desarrollar nuevos métodos objetivos y rápidos que permitan establecer el momento óptimo de la maduración, un factor fundamental para la calidad del vino.

En los últimos años se ha desarrollado un novedoso instrumento llamado lengua electrónica que opera de manera análoga a los sentidos humanos pudiendo percibir sabores y ser aplicada al análisis de líquidos complejos. Según la definición dada por la IUPAC, estos sistemas se basan en la combinación de sensores electroquímicos no selectivos con gran selectividad cruzada acoplados con métodos quimiométricos (PCA, LDA, ANN). El sistema es capaz de detectar simultáneamente una gran cantidad de compuestos proporcionando información global de la muestra, en lugar de información de componentes específicos

La mayoría de los trabajos en el campo de las lenguas electrónicas aplicadas a la enología utilizan redes de sensores potenciométricos donde se mide el potencial de membrana creado por la difusión de iones a través de una membrana selectiva. También se han descrito sensores impedimétricos y amperométricos modificados con diferentes materiales como ftalocianinas, polímeros conductores, nanopartículas...

La posibilidad de utilizar electrodos voltamétricos es especialmente interesante debido a su alta sensibilidad y versatilidad, ya que es posible modular el rango de potencial, la forma de la curva y el material del 
electrodo. Esta versatilidad permite obtener diferentes sensores con diferente selectividad y sensitividad.

La selectividad de estos dispositivos se puede aumentar modificando la superficie de los mismos con materiales electroactivos. Las interacciones que ocurren entre el electrodo y la disolución pueden aumentar extraordinariamente la selectividad del análisis. Esas interacciones incluyen:

i) El carácter oxidante o reductor de la disolución puede modificar el potencial de oxidación del material electródico.

ii) La actividad electrocatalítica del material del electrodo puede facilitar la oxidación de los compuestos disueltos en la disolución de estudio.

iii) La respuesta del material del electrodo está relacionada con la capacidad del sensor para permitir la difusión de los iones entre la disolución y la masa electrónica, este flujo es necesario para conservar la electroneutralidad macroscópica del electrodo.

Pueden usarse diferentes familias de materiales como modificadores, por ejemplo, polímeros conductores, ftalocianinas, nanopartículas... Se ha demostrado que el empleo de diferentes materiales sensibles con reactividad complementaria mejora la selectividad cruzada del conjunto de sensores y aumenta su capacidad de discriminación (Figura 1).
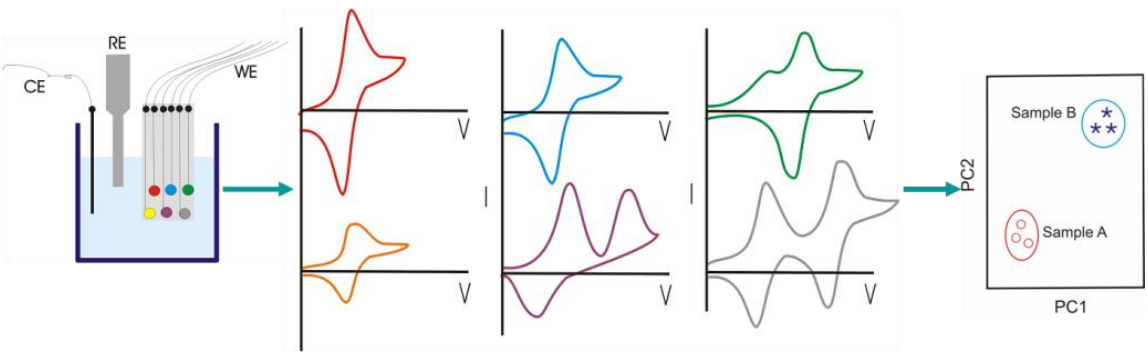

Figura 1. Ilustración de la selectividad cruzada obtenida con sensores voltamétricos modificados con materiales electroactivos diferentes. Red expuesta a la misma sustancia. 
Durante los últimos años, se han hecho muchos esfuerzos para desarrollar biosensores electroquímicos enzimáticos para la detección de diversos compuestos y en especial antioxidantes y azúcares. Las enzimas reaccionan con sustratos específicos consumiendo oxígeno (oxidasas) o produciendo la forma reducida del $\mathrm{NAD}(\mathrm{P}) \mathrm{H}$ (deshidrogenasas). Estas transformaciones pueden medirse mediante métodos electroquímicos.

Los sensores y biosensores pueden ser preparados mediante diferentes técnicas (pasta de carbono, spin coating, screen printed...). Dependiendo del método utilizado, se pueden obtener diferentes morfologías en la superficie del electrodo que influyen directamente en el comportamiento del mismo y en la respuesta obtenida.

El uso de nanotecnología aporta nuevas perspectivas en el desarrollo de sensores ya que permite obtener dispositivos con una alta relación superficie-volumen, facilitando la difusión de iones dentro de la película. Las películas nanoestructuradas preparadas mediante self-assemblig (SAM), Layer by Layer (LbL) o Langmuir-Blodgett (LB) han mostrado una interesante capacidad como sensores para una gran variedad de sustancias, con cinéticas más rápidas que los electrodos tradicionales.

Los éxitos en investigaciones previas en la aplicación de lenguas electrónicas en el campo de la enología han hecho al grupo profundizar en esta línea de investigación desarrollando nuevas redes de sensores aplicadas en el control de calidad y madurez de la uva.

\section{2- OBJETIVOS}

De acuerdo con estas ideas generales los objetivos de la presente tesis son:

1- Diseñar nuevos sensores y biosensores voltamétricos modificados con diferentes materiales electrocatalíticos (nanopartículas, ftalocianinas...) y enzimas (tirosinasa, lacasa, glucosa oxidasa y Dfructosa deshidrogenasa). 
2- Desarrollar nuevas tecnologías para depositar los materiales sesibles y para inmobilizar los enzimas. Los métodos varían desde técnicas simples que permiten preparar sensores sencillos y baratos hasta técnicas más sofisticadas que producen sensores nanostructurados con mejores prestaciones pero a un coste mayor.

3- Aplicar estos sensores en el análisis de diferentes analitos de interés en la industria enológica como antioxidantes, azúcares y ácidos orgánicos.

4- Combinar los sensores y biosensores para obtener lenguas (bio)electrónicas aplicadas al análisis de mostos.

5- Desarrollar una lengua bioelectrónica que contenga enzimas para la detección de fenoles y azúcares y aplicarla en el control de maduración de uvas.

\section{3- METOD OLOGÍA Y RESULTADOS}

Para alcanzar los objetivos fijados en esta tesis se han llevado a cabo los siguientes experimentos, obteniendo los resultados que se presentan a continuación:

\subsection{Sensores nanostructurados mediante la técnica de} Langmuir-Blodgett

La técnica de Langmuir-Blodgett permite controlar la estructura del sensor a nivel nanométrico aumentando la superficie de interacción entre el electrodo y el analito. Empleando esta técnica se han desarrollado cinco trabajos a lo largo de esta tesis.

El primer trabajo consistió en el uso de nanopartículas de oro funcionalizadas con dodecanotiol como modificador. En primer lugar se evaluó la respuesta de las nanopartículas frente a electrolitos básicos como $\mathrm{KCl}, \mathrm{KBr}, \mathrm{KNO}_{3}, \mathrm{KClO}_{4}$ y $\mathrm{MgCl}_{2}$. Los voltamogramas obtenidos en electrolitos que contenían potasio fueron muy parecidos y mostraban los picos característicos de las nanopartículas sin embargo, en presencia de cationes divalentes la intensidad de estos picos se vio reducida. De estos resultados se pudo concluir que son los cationes quienes difunden 
en el electrodo para mantener la electroneutralidad además, el estudio del comportamiento dinámico indicó que el proceso está controlado por transferencia electrónica. Cuando se analizaron ácidos orgánicos se observaron los picos típicos de los protones a potenciales negativos siendo posible distinguir entre ácidos monopróticos (tartárico) y dipróticos o tripróticos (málico y cítrico). En el caso de los ácidos fenólicos, los voltamogramas estaban dominados por los picos correspondientes al proceso oxidativo de los fenoles en un rango de potenciales entre 0.5-0.8 V. En ambos casos el proceso estuvo controlado por la difusión de iones y los límites de detección encontrados para todas las especies analizadas fueron de $10^{-5}-10^{-6} \mathrm{~mol}$. $\mathrm{L}^{-1}$. En último lugar se llevó a cabo el análisis de mezclas de ácido tartárico y ácido cafeico siendo posible la determinación de ambos sin ninguna interferencia.

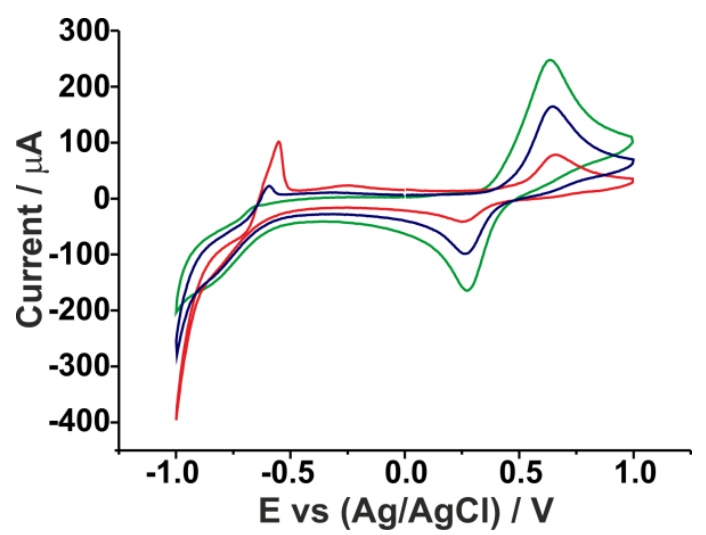

Figura 4. Voltamograma registrado empleando el sensor de AuNP-LB en mezclas de cafeico:tartárico: 40:10 (línea verde), 25:25 (línea azul) y 10:40 (línea roja).

En segundo lugar se analizaron las propiedades electroquímicas de bisoctacloro-ftalocianato de lutecio $\left(\mathrm{LuPc}_{2} \mathrm{Cl}_{32}\right)$ y se compararon con resultados obtenidos con sensores modificados con bisftalocianina de lutecio $\left(\mathrm{LuPC}_{2}\right)$. También se prepararon sensores mediante la técnica de Langmuir-Schaefer comprobando si la deposición de las películas sobre el electrodo influía en las propiedades finales del sensor. La 
caracterización estructural se llevó a cabo mediante UV-Visible, espectrometría de infrarrojo y de Raman. Los resultados obtenidos para ambos tipos de películas fueron muy similares aunque difirieron de aquellos encontrados en disolución o para películas no organizadas realizadas mediante la técnica de casting. Las propiedades electroquímicas de los sensores fueron testadas frente a una disolución de catecol. La presencia de $\mathrm{LuPC}_{2} \mathrm{Cl}_{32}$ y $\mathrm{LuPC}_{2}$ provocó un desplazamiento de los picos relacionados con los procesos redox del catecol hacia potenciales menores y un aumento en la intensidad de corriente, evidenciando el efecto electrocatalítico de ambas. Además, la presencia de los sustituyentes clorados produjo una mayor desplazamiento y un aumento de corriente mayor ( $25 \%$ versus $10 \%$ para $\mathrm{LuPc}_{2}$ ). El análisis del comportamiento dinámico evidenció un proceso controlado por transferencia electrónica en ambos casos. Los límites de detección calculados para este tipo de sensores fueron de $10^{-5} \mathrm{~mol} \cdot \mathrm{L}^{-1}$.

En un tercer trabajo, se empleó la técnica de Langmuir-Blodgett para modificar electrodos con dos moléculas electrocatalíticas como son las nanopartículas de oro (AuNPs) y la bisftalocianina de lutecio ( $\mathrm{LuPC}_{2}$ ). La formación de películas delgadas de $\mathrm{LuPc}_{2}$ permitió la inclusión de AuNP solubles en agua mediante la adsorción de las mismas en la película de Langmuir. La formación de películas estables y homogéneas fue comprobada empleando microscopía de ángulo de Brewster (BAM), UVVisible y espectrometría de Raman, así como microscopía electrónica de barrido (SEM) y de transmisión (TEM). El efecto electrocatalítico de ambos materiales se caracterizó mediante el análisis de hidroquinona. La presencia de ambos electrocatalizadores se tradujo en un desplazamiento hacia potenciales menores de los picos asociados a los procesos redox del antioxidante así como un aumento de la intensidad de corriente. Los límites de detección encontrados para este tipo de sensores fueron de $10^{-7} \mathrm{~mol} \cdot \mathrm{L}^{-1}$ corroborando así la mejora alcanzada. EI comportamiento dinámico de los sensores estuvo controlado por el proceso de difusión. Además, cuando se compararon los resultados obtenidos con sensores de $\mathrm{LuPC}_{2}$ con y sin AuNPs, se encontró que la 
velocidad del proceso de transferencia era dos veces más rápida con la presencia de AuNPs.

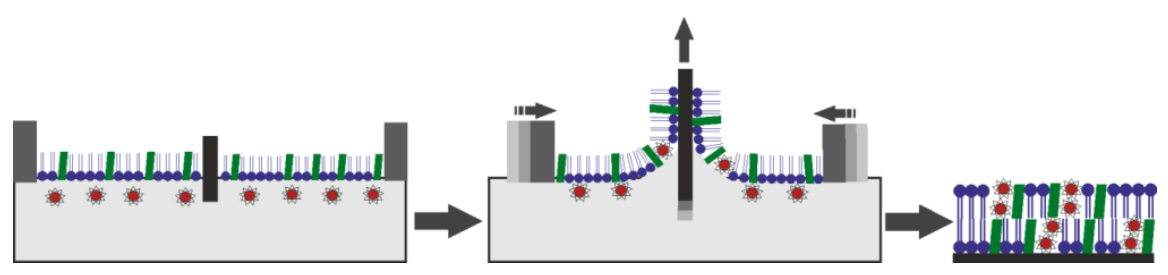

Figura 5. Método de preparación de películas de $\mathrm{LuPc}_{2}: \mathrm{DODAB} / \mathrm{AuNPs}: \| D O D A B$, LuPc $_{2}$, AuNPs.

A la hora de preparar biosensores preservar la actividad del enzima es un paso clave. La técnica de Langmui-Blodgett permite preparar películas formadas por lípidos que simulan las membranas celulares en las cuales los enzimas son absorbidos, favoreciendo así su actividad. En un cuarto trabajo, se desarrolló una lengua bioelectrónica destinada al análisis de fenoles y como objetivo final, la discriminación de mostos. Para ello se empleó ácido araquídico como lípido para simular la membrana celular, $\mathrm{LuPc}_{2}$ como mediador electrónico y tirosinasa y lacasa como enzimas específicos para el análisis de antioxidantes. La caracterización estructural de las películas y de los sensores se llevó a cabo mediante isotermas, BAM y miscroscopía de fuerza atómica (AFM). Todas las técnicas corroboraron la presencia del enzima tanto en las películas como en los sensores. En primer lugar se realizó la caracterización electroquímica de los electrodos frente a disoluciones de distintos tipos de fenoles (mono, di y tri-fenoles). Todos los sensores proporcionaron una respuesta diferente demostrando la selectividad cruzada de la red y evidenciando la especificidad enzima-sustrato. Los límites de detección alcanzados fueron del orden $10^{-7}-10^{-8} \mathrm{~mol} \cdot \mathrm{L}^{-1}$. La PCA de estos resultados demostró que la red no sólo es capaz de discriminar las muestras sino que éstas aparecen organizadas en función de los grupos fenólicos presentes en su estructura. Cuando la lengua bioelectrónica fue empleada para el análisis de mostos, las muestras fueron discriminadas en función de su contenido polifenólico. 
Debido al buen funcionamiento de la red anterior, decidimos ampliarla con enzimas específicos para el análisis de azúcares y llevar a cabo en análisis de mostos desde el envero hasta post-vendimia. La caracterización de las películas y sensores con glucosa oxidasa y dfructosa deshidrogenasa se realizó mediante isotermas y BAM. El incremento en el área por molécula encontrado con la inclusión de los enzimas en la película y el cambio en la rugosidad de las mismas confirmó la absorción de las proteínas en la monocapa de Langmuir. En un primer set de experimentos se analizaron mostos de 5 variedades de uvas cosechados en dos años consecutivos (2012 y 2013). Los voltamogramas mostraron picos asociados tanto a fenoles como a azúcares obteniendo diferentes respuestas en función del sensor empleado. La PCA de esto resultados mostró que la red era capaz no solo de discriminar los mostos sino de agruparlos por variedades, a pesar de las añadas, y en función de su composición química. Este resultado evidenció que la lengua bioelectrónica produce una respuesta muy semejante a los análisis tradicionales donde las características fundamentales de cada variedad se mantienen a lo largo de las añadas.

Cuando se analizaron muestras con diferente grado de maduración se observó que los cambios encontrados en los voltamogramas estaban de acuerdo con los cambios en la composición química de la uva. Los resultados de la PCA mostraron la capacidad de la red para seguir el proceso de maduración de la baya. Los clusters pertenecientes a las muestras analizadas desde el envero hasta la vendimia se encuentran colocados en el sentido de las agujas del reloj, mientras que las muestras cosechadas después de la vendimia no siguen esa tendencia. En último lugar se llevaron a cabo correlaciones entre los resultados electroquímicos obtenidos con la lengua bioelectrónica y los parámetros químicos tradicionales encontrando excelentes correlaciones con los parámetros relacionados con el azúcar, los fenoles e incluso el $\mathrm{pH}$ debido a su influencia en el comportamiento de los enzimas. 


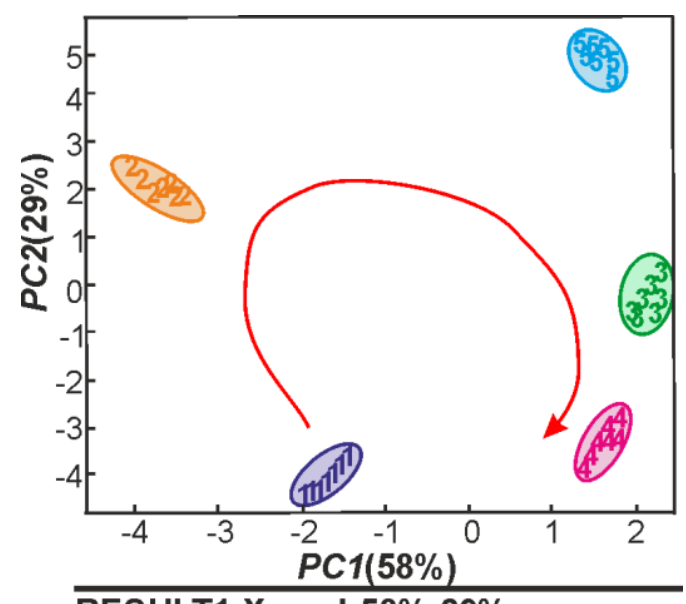

RESULT1,Xexpl:58\%,29\%

Figura 6. Gráfico de Scores que ilustra la capacidad de discriminación de la lengua bioelectrónica inmersa en mostos de la variedad Tempranillo (año 2013). 1-primera semana (envero), 2-segunda semana, 3- tercera semana, 4cuarta semana (vendimia) y 5- quinta semana (post-vendimia).

\subsection{Sensores de pasta de carbono}

Los sensores de pasta de carbono se prepararon mediante la mezcla de un material carbonaceo con un aglutinante y añadiendo a la mezcla, en caso necesario, un modificador. La pasta obtenida se comprimió en el interior de un tubo de PVC empleando como contacto un hilo de cobre. En esta tesis se han desarrollado dos trabajos diferentes basados en electrodos de pasta de carbono.

En primer lugar se desarrollaron sensores formados por diferentes materiales carbonaceos (polvo de grafito, microesferas de carbono y nanotubos de carbono) incluyendo ftalocianina de dilitio $\left(\mathrm{Li}_{2} \mathrm{Pc}\right)$ como modificador. Las respuestas voltamétricas obtenidas frente a una disolución de ácido cítrico mostraron ser dependientes del material carbonaceo empleado como matriz del sensor. $\mathrm{Li}_{2} \mathrm{Pc}$ presentó un efecto electrocatalítico aumentando las intensidades de corriente de los picos asociados al ácido cítrico en un orden de magnitud comparado con los electrodos de carbono sin modificar. Además, la combinación de nanotubos de carbono con $\mathrm{Li}_{2} \mathrm{Pc}$ produjo un efecto sinérgico que mejoró 
el efecto electrocatalítico frente al ácido cítrico. El análisis del comportamiento dinámico mostró que las respuestas de los tres sensores estaban controladas por un mecanismo de difusión.

En segundo lugar se desarrolló una lengua electrónica formada por sensores y biosensores modificados con distintas ftalocianinas cuyo objetivo final fue la discriminación de variedades de uvas tintas. Los sensores de pasta de carbono se modificaron con distintas ftalocianinas metálicas: ftalocianina de cobre ( $\mathrm{CuPc}$ ), ftalocianina de cobalto (CoPc), ftalocinina de cinc $(\mathrm{ZnPC})$ and bisftalocianina de lutecio $\left(\mathrm{LuPC}_{2}\right)$. Los biosensores se prepararon mediante la técnica de casting and crosslinking. Una gota de la disolución del enzima deseado (tirosinasa o glucosa oxidasa) se depositó en la superficie del electrodo y una vez que el disolvente se evaporó, se llevó a cabo el proceso de cross-linking con una disolución de glutaraldehído. En un primer set de experimentos se analizó la respuesta de los diferentes sensores frente a disoluciones patrón de glucosa y catecol a dos pHs diferentes (3.1 y 7.0) observándose que la respuesta obtenida dependió del metal central de la ftalocianina y del pH de la disolución. La inclusión de los enzimas demostró una mejora en la detección de los analitos, catecol en el caso de la tirosinasa y glucosa para glucosa oxidasa, incrementando las intensidades de los picos asociados con sus procesos redox $y$ desplazando los mismos hacia potenciales menores. Una vez comprobado el buen funcionamiento de los sensores en la detección de azúcares y fenoles, fueron empleados para el análisis de mostos. Para disminuir la complejidad de la muestra, los mostos a analizar fueron diluidos 1:2 en agua. Los voltamogramas mostraron picos relacionados tanto con los fenoles como con los azúcares aunque debido a la complejidad del medio estos fueron más anchos que los encontrados para las disoluciones patrón. Cada electrodo mostró una respuesta diferente para cada muestra analizada evidenciando la alta selectividad cruzada alcanzada con la red. El Análisis de Componentes Principales (PCA) demostró que la lengua electrónica era capaz de discriminar las muestras de mostos. Este resultado mejoró cuando los biosensores 
fueron incluidos en la red, organizando las muestras en el gráfico en función de su composición química.

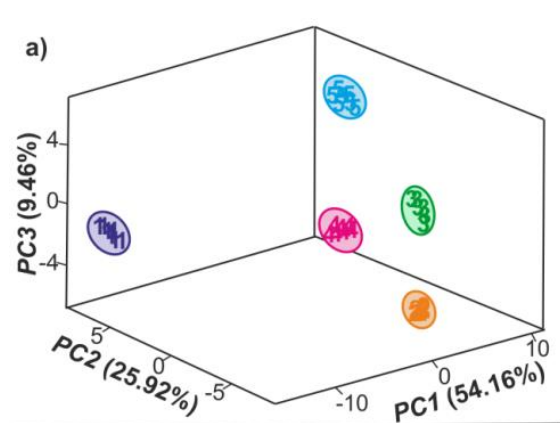

RESULT1,X-expl:54.16\%,25.92\%,9.46\%

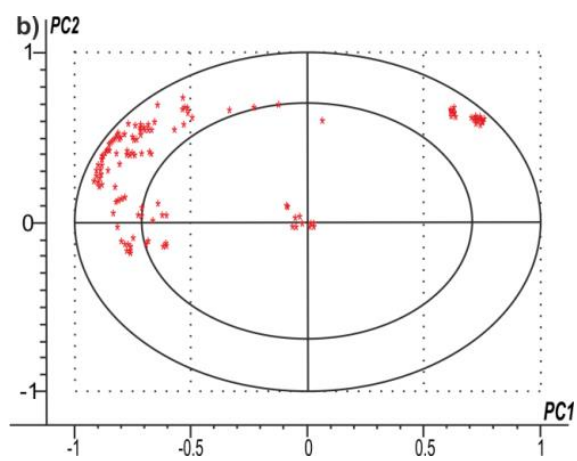

Figura 3. PCA de los resultados obtenidos del análisis de mostos con la lengua bioelectrónica. a) Gráfico de Scores. 1- Tempranillo, 2- Prieto Picudo, 3- Mencía, 4- Cabernet-Sauvignon, 5- Garnacha. b) Gráfico de loadings donde aparecen 10 variables por cada sensor de la red.

\subsection{Sensores serigrafiados}

Electrodos serigrafiados desechables fueron modificados con enzimas (tirosinasa y glucosa oxidasa) para formar una lengua bioelectronica dedicada a la discriminación de mostos. Los mediadores electrónicos empleados en el estudio fueron: carbono, platino, oro, grafeno, azul de Prusia y nanopartículas de óxido de níquel. Los biosensores fueron modificados con enzimas mediante la técnica de casting seguida de cross-linking. Un gota de la disolución del enzima deseado (tirosinasa o glucosa oxidasa) se depositó en la superficie del electrodo de trabajo y una vez que el disolvente se evaporó se llevó a cabo el proceso de crosslinking con vapores de glutaraldehído. Durante este proceso, el electrodo de referencia y el contraelectrodo fueron protegidos por una máscara para evitar su contaminación. Como experimento preliminar, los electrodos fueron empleados en el análisis de disoluciones patrón de fenoles y azúcares (catecol y glucosa). Todos los sensores mostraron los picos característicos de los analitos produciéndose un aumento en la intensidad y un desplazamiento de éstos hacia potenciales menores cuando fueron analizados con los biosensores. Se observaron grandes 
diferencias en las respuestas en función del mediador electrónico empleado siendo grafeno, nanopartículas de óxido de niquel y azul de Prusia los modificadores que presentaron mejor comportamiento y mayor efecto electrocatalítico.

Cuando la lengua (bio)electrónica fue empleada para analizar mostos de diferentes variedades se obtuvieron voltamogramas con diversos picos: unos de ellos relacionados con las especies electroactivas presentes en la muestra (antioxidantes y azúcares) y otros relacionados con el modificador electrónico (ej. azul de prusia). Los mostos fueron diluidos 1:2 en tampón fosfato para disminuir la irreproducibilidad de la medida debido a la complejidad de la muestra. La interacción entre los electrodos y el mosto produjo respuestas muy complejas y diferentes para cada uno de ellos, demostrando el alto grado de selectividad cruzada alcanzado con la red de electrodos. La capacidad de discriminación de la red de sensores fue analizada mediante PCA. Cinco cálculos diferentes fueron llevados a cabo: i) red de sensores sin modificar, ii) red de sensores de tirosinasa, iii) red de sensores de glucosa oxidasa, iv) ambas redes de biosensores juntas y v) todas las redes juntas. Las redes por separaron mostraron una discriminación parcial de las muestras que se vio mejorada en las redes de biosensores, sin embargo, cuando las respuestas de las dos redes de biosensores son tratadas conjuntamente las muestras no sólo son discriminadas sino que en el gráfico aparecen ordenadas en función de su composición química. Este sistema mostró una discriminación muy próxima a la alcanzada por otros sistemas mucho más caros y complejos. En último lugar, se correlacionaron los resultados obtenidos con los parámetros químicos tradicionales encontrando muy buenas correlaciones con el grado Brix y el Índice Total de Polifenoles.

\subsection{Sensores modificados con nanopartículas core-shell}

Nanopartículas bimetálicas de Au-In con diferentes composiciones se sintetizaron mediante sputtering magnético de cantidades controladas de Au y de In sobre electrodos de ITO. El análisis de la morfología y la composición de las nanopartículas se realizó mediante microscopía 
electrónica de transmisión (TEM), microscopía electrónica de barrido (SEM), espectrometría de rayos X (XPS) y espectrometría de dispersión de energía de rayos $X$ (EDS). Las nanopartículas presentaron centros de Au-In y mezclas de Au-Óxido de In en la capa exterior. La voltametría cíclica se empleó para la caracterización electroquímica de los diferentes sensores frente a una disolución de hidroquinona. La presencia de nanopartículas Au-In produjo un desplazamiento de los picos asociados a los procesos redox de la hidroquinona demostrando así su efecto electrocatalítico. Las respuestas voltamétricas obtenidas con cada uno de los sensores dependieron de la proporción Au-In presente en las nanopartículas. Mientras que las nanopartículas con proporciones Au:In 1:1 y 1:2 dieron lugar a un proceso redox de dos electrones, cuando la proporción fue 3:1 el mecanismo del proceso redox encontrado fue de dos pasos consecutivos de un electrón. El análisis del comportamiento dinámico de los electrodos de nanopartículas mostró que la reacción electroquímica está controlada por el mecanismo de difusión, indicando que la alta relación superficie volumen de las nanopartículas facilitó una rápida transferencia electrónica entre la superficie del electrodo y el analito. Los límites de detección encontrados para estos sensores estuvieron en el rango de $10^{-5}-10^{-6} \mathrm{~mol} \cdot \mathrm{L}^{-1}$. 

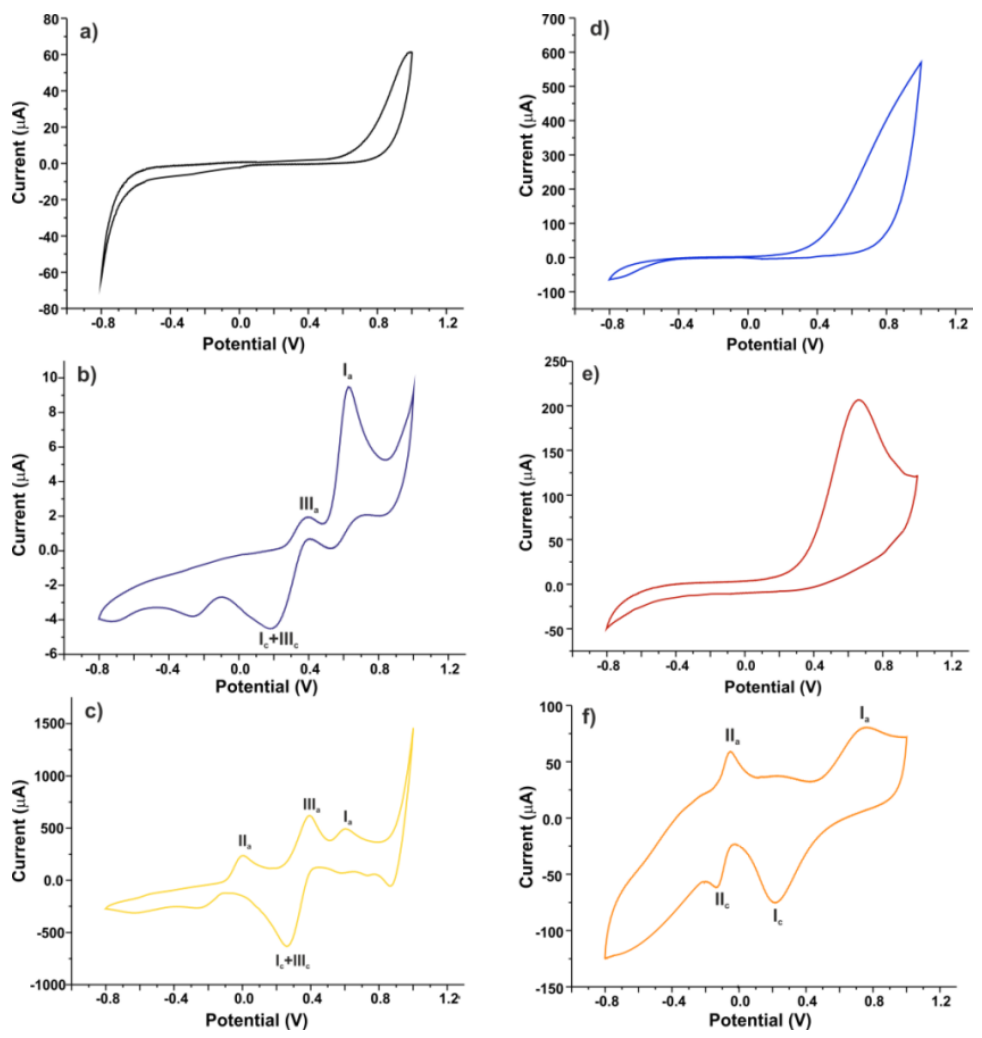

Figura 2. Voltametría cíclica de a )ITO, b)electrodo de Au, c)nanopartículas de $\mathrm{Au}, \mathrm{d})$ nanopartículas de Auln $_{2}$, e)nanopartículas de Auln, y f)nanopartículas de $\mathrm{Au}_{3} \mathrm{ln}$ inmersas en una disolución de hidroquinona $10^{-3} \mathrm{~mol} \cdot \mathrm{L}^{-1}$.

\section{4- CONCLUSIONES}

De acuerdo con los objetivos establecidos, las conclusiones obtenidas en el desarrollo de esta tesis son:

1- Se han diseñado y construido un conjunto de sensores y biosensores voltamétricos mediante diferentes técnicas y empleando diferentes materiales electrocatalíticos y se han aplicado en el análisis de diferentes analitos presentes en mostos como antioxidantes, ácidos orgánicos y azúcares

a) Nanopartículas de oro funcionalizadas con n-dodecanotiol se emplearon para modificar electrodos mediante la técnica de Langmuir- 
Blodgett. Los electrodos mostraron un gran efecto electrocatalítico frente a ácidos fenólicos y orgánicos siendo capaces de proporcionar información sobre mezclas de ácido cafeico/tartárico sin ninguna interferencia.

b) Las técnicas de Langmuir-Blodgett y Langmuir-Schaefer se emplearon para el desarrollo de sensores con bis-octacloro-ftalocianato de lutecio. Las películas presentaron buena estabilidad y sensibilidad alcanzando límites de detección de $10^{-5} \mathrm{~mol} \cdot \mathrm{L}^{-1}$ para la detección de catecol.

c) Dos materiales electrocatalíticos fueron empleados para modificar un electrodo de óxido de indio y estaño (ITO) mediante la técnica de Langmuir-Blodgett. Se observó un efecto sinérgico electrocatalítico en el análisis de hidroquinona, obteniendo un aumento de la corriente y alcanzando límites de detección del orden de $10^{-7} \mathrm{~mol} \cdot \mathrm{L}^{-}$ 1.

d) La influencia de la estructura del material cabonaceo empleado en el desarrollo de sensores de pasta de carbono ha sido evaluada en el análisis de ácido cítrico. La respuesta obtenida fue dependiente del material empleado, encontrando un efecto sinérgico entre la ftalocianina de litio empleada como modificador y los nanotubos de carbono.

e) Nanopartículas core-shell de Au-In fueron preparadas mediante sputtering magnético. Estos sensores se emplearon en la detección de hidroquinona observándose un gran efecto electrocatalítico y alcanzando límites de detección del orden de $10^{-5}-10^{-6}$ $\mathrm{mol} \cdot \mathrm{L}^{-1}$. La actividad electrocatalítica y el mecanismo del proceso redox dependieron de la cantidad de oro estabilizada en la superficie.

2- Las redes de sensores y biosensores se emplearon en el análisis de mostos. Para conocer el funcionamiento de los electrodos fueron empleados previamente para el análisis de disoluciones patrón. Tres lenguas (bio)electrónicas se desarrollaron con éste propósito. 
a) Una lengua (bio)electrónica formada por sensores y biosensores de pasta de carbono modificados con diferentes metaloftalocianinas y enzimas. La respuesta obtenida dependió del metal central de la ftalocianina y mejoró con la inclusión de enzimas.

b) Una red formada por electrodos comerciales miniaturizados con diferentes mediadores electrónicos modificados con enzimas. Los resultados obtenidos presentaron buenas correlaciones con el ${ }^{\circ} \mathrm{Brix}$ y el Índice Total de Polifenoles. Las ventajas de esta legua electrónica son el bajo precio de los sensores, la facilidad de uso y la portabilidad.

c) Un lengua bioelectrónica nanoestruturada formada por sensores modificados con fenol oxidasas empleando bisftalocianina de lutecio como mediador electrónico, desarrollada mediante la técnica de Langmuir-Blodgett. Los límites de detección obtenidos en el análisis de disoluciones patrón de fenoles fueron de $10^{-8} \mathrm{~mol} \cdot \mathrm{L}^{-1}$.

Las redes fueron capaces de discriminar las muestras de uva en función de su contenido polifenólico y de la concentración de azúcares.

3- Una lengua bioelectrónica formada por sensores con enzimas para el análisis de fenoles y azúcares fue empleada para controlar el proceso de maduración de la uva. La técnica empleada para desarrollar los sensores fue Langmuir-Blodgett favoreciendo el funcionamiento del enzima mediante la formación de un entorno biomimético. Las muestras fueron cosechadas semanalmente desde el envero hasta post-vendimia. Los resultados electroquímicos obtenidos fueron correlacionados con los parámetros químicos analizados por los métodos tradicionales mediante PLS-1 obteniendo excelentes correlaciones para los parámetros relacionados con fenoles y azúcares. 

ANEX 

The work carried out during this thesis period has led to the following publications:

18- C. Medina-Plaza, J.A de Saja, J.A. Fernández-Escudero, E. Barajas, G. Medrano, M.L. Rodriguez-Mendez. Array of biosensors for discrimination of grapes according to grape variety, vintage and ripeness. Analytica Chimica Acta. 2016, Submitted.

17- M.L. Rodríguez-Méndez, J.A. de Saja, C. Medina-Plaza, C. GarciaHernandez. Electrochemical Sensors for the Detection of Antioxidants. In Bioactive compounds: natural sources, physicochemical characterization, applications. Eds. C. Apetrei. Ed. Benthan Science Publishers. Sharjah. United Arab Emirates. 2016, Accepted.

16- M.L. Rodriguez-Mendez, C. García-Hernandez, C. Medina-Plaza, C. García-Cabezón, J.A. de Saja. Application of multisensor systems based on phthalocyanines in oenology. Case study: monitoring the quality and ripeness of grapes. Journal of Porphyrins Phthalocyanines. 2016, Accepted.

15- M.L. Rodríguez-Méndez, J.A. de Saja, C. Medina-Plaza, C. GarciaHernandez. Electronic tongues for the organoleptic characterization of wines. In Electronic tongues and noses in food science. Eds. M.L. Rodriguez-Mendez. Ed. Elsevier, San Diego. 2016, 265-273.

14- M.L. Rodriguez-Mendez, C. Medina-Plaza, C. García-Hernández, S. Rodriguez, C. García-Cabezon, D. Paniagua, M.A. Rodriguez-Perez, J.A de Saja. Improvement of electrocatalytic effect in voltammetric sensors based on phthalocyanines. Journal of Porphyrins Phthalocyanines. 2016, 20, 1-8.

13- C. Medina-Plaza, M.L Rodriguez-Mendez, P. Sutter, X. Tong, E. Sutter. Nanoscale Au-In alloy-oxide core-shell particles as electrocatalysts for efficient hydroquinone detection. Journal of Physical Chemistry-C. 2015, 119 (44), 25100-25107. 
12- C. Garcia-Hernandez, C. Medina-Plaza, C. Garcia-Cabezon, F. MartinPedrosa, I. del Valle, J.A. de Saja, M.L. Rodriguez-Mendez. An electrochemical quartz crystal microbalance multisensor system based on phthalocyanine nanostructured films: Discrimination of musts. Sensors. 2015, 15, 29233-29249.

11- C. Garcia-Hernandez, C. Garcia-Cabezon, C. Medina-Plaza, F. MartinPedrosa,Y. Blanco, J. A. deSaja, M.L Rodriguez-Mendez. Electrochemical behavior of polypyrrol/AuNP composites deposited by different electrochemical methods. Sensing properties towards catechol. Beilstein Journal of Nanotechnology. 2015, 6, 2052-2061.

10- C. Medina-Plaza , C. Garcia-Hernandez, J.A. de Saja, J.A. FernandezEscudero, E. Barajas-Tola, G. Medrano, C. García-Cabezón, F. MartínPedrosa, M.L. Rodriguez-Mendez. The advantages of disposable screenprinted biosensors in a bioelectronic tongue for the analysis of grapes. LWT- Food Science and Technology. 2015, 62, 940-947.

9- M.L. Rodriguez-Mendez, C. Medina-Plaza, J.A. de Saja, J.A. FernandezEscudero, E. Barajas-Tola, G. Medrano. Analysis of grapes and wines using a voltammetric bioelectronics tongue. Correlation with the phenolic and sugar content. IEEE Sensors Journal. 2014, IEEE Conference Publications, 2139-2142.

8- C. Medina-Plaza, C. García-Cabezón, C. García-Hernandez, C. Bramorski, Y. Blanco-Val, F. Martín-Pedrosa, T. Kawai, J.A. de Saja, M.L. Rodriguez-Mendez. Analysis of organic acids and phenols of interest in the wine industry using Langmuir-Blodgett films based on functionalized nanoparticles. Analytica Chimica Acta. 2014, 853, 572-578.

7- C. Medina-Plaza, L.N. Furini, C.J.L. Constantino, J.A. de Saja, M.L. Rodriguez-Mendez. Synergistic electrocatalytic effect of nanostructured mixed films formed by functionalized gold nanoparticles and bisphthalocyanines. Analytica Chimica Acta.2014, 851, 85-102.

6- C. Medina-Plaza, M.L. Rodriguez-Mendez, J.A. de Saja. Bioelectronic tongue based on lipidic nanostructured layers containing phenol 
oxidases and lutetium bisphthalocyanine for the analysis of grapes. Biosensors\&Bioelectronics. 2014, 57, 276-283.

5- M.L. Rodríguez-Méndez, C. Apetrei, M. Gay, C. Medina-Plaza, J.A. de Saja, S.Vidal, O.Aagaard, M.Ugliano,J. Wirth,V. Cheynier. Evaluation of oxygen exposure levels and polyphenolic content of red wines using an electronic panel formed by an electronic nose and an electronic tongue. Food Chemistry. 2014, 155, 91-97.

4- P.Alessio, C.Apetrei, R.J.G.Rubira, C.J.L.Constantino, C.Medina-Plaza, J.A.de Saja, M.L. Rodríguez-Méndez. Structural and electrochemical properties of a bis-octachloro-phthalocyaninate nanostructured films. Application as voltammetric sensor. J. Nanoscience and Nanotechnology.2014, 14, 6574-6773.

3- M.L. Rodríguez-Méndez, C. Apetrei, C. Medina-Plaza, R. Muñoz, J.A. de Saja. Sensor array based on phthalocyanines: New developments on nanostructured and biomimetic electrochemical sensors. In Multisensor systems for chemical analysis: materials and sensors. Eds. L. Lvova, D. Kirsanov, C. Di Natale, and A. Legin. Ed. Pan Standford Publishing Pte. Ltd. Singapore, 2014, 139-179.

2- C. Medina-Plaza, G.Revilla, R.Muñoz, J.A. Fernandez-Escudero, E.Barajas, G.Medrano, J.A. de Saja, M.L. Rodríguez-Méndez. Electronic tongue formed by sensors and biosensors containing phthalocyanines as electron mediators. Application to the analysis of red grapes. Journal of Porphyrins and Phthalocyanines. 2013, 17, 1-11.

1- C. Apetrei, C. Medina-Plaza, M.L. Rodríguez-Méndez, J.A. de Saja. Electrochemical characterization of dilithium phthalocyanine carbonaceous electrodes. Journal of Porphyrins and Phthalocyanines.2013, 17, 1-7. 

